\title{
THE ECOLOGY AND BEHAVIOUR OF PUMAS (PUMA CONCOLOR) IN NORTHERN CALIFORNIA, U.S.A.
}

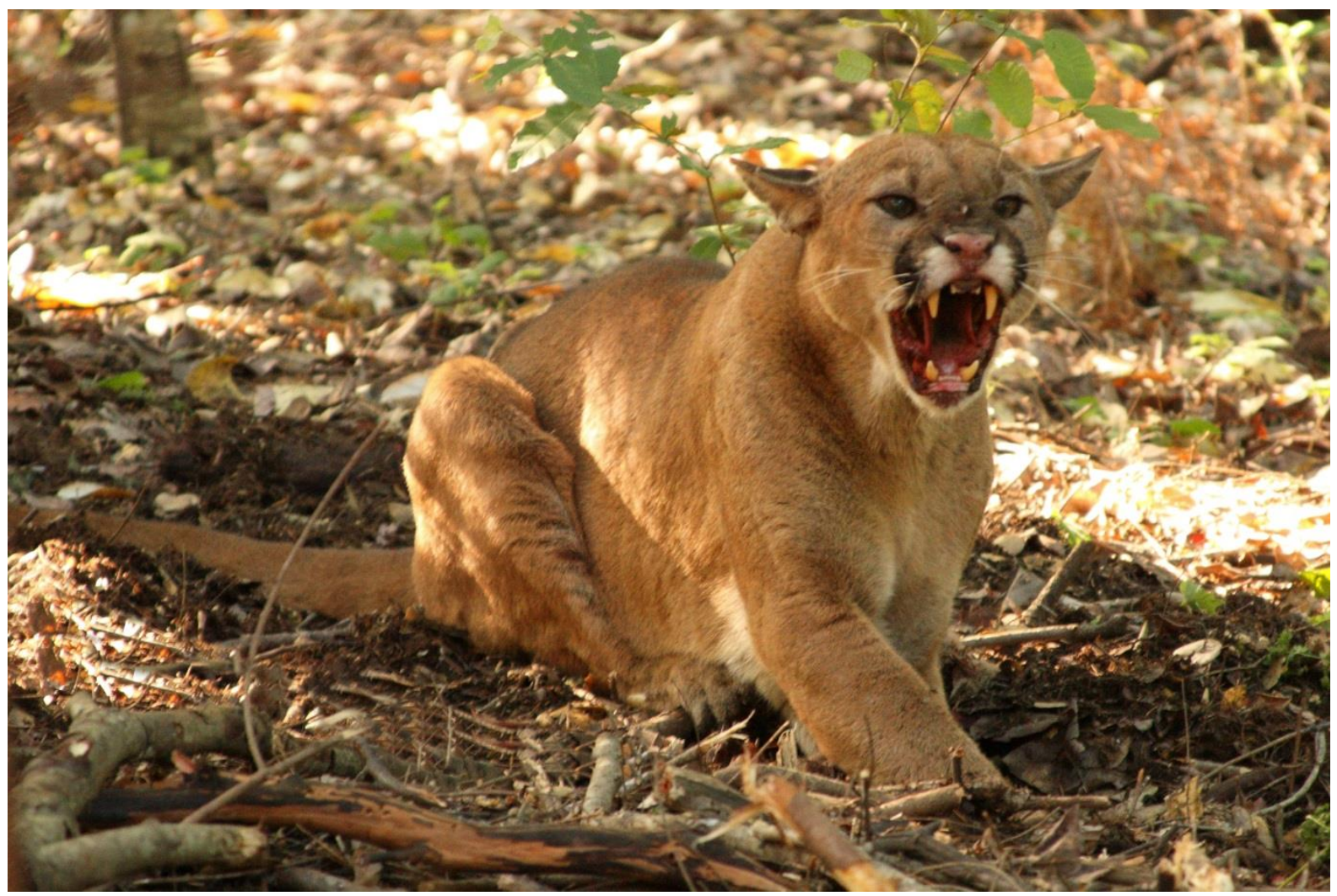

By

Maximilian L Allen

A dissertation submitted to the Victoria University of Wellington in fulfilment of the requirements for the degree of Doctor of Philosophy in Biological Sciences Victoria University of Wellington VICTORIA UNIVERSITY OF WELLINGTON Te Whare Wananga o te Upoko o te Ika a Maui

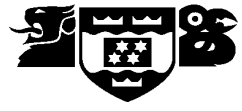




\section{Dissertation Abstract}

Large carnivores are important components of many ecosystems and play an integral role in determining the composition and structure of ecological communities. The influences of pumas (Puma concolor) on other species, including prey and competitors, vary across their range and among individuals. I used novel methodologies, including intensive real-time GPS investigations of potential kill sites using ARGOS satellite collars, and motion-triggered video cameras to study the intra- and inter-specific interactions of pumas and understand their influences on ecological communities. Results from my dissertation support previous findings that pumas play an integral role in shaping their respective ecosystem, but that pumas are also influenced substantially by their local environment. Overall, my dissertation highlights the importance of understanding intra- and inter-specific interactions of large carnivores when attempting to understand their influences on ecological communities.

I tested whether pumas exhibited sexual variation in their use of communication behaviours at community scrape areas, and what factors influenced their mating strategies. I found that males more frequently exhibited and spent longer durations on 'producing' behaviours (scraping and body rubbing), while females more frequently exhibited and spent longer durations on 'consuming' behaviours (olfactory investigation and flehmen response behaviours). This suggests that male reproductive strategy is based on advertisement for possible mates, while female reproductive strategy is based on assessment of potential mates. Pumas also exhibited sexual variation in their patterns of visitation. Males were regular visitors, while females were irregular visitors whose visitation cycles were apparently correlated with oestrus. Mate selection by females was complex and based on multiple cues, the two most important of which were the visitation rate and mass of males. The frequency of male visits and the display of some behaviours were influenced most by visits from female pumas, but were also influenced by visits from competing males. 
I used real-time and fine-scale GPS location data to find prey killed by individual pumas, and analysed seasonal patterns to understand local influences on puma behaviour and feeding ecology. I found that black-tailed deer (Odocoileus hemionus columbianus) were the main prey of pumas, constituting $98.6 \%$ of their diet by mass, and that the elevations at which pumas killed black-tailed deer correlated significantly with seasonal elevations used by black-tailed deer. I found pumas had relatively high ungulate kill rates $(\bar{x}=1.07$ ungulates/week, and $\bar{x}=5.78 \mathrm{~kg} /$ day), and that kill rates in ungulates/week varied among seasons and were highest in summer and autumn. Importantly, the handling times of blacktailed deer $\geq 1$ year old showed an inverse seasonal relationship with kill rates in ungulates/week, and the lower handling times may have been due to black bear kleptoparasitism. These findings suggest that puma feeding ecology can be strongly influenced by seasonal behaviour of their prey and dominant scavengers.

Given the potential for large carnivores to influence scavengers, I studied the influences of both pumas and black bears on the scavenger community. I found that pumas and black bears were a source of limitation for scavengers, both on the species richness and sum feeding times of the scavenger community, as well as the occurrence, total feeding times, and mean feeding bout durations of scavenger species. However, pumas had some positive influences, for example they facilitated the acquisition of carrion by scavengers, and they apparently initiated a cascading pattern that led to an increase in the acquisition of carrion by small carnivores. In contrast, black bears, as dominant scavengers, monopolized carrion resources and substantially limited the acquisition of carrion by other scavengers, and in fact they had larger limitations for scavengers than pumas as top-level predators. The influences on carrion acquisition suggest that large carnivores have important influences on the scavenger community, and their influences could be a mechanism for the effects large carnivores have on community composition. 


\section{Acknowledgements}

My dissertation would not have been possible without the help of a great many people. I thank my advisers, Heiko Wittmer and Chris Wilmers, for providing me with this opportunity and their support with funding. The guidance they have given me through the past 3 years has been invaluable. Mark Elbroch has been guiding my development as an ecologist for over 10 years, and his help was instrumental in completing many aspects of my dissertation. David Casady was also integral to the project, helping with funding, capture of pumas, and overall support. Norman and Elizabeth Powell provided inspiration throughout the project, while A.D. and R.C. provided motivation to complete the project. The administrative staff within the School of Biological Sciences was also very helpful, particularly Patricia Stein.

Financial support for my dissertation research was generously provided by a Victoria University of Wellington $\mathrm{PhD}$ Tuition Scholarship, the University of California at Davis, the California Department of Fish and Wildlife, the Fresno State Auxiliary Fund, the University of California at Santa Cruz, and grants from the National Science Foundation and the Gordon and Betty Moore Foundation.

My project was an intensive effort that took every ounce of effort I could muster. I worked constantly in order to collect all of the data I needed, analyse the data, and write up the results. However, by taking only 19 days off over the course of my $\mathrm{PhD}$ meant that I let many of my relationships with friends and relatives atrophy. Thanks for your understanding, good humour, and support. I would like to particularly thank A. Preston Taylor III \& Heather Wadhams, Jerilyn Brownstein \& family, Dan Gardoqui \& family, Dan \& Elyse Perambo, Mike Wight \& Julie Gwyther, Lynn \& Michael Trotta, Ben \& Angela Gorman, Jerry \& Liz Volpe, and Mike \& Karyn Stannard for their support and advice. I would also like to thank my parents and extended family for their love and support.

My Mendocino study area was a wild and mountainous country, with unpaved roads that wind their way through the steep mountainsides that cling to narrow river valleys, but offer limited access to many areas frequently used by pumas. I hiked countless miles over the project, wearing through 4 pairs of hiking boots and 1 knee. I thank the many people who made contributions to this extensive and intensive field work. Julie Golla was instrumental in gathering data during her time on the project. Bryn Evans was always available to help over the course of the project and made many contributions over the years. Justine Smith was very 
helpful and contributed in both Mendocino and Santa Cruz. Paul Houghtaling, Yasaman Shakeri, and Yiwei Wang were very helpful in all the work I did in Santa Cruz. I also want to thank the other field technicians who worked on the project: Ryan Carrothers, Greta Schmidt, Phillip Johnston, and Cody Wallace.

I also want to thank the houndsmen that worked on the project. I am indebted to Blue Millsap, Cliff Wiley, and Dan Tichenor. Each was a valuable source of information on puma natural history, and they were always up for another capture attempt, no matter the conditions. I will always remember the 4 hour hike Cliff out of Grindstone without flashlights on the winter solstice, and also the final capture of M33 with Dan and Bryn that finally ended at $4 \mathrm{am}$.

With so many people to thank I am sure I have unintentionally overlooked some; I sincerely apologize for this.

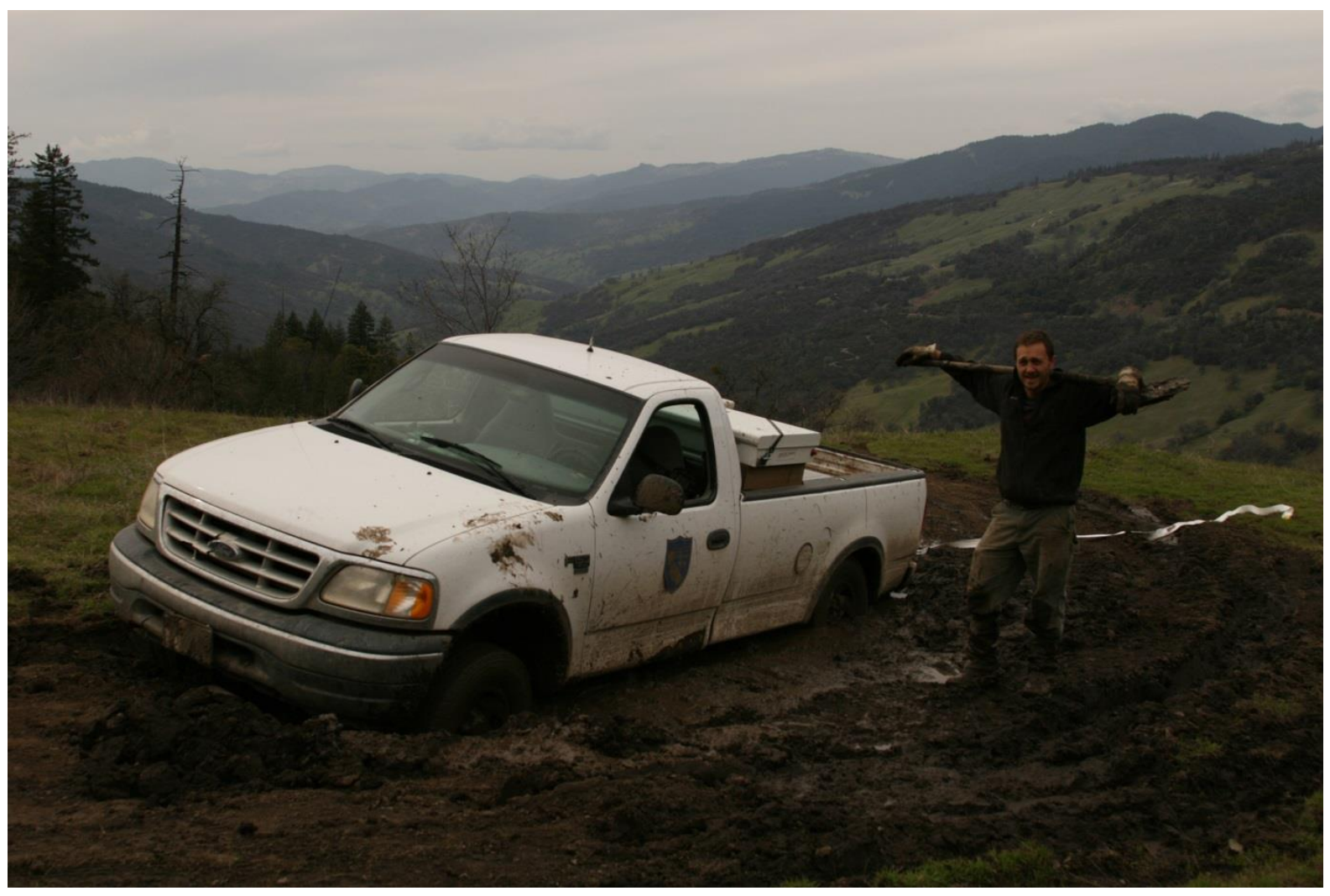

Figure 1. Hopelessly stuck in my Mendocino study area; one of the many times I needed support while completing my dissertation. 


\section{Table of Contents}

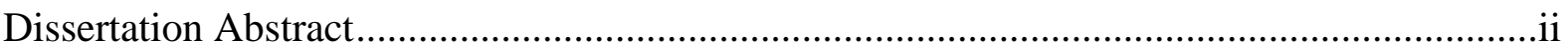

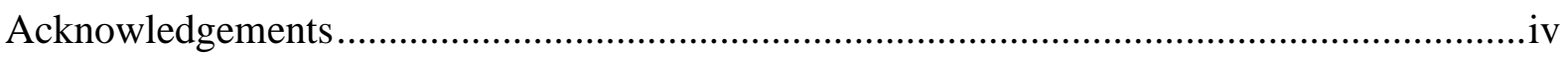

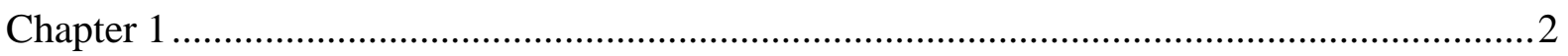

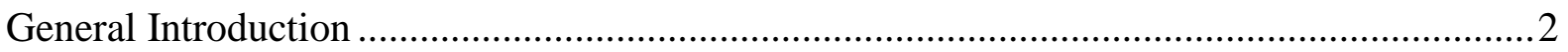

The Importance of Large Carnivores ................................................................... 3

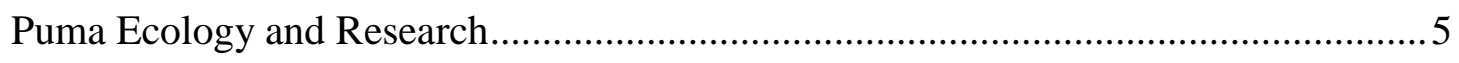

Puma Research Needs ................................................................................. 7

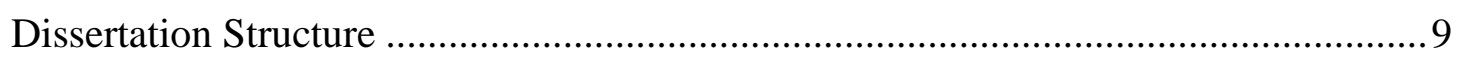

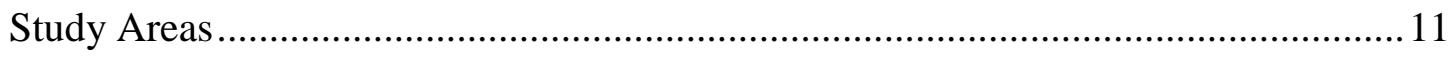

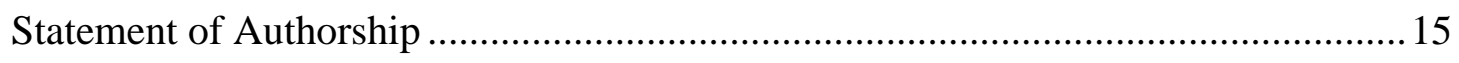

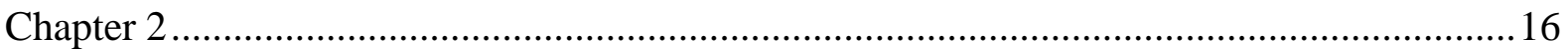

Puma Scrape and Communication Behaviours: Understanding Functional Use and the

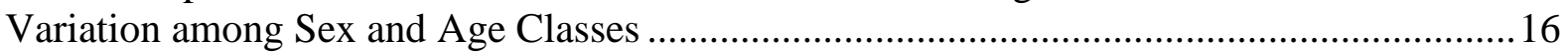

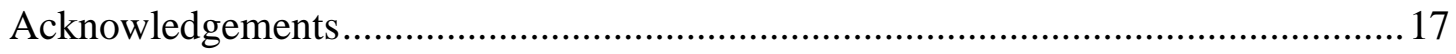

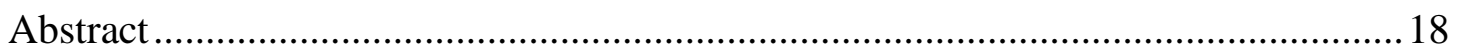

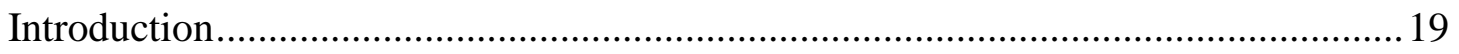

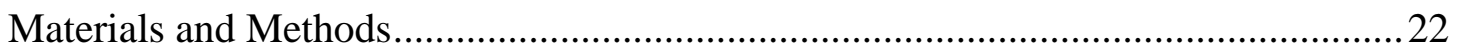

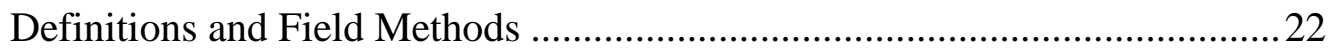

Design of Experimental Treatments ........................................................2 24

Design of Communication Behaviours Research ........................................26

Statistical Analyses Overview .............................................................28

Experimental Treatments Statistical Analyses ...........................................28

Communication Behaviours Statistical Analyses .........................................29

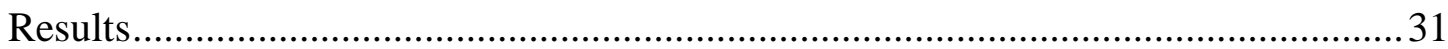

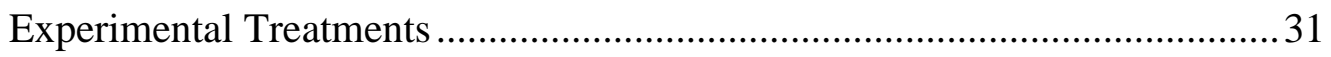

Communication Behaviours ........................................................................ 32

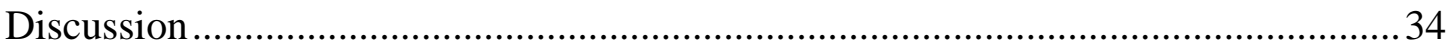

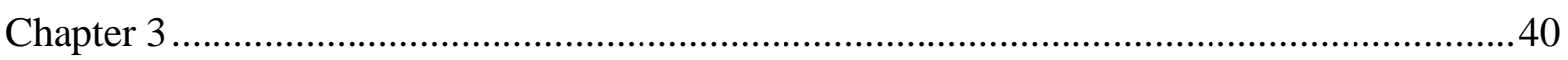

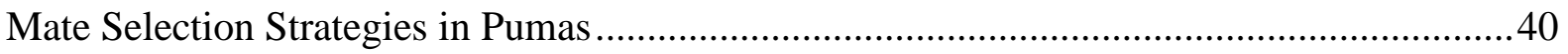

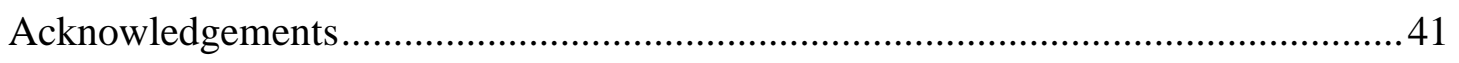

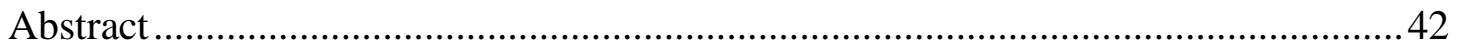

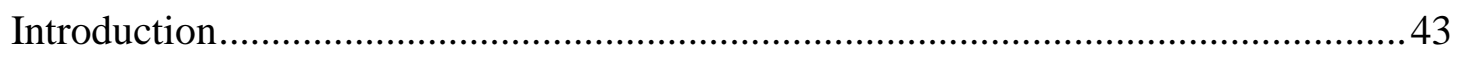

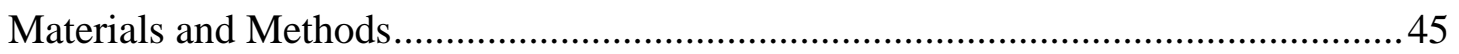

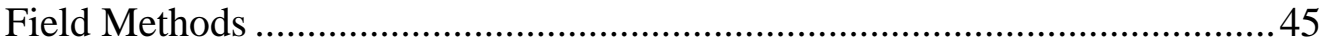

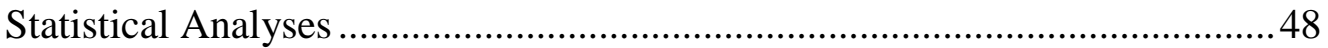

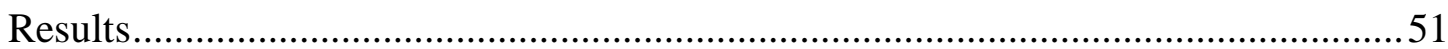

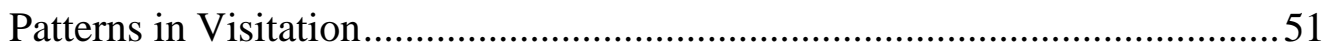

Seasonal Variation in Visitation ..............................................................52

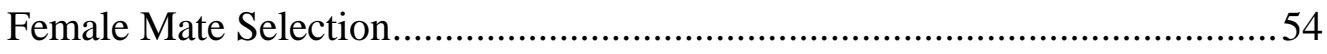


Chapter 4

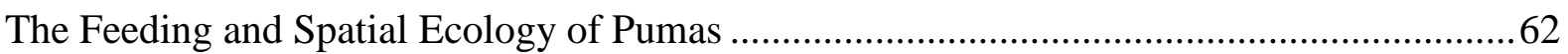

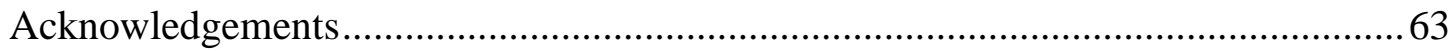

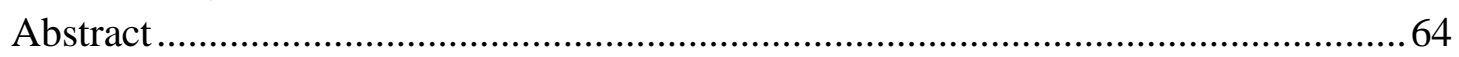

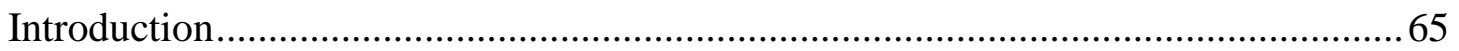

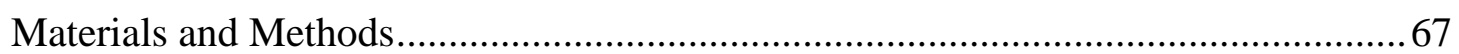

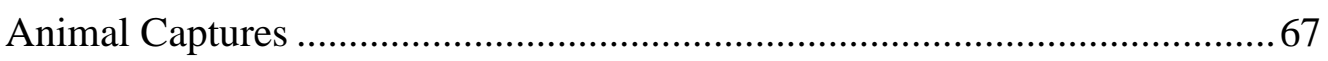

Collar Programming and Field Methods .....................................................6 67

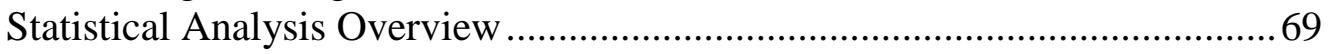

Kill Rate and Diet Composition Statistical Analyses ...................................69

Hunting and Feeding Behaviour Statistical Analyses...................................69

Spatial Use and Population Density Statistical Analyses .............................. 71

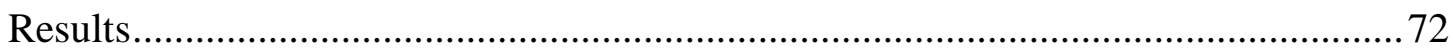

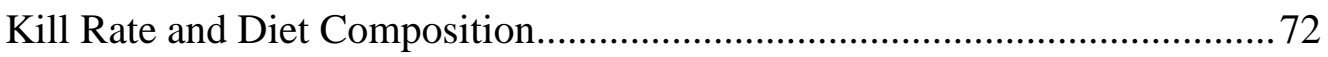

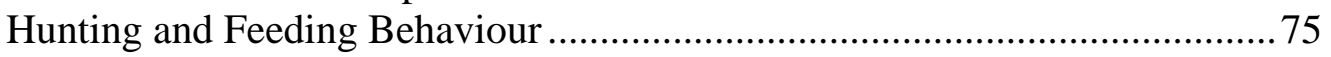

Home Range Sizes and Population Density ................................................ 76

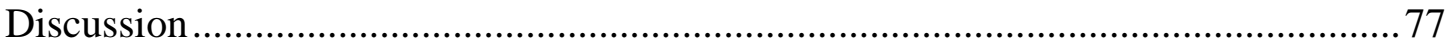

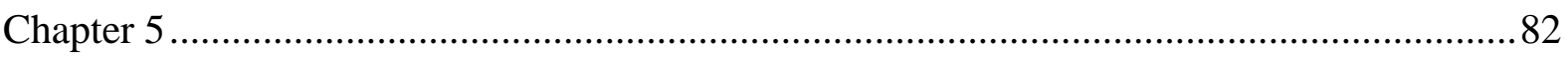

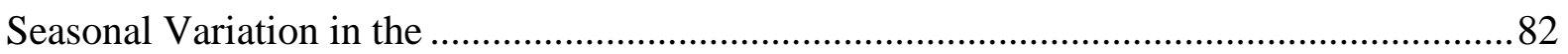

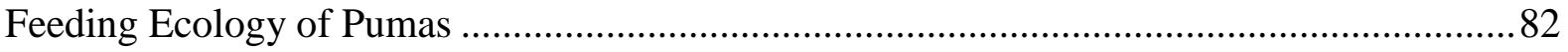

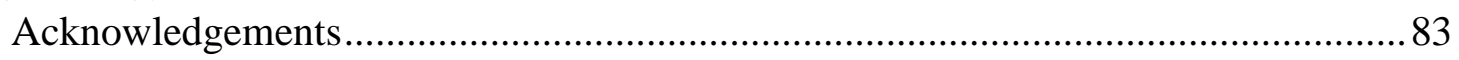

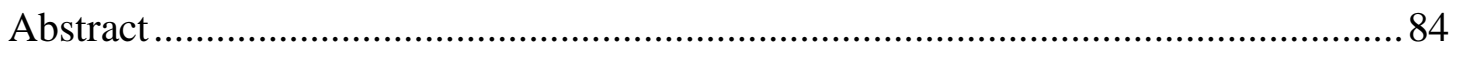

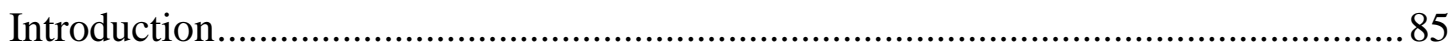

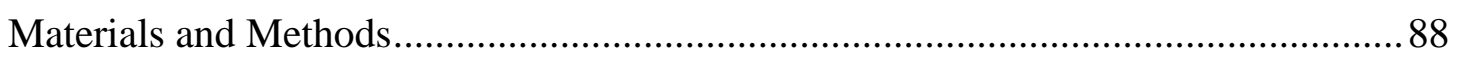

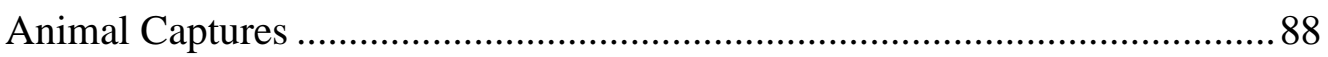

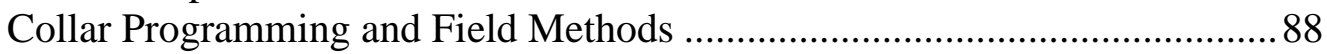

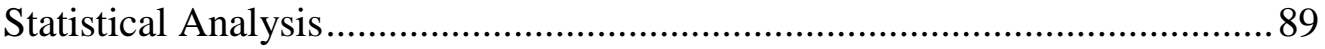

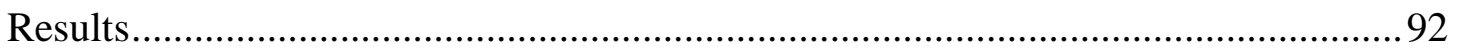

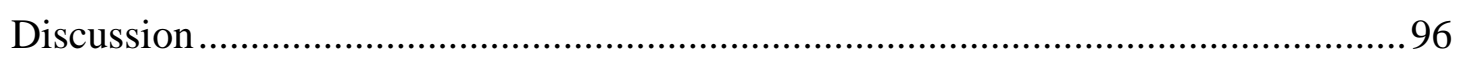

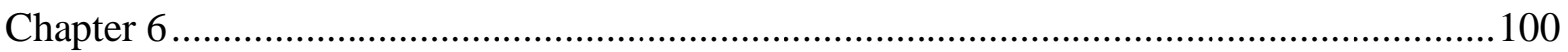

Trophic Facilitation or Limitation? Comparative Effects of Pumas and Black Bears on the

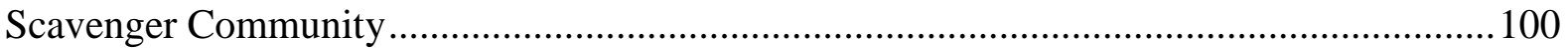

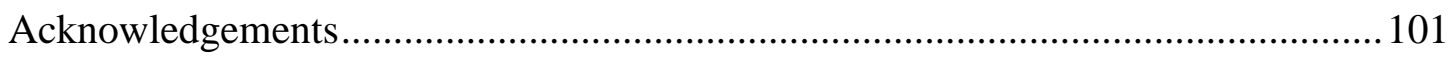

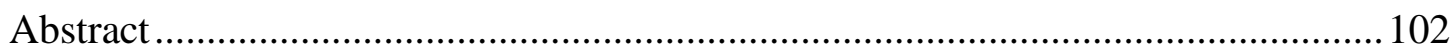

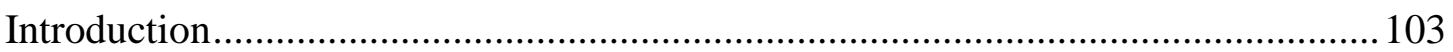

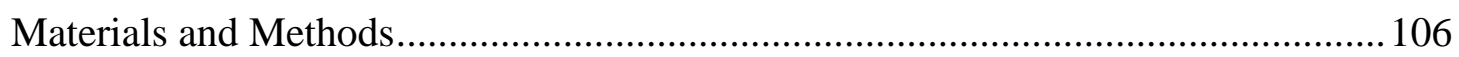

Experimental Design and Field Methods................................................... 106

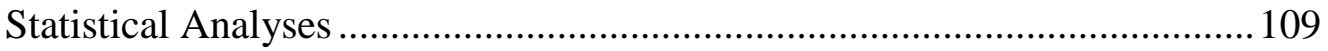

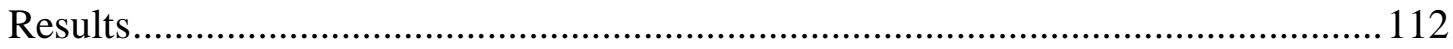




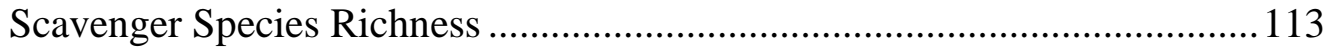

Scavenger Sum Feeding Times.............................................................. 115

Nestedness of Scavenger Communities ................................................. 117

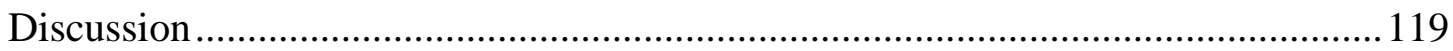

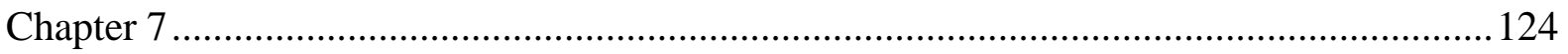

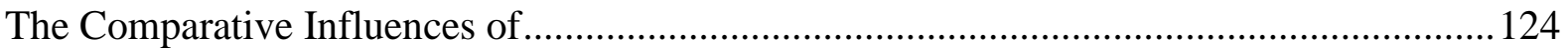

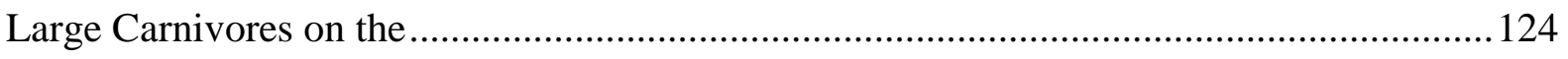

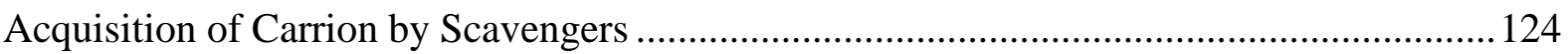

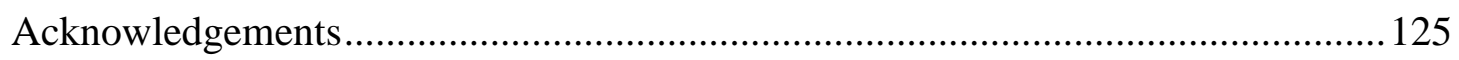

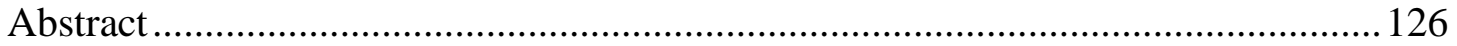

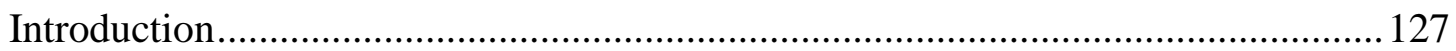

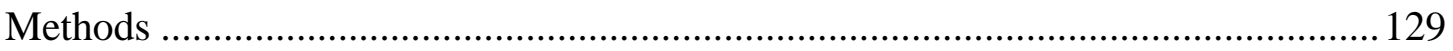

Experimental Design and Field Methods................................................ 129

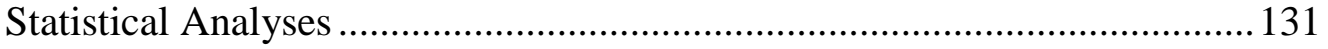

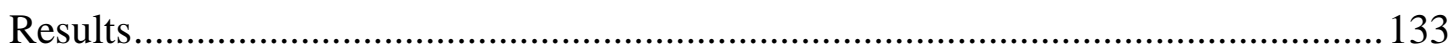

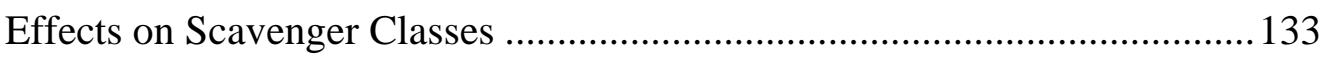

Effects on Scavenger Species .................................................................. 137

Effects of Pumas and Black Bears on Each Other ....................................... 137

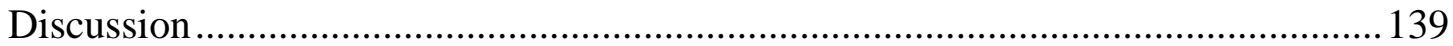

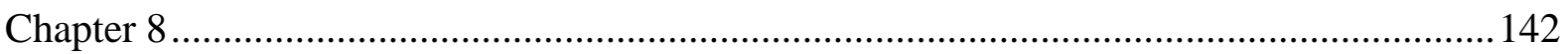

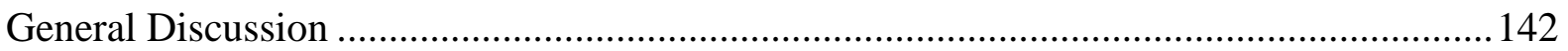

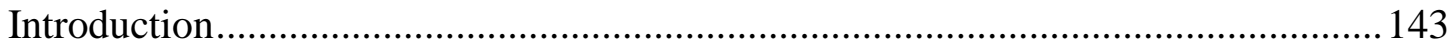

The Importance of Intraspecific Interactions ........................................................ 145

The Influence of Pumas on Other Species ............................................................... 147

The Influence of Other Species on Pumas ...................................................................... 149

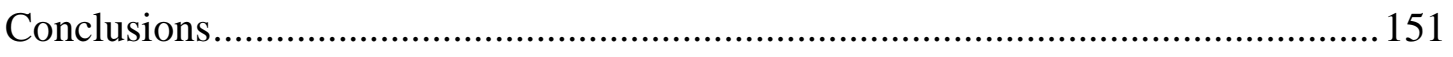

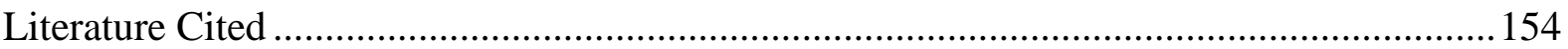

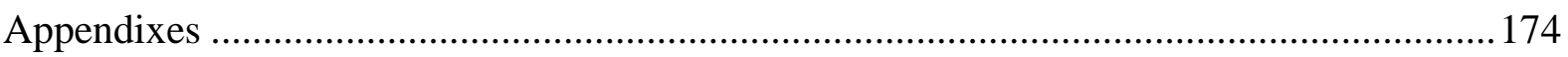

Appendix A - Habitat characteristics at puma experimental carcasses.................... 175

Appendix B - Habitat characteristics at black bear experimental carcasses ............. 179 


\section{Chapter 1}

\section{General Introduction}

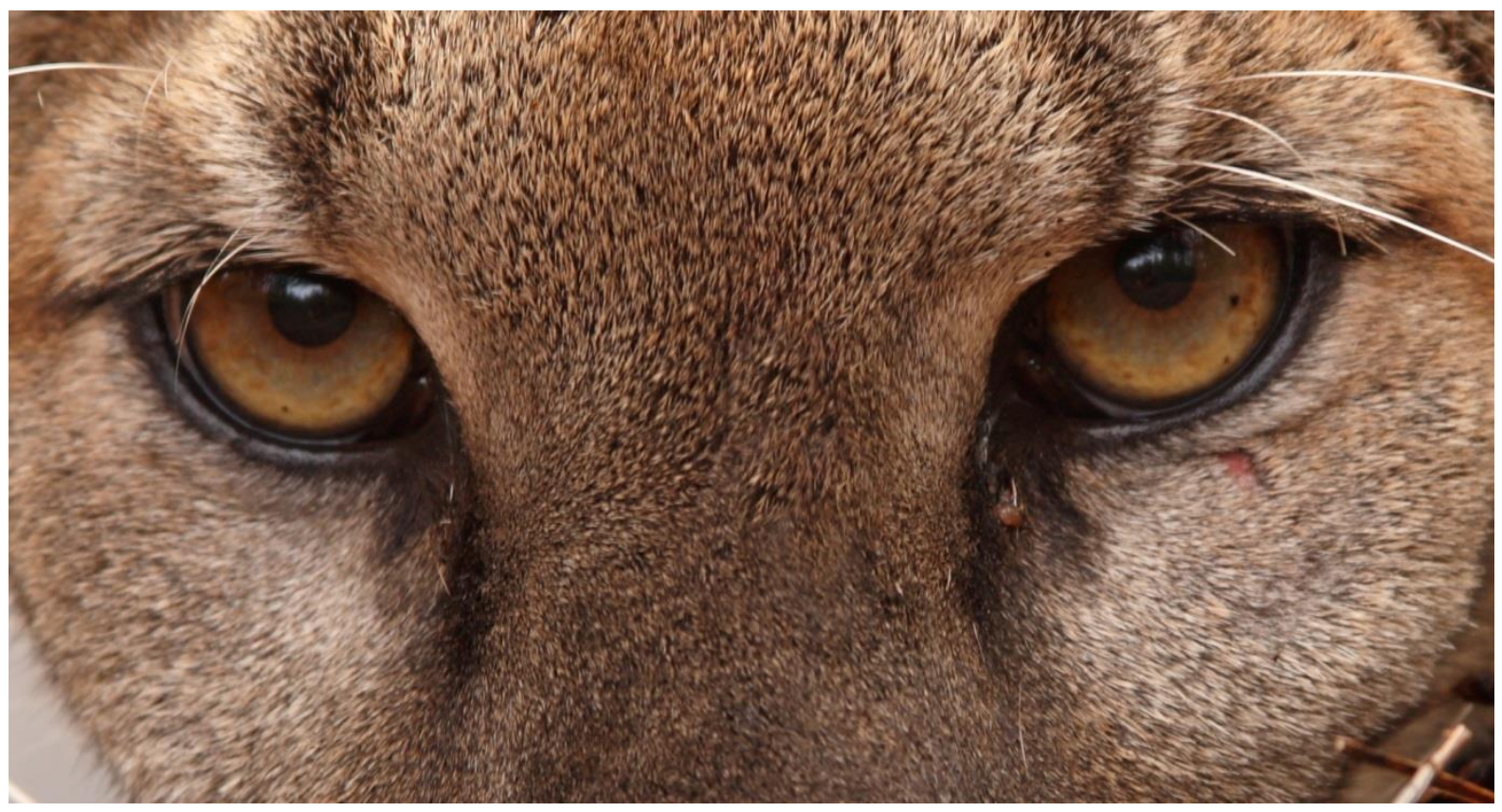




\section{The Importance of Large Carnivores}

Large carnivores are an important component of ecosystems and have wide-ranging influences on the composition and function of ecological communities. However, worldwide, many large carnivore populations are threatened and diminished, and humans are often the leading cause of large carnivore mortalities (Laliberte and Ripple 2004, Ripple et al. 2014). This suggests that management is an important factor in whether a large carnivore population remains stable or declines (Mech 1996, Shivik 2006, Bruskotter and Shelby 2010). Due to their effects on communities, the loss of large carnivores has the potential to change ecosystems, and necessitates research on large carnivores. For these reasons, large carnivores are intrinsically valuable to the fields of conservation biology, ecology, and wildlife management.

Large carnivores are among the most charismatic of wildlife species and are popular among the general public (Kellert 1997), and this allows large carnivores to play an important role in conservation. One example is that large carnivores are often used as umbrella species (Woodruffe and Ginsberg 1998). Umbrella species are those which require large protected areas for viable populations and through their preservation protect the habitat needed for many other co-occurring species (Roberge and Angelstam 2004). The umbrella species strategy has been used successfully for large scale conservation planning by focusing conservation efforts on preserving habitats and species with a high strategic value (Woodruffe and Ginsberg 1998). For instance, umbrella species have been found to allow for higher species richness and abundance in their presence (Branton and Richardson 2010). The movement patterns of large carnivores are also often used in the creation of corridors between preserved areas to provide for adequate gene flow and population viability (Noss et al. 1996, Roberge and Angelstam 2004), and also to determine proper reserve size for the preservation of ecological communities (Caro 2003). However, the true value of using large carnivores as 
umbrella species is that their value to conservation parallels their value to ecological communities.

Large carnivores have important ecological value through their role as keystone species (i.e. a species which has larger effects on ecosystems than expected based on their relative abundance, Power et al. 1996). Large carnivores influence the composition and structure of communities through predation (Estes and Palmisano 1974, McLaren and Peterson 1994, Estes 1996). Studies also suggest that large carnivores affect the behaviour and populations of their prey both directly through predation (Estes 1996, Ripple et al. 2014) and indirectly through changes in habitat selection to avoid predation (Brown et al. 1999, Altendorf et al. 2001, Ripple and Beschta 2004, Atwood et al. 2007). The influences of large carnivores can be detrimental for prey species with low populations (Wittmer et al. 2005, Ross et al. 1997). However, large carnivores also sometimes increase the fitness of populations by selecting sick, diseased, or aberrant individuals from populations (Robinson and Bolen 1989). In addition, large carnivores can also influence the composition and abundance of non-prey species in communities (Estes and Palmisano 1974, Hunter and Price 1992, Estes 1996, Courchamp et al. 1999, Prugh 2009).

Despite the apparent similarities in the ecological roles of large carnivores, they often occupy different ecological niches, and many of their influences depend upon their prey and other local conditions. The specific effects a large carnivore species has on communities are based on their size, natural history, and hunting tactics (Ripple et al. 2014). The influences of large carnivores are therefore many and varied, and it is important for both researchers and managers to understand the ecological roles of large carnivore species and how they interact with and influence their local environment. This necessitates species-specific research in order to understand the influences of different large carnivores on their respective communities. 


\section{Puma Ecology and Research}

Pumas (Puma concolor) are a solitary, large carnivore with an extensive range throughout North and South America. Pumas are efficient and adaptable ambush hunters that specialize in the predation of ungulates, and can have important influences on ungulate populations (Murphy and Ruth 2010). Pumas occupy the highest trophic levels, and as with other large carnivores, this leads to low birth rates and population densities (Ripple et al. 2014). Pumas have a long history of persecution from humans, but their cryptic nature and use of inaccessible terrain has limited their range contractions in comparison to other large carnivores (e.g. gray wolves, Canis lupus, and grizzly bears, Ursus horriblis) (Laliberte and Ripple 2004, Prugh et al. 2009, Gill 2010). Instead, pumas have the most extensive range of any terrestrial carnivore in the western hemisphere (Sunquist and Sunquist 2002).

The cryptic nature of pumas makes them difficult to study, and less is known about their ecology than of many other large carnivores (Quigley and Hornocker 2010). In the 1960's pumas were first captured and marked in a seminal study by Hornocker (1970), which later added VHF collars in order to understand puma social organization (Seidensticker et al. 1973). These studies of puma ecology were soon replicated, and as field skills and technology increased, studies became more common and complex. Studies of puma ecology and social organization culminated in a long-term study of 10 years by Logan and Sweanor (2001). Importantly, Logan and Sweanor (2001) tested the previous hypotheses that puma populations were self-limiting through their social organization (e.g., Hornocker 1970, Seidensticker et al. 1973), and refuted this hypothesis. Instead, they hypothesized that male and female pumas had different reproductive strategies, and the social organization of pumas was an adaptation to maximize the reproductive success of both male and female pumas. However, how behaviours are used by pumas for communication and mate selection is still 
relatively unknown due to the difficulty of observing these behaviours in such a cryptic species.

In the 1990's research became more focused on puma conservation and management. Pumas were found to be strongly influenced by development (Crooks 2002), and it became important to understand how pumas disperse, including their use of corridors (Beier 1993, Beier 1995). The interactions between pumas and humans also gained importance (Beier 1991, Torres et al. 1996). The focus on puma management was partly due to the shifting views of Americans towards large carnivores (Kellert 1997), which suggested an increase in their intrinsic value. One important outcome was the use of ballot initiatives in California to ban the hunting of pumas (Torres et al. 1996, Cougar Management Working Group 2005). Research continues in this area, focusing on how large carnivores can successfully co-exist with humans, especially in developing habitats.

The focus of research often revolves around new advances in technology and methods. For example, recent advances include genetic analyses to understand puma populations and evolution (Culver 2010), especially the increase in understanding the connectivity between puma populations. One area of puma ecology that has been particularly well-studied is their feeding ecology, and the use of new GPS collar technology is now being used to better understand prey selection, kill rates, and spatial ecology. The use of GPS collar technology allows for a great increase in the quantity and quality of location data available. For example, collecting location data at finer scales allows for more accuracy in kill site investigations (e.g., Knopff et al. 2010), as well as understanding puma movements and how they are influenced by development (Wilmers et al. 2013). Although our understanding of puma ecology has made corresponding increases with technological and methodological advances in the last 50 years, there are still large gaps in our knowledge of puma behaviour 
and ecology. In order to understand how the influences of pumas shape ecosystems, it is necessary to gain a better understanding of their intra- and inter-specific interactions.

\section{Puma Research Needs}

Intraspecific interactions are important because of their influence on puma populations and densities (Quigley and Hornocker 2010). However, little is known about intraspecific interactions among pumas or their communication behaviours. Large carnivores are often neglected in the study of animal behaviour, including intraspecific communications, due to the difficulty of making observations in the wild. These behaviours are currently not well understood (Logan and Sweanor 2001, Logan and Sweanor 2010), but understanding puma behaviour may have important applications for their ecology and conservation. For example, behaviour and communication could be used to census large carnivore populations (Sutherland 1998, Caro 1999), which is particularly difficult for pumas (Cougar Management Working Group 2005, Choate et al. 2006).

Pumas are thought to communicate most often through scraping and associated communication behaviours (Currier 1983, Logan and Sweanor 2001). Scraping is a form of scent marking that includes visual and olfactory components, as pumas scrape with their hind feet to create a mound of material and then urinate and sometimes defecate upon it (Elbroch 2003). Pumas are considered to be a sight-oriented species, with a less developed sense of smell (Currier 1983), but scrape communication could use both senses. Associated behaviours also include body rubbing, caterwauling, and flehmen response. Understanding the use of these behaviours could allow us to understand intraspecific communication in pumas, and if it plays a role in the regulation of puma populations.

Puma predation is one of the most researched areas of their ecology, because their predation has direct effects on game populations and ecological communities, but further 
research is still needed. For example, there are numerous published estimates for puma kill rates, but the estimates show a wide variation due to statistical and methodological differences (Knopff et al. 2010, Murphy and Ruth 2010). Recent studies have used new GPS collar technology to increase our understanding of puma prey selection and kill rates (Anderson and Lindzey 2003, Knopff et al. 2010, Elbroch and Wittmer 2013a), and these methods are likely to lead to more accurate kill rate estimates. Further research is needed to determine the factors that influence puma kill rates, including if there is variation in kill rates among seasons. The use of real-time investigations made possible by satellite-linked GPS collars may help determine how pumas select and hunt prey, and allow documentation of interactions with competitors. Additional areas of predation research include documentation of individual variation and adaptations to local environments, both of which may help contribute to understanding the influences of puma predation on ecological communities.

Puma predation may also have important indirect effects on ecological communities. Large carnivores are well known for initiating trophic cascades, and through predation influencing vegetation and other non-prey species (Estes and Palmisano 1974, Ripple et al. 2014), but their interactions with scavengers may also influence the composition and stability of ecological communities. Scavenging is an important process for distributing energy among trophic levels (DeVault et al. 2003, Wilmers et al. 2003a, Melis et al. 2007), and is also often an important component to food webs (Wilson and Wilkovich 2011). Many large carnivores also interact with and provision scavengers with energy from their kills (Cooper 1991, Honer et al. 2002, Wilmers et al. 2003a, Hunter et al. 2006), but studies of puma interactions with scavengers are limited and currently restricted to South America (Elbroch and Wittmer 2012b, Elbroch and Wittmer 2013b). Pumas are likely to provision scavengers with carrion from their kills, but may also cause responses in scavengers that influence scavenger behaviour and populations. 
Both top-down and bottom-up effects shape the dynamics of populations and communities (Hairston et al. 1960, Sinclair and Krebs 2002, Borer and Gruner 2009), and similarly, interspecific interactions with prey and competitors could have important influences on puma behaviour and ecology. For example, prey density may influence puma populations (Quigley and Hornocker 2010), and pumas may also exhibit behavioural responses to overcome defence strategies exhibited by their prey. Interspecific interactions with other large carnivores may also be important, as dominant scavengers are able to usurp prey from pumas (Ruth and Murphy 2010b, Elbroch and Wittmer 2013b), and could cause changes to puma behaviours. For example, as a solitary carnivore, pumas may need to spend more time defending their kills than social carnivores, and may be prone to losses from scavengers. Both of these factors could influence puma kill rates by influencing handling time of prey and search time for prey (Krofel et al. 2012, Elbroch and Wittmer 2013b).

\section{Dissertation Structure}

I studied the intra- and inter-specific interactions of pumas, to gain a mechanistic understanding of how pumas influence and are influenced by their local system. I overcame the limitation of pumas being cryptic and difficult to study by using novel methodologies, including intensive real-time GPS investigations using ARGOS satellite collars, and motiontriggered video cameras. In particular, my dissertation focuses on 3 topics; 1) understanding puma communication behaviours and how they are used for mate selection, 2) understanding local patterns in feeding ecology and the causes of observed seasonal variation, and 3) understanding the influences of pumas and black bears (Ursus americanus) on the scavenger guild. An understanding of the intra- and inter-specific interactions of pumas at multiple levels (how pumas influence each other, their prey, and other carnivores) is a first step towards understanding their influence on ecological communities. 
In Chapters 2 and 3, I use an experimental framework and motion-triggered cameras to understand the use of scraping and associated communication behaviours for intraspecific communication and mate selection in pumas. In Chapter 2, I investigate my hypotheses that the display and duration of communication behaviours will vary between sexes of pumas based on their different life history patterns. In Chapter 3, I investigate the use of communication behaviours for mate selection by pumas. I investigate my hypotheses that male visitation to and communication behaviours at community scrapes will be influenced by potential mates and competitors. In addition, I analyse seasonal patterns in visitation and denning by females, and investigate my hypothesis that visitation and behaviours are as important in mate selection by females as physical traits like mass and age. Through these chapters I hope to gain a mechanistic understanding of the function of puma behaviours for communication and mate selection.

In Chapters 4 and 5, I use real-time and fine-scale GPS location data to find prey killed by individual pumas, and analyse seasonal patterns to understand local influences on puma behaviour and feeding ecology. In Chapter 4, I investigate the feeding and spatial ecology of pumas in a single prey system. I determine kill rates and diet composition, as well as determine home range sizes and population densities within my study area. I also investigate my hypotheses that pumas will vary individually in their diet composition, and that pumas will select feeding sites that differ in habitat characteristics from their kill sites. In Chapter 5, I investigate my hypotheses that pumas will exhibit seasonal variation in their feeding ecology due to their prey and competitors. I analyse seasonal patterns in kill rates, elevation at which black-tailed deer (Odocoileus hemionus columbianus) are killed, handling times of black-tailed deer, and daily movement rates. I hypothesize that kill rates and elevations of kills will vary based on the migration of black-tailed deer and changes to their abundance from the birth pulse. I further hypothesize that black bears will influence puma 
handling times of kills in seasons when they are most abundant, and thereby influence their kill rates. Through these chapters I attempt to understand the feeding ecology of pumas in a single-prey system, and how feeding ecology is influenced by prey and competitors.

In Chapters 6 and 7, I study the influences of both pumas and black bears on the scavenger guild, which is important because of the potential for large carnivores to indirectly influence scavengers through predation on ungulates. In Chapter 6, I investigate my hypotheses that both pumas and black bears will limit scavenger species richness and feeding times through competition. I also investigate my hypothesis that pumas and black bears will increase the nestedness, or structure, of the scavenger community due to specific strategies and adaptations of scavenger species. In Chapter 7, I investigate my hypotheses that pumas and black bears will influence 3 aspects of carrion acquisition (occurrence, total feeding time, and mean feeding bout duration) for scavenger classes and species. I also investigate my hypotheses that black bears, as a dominant scavenger, will influence the feeding behaviours of pumas. Through these chapters I attempt to determine how large carnivores, and their respective ecological niches, influence scavengers and the ecological community.

\section{Study Areas}

Puma management in California is particularly volatile, and is the result of decades of political battles and public ballot initiatives. In 1972 a moratorium on the sport hunting of pumas was declared by the California state legislature. The moratorium ended in 1986, and the California Fish and Game Commission attempted to re-instate sport hunting, but were met with disapproval by large portions of the public. In response, Proposition 117, a ballot initiative to outlaw all hunting of pumas, was passed by public vote in 1990 (Torres 1996). Due to this ballot initiative, pumas are listed as a "specially protected species" in California, and are essentially a protected species aside from individuals killed for livestock depredations 
or public safety. California is therefore the only western state to not have a hunting season on pumas (Anderson et al. 2010). I used two study sites in California, the first based in Santa Cruz County for Chapters $2 \& 3$, and the second in Mendocino National Forest for Chapters $4,5,6 \& 7$.

In my Santa Cruz study area, I conducted my study in a $1,700 \mathrm{~km}^{2}$ study area in the Santa Cruz Mountains, including parts of Santa Cruz, San Mateo, and Santa Clara counties of California (Figure 1). The puma population is not hunted and was considered to be at high density, with most mortality caused by humans (e.g. killed due to livestock depredations or through vehicle collisions). The study area was bounded by the Pacific Ocean to the west, the cities of San Francisco and San Jose to the north, and Highway 101 to the east. A major highway (Highway 17) bisects the study area.

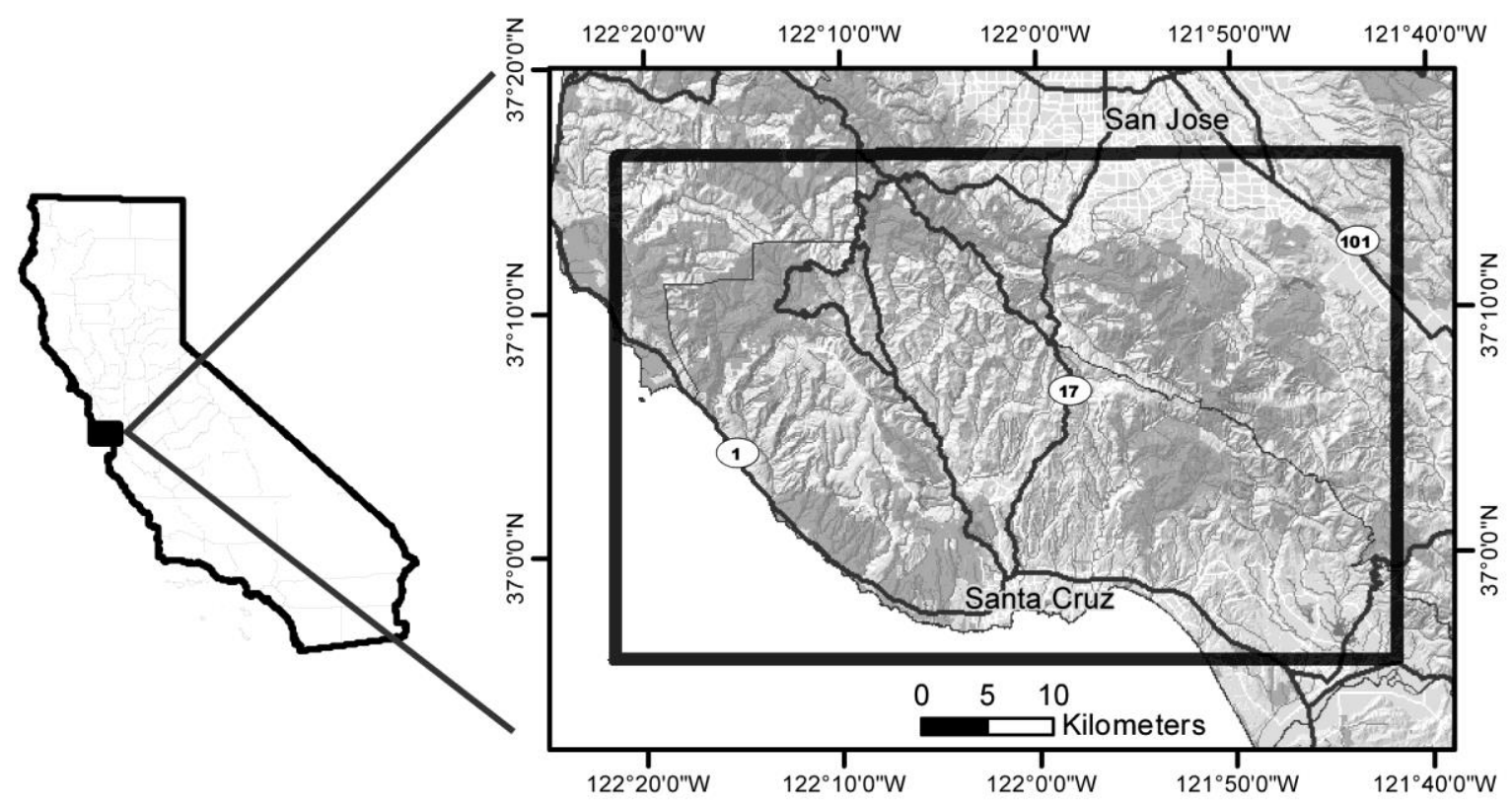

Figure 1. A map of my Santa Cruz study area, the study area included areas in Santa Cruz, San Mateo, and Santa Clara Counties in California. The study area is outlined by the thick black line, within the greater context of major highways and the cities of Santa Cruz and San Jose. 
Major habitat types in the study area changed with distance from the coast, and included: coastal scrub, coastal oak woodland, annual grassland, redwood (Sequoia sempervirens), montane hardwood-conifer, montane riparian, mixed chaparral, montane chaparral, montane hardwood, ponderosa pine (Pinus ponderosa), eucalyptus, valley foothill riparian, and valley oak woodland (Mayer and Laundenslayer 1988). Elevation ranged from sea level to $1,155 \mathrm{~m}$, and the climate is best described as mild Mediterranean. Historical average daily high temperatures ranged from $15.5-24.4^{\circ} \mathrm{C}$ and average daily low temperatures ranged from $3.9-11.1^{\circ} \mathrm{C}$. The annual rainfall varied from $58-121 \mathrm{~cm}$, the majority of which occurred from November to April (Wilmers et al. 2013).

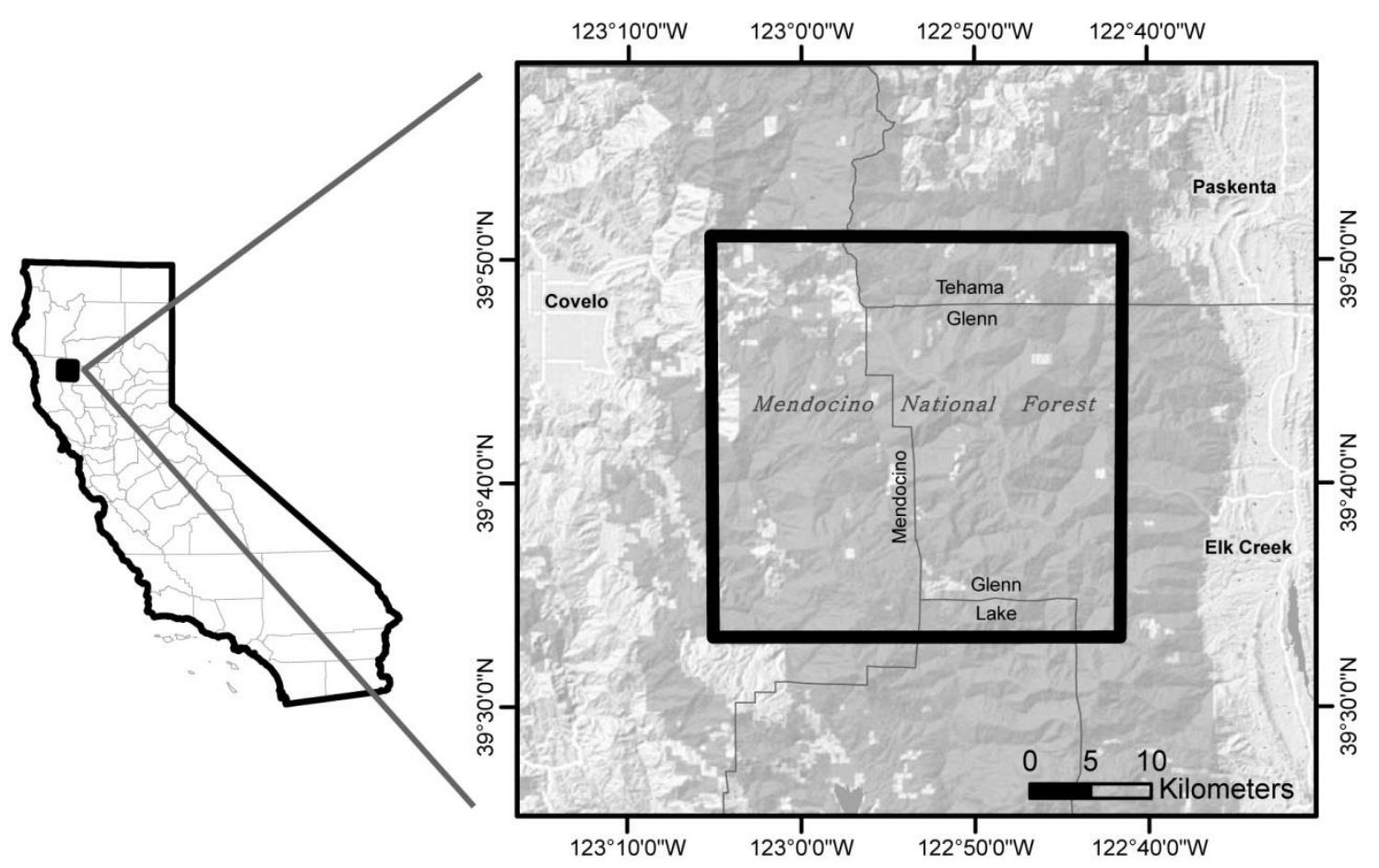

Figure 2. A map of my Mendocino study area, the study area included Mendocino National Forest and adjacent private lands. The study area is outlined by the thick black line, within the greater context of the North Coast Range and California. 
In my Mendocino study area I conducted my studies in and adjacent to the Mendocino National Forest, California. Our study area encompassed approximately $1,024 \mathrm{~km}^{2}$ and included portions of Mendocino, Tehama, Glenn, and Lake Counties (Figure 2). Elevations in the study area ranged from 396 to $2,466 \mathrm{~m}$, with moderately rolling terrain at lower elevations and moderately steep, mountainous terrain at higher elevations. Climate varied seasonally, with mean daily temperatures ranging from $-1{ }^{\circ} \mathrm{C}$ to $24^{\circ} \mathrm{C}$ and extreme temperatures ranging from $-12^{\circ} \mathrm{C}$ to $45.5^{\circ} \mathrm{C}$ (NOAA-Mendocino Pass, CA Weather Station). Mean annual precipitation averaged $132 \mathrm{~cm}$; the majority of precipitation occurred from December through March with only trace precipitation from May through September (NOAA-Ukiah Municipal Airport, CA Weather Station). Below 1,000 m precipitation was predominantly in the form of rain, while at higher elevations, snow was common.

Major habitat types based on the California Wildlife Habitat Relationships categories (Mayer and Laundenslayer 1988) changed with elevation, and included (in order of increasing elevation): blue oak (Quercus douglasii) woodland, annual grassland, montane hardwood conifer, Douglas fir (Pseudotsuga menziesii), mixed chaparral, montane hardwood, ponderosa pine (Pinus ponderosa), Klamath mixed conifer, montane riparian and montane chaparral. Black-tailed deer were the most common large ungulate in the area. Other ungulates present include non-native wild pigs (Sus scrofa), tule elk (Cervus canadensis nannodes), and domestic cattle (Bos taurus), all of which occurred at very low densities. Frequent non-ungulate prey species included California ground squirrels (Otospermophilus beecheyi), black-tailed jackrabbits (Lepus californicus), raccoons (Procyon lotor), and Western gray squirrels (Sciurus griseus). Competitors and scavengers noted at puma kills included black bears (Ursus americanus), coyotes (Canis latrans), gray foxes (Urocyon cinereoargenteus), turkey vultures (Cathartes aura), and common ravens (Corvus corvax). 


\section{Statement of Authorship}

Chapters 2 through 7 are intended for publication and have or will be submitted with my supervisors and others as co-authors for their help during the research process. However, for each of the chapters I conceived the questions, collected the samples and performed the experiments, conceptualized and conducted the analyses, and wrote each draft. I am the sole author of this dissertation, and I fully acknowledge and cite the ideas and work of other scientists.

All capture methods were approved by the Wildlife Investigations Lab of the California Department of Fish and Wildlife, and followed the guidelines of the American Society of Mammalogists (Sikes et al. 2011). In addition, the capture methods in my Mendocino study area were approved by independent Institutional Animal Care and Use Committee at the University of California, Davis, and the capture methods in my Santa Cruz study area were approved by independent Institutional Animal Care and Use Committee at the University of California, Santa Cruz.

Various collaborators have been recognized as co-authors on the individual manuscripts contained in this dissertation, all of whom provided comments on earlier drafts of manuscripts. Heiko Wittmer and Christopher Wilmers were my advisers, and gave me advice in planning and executing each aspect of the projects. Their support also included gaining permits and funding, commenting on my study proposals, and providing advice on numerous topics from study design to statistical analyses. Mark Elbroch and David Casady also provided helpful advice and feedback and are co-authors on various chapters. Numerous other people also helped with my dissertation, either with comments and reviews, or help with field work, and each is mentioned in the acknowledgements section of the appropriate chapter. 


\title{
Chapter 2
}

\section{Puma Scrape and Communication Behaviours:}

\author{
Understanding Functional Use and the
}

Variation among Sex and Age Classes

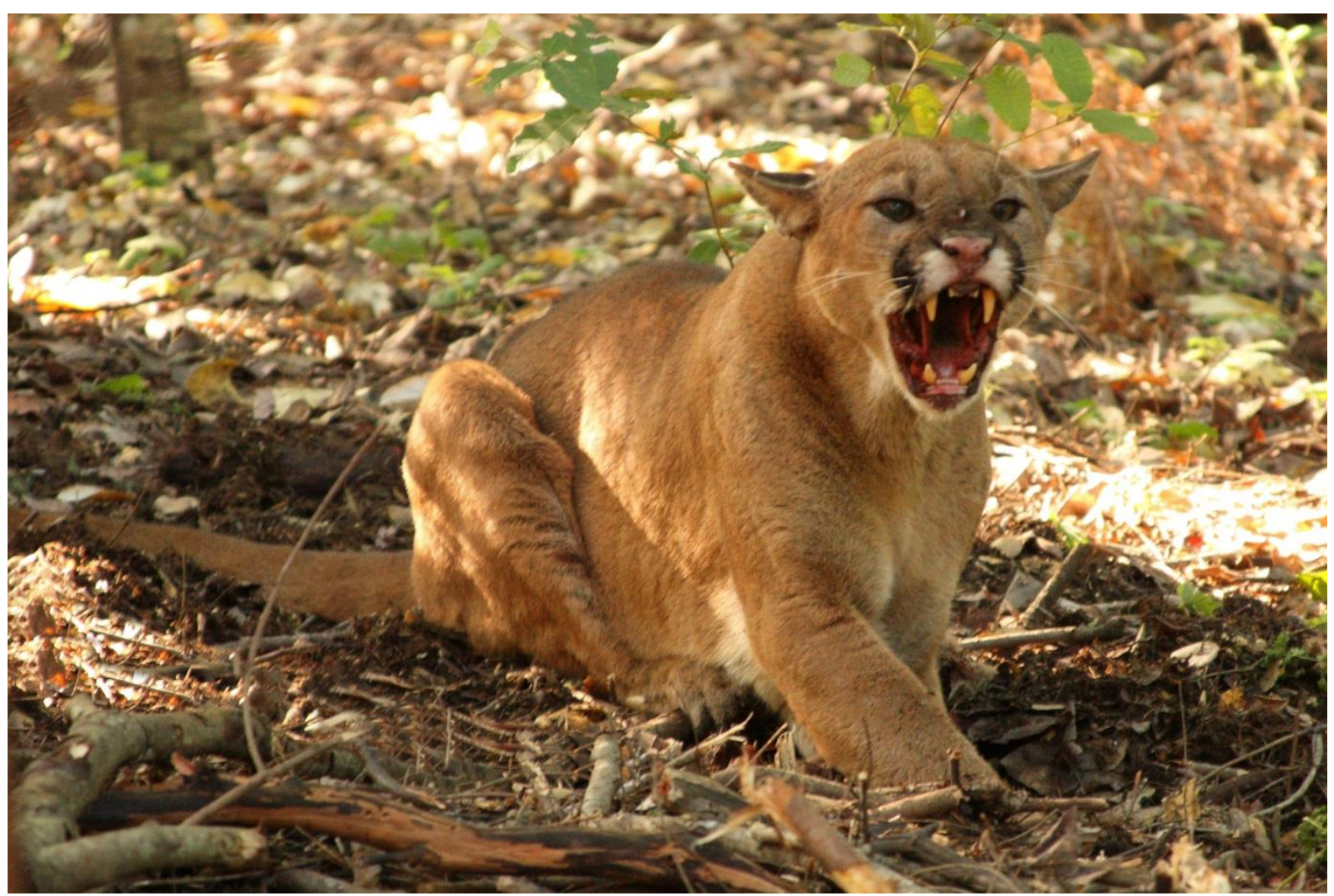


A version of this chapter was published as:

Allen, M.L., H.U. Wittmer, and C.C. Wilmers. 2014. Puma scrape and communication behaviours: Understanding functional use and variation by sex and age. Behaviour 151: 819-840. DOI:10.1163/1568539X-00003173.

\section{Acknowledgements}

Funding was provided by the California Department of Fish and Wildlife, the University of California at Santa Cruz, the University of California at Davis, NSF grant \#0963022, and the Gordon and Betty Moore Foundation. M. Allen was supported by a Victoria University of Wellington tuition scholarship. L. Sweanor, J. Munsi-South, and an anonymous reviewer provided comments on the published manuscript which greatly improved the quality of the manuscript. I also thank C. Wylie and D. Tichenor for their significant support in helping to capture pumas with hounds, K Cripe Fien for ArcGIS support, and D. Casady, P. Houghtaling and Y. Shakeri and numerous field technicians for their help on the project. 


\begin{abstract}
Intraspecific communication for mate selection sometimes varies between sexes based on different evolutionary life history patterns. Solitary felids use communication for territorial defence and location of mates, for which they use scent-marking behaviours including scraping, urine spraying, body rubbing, caterwauling, cheek rubbing, and the flehmen response, but these behaviours are not well understood in pumas (Puma concolor). I used motion-triggered video cameras to document the use of communication behaviours by male and female pumas, and used a series of experimental treatments to determine the mechanisms and importance of visual and olfactory cues in puma scrapes. I found that pumas use the physical scrape to locate communications, and then use urine to convey and interpret the communication itself. I also found significant differences among puma age and sex classes in the proportion of use and duration of time behaviours were displayed. Mature males spent significantly longer durations $(\bar{x}=22.1$ s) on producing behaviours (scraping, body rubbing, and caterwauling behaviours) than mature females $(\bar{x}=3.3 \mathrm{~s})$, and males used scraping (78.5\%) and body rubbing (12.4\%) behaviours at a higher proportion of visits than females (13.6\%, and 2.7\% respectively). Mature females spent significantly longer durations $(\bar{x}=30.4 \mathrm{~s})$ on consuming behaviours (investigating and flehmen response behaviours) than mature males $(\bar{x}=13.7 \mathrm{~s})$, and females used flehmen response $(30.6 \%)$ and caterwauling (9.3\%) behaviours at a higher proportion of visits than mature males $(6.5 \%$ flehmen and $0.4 \%$ caterwauling). Male reproductive strategy appears based on advertisement for possible mates, while female reproductive strategy appears based on assessment of possible mates. The use of communication behaviours also appears to develop with age, as immature pumas rarely visited and acted as non-participants in communication behaviours.
\end{abstract}




\section{Introduction}

Communication, defined as the transfer of information by an individual or group to another individual or group (Gunderson 1976), is an important component to understanding functions and evolution of animal behaviour. Intraspecific communication is important because it is one of the key aspects of social organization, and has been shown to directly affect individual fitness (Breed and Moore 2011, Davies et al. 2012). The use of intraspecific communication for mate selection is often dramatically different between sexes, and based on different evolutionary reproductive strategies (Logan and Sweanor 2001, Breed and Moore 2011, Davies et al. 2012). How drastic the sexually dimorphic differences in communication are, varies among taxonomic groups and depends upon life history patterns (Verberne and Leyhausen 1976, Mellen 1993).

Many solitary felids exhibit sexually dimorphic traits in both communication and life history patterns, including their use of scent-marking and courtship behaviours (Logan and Sweanor 2001, Sunquist and Sunquist 2002, Harmsen 2010). Solitary felids have spatially dispersed populations and intraspecific communication is most frequently via indirect signals through scent-marking (Seidensticker et al. 1973, Bailey 1993, Smith et al. 1989, Logan and Sweanor 2001, Harmsen 2010, Logan and Sweanor 2010). Due to this, their most frequent forms of communication are visual and olfactory signals, along with less common auditory and tactile signals (Bailey 1993, Logan and Sweanor 2001, Sunquist and Sunquist 2002, Logan and Sweanor 2010). In many species males create scent-marks more often than females (Seidensticker et al. 1973, Logan and Sweanor 2001, Sunquist and Sunquist 2002, Harmsen 2010, Logan and Sweanor 2010). Mellen (1993) documented a variety of communication behaviours in captive felids, including scraping, urine spraying, and body rubbing (see Table 2 for definitions), with sexually dimorphic tendencies in many species. 
However, the differences in the use of communication behaviours between sexes and the mechanisms behind mate selection among different felid species are understudied.

Though many aspects of puma (Puma concolor) behaviour are similar to other felids (Sunquist and Sunquist 2002), they differ in their distribution pattern and reproductive behaviours. Most large felids inhabit equatorial regions, and breed throughout the year (e.g. cheetahs, Acinonyx jubatus, and jaguars, Panthera onca), while most felids that inhabit northern latitudes (i.e. Eurasian lynx, Lynx lynx, bobcat, L. rufus, Canada lynx, L. canadensis, European wildcat, Felis silvestris) are smaller and have very short breeding periods during the late winter or early spring (Sunquist and Sunquist 2002). Pumas range extends high into northern and southern latitudes in the Americas (Sunquist \& Sunquist 2002), and unlike most other felids in northern latitudes, they mate throughout the year (though there are other exceptions, e.g. tiger, Panthera tigris, and leopard, Panthera pardus). Logan \& Sweanor $(2001,2010)$ hypothesized that the result of pumas being spatially dispersed and reproductive behaviours occurring throughout the year, has led to sexually dimorphic evolutionary reproductive strategies, including the avoidance of males by females when they are caring for young. If so, these strategies would extend to their use of communication behaviours, which are important to the success of the strategy.

Pumas use indirect methods of scent-marking and other behaviours to communicate with conspecifics. The most common form of puma communication is scraping (Currier 1983, Logan and Sweanor 2001), which is a combination of visual and olfactory signals. Scrapes are depressions in the ground excavated by the puma's hind feet, most commonly comprised of leaf litter or duff, and usually accompanied by urine and occasionally faeces (Seidensticker et al. 1973, Currier 1983, Logan and Sweanor 2001, Elbroch 2003). Currently, the relative importance of visual and olfactory components in scrape communications is unknown (Logan and Sweanor 2010). Scrapes are regularly created along territorial 
boundaries or prominent travel-ways (Seidensticker et al. 1983, Logan \& Sweanor 2010), and are thought to be made primarily by adult males and less often or not at all by females or subadult males (Seidensticker et al. 1983, Logan and Sweanor 2001, Harmsen 2010, Logan and Sweanor 2010). Other communication behaviours used by pumas in conjunction with scraping behaviour include caterwauling, cheek rubbing, and the flehmen response (Verberne and Leyhausen 1976, Mellen 1993, Harmsen 2010, McBride and McBride 2010, McBride and Sensor 2012).

I initiated a study to determine intraspecific functions of scraping behaviour based on videos recorded by motion-triggered cameras placed at known scent-marking areas of pumas in California. My first objective was using an experimental treatment design to determine the mechanisms and importance of different components of scrapes. I hypothesized that visual cues (the physical scrape) would be used to locate the scrape, while olfactory cues (the urine) would be used to transmit signals (hypotheses for each treatment noted in Table 1). My second objective was to determine whether scraping and associated behaviours were used in different proportions or durations by sex and age classes, based on the hypothesis of Logan and Sweanor $(2001,2010)$ that male and female pumas have evolutionarily different breeding strategies. I first set out to determine if differences occurred in the proportion of use of communication behaviours among puma sex and age classes (hypotheses for each behaviour are noted in Table 2). I next set out to determine if puma sex and age classes spent different durations of time displaying producing (scraping, body rubbing, and caterwauling behaviours) and consuming (investigating and flehmen response behaviours) behaviours at scrapes (hypotheses noted in Table 2). 


\section{Materials and Methods}

\section{Definitions and Field Methods}

Among puma biologists there has arisen a unique and dispersed terminology regarding scraping behaviour; for the purposes of this study, I differentiated between what I termed "individual scrapes" and "community scrapes". Individual scrapes are the outcome of scraping behaviour - at its most simple, a scrape. Community scrapes are defined as scrape areas used regularly to communicate with conspecifics, and are therefore used by more than one puma. These areas were previously described by Logan \& Sweanor (2001) as shared scrape sites, and by Harmsen et al. (2010) as scrape clusters. Community scrapes were identified by an abundance of scrapes in a concentrated area (roughly $\geq 3$ scrapes within $9 \mathrm{~m}^{2}$, though this can vary depending on substrate and visitation), which had no association with either kill or bedding sites.

My first step was to find and document individual and community scrapes. I initially found community scrapes by searching dominant landscape features, areas commonly used by pumas, and by following puma tracks across the landscape. As the study progressed, I used a modification of a custom program developed by C. Wilmers (see Wilmers et al. 2013) for identifying kill sites through GPS data, and used it to locate potential community scrapes based on clusters of GPS locations more than 7 days apart from each other in time (Wilmers et al. 2013). I used the data from my first 9 males (ages 2.5-9 years) and then visited these sites and searched the area for the presence of scrapes. I took measurements of width and length of individual scrapes and accompanying tracks to confirm the scrapes were created by pumas (Elbroch 2003). I set up motion-triggered video cameras with infrared flash (Bushnell TrophyCam, Overland Park, KS) at 26 spatially independent community scrapes for the experimental treatments (see below); with each community scrape being at least $200 \mathrm{~m}$ from each other. I then added additional cameras for monitoring communication behaviours, 
though not always spatially independent, for a total of 45 community scrapes monitored (camera locations noted on Figure 1). The cameras were programmed for maximum recording and viewing, with a set-up to record a 60 s video every time motion was detected with a 1s delay before triggering again.

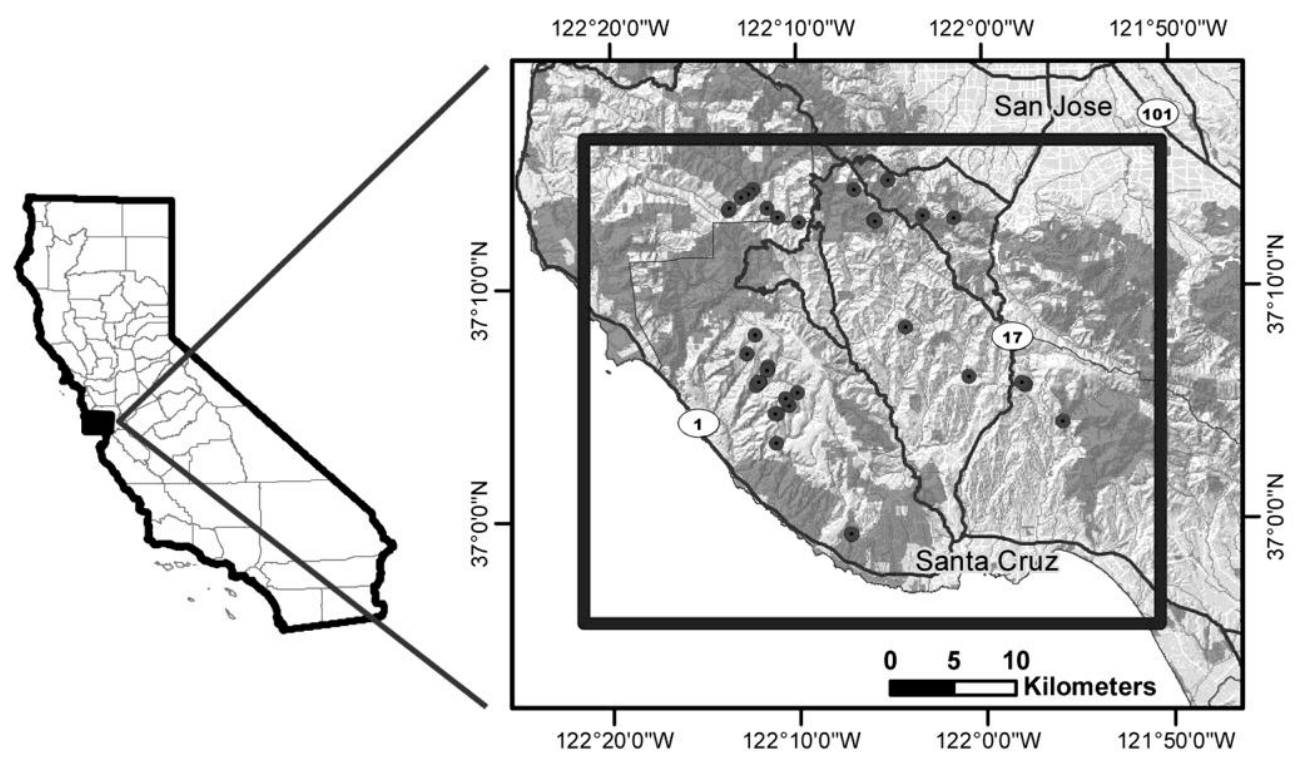

Figure 1. A map of the study area; outlined by the thick black line within the greater context of major highways and the cities of Santa Cruz and San Jose. The locations of the 45 community scrapes I monitored with motiontriggered video cameras are noted.

I concurrently captured 36 pumas from 2008-2012 using trailing hounds, cage traps, or leg-hold snares. Upon capture pumas were anesthetized with Telazol (Fort Dodge, IW). Once anesthetized, pumas were sexed, weighed, and measured, and then fit with an ear tag and a combined GPS/radio telemetry collar (Vectronics Aerospace). When possible, individual collared pumas detected on cameras were identified by unique collar identifiers and/or ear tags, while pumas without collars were identified by the spotting patterns on the 
inside of the upper leg and other unique features including scarring, kinks in their tail, and old injuries (Kelly et al. 2008). During captures age was determined through measurements of gum line recession (Laundré et al. 2000) for each individual. When possible, I determined the sex and age classes (mature $\geq 2.5$ years old, immature $<2.5$ years old) for individuals without collars through the position of genitals and external physical characteristics (Ashman et al. 1983, Currier 1983).

\section{Design of Experimental Treatments}

After community scrapes were located, I created a series of experimental treatments at 26 community scrapes, to determine the roles of the visual and olfactory cues in puma individual scrapes. I created the experimental treatments based on a crossover design (Table 1), and distributed the paired experimental treatments in a random design. Each community scrape was given a numeric label, and each treatment variable pair was assigned to a numbered community scrape, before rotating to the next sequential number the following month. Each community scrape had a most common route of travel for the pumas (though the pumas were as likely to enter or exit from either direction). I determined the most likely route of travel, and created the treatment variables on either side of this route to allow equal probability of detection. This was accounted for in the random design with each treatment variable pair switching sides (from left to right from the cameras perspective) in the sequential pairs. The experimental treatments involved 6 different pairs of scrape variables; the designs each involve the presence or absence of male puma urine $(a)$, a physical scrape $(b)$, and control $(0)$. I used the first visit by a puma to each experimental treatment set as my samples for analyses.

All experimental treatments were created by the same person to control for reliability and variation. Physical scrape components were created by hand using scent-free latex 
gloves, and I administered $0.5 \mathrm{cc}$ of puma urine from a glass eyedropper for the urine components. For the control, I did not use either a physical scrape or urine, and instead patted the ground with gloved hands three times to control for human presence or any novel scents created at the community scrape. I purchased the un-neutered male puma urine from a captive facility (InHeatScents, Alabama, USA) where they collected the urine from live pumas. The set of experimental treatments were monitored for 3-4 weeks, and then at the end of the monitoring period I raked the community scrape and created the new set of experimental treatments based on my random design.

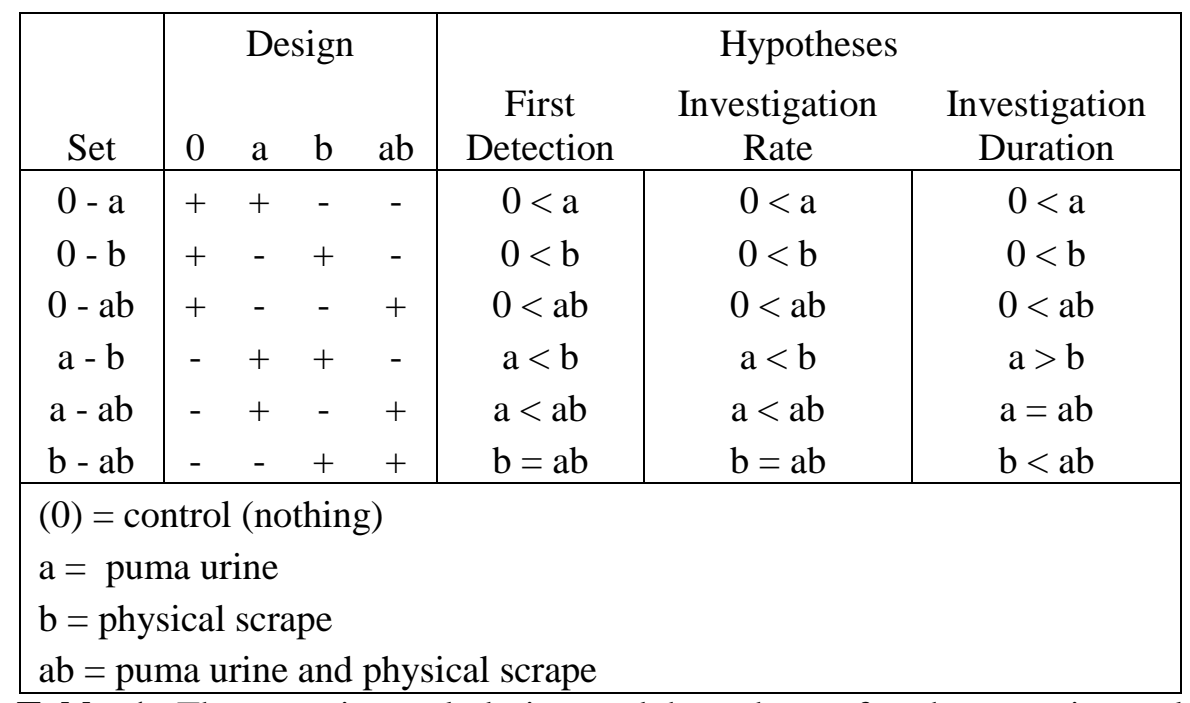

Table 1. The experimental design and hypotheses for the experimental treatment sets. The design breaks down which variables were present at each experimental treatment set. The hypotheses show how I expected variables to perform against each other, including first detection rates, investigation rates, and investigation duration.

I viewed each video for puma activity and reaction to the experimental treatments, and quantified 3 olfaction responses: first investigation, investigation rate, and the investigation duration. I defined olfactory investigation as when a puma was actively sniffing 
one of the components of the experimental treatment with its nose within $15 \mathrm{~cm}$ of it. I defined first investigation as the treatment variable which the puma olfactory investigated first during its visit. Investigation rate was determined as the proportion of each treatment variable which was olfactory investigated by the pumas during visits. I determined the investigation duration by recording the duration of time the puma olfactory investigated each of the experimental treatments.

\section{Design of Communication Behaviours Research}

I attempted to determine whether scraping and associated behaviours were used differently by pumas of different sex and age classes. I first removed any videos where pumas were reacting to the experimental scrape treatments I had created, in case my experiments caused changes in the puma's behaviour, and then analysed the remaining videos of puma visits. When possible, I identified the individual puma (either collared pumas or pumas without collars with distinctive markings), and categorized the puma as mature male, mature female, immature male, or immature female, with immature pumas either independent or traveling with their mother. I censured any videos where I was unable to determine the class of pumas without collars. I watched each video which recorded a puma visiting a community scrape from February 2010-December 2012, and quantified the different behaviours it displayed while at the community scrape. In each video I recorded the duration of the overall visit to the closest second; and I then noted the occurrence of 5 behaviours and recorded the durations of each of the behaviours to the closest second. The behaviours included: scraping, olfactory investigation, body rubbing, flehmen response, and caterwauling (with definitions in Table 2). I then grouped scraping, body rubbing, and caterwauling into the category of producing behaviours, and grouped olfactory investigation and flehmen responses into consuming behaviours. 


\begin{tabular}{|c|c|c|c|}
\hline Behaviour & Definition & Hypothesis & Rationale \\
\hline Scraping & $\begin{array}{l}\text { Where the puma scraped in substrate with } \\
\text { their hind feet and sometimes urinated } \\
\text { and/or defecated on the scrape. }\end{array}$ & $\begin{array}{l}\text { Mature males will scrape } \\
\text { at higher rates than other } \\
\text { classes. }\end{array}$ & $\begin{array}{l}\text { Due to female mate choice and male } \\
\text { territoriality, I expect males to advertise their } \\
\text { fitness most often, and expect females to } \\
\text { advertise only when in oestrus. }\end{array}$ \\
\hline $\begin{array}{l}\text { Olfactory } \\
\text { Investigation }\end{array}$ & $\begin{array}{l}\text { Where the puma is using its olfactory } \\
\text { sense to investigate cues and signals, } \\
\text { noted by the pumas nose within } 15 \mathrm{~cm} \text { of a } \\
\text { scrape or other cue. }\end{array}$ & $\begin{array}{l}\text { Investigation rates will be } \\
\text { similar among all three } \\
\text { classes. }\end{array}$ & $\begin{array}{l}\text { Because scraping behaviour is the most common } \\
\text { form of intraspecific communication, I would } \\
\text { expect all classes of pumas to be investigating at } \\
\text { equal rates. }\end{array}$ \\
\hline Body Rubbing & $\begin{array}{l}\text { Where the puma rubs its cheek or shoulder } \\
\text { on the ground, a stump, or tree branch, or } \\
\text { rolls back and forth on the ground. }\end{array}$ & $\begin{array}{l}\text { Mature males will body } \\
\text { rub at higher rates than } \\
\text { other classes. }\end{array}$ & $\begin{array}{l}\text { Due to female mate choice and male } \\
\text { territoriality, I expect males to advertise their } \\
\text { presence most frequently. }\end{array}$ \\
\hline Caterwauling & $\begin{array}{l}\text { Where the puma gives a loud and } \\
\text { reverberating call characterized by } \\
\text { multiple changes in pitch. }\end{array}$ & $\begin{array}{l}\text { Mature females will } \\
\text { caterwaul at higher rates } \\
\text { than other classes. }\end{array}$ & $\begin{array}{l}\text { Females are thought to caterwaul to attract } \\
\text { prospective mates when they are in oestrus; this } \\
\text { behaviour has not been recorded in males. }\end{array}$ \\
\hline $\begin{array}{l}\text { Flehmen } \\
\text { Response }\end{array}$ & $\begin{array}{l}\text { Where the puma picked up its head and } \\
\text { curled back its upper lip, sometimes } \\
\text { arching its neck backwards, in order to } \\
\text { expose its vomeronasal organ. }\end{array}$ & $\begin{array}{l}\text { Mature female flehmen } \\
\text { response rates will be } \\
\text { higher than other classes. }\end{array}$ & $\begin{array}{l}\text { Because the flehmen response is used to assess } \\
\text { potential mates, females will use flehmen } \\
\text { response at higher rates based on classic female } \\
\text { choice theory. }\end{array}$ \\
\hline Producing & $\begin{array}{l}\text { The communication behaviours of } \\
\text { scraping, body rubbing, and caterwauling. }\end{array}$ & $\begin{array}{l}\text { Mature males would spend } \\
\text { longer durations on } \\
\text { producing behaviours than } \\
\text { other classes. }\end{array}$ & $\begin{array}{l}\text { If male strategy is based on advertisement they } \\
\text { would be motivated to spend longer durations } \\
\text { producing signals for prospective mates to find } \\
\text { than other classes }\end{array}$ \\
\hline Consuming & $\begin{array}{l}\text { The communication behaviours of } \\
\text { investigating and flehmen responses. }\end{array}$ & $\begin{array}{l}\text { Mature females would } \\
\text { spend longer durations on } \\
\text { consuming behaviours } \\
\text { than other classes. }\end{array}$ & $\begin{array}{l}\text { If female puma strategy is based on assessment } \\
\text { they would be motivated to assess the status of } \\
\text { all possible mates and spend longer durations } \\
\text { consuming signals than other classes. }\end{array}$ \\
\hline
\end{tabular}

Table 2. Definitions of puma communication behaviours, and my hypotheses regarding differences in the proportion and duration of communication behaviours among puma sex and age classes. Puma classes include mature males and females ( $\geq 2.5$ years), and immature pumas $(<2.5$ years $)$. The behaviour hypotheses regard the proportion of visits where pumas of each class would exhibit the five behaviours, while the producing and consuming hypotheses regard the differences in duration between puma classes. 


\section{Statistical Analyses Overview}

I used program $R$ version 3.0.0 (R Core Team 2013) for all statistical analyses. Following $R$ guidelines (R Core Team 2013), I cite any associated packages used in the analyses. Before performing statistical analyses I tested each continuous variable data set for normality with a Shapiro-Wilk test and for variance equality with a Levene's test (Sokal and Rohlf 1987). In each analysis, I considered $p \leq 0.05$ significant.

\section{Experimental Treatments Statistical Analyses}

I analysed the experimental treatments based on the paired design of the experiments, with each statistical test between the variables present at an experimental treatment set (Table 1). I tested three different sets of hypotheses (Table 1) for each experimental treatment: which variable was investigated first, the investigation rate for each variable, and the duration of time each variable was investigated. For example, I first tested the experimental treatment set of puma urine versus the control, and tested for differences in the two treatment variables in first investigation, investigation rate, duration of investigation (using the analyses below), and then progressed through each experimental treatment set in turn.

For first investigation, I first removed samples where no variable was investigated, and then used a binomial probability test (Sokal and Rohlf 1987) to determine if the treatment variables were different in their rate of being investigated first. For investigation rate, I used a z-test of proportions between two populations (Sokal and Rohlf 1987) to determine if treatment variables were investigated in a different proportion of puma visits. For duration of investigation, because of a lack of homoscedasticity I used a two-way Student's t-test with unequal variances (Sokal and Rohlf 1987) to test for differences between the treatment variables. After testing my hypotheses, I created post-hoc effect sizes based on Cohen's $d$ 
score (Cohen 1992) for values with significant differences, and I considered scores of 0.20 small effects, 0.50 medium effects, and 0.80 large effects (Cohen 1992).

\section{Communication Behaviours Statistical Analyses}

I used a series of analyses to determine if pumas of different sex and age classes varied in their use of communication behaviours at community scrape sites (Table 2). To account for malfunctions of cameras and ensure I recorded the majority of a visit I removed samples with substandard quality and videos where I recorded less than 8 seconds of a puma visit. I initially had 5 puma age and sex classes: mature males $(\mathrm{n}=535)$, mature females alone $(n=152)$, mature females with cubs $(n=14)$, immature males $(n=40)$, and immature females $(n=11)$. I first did pre-tests for each of the behaviours, first testing for differences between females with cubs against females without cubs, and then testing immature males against immature females. I did not find any statistical significant differences in the pre-tests, and I therefore pooled the visits for females with and without cubs, and also pooled all immature pumas together. In each analysis I then tested among 3 puma classes: mature males, mature females, and immature pumas. Because the majority of visits were by mature male pumas, I only used the first 10 visits by each individual mature male puma to each monitored community scrape in order to control for the large sample size of males in comparison to females and immature pumas.

First, I tested for differences in the duration of visits to community scrapes among each puma class (mature males, mature females, and immature pumas). I determined duration of time for each visit to the closest second, and then used a mixed-model Analysis of Variance (ANOVA) to test for differences among puma classes using the nlme package (Pinheiro et al. 2013). I used the visit duration as my dependent variable, puma class as a 
fixed independent variable, and known individual pumas as a random independent variable (to account for the variable number of samples among individual pumas).

Second, I tested if puma classes displayed each of the communication behaviours (scraping, olfactory investigation, caterwauling, flehmen response, and body rubbing) in a different proportion of visits using a chi-square test (Sokal and Rohlf 1987). In some cases, because of very low proportions of behaviours, I used a Fisher's exact test instead of a chisquare test (Sokal and Rohlf 1987); in these cases I just report the degrees of freedom and pvalues. I then calculated post hoc effect sizes for behaviours with significant statistical differences by calculating phi coefficients (Yule 1912), using the vcd package (Meyer et al. 2013), and I considered scores of 0.10 small effects, 0.30 medium effects, and 0.50 large effects (Cohen 1992).

Third, I determined the duration of time pumas displayed each type of behaviour during visits to the closest second, and then tested for differences in the duration of time puma classes spent displaying producing and consuming behaviours (Table 2). Due to the lack of linearity and homoscedasticity, I performed a logarithmic transformation (Sokal and Rohlf 1987) in order to meet the assumptions of the ANOVA. I then used two mixed-model ANOVA's in the nlme package (Pinheiro et al. 2013), with the first model used for producing behaviours and the second model used for consuming behaviours. I used the duration spent on the behaviour during a visit as my dependent variable, puma class as a fixed independent variable, and known individual pumas as a random independent variable (to account for the variable number of samples among individual pumas). 


\begin{tabular}{|c|ccc|cccc|}
\hline $\begin{array}{c}\text { Variable } \\
\text { Pair }\end{array}$ & \multicolumn{3}{|c|}{$\begin{array}{c}\text { First Investigation } \\
\text { Percentage of }\end{array}$} & First Detection & $p$ & df & Percentage \\
Investigated & z-score & $p$ \\
\hline (0) vs a & 33 & 0.61 vs 0.39 & 0.2962 & 118 & 0.40 vs 0.32 & 0.9519 & 0.3412 \\
(0) vs b & 20 & 0.25 vs 0.75 & 0.0414 & 40 & 0.43 vs 0.91 & -3.2733 & 0.0011 \\
(0) vs ab & 21 & 0.14 vs 0.86 & 0.0015 & 40 & 0.38 vs 0.91 & -3.5423 & 0.0004 \\
a vs b & 25 & 0.24 vs 0.76 & 0.0146 & 64 & 0.27 vs 0.67 & -3.2063 & 0.0013 \\
a vs ab & 22 & 0.09 vs 0.91 & 0.0001 & 44 & 0.22 vs 0.96 & -5.0906 & $<0.0001$ \\
b vs ab & 28 & 0.50 vs 0.50 & 1.0000 & 58 & 0.70 vs 0.77 & -0.5839 & 0.5593 \\
\hline
\end{tabular}

Table 3. Differences in first detection and probabilities of detection between variables in the experimental treatments. The percentage of visits where a variable was investigated first is noted along with their p-values. The probability of detections for the variables is represented as percentages, and I also report z-scores and p-values.

\section{Results}

\section{Experimental Treatments}

My analyses revealed that when compared to the control the puma urine was not investigated first more frequently, nor investigated at a higher rate, or investigated for longer durations of time (Tables 3 and 4). In contrast, when compared to the control, the physical scrape and the physical scrape with urine were investigated first more frequently $\left(p_{\mathrm{b}}=\right.$ 0.0414, $\left.p_{\mathrm{ab}}=0.0015\right)$, investigated at a higher rate $\left(p_{\mathrm{b}}=0.0011, p_{\mathrm{ab}}=0.0004\right)$, and investigated for longer durations of time $\left(p_{\mathrm{b}}=0.0004, d_{\mathrm{b}}=1.29, p_{\mathrm{ab}}<0.0001, d_{\mathrm{ab}}=1.74\right)$. When compared to the puma urine, the physical scrape and the physical scrape with urine were investigated first more often $\left(p_{\mathrm{b}}=0.0146, p_{\mathrm{ab}}=0.0001\right)$, investigated at a higher rate $\left(p_{\mathrm{b}}\right.$ $\left.=0.0013, p_{\mathrm{ab}}<0.0001\right)$, and investigated for longer durations of time $\left(p_{\mathrm{b}}=0.0024, d_{\mathrm{b}}=0.80\right.$, $\left.p_{\mathrm{ab}}=0.0006, d_{\mathrm{ab}}=1.14\right)$. In addition, I found that when compared to the physical scrape the physical scrape with puma urine was not investigated first more frequently, or investigated at a higher rate, but was investigated for longer durations of time $(p=0.0465, d=0.53)$. 


\begin{tabular}{|c|c|c|c|}
\hline Variable Pair & df & Mean \pm Standard Error & $p$ \\
\hline$(0)$ vs a & 118 & $0.5 \pm 0.1$ vs $0.8 \pm 0.2$ & 0.2728 \\
\hline$(0)$ vs b & 40 & $0.7 \pm 0.2$ vs $4.8 \pm 1.0$ & 0.0004 \\
\hline$(0)$ vs ab & 40 & $0.5 \pm 0.2$ vs $6.8 \pm 1.1$ & $<0.0001$ \\
\hline a vs b & 64 & $0.4 \pm 0.1$ vs $2.0 \pm 0.5$ & 0.0024 \\
\hline a vs ab & 44 & $0.9 \pm 0.5$ vs $5.3 \pm 1.1$ & 0.0006 \\
\hline b vs ab & 58 & $1.9 \pm 0.4$ vs $3.7 \pm 0.8$ & 0.0465 \\
\hline
\end{tabular}

Table 4. Differences in investigation duration between paired treatment variables in the experimental treatments. The average duration of investigation in seconds and their standard error are noted, along with the pairwise $\mathrm{p}$-values between the variables.

\section{Communication Behaviours}

I recorded 762 visits by pumas of known age classes, including 37,632s of puma activity, and a minimum of 25 individuals. Mature male pumas were the most common visitor to community scrapes, with $73.1 \%$ of visits, in comparison to $22.1 \%$ for mature females, and $3.4 \%$ for immature pumas, while $1.4 \%$ were visits by a mature male and female traveling together. My analysis of the duration of visits to community scrapes did not find a significant difference among classes $\left(\mathrm{df}_{2,522} \mathrm{~F}=1.59, p=0.2040\right)$, with an average visit duration of $57.6(95 \% C I=52.2-63.1)$ seconds.

My analyses of communication behaviours revealed significant differences among puma classes in the proportion of visits for each behaviour. Mature males exhibited scraping at $78.5 \%$ of visits, a significantly higher proportion of visits than the $13.6 \%$ for mature females $\left(d f_{1,637} X^{2}=202.67, p<0.0001\right.$, phi $\left.=0.57\right)$ and the $12.8 \%$ for immature pumas $\left(d f_{1}\right.$, ${ }_{529} X^{2}=76.84, p<0.0001, p h i=0.39$ ) (Figure 2), while mature females and immature pumas did not differ significantly. Mature males exhibited olfactory investigation at $89.6 \%$ of visits, a significantly higher proportion than the $76.9 \%$ for immature pumas $\left(d f_{1,529} X^{2}=4.63, p=\right.$ $0.0301, p h i=0.11)$. Mature females exhibited olfactory investigation at $85.7 \%$ of visits, and were not significantly different than mature males or immature pumas. 


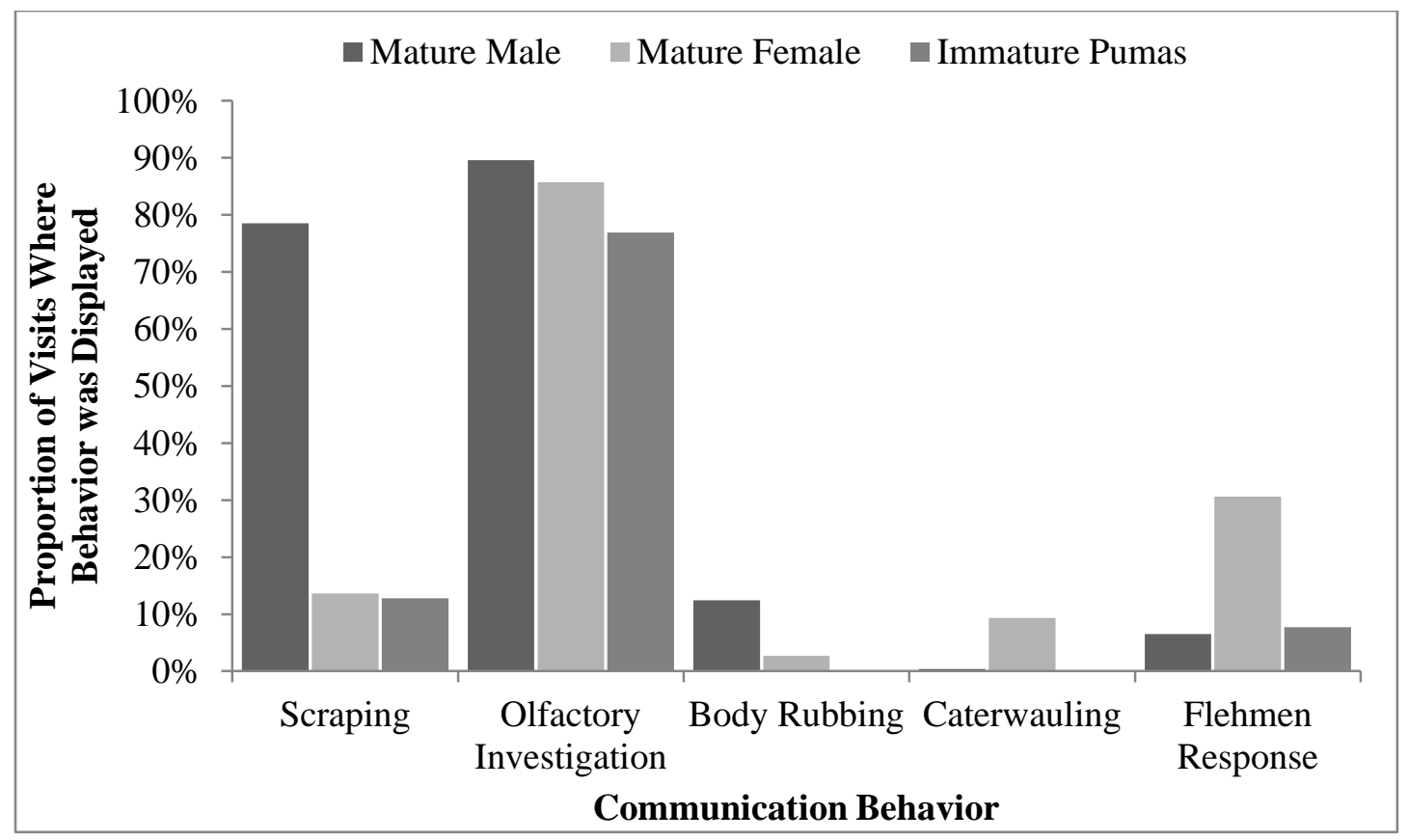

Figure 2. The proportion of visits where scraping and communication behaviours occurred for each puma age class. Behaviours include scraping, olfactory investigation, body rubbing, caterwauling, and flehmen responses.

Mature males exhibited body rubbing at $12.4 \%$ of visits, a significantly higher proportion of visits than the $2.7 \%$ for mature females $\left(d f_{1,637} X^{2}=10.57, p=0.0012\right.$, phi $=$ $0.14)$ and the $0.0 \%$ for immature pumas $\left(d f_{1,529} p=0.0153\right.$, phi $\left.=0.10\right)$, while mature females and immature pumas did not differ significantly. Mature females exhibited flehmen responses at $30.6 \%$ of visits, a significantly higher proportion of visits than the $6.5 \%$ for mature males $\left(d f_{1,637} X^{2}=59.82, p<0.0001, p h i=0.31\right)$ and the $7.7 \%$ for immature pumas $\left(d f_{1,184} X^{2}=\right.$ 7.30, $p=0.0069$, phi=0.21), while mature males and immature pumas did not differ significantly. Mature females exhibited caterwauling at $9.3 \%$ of visits, a significantly higher proportion of visits than the $0.4 \%$ for mature males $\left(d f_{1,612} p<0.0001\right.$, phi $\left.=0.24\right)$ and the $0.0 \%$ for immature pumas $\left(d f_{1,177} p=0.0401, p h i=0.39\right)$, while mature males and immature pumas did not differ significantly.

The duration of producing behaviours was significantly different among puma classes $\left(\mathrm{df}_{2,522} \mathrm{~F}=41.38, p<0.0001\right)$ (Figure 3). My post hoc analysis revealed that mature males spent longer durations $(\bar{x}=22.1 \mathrm{~s} \pm 1.5 S E)$ on producing behaviours than mature females $(\bar{x}$ 
$=3.3 \pm 1.0 S E \mathrm{~s}, \mathrm{p}<0.0001)$ or immature pumas $(\bar{x}=2.7 \mathrm{~s} \pm 1.4 S E, p<0.0001)$, but there was not a significant difference between immature pumas and mature females. The duration of consuming behaviours was significantly different among puma classes $\left(\mathrm{df}_{2,522} \mathrm{~F}=14.31, p\right.$ $<0.0001)$. My post hoc analysis revealed that mature females spent longer durations $(\bar{x}=$ $30.4 \mathrm{~s} \pm 3.0 \mathrm{SE})$ on consuming behaviours than mature males $(\bar{x}=13.7 \mathrm{~s} \pm 1.0 \mathrm{SE}, p=0.0001)$ or immature pumas $(\bar{x}=17.5 \mathrm{~s} \pm 5.2 S E, p<0.0001)$, but there was not a significant difference between immature pumas and mature males.

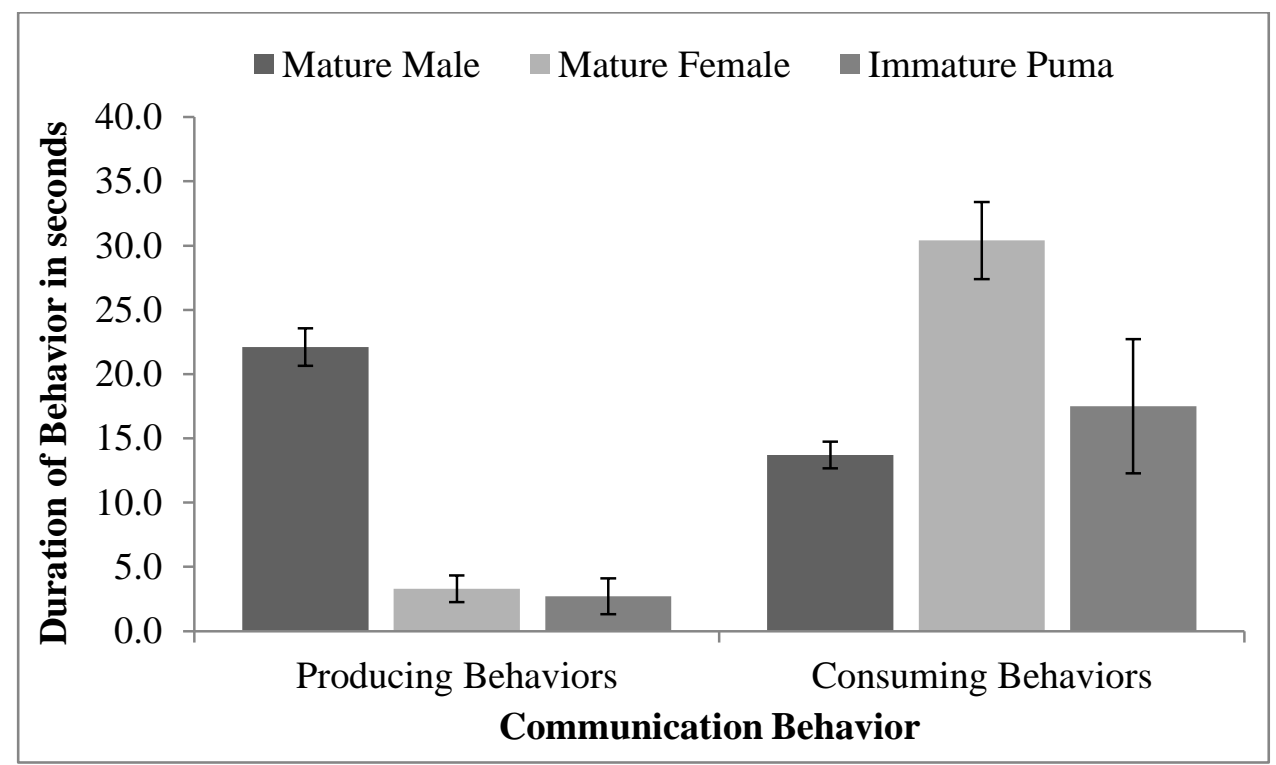

Figure 3. Mean duration in seconds of producing and consuming behaviours during visits to community scrapes by each class of pumas. The error bars represent the standard error. Producing behaviours include scraping, body rubbing, and caterwauling, while consuming behaviours include investigating and flehmen responses.

\section{Discussion}

My results suggest that pumas exhibit strong sexually dimorphic differences in their scrape communication behaviours, and pumas appear to be a good study species for further study of sexually dimorphic behaviours including mate selection. Male and female pumas exhibited differences in their duration of producing and consuming behaviours, as well as the 
proportion of communication behaviours used during visits. My results support the hypothesis of Logan \& Sweanor $(2001,2010)$ that the differences in use of communication behaviours at community scrapes can be explained through different life history patterns and evolutionary reproductive strategies of the sexes. Male strategy appears to be based on regular visitation and the production of signals for potential mates to find. In contrast, female visitation is infrequent, in order to limit potentially dangerous encounters with males which could lead to infanticide. Female strategy is apparently to limit risk, and then visit community scrapes for short time periods just before and during oestrus, and use these visits to assess potential mates.

I found that mature males spent longer durations exhibiting producing behaviours than mature females, and also exhibited scraping and body rubbing behaviours at a higher proportion of visits than mature females. Mature males have large home ranges, and need to leave sign for potential mates to find as well as for territorial defence. Dominance has been linked to frequency of scent-marking in mice (Hurst \& Benyon 2004, Thonhauser et al. 2013), and male strategy may be based on trying to produce as many signals as possible for potential mates to find. The bi-functional role of scraping for territorial maintenance and advertisement for mates suggests male strategy is based on production of signals for others to find. However, although scraping behaviour was frequently used during visits by mature males, there appeared to be variation in both the duration of visits and the number of scrapes created. I hypothesize that when males detect recent visits by female pumas they increase the duration of their visits and the number of scrapes they create. Similar to Logan \& Sweanor (2001), I never recorded pumas spraying urine, while in contrast to Harmsen (2010), I never recorded pumas scraping with their front feet, and I am doubtful that pumas exhibit these behaviours in my study area. I found body rubbing behaviour to be used at a higher proportion of visits by mature males, and while I am unclear what triggers body rubbing 
behaviours in pumas, I hypothesize that it is used as an additional form of communication attempts for potential mates.

Mature females were less frequent visitors to community scrapes, and spent less time using producing behaviours. Although there are more mature females than mature males in any given puma population (Sunquist \& Sunquist 2002), mature females were less frequent visitors, accounting for $22.1 \%$ of visits. The simplest explanation is that mature females visit for short bouts of temporally clustered visits while in oestrus, as hypothesized by Logan \& Sweanor $(2001,2010)$. However, females may not just appear when ready to mate, and their visits to community scrapes may instead occur in a progression, from investigation and assessment to advertising their receptive status, and eventually to mating. Logan \& Sweanor (2001) rarely documented scraping behaviour in females, and believed that females squatted and urinated on scrapes made by males more frequently than making scrapes themselves. Through the use of video cameras I also documented female pumas both scraping and urinating on top of scrapes made by male pumas, but found that among females scraping was actually more common than urinating on the scrapes of males ( $13.6 \%$ to $2.2 \%$ respectively). I found that caterwauling behaviour was more frequently used by mature females, only being used by mature males at $0.4 \%$ of visits. Caterwauling in some instances is likely more effective than scraping to advertise for potential mates, for instance, caterwauling can be used for immediate attraction and to advertise from a distance (Logan and Sweanor 2001).

I found that mature females spent longer durations exhibiting consuming behaviours than mature males, while also exhibiting flehmen response behaviour at a higher proportion of visits. Mellen (1993) found that the use of the flehmen response behaviour by felid species was common at each investigation of urine; however I found flehmen response behaviour to be less frequently used by wild pumas (it occurred at $11.8 \%$ of visits). Rather than being a difference between pumas and other felid species, Mellen's (1993) findings may have been a 
by-product of studying felids in captivity, where the usually solitary felids come in contact with scent-markings more often than in the wild. For example, de Boer (1977) found that urine less than 4 hours old triggered a flehmen response significantly more often than urine which was over 24 hours old. Mellen (1993) also found that flehmen response behaviour was more common in male felids, which contradicted my findings with wild pumas. I hypothesize that the longer durations of consuming behaviours and the higher rate of flehmen response behaviour by females is due to females using visits to assess potential mates. In contrast, male pumas apparently spend shorter durations investigating competitors, and instead may only use flehmen response behaviour to investigate scent left by females or unknown individuals, both of whom are less frequent visitors to community scrapes.

The scraping and associated communication behaviours appear to develop with age, and to only be used by mature females when traveling without cubs. Intraspecific strife is a frequent source of mortality in juvenile pumas, with mature males killing cubs and sub-adult males (Logan \& Sweanor 2001, Logan \& Sweanor 2010). Logan \& Sweanor (2001) also documented that over $25 \%$ of encounters between mature males and females which were not in oestrus were violent. For this reason, it increases survival and hence fitness for both immature pumas and females with cubs to not openly advertise their presence at community scrapes. I were unable to find a significant difference between females with and without cubs, possibly due to my low sample size of females with cubs visiting community scrapes, however females may use community scrapes differently based on whether they are with or without cubs. For example, females with cubs were never recorded displaying either scraping or caterwauling behaviours, and I hypothesize that females with cubs are more closely aligned to immature pumas in regards to being "non-participants" in behaviours at community scrapes. 
My experimental treatments showed that the physical scrape and urine components had different roles, and were both necessary to scrape communications. Experimental components with a physical scrape were detected first more often and at a higher proportion of visits than urine alone, while urine alone was not significantly different than the control. Additionally, pumas did not show difference in first investigation or proportion of investigation for just physical scrape in comparison to physical scrape with puma urine. However, there was a significant difference between the two variables in regards to duration of investigation with the physical scrape with urine being investigated for a significantly longer duration than just the physical scrape. These results show that pumas rely on the physical scrape to locate communication attempts by other pumas, and then use the urine to convey and interpret the communication itself.

Scrapes are the most obvious signals pumas leave on the landscape, and males appear to use scrapes to compete against each other. The scrapes created appear to compete against each other, as the more stimuli available the less experimental treatments were detected and investigated. For example, the proportion of visits where urine was investigated steadily decreased in response to stimuli, from $32 \%$ against control to $27 \%$ against a physical scrape and $22 \%$ against a physical scrape with urine; and the duration of investigation of physical scrapes with urine decreased from $6.7 \mathrm{~s}$ against control to $5.3 \mathrm{~s}$ against urine and $3.7 \mathrm{~s}$ against the physical scrape. Some male pumas may use this to their advantage to create dishonest signals in order to increase their attractiveness to females. For example, some individual males may create an excess of scrapes in order to overwhelm females with stimuli and increase the probability that their scrapes are detected over that of competitors. Pumas intentionally leave scrapes as signals for other pumas, however scrapes are made in areas frequented by other species, and they may also be using scrape communications as cues. For example, numerous scavengers have been noted at puma kills (Ruth \& Murphy 2010), and it 
is possible that the mammalian scavengers are using puma scent communications to find and track the pumas to their kills.

The importance of the visual component of physical scrapes reinforces the importance of community scrapes, and could be applied to puma census efforts. Each individual scrape is an attempt at communication, and if pumas created scrapes in random areas they would be much more difficult for the signals to be received by other pumas. This is especially true in species with spatially dispersed populations, such as pumas or other solitary carnivores, where having regular areas for communication (i.e. community scrapes) increases their likelihood of being found. Puma populations have historically been difficult to census, and many wildlife professionals believe the only truly accurate way to census puma populations is through long-term study of the population with known individuals through radio-telemetry or GPS collars (Cougar Management Working Group 2005). However, many attempts are still made to develop accurate census techniques for puma populations (Cougar Management Working Group 2005, Choate et al. 2006), and using census techniques involving camera traps (see Kelly et al. 2008) at community scrapes rather than random areas would likely increase the rate of capture and hence success. In addition, there are numerous efforts, either for population census or study capture, to detect pumas through various types of scent lures often without great success (Long et al. 2003, Choate et al. 2006, Walker \& Novaro 2010). However, the findings of this study show that the use of scent lures is not the best strategy for pumas and possibly other felids, and instead, the use of visual lures (possibly in conjunction with auditory lures) would be more effective. 


\section{Chapter 3}

\section{Mate Selection Strategies in Pumas}

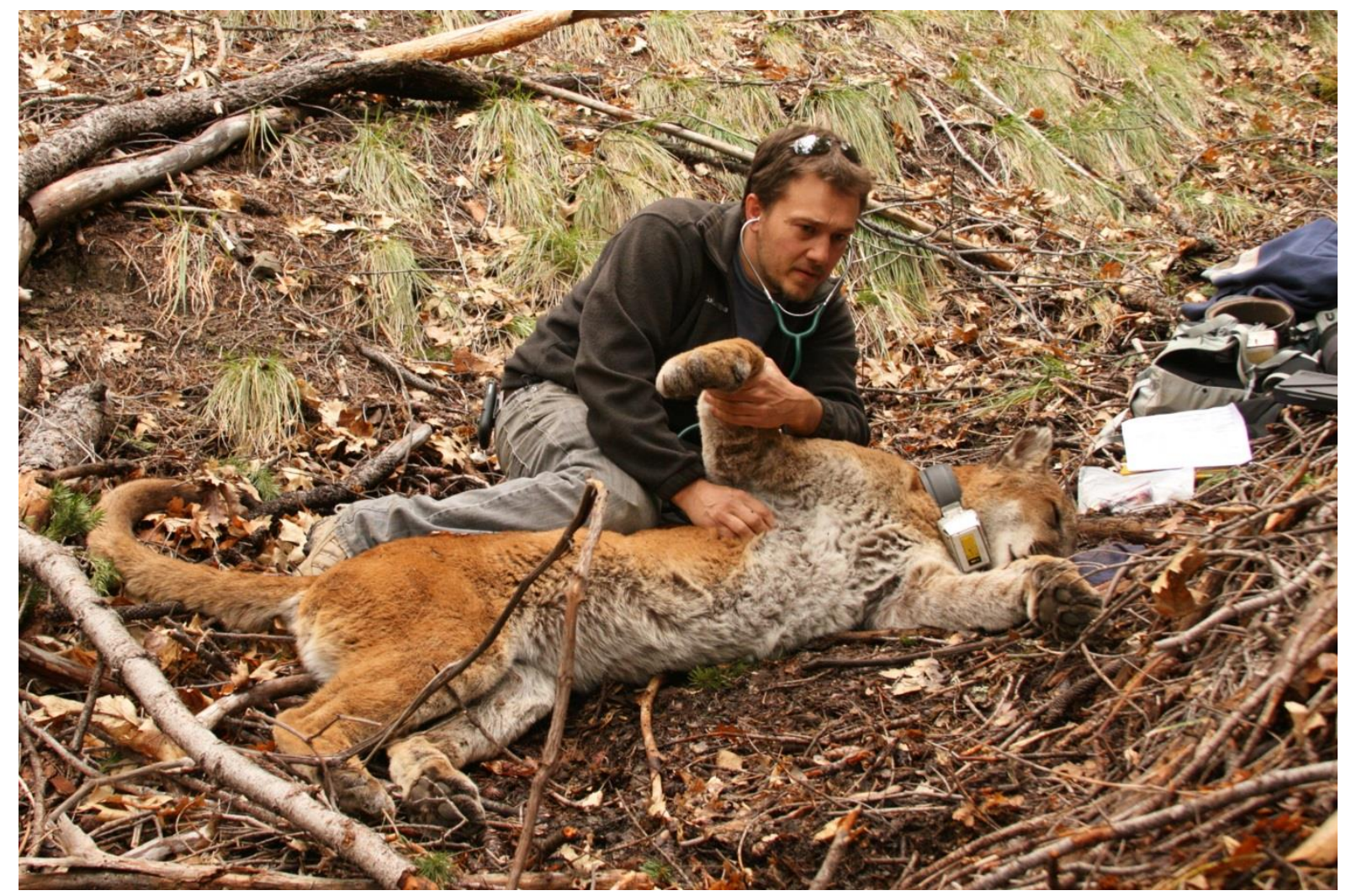


A version of this paper will be submitted for review and publication as:

Allen, M.L., H.U. Wittmer, P. Houghtaling, and C.C. Wilmers. Mate selection strategies in pumas (Puma concolor).

\section{Acknowledgements}

Funding was provided by NSF grant \#0963022, the Gordon and Betty Moore Foundation the California Department of Fish and Wildlife, the University of California at Santa Cruz, and the University of California at Davis. M. Allen was supported by a Victoria University of Wellington tuition scholarship. I thank C. Wylie and D. Tichenor for their significant support in helping to capture pumas with hounds, H. Ernest for the genetic analysis, along with Y. Shakeri and numerous field technicians for their help on the project. 


\begin{abstract}
Mate selection is an important aspect of intraspecific interactions, and often includes complex behaviours for communication. It can be difficult, however, to understand mate selection in in cryptic species, such as pumas (Puma concolor). I captured and marked 39 pumas, and used motion-triggered cameras at communication areas (e.g., community scrapes) to record the use of intraspecific communication behaviours and how they are used for mate selection by pumas. I found that males were regular visitors to community scrapes, while females were irregular visitors whose visitation cycle was apparently correlated with the onset of oestrus. Mate selection by females was complex and based on multiple cues, the most important of which were male visitation rate and weight. Visitation by males varied seasonally and was correlated with seasonal patterns of female visitation and parturition, suggesting that male visitation is more based on the activity patterns of potential mates than competitors. Surprisingly, the number of scrapes created was not influenced by potential mates or competitors, and instead had an inverse relationship with visitation rates, suggesting that males created more scrapes in seasons with less frequent visitation. I also documented that female pumas were sometimes polyandrous, which may increase the survival of their cubs by confusing paternity and decreasing the risk of infanticide from adult males. These findings provide a mechanistic understanding of the function of puma communication behaviours for mate selection.
\end{abstract}




\section{Introduction}

Reproductive success is essential for individual traits to reach, and hence modify, future generations (Darwin 1859), and behaviours associated with reproduction are therefore an important source of adaptation and evolution. How individuals select mates is complex and often involves multiple cues that vary among species (Candolin 2003, Gibson and Langen 1996), and many species have specific behaviours associated with mate selection (i.e. the creation of signals to advertise for and communicate with potential mates) (Bailey 1974, Stenström et al. 2000, Hurst and Benyon 2004, Stein and Hayssen 2013). In order to understand the adaptive significance of behaviours used for mate selection it is necessary to understand each cue and its function. However, understanding communication and mate selection of cryptic mammals such as solitary felids in natural environments is difficult due to the lack of direct observation (Logan and Sweanor 2001, Andersson and Simmons 2006). Reproductive strategies in solitary felids are expected to vary between males and females. In these species, males are polygynous and often larger than females, and males are thought to compete with each other for territories that encompass multiple female home ranges (Seidensticker et al. 1973, Bailey 1974, Bailey 1993, Logan and Sweanor 2001, Stein and Hayssen 2013). The resulting spatiotemporal dispersed population structure necessitates indirect communication, and therefore most male solitary felids are hypothesised to rely on indirect scent-marking to advertise reproductive status to possible mates (Seidensticker et al. 1973, Bailey 1974, Bailey 1993, Stein and Hayssen 2013). In contrast, females actively select from among potential mates the best mate to enhance the survival of their offspring (Gibson and Langen 1996, Smith et al. 1989, Logan and Sweanor 2001, Sunquist and Sunquist 2002). A key aspect of female mate selection is thought to be male size; larger size in males is selected for across generations, and is thought to indicate fitness because they are physically 
dominant, and are capable of maintaining large home ranges (Logan and Sweanor 2001, Sunquist and Sunquist 2002, Andersson and Simmons 2006). However, recent advances in mate selection suggest that viewing female selection through male ornamentation alone is overly simplistic (Andersson and Simmons 2006).

Many aspects of puma (Puma concolor) behaviour, including territoriality and communication behaviours, are believed to be similar to those of other solitary felids (Logan and Sweanor 2001, Sunquist and Sunquist 2002, Logan and Sweanor 2010). However, pumas differ in their distribution pattern and reproductive behaviours. In particular, pumas range into high northern and southern latitudes in the Americas, but unlike most other felids in higher latitudes, pumas mate throughout the year (Logan and Sweanor 2001, Sunquist and Sunquist 2002, Logan and Sweanor 2010). Mate selection in pumas might be further complicated due to frequent aggressive behaviours of males towards females not in oestrus (Logan and Sweanor 2001). Given the dispersed population structure, lack of predictability of reproductive status in females, and potential risks of females from much larger males, mate selection strategies and associated behaviours are expected to be sex specific.

In Chapter 2 I hypothesized, that communication behaviour associated with mate selection should therefore vary between males and females. Scraping is the most frequently observed communication behaviour in pumas (Logan and Sweanor 2001, Harmsen 2010, Logan and Sweanor 2010, Chapter 2), and is concentrated in areas called 'community scrapes' which are used by multiple pumas. In Chapter 2 I hypothesized that communication by males is primarily be based on frequent advertisement for mates, which may also deter competitors. In contrast, they hypothesized that female strategy was based on periodic assessment of potential mates, as females in many species use indirect communication cues (i.e. scent-marks) to pre-select mates (Gibson and Langen 1996). Although recent research 
has started to explain how scraping and associated behaviours are used by pumas for intraspecific communication (e.g. Logan and Sweanor 2001, Harmsen 2010, Logan and Sweanor 2010, Chapter 2), we do not understand their functions for mate selection.

I monitored a puma population with 39 tagged individuals from 2011-2013 in order to better understand their mate selection behaviours. Pumas are difficult to observe due to their cryptic nature, and I therefore deployed motion-triggered video cameras at community scrapes to record intraspecific communication behaviours and their relevance for mate selection. My specific objectives were to 1) determine if males and females differed in respective visitation rates, and if so, hypothesize possible reasons for the adaptive significance of these differences; 2) determine if seasonal variation occurred in visitation and behaviours at community scrapes, and if so, understand their underlying mechanisms; 3) determine the preferred traits of mates selected by females among male behaviours at community scrapes and male ornamentation; and 4) determine how male visitation and behaviours at community scrapes are influenced by the visitation of possible mates and competitors.

\section{Materials and Methods}

\section{Field Methods}

I monitored behaviour of pumas at community scrapes between May 2011 and July 2013 using motion-triggered video cameras with infrared flash (Bushnell TrophyCam, Overland Park, KS) (Camera locations noted on Figure 1). I defined community scrapes as scrape areas used for communication by more than one puma; community scrapes were typically characterized by an abundance of scrapes in a concentrated area and were not associated with either kill or bedding sites (Chapter 2), and I found community scrape areas 
as described by Wilmers et al. (2013). I programmed cameras to record the maximum amount of data, with a 60 s video recorded at each trigger with a $1 \mathrm{~s}$ delay before becoming active again.

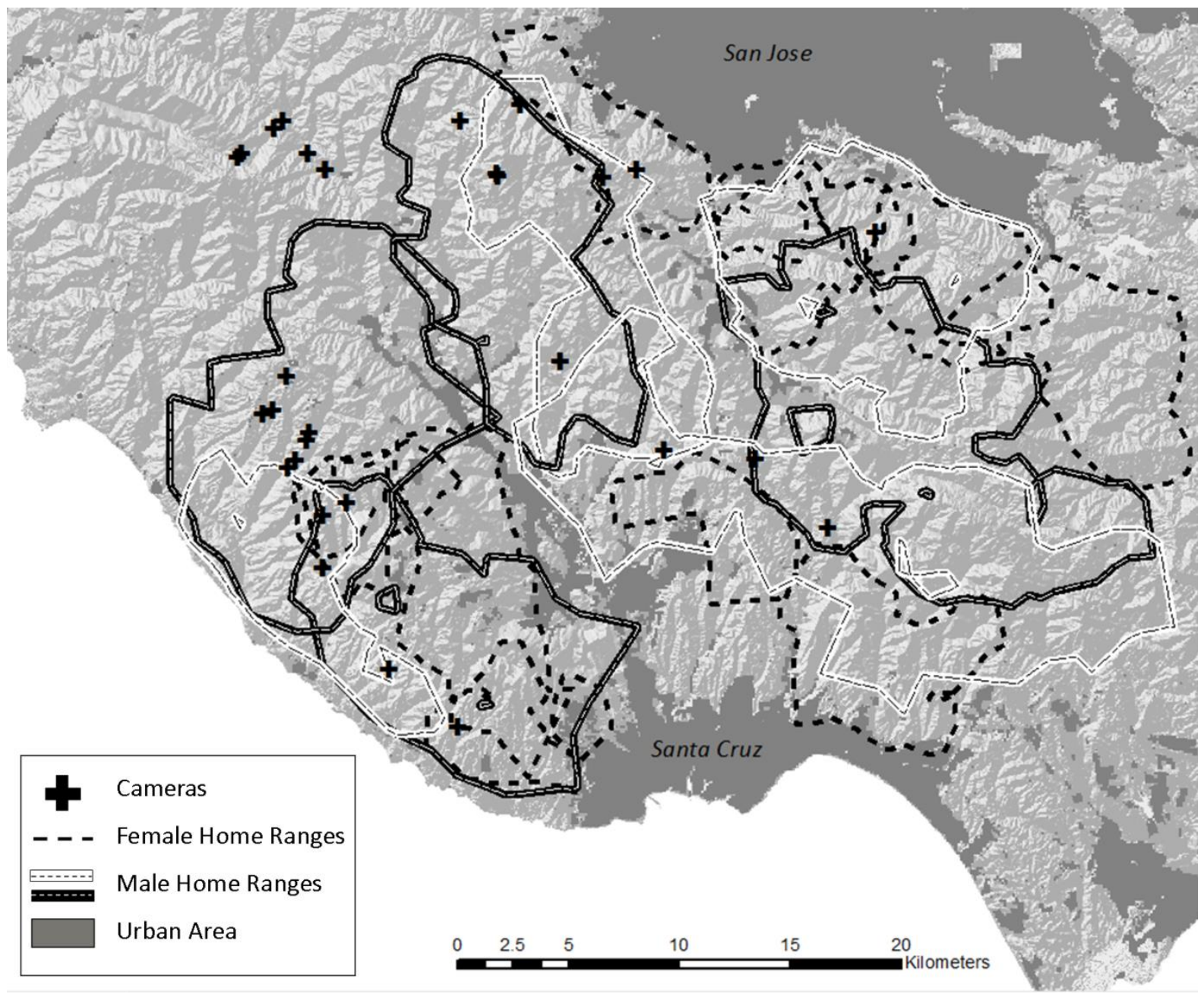

Figure 1: The location of the community scrape areas monitored, within the context of the Santa Cruz study area and puma home ranges. Puma home ranges were calculated as 95\% $\mathrm{LoCoH}$ using location data from July 2011 to June 2013. Male home ranges are shown using two different colours in order to highlight the overlap among individuals.

I concurrently captured and placed GPS-enabled collars with unique identifiers on 39 pumas from 2008-2013, using the methods described by Wilmers et al. (2013). The Independent Animal Care and Use Committee at the University of California, Santa Cruz 
approved all animal handling procedures. I investigated location clusters for females wearing GPS collars to find dens, and estimated the date of parturition based on movement behaviour inferred from the location data. I also obtained genetic samples from kittens of 8 litters, and performed genetic analyses to determine paternity.

When possible, I identified the individual puma recorded in videos and placed the pumas into age and sex classes as: mature male, mature female, immature male, or immature female. The identity of individuals and their age were determined using the unique collar identifiers, and when possible for pumas without collars, through unique spotting patterns on the inside of the upper leg or other distinct features including scarring, kinks in their tail, and old injuries (Kelly et al. 2008). I removed immature pumas and mature females traveling with kittens from my analyses, as they were less regular visitors and tend to act as non-participants in mating behaviours (Chapter 2). I pooled the data from cameras placed at community scrapes $<200 \mathrm{~m}$ apart to ensure spatially independent samples and minimize pseudoreplication. I removed from my analyses any community scrapes I monitored for $<3$ months, and excluded any periods with camera malfunctions from my visitation samples.

I watched each video that met my assumptions, and quantified parameters associated with recorded visits as well as behaviours displayed during each visit. I monitored the 30 community scrape areas for a mean of 501d +/- 202 SD (range 125-791), and recorded 676 visits by mature males (a minimum of 10 individuals) and 179 visits by mature females traveling without cubs (a minimum of 23 individuals). For each visit, I recorded the date and time, length of visit to the closest second (averaged for pooled samples), and number of scrapes created (averaged for pooled samples). I also recorded behaviours possibly associated with mate selection, including scraping, investigating, flehmen response, body rubbing, and 
consorting with pumas of the opposite sex; with the behaviours defined based on the descriptions of (Chapter 2) (Table 1).

\begin{tabular}{|c|c|}
\hline Behaviour & Definition \\
\hline Scraping & $\begin{array}{l}\text { Where the puma scraped in substrate with their hind feet } \\
\text { and then sometimes urinated and/or defecated on the } \\
\text { scraped mound of material. }\end{array}$ \\
\hline Investigating & $\begin{array}{l}\text { Where the puma is using its olfactory sense to investigate } \\
\text { cues and signals, noted by the pumas nose within } 15 \mathrm{~cm} \text { of } \\
\text { a scrape or other cue. }\end{array}$ \\
\hline Body Rubbing & $\begin{array}{l}\text { Where the puma rubs its cheek or shoulder on the ground } \\
\text { or an object, or rolls back and forth on the ground. }\end{array}$ \\
\hline $\begin{array}{l}\text { Flehmen } \\
\text { Response }\end{array}$ & $\begin{array}{l}\text { Where the puma picked up its head and curled back its } \\
\text { upper lip, sometimes arching its neck backwards, in order } \\
\text { to expose its vomeronasal organ. }\end{array}$ \\
\hline
\end{tabular}

Table 1. The definitions of behaviours exhibited by pumas from Chapter 2 .

\section{Statistical Analyses}

I used program $R$ version 3.0.0 (R Core Team 2013) for all statistical analyses, and following $R$ guidelines I cited any associated packages used in analyses. In each analysis, I considered $p \leq 0.05$ significant.

I hypothesized that male and female pumas would exhibit differences in visitation rates due differences in reproductive strategies (Logan and Sweanor 2001). I tested potential differences in visitation rates by modelling 'days until next visit' using a generalized linear mixed model Analysis of Variance (ANOVA) with a Poisson link in the lme 4 package (Bates et al. 2013). I used the entire monitoring period for males. However, because female visitation was in irregular bouts, I used individual visitation cycles for females. I defined visitation cycles as repeated visits by an individual female without $>60$ days between visits. I used 'days until next visit' as my dependent variable, sex of the puma as my fixed predictor 
variable, and included individual puma as a random effect to control for variation among individuals.

I hypothesized that due to male territoriality, their behaviours at community scrapes would not vary among seasons (winter, spring, summer, and autumn; as defined by Julian calendar), and I tested for variation among seasons for 3 behaviours: 'days until next visit', 'number of scrapes created per visit', and the 'duration of visit'. I modelled each of the variables using a generalized linear mixed model ANOVA with a Poisson link, using the lme4 package (Bates et al. 2013). I used the behaviour variables as my dependent variables in the models, used season as my fixed predictor variable, and included individual pumas as random effects. When significant differences were found I used a post hoc Tukey's HSD test (Sokal and Rohlf 1987) using the multcomp package (Hothorn et al. 2008) to determine where significant differences occurred.

I then used a series of post hoc linear regression analyses, after first testing each continuous variable data set for normality with a Shapiro-Wilk test and for variance equality with a Levene's test (Sokal and Rohlf 1987). I first tested for seasonal correlations among the 3 male behaviours: 'days until next visit', 'number of scrapes created per visit', and the 'duration of visit', using the seasonal means of each variable. I then tested for the relationship between male behaviours of 'days until next visit' and 'number of scrapes created per visit' against the dates my monitored females gave birth, hypothesizing that behaviours by male pumas were influenced by female behaviour. I used the seasonal means of the behavioural variables as dependent variables and the seasonal totals of birth dates as my predictor variable.

I next tested which variables best predicted female mate selection. I compared between the categories of visitation behaviours to male ornamentation, among 4 time periods: 
during identified visitation cycles, and 30, 90, and 180 days previous to the consorting. I used the females which consorted with at least one male, and defined consorting as traveling with a male $(n=16)$ or visiting scrapes within two hours of each other $(n=7)$. Selection of a male was my dependent variable; and I tested multiple predictor variables for visitation behaviours (total number of scrapes created, mean number of scrapes created per visit, number of visits, and mean duration of visits) and male ornamentation (weight during most recent capture, and age). I first determined the best single predictor of whether a male was selected for each category for each time period. I modelled each of the predictor variables using a generalized linear mixed model logistic regression, using a binomial link in the rms package (Harrell 2013), and chose the best predictor for each category using C-statistic scores (Hosmer and Lemeshow 2000). I then used a stepwise AIC procedure in the MASS package (Venables and Ripley 2002) to determine the best model for each category for each time period, using all of the possible predictor variables in each category. I then modelled the best models for each category for each time period using a generalized linear mixed model logistic regression, using a binomial link in the rms package (Harrell 2013), and compared the visitation behaviours to male ornamentation for each time period using C-statistic scores (Hosmer and Lemeshow 2000).

I determined the influence of visitation by females and other males on 3 behaviours of male pumas: 'days until next visit', 'number of scrapes created per visit', and the 'duration of visit', hypothesizing that these behaviours would be influenced by competitors and possible mates (Chapter 2). I modelled each of the variables using a generalized linear mixed model Analysis of Variance (ANOVA) with a Poisson link, using the lme4 package (Bates et al. 2013). I used the behaviour variables as my dependent variables in the models, used a categorical predictor of presence of other pumas (first other males, then females) for 2 time 
periods ( 3 days and 1 month) as my fixed predictor variable, and included the individual puma and the community scrape as random effects in the models. When significant differences were found I used a post hoc Tukey's HSD test (Sokal and Rohlf 1987) using the multcomp package (Hothorn et al. 2008) to determine where significant differences occurred. I also calculated post hoc effect sizes using Cohen's $d$ score, and considered scores of 0.20 small effects, 0.50 medium effects, and 0.80 large effects (Cohen 1992).

Last, I determined the influence of visitation by females and other males on the display of 4 communication behaviours of male pumas: 'scraping', 'olfactory investigation', 'flehmen response', and 'body rubbing; hypothesizing that the behaviours would be influenced by competitors and possible mates (Chapter 2). I compared the proportion of visits each behaviour was displayed based on the presence of other pumas (first other males, then females) in the previous month using a chi-square test (Sokal and Rohlf 1987). I then

calculated post hoc effect sizes for behaviours with significant statistical differences by calculating phi coefficients (Yule 1912), using the vcd package (Meyer et al. 2013), and compared effect sizes at 3 days and 1 month to tell if proximity of visits by other pumas influenced the display of these behaviours. I considered scores of 0.10 small effects, 0.30 medium effects, and 0.50 large effects (Cohen 1992).

\section{Results}

\section{Patterns in Visitation}

Male and female pumas varied in their visitation patterns to community scrapes. Female visits occurred in short visitation cycles $(n=40)$ or singe visits $(n=28)$. Visitation cycles had a mean duration of $31.8( \pm 5.1 \mathrm{SE})$ days, and for individual females were frequently separated by large gaps in time (mean $=367 \pm 62$ SE days). In contrast, visitation 
by males at community scrapes was characterized by regular visits throughout my monitoring periods. I found that females during visitation cycles had a significantly shorter visitation rate than males $(\mathrm{df}=1,649, \mathrm{~F}=10.56, \mathrm{p}=0.0012, d=0.13)$. Females averaged $11.8( \pm 1.5 \mathrm{SE})$ days until next visit during a given visitation cycle, while males averaged $17.7( \pm 2.1 \mathrm{SE})$ days until next visit. On 3 occasions an individual male was detected at a community scrape for the first time during a female visitation cycle. On these occasions, the males were present during the visitation cycle, and then their visitation to the community scrape tapered off after the female left.

\section{Seasonal Variation in Visitation}

Visitation behaviours by male pumas varied among seasons; including the days until next visit $(\mathrm{df}=3,578, F=6.36, p=0.0003)$, the number of scrapes created $(\mathrm{df}=3,578, F=$ $7.06, p=0.0001)$, and the duration of visits $(\mathrm{df}=3,578, F=3.18, p=0.0237)$. For days until next visit, the mean of $24.8( \pm 1.2 \mathrm{SE})$ days in summer was significantly longer than the mean of $15.0( \pm 1.2 \mathrm{SE})$ days in spring, the mean of $16.0( \pm 1.2 \mathrm{SE})$ days for winter, and the $20.2( \pm$ 1.2 SE) days in autumn $\left(\mathrm{p}_{\text {spring }}<0.0001, \mathrm{p}_{\text {winter }}<0.0001, \mathrm{p}_{\text {autumn }}<0.0001\right)$; autumn was also significantly longer than spring or winter $\left(\mathrm{p}_{\text {spring }}<0.0001, \mathrm{p}_{\text {winter }}<0.0001\right)$. For the number of scrapes made during a visit, the mean of $1.74( \pm 0.2 \mathrm{SE})$ scrapes in summer was significantly higher than the mean of $1.24( \pm 0.2 \mathrm{SE})$ scrapes in spring, and the mean of $1.30( \pm 0.2 \mathrm{SE})$ scrapes in winter $\left(\mathrm{p}_{\text {spring }}=0.0051, \mathrm{p}_{\text {winter }}=0.0176\right)$. For the duration of visits, the mean of $63.3( \pm 6.9 \mathrm{SE})$ seconds in summer was significantly longer than the mean of $51.2( \pm 6.2 \mathrm{SE})$ seconds in spring $(\mathrm{p}=0.0387)$. A post hoc test showed that the seasonal mean for days until next visit had a strong inverse correlation with the number of scrapes made during visits $(\mathrm{df}=$ $\left.1,3, p=0.0320, r^{2}=0.94\right)$, suggesting that male pumas create more scrapes during seasons 
with less frequent visitation (Figure 2). The duration of visit did not have a significant correlation with either days until next visit $\left(\mathrm{df}=1,3, \mathrm{p}=0.2918, \mathrm{r}^{2}=0.50\right)$, nor number of scrapes created $\left(\mathrm{df}=1,3, \mathrm{p}=0.1853, \mathrm{r}^{2}=0.66\right)$.

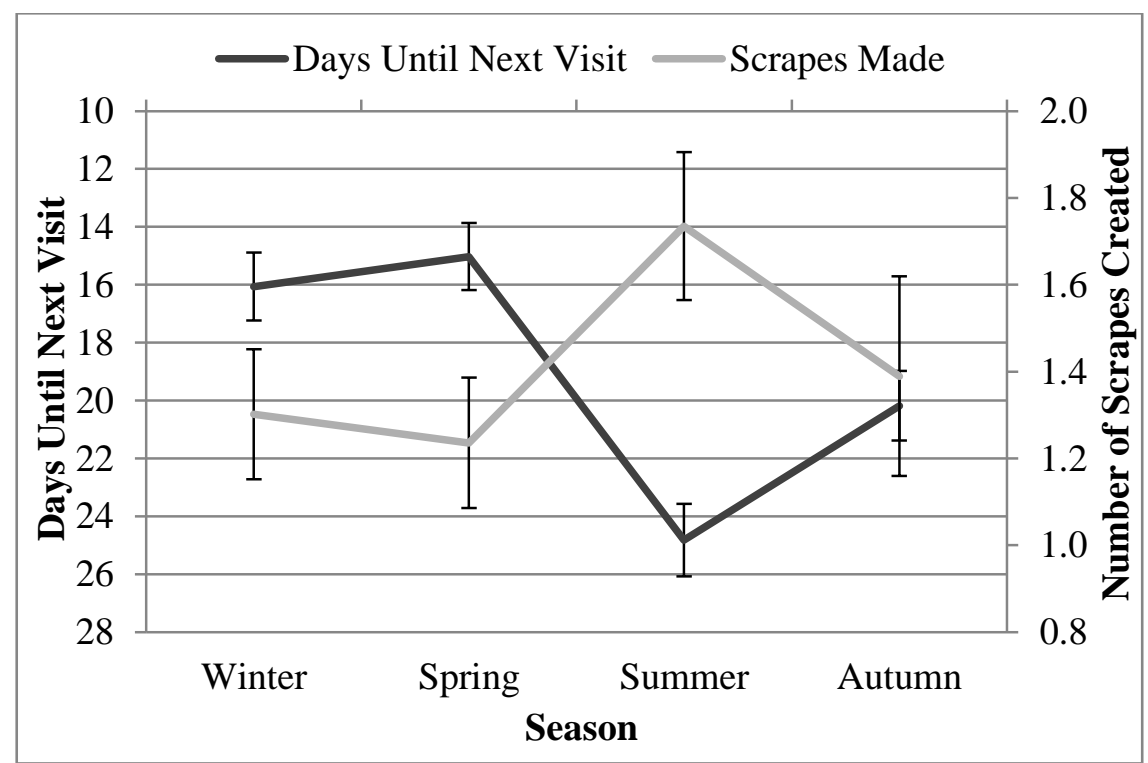

Figure 2. The days until next visit and scrapes created by male pumas during each season. Each variable is represented as its mean value for the season, with error bars representing the standard error. The values have a significant inverse relationship, suggesting that male pumas create more scrapes in seasons with less frequent visits.

Female visitation cycles at community scrapes and onset of denning behaviour occurred throughout the year. The peak in the birth pulse $(n=8)$ occurred in summer with $44.4 \%$ of births, compared to $22.2 \%$ in autumn, and $16.7 \%$ in both of winter and spring. A post hoc test showed the male seasonal mean for days until next visit had a significant inverse correlation dates of birth $\left(\mathrm{df}=1,3, \mathrm{p}=0.0492, \mathrm{r}^{2}=0.90\right)$, while the seasonal mean of scrapes made by males during visits also had a significant correlation with dates of birth $(\mathrm{df}=1,3, \mathrm{p}$ $\left.=0.0217, \mathrm{r}^{2}=0.95\right)$. 


\begin{tabular}{|c|c|c|c|c|c|c|c|c|}
\hline \multirow{2}{*}{$\begin{array}{l}\text { Time } \\
\text { Period }\end{array}$} & \multirow[b]{2}{*}{ Type } & \multicolumn{4}{|c|}{ Best Single Predictor } & \multicolumn{3}{|l|}{ Comparative Models } \\
\hline & & Variable & coef & Odds & $\mathrm{C}$ & Model & $\mathrm{C}$ & AIC \\
\hline \multirow{2}{*}{ During } & Behaviour & VSTS & 0.563 & 1.756 & 0.71 & AVGDUR +TOTSCR + VSTS & 0.78 & 36.8 \\
\hline & Ornamentation & WGHT & 0.086 & 1.089 & 0.75 & $\mathrm{AGE}+\mathrm{WGHT}$ & 0.94 & 14.7 \\
\hline \multirow{2}{*}{30 days } & Behaviour & VSTS & 0.575 & 1.777 & 0.83 & AVGSCR + VSTS & 0.80 & 34.9 \\
\hline & Ornamentation & WGHT & 0.083 & 1.087 & 0.76 & $\mathrm{AGE}+\mathrm{WGHT}$ & 0.94 & 14.6 \\
\hline \multirow{2}{*}{90 days } & Behaviour & VSTS & 0.256 & 1.292 & 0.77 & AVGDUR + TOTSCR & 0.81 & 33.5 \\
\hline & Ornamentation & WGHT & -0.026 & 0.975 & 0.58 & WGHT & 0.58 & 20.6 \\
\hline \multirow{2}{*}{180 days } & Behaviour & VSTS & 0.222 & 1.249 & 0.80 & TOTSCR + AVGDUR & 0.83 & 29.8 \\
\hline & Ornamentation & WGHT & 0.046 & 1.047 & 0.58 & $\mathrm{WGHT}+\mathrm{AGE}$ & 0.82 & 20.4 \\
\hline
\end{tabular}

${ }^{1}$ TOTSCR $=$ The total number of scrapes made, AVGSCR $=$ The mean number of scrapes made, VSTS $=$ The number of visits made, AVGDUR $=$ The mean duration of visits, WGHT $=$ The weight of the male, AGE=The age of the male.

Table 2. Predictors of female mate selection, represented by best single predictor and best comparative models for each time period tested (during the female's visitation cycle, and 30, 90, and 180 days previous to consorting with males). For best single predictor, I report the best variable ${ }^{1}$, correlation coefficient, odds ratio, and C-statistic score (with scores of $>0.80$ considered strong). For the best models, I compare the best models for behaviour variables and ornamentation variables, for each model I report the variables of the best model $^{1}$, the $\mathrm{C}$-statistic score, and the AIC score.

\section{Female Mate Selection}

I documented 23 incidents of consorting behaviour by 17 female pumas. Females who consorted with a male chose from a mean of 1.7 males (range of 1-3), and all the males selected of known age $(n=7)$ were between the ages of 3 to 7 years old. Among variables in the behaviour category, the number of visits made was the best predictor of a male being selected in each time period (Table 2). Among variables in the male ornamentation category, weight was the best predictor of a male being selected in each time period (Table 2). The male ornamentation models had lower AIC scores than the behaviour models in each time period (Table 2). Of females I recorded consorting with a male, $14.2 \%$ consorted with 2 
different males during a visitation cycle. A post hoc genetic analysis of 8 litters of kittens revealed 1 instance of a litter with multiple sires (12.5\% of litters).

\begin{tabular}{|c|c|c|c|c|c|c|c|c|c|}
\hline \multirow[b]{2}{*}{ Variable } & \multirow[b]{2}{*}{ Sex } & \multirow[b]{2}{*}{ Days } & \multicolumn{2}{|r|}{ Present } & \multicolumn{2}{|c|}{ Not Present } & \multirow[b]{2}{*}{$F$} & \multicolumn{2}{|r|}{ Effect } \\
\hline & & & Mean & $95 \%$ CI's & Mean & $95 \%$ CI's & & $p$ & Size \\
\hline \multirow{4}{*}{$\begin{array}{l}\text { Days } \\
\text { Until } \\
\text { Next } \\
\text { Visit }\end{array}$} & \multirow{2}{*}{ Male } & 30 & 16.8 & $11.2-22.4$ & 21.5 & $16.0-27.1$ & 15.54 & $<0.0001$ & 0.10 \\
\hline & & 3 & 17.0 & $11.0-22.9$ & 20.4 & $14.5-26.3$ & 5.45 & 0.0199 & 0.05 \\
\hline & \multirow{2}{*}{ Female } & 30 & 15.7 & $10.1-21.4$ & 21.2 & $15.6-26.9$ & 9.89 & 0.0018 & 0.10 \\
\hline & & 3 & 14.0 & $8.3-19.8$ & 20.5 & $14.8-26.2$ & 8.66 & 0.0034 & 0.10 \\
\hline \multirow{4}{*}{$\begin{array}{l}\text { Scrapes } \\
\text { Created }\end{array}$} & \multirow{2}{*}{ Male } & 30 & 1.56 & $0.96-2.52$ & 1.30 & $0.91-2.20$ & 3.36 & 0.0671 & 0.06 \\
\hline & & 3 & 1.43 & $0.74-2.17$ & 1.37 & $0.97-2.34$ & 0.68 & 0.4110 & 0.01 \\
\hline & \multirow{2}{*}{ Female } & 30 & 1.39 & $0.79-2.18$ & 1.37 & $0.97-2.33$ & 1.18 & 0.2780 & 0.01 \\
\hline & & 3 & 1.37 & $0.70-2.07$ & 1.38 & $0.98-2.35$ & 0.67 & 0.4150 & 0.00 \\
\hline \multirow{4}{*}{$\begin{array}{l}\text { Duration } \\
\text { of Visit }\end{array}$} & \multirow{2}{*}{ Male } & 30 & 64.1 & $39.4-103.5$ & 51.5 & $36.3-87.8$ & 6.92 & 0.0088 & 0.08 \\
\hline & & 3 & 60.2 & $29.8-90.0$ & 54.8 & $39.6-94.3$ & 3.97 & 0.0468 & 0.03 \\
\hline & \multirow{2}{*}{ Female } & 30 & 62.0 & $37.6-99.6$ & 52.7 & $37.5-90.1$ & 13.70 & 0.0002 & 0.06 \\
\hline & & 3 & 69.4 & $41.7-111.1$ & 53.5 & $38.5-92.0$ & 7.69 & 0.0057 & 0.09 \\
\hline
\end{tabular}

Table 3. The influences of visitation by male and female pumas on visitation behaviours of male pumas. Visitation behaviour variables include the days until next visit (in days), the number of scrapes created (in number of scrapes), and duration of visit (in seconds). I tested the influence of females and other males in two time periods, whether the other puma had been present in the previous 28 days and if they had been present in the previous 3 days. I report the mean, 95\% confidence intervals, p-value, and effect size as Cohen's d scores.

\section{Male Visitation and Behaviours}

For male pumas, the days until next visit were significantly influenced by visits within 1 month by both male $\left(F_{1,579}=15.54, p<0.0001\right)$ and female $\left(F_{1,579}=9.89, p=0.0018\right)$ pumas (Table 3). Their visitation rate showed an increasing trend depending on how recently a female had been present (increasing from 14.0 days when a female had been present within 3 days to 15.7 days when a female had been present within 1 month) (Table 3). Duration of visit was also significantly influenced by visits within one month by both male $\left(F_{1,601}=6.92\right.$, $p=0.0088)$ and female $\left(F_{1,601}=13.70, p=0.0002\right)$ pumas (Table 3). Durations of visit showed an increasing trend depending on how recently a female had been present (increasing from 62.0 seconds when a female had been present within 1 month to 69.4 seconds when 
females were present within 3 days); and durations showed a decreasing trend depending on how recently another male had been present (increasing from 60.2 seconds when a male was present within 3 days to 64.1 seconds when another male had been present within 1 month) (Table 3). The number of scrapes created in a given visit was not significantly influenced by visitation by other males or female pumas (Table 3).

\begin{tabular}{|c|c|c|c|c|c|c|c|}
\hline \multirow[b]{2}{*}{ Behaviour } & \multicolumn{6}{|c|}{ \% Displayed } & \multirow[b]{2}{*}{ phi } \\
\hline & Sex & Days & Present & Absent & $X^{2}$ & $p$ & \\
\hline \multirow{4}{*}{ Scraping } & \multirow{2}{*}{ Male } & 28 & $75.6 \%$ & $70.5 \%$ & 1.74 & 0.1866 & 0.05 \\
\hline & & 3 & $75.3 \%$ & $72.0 \%$ & 0.22 & 0.6389 & 0.02 \\
\hline & \multirow{2}{*}{ Female } & 28 & $77.8 \%$ & $69.8 \%$ & 4.27 & 0.0389 & 0.08 \\
\hline & & 3 & $81.8 \%$ & $71.1 \%$ & 3.39 & 0.0657 & 0.08 \\
\hline \multirow{4}{*}{$\begin{array}{c}\text { Body } \\
\text { Rubbing }\end{array}$} & \multirow{2}{*}{ Male } & 28 & $14.3 \%$ & $6.4 \%$ & 10.60 & 0.0011 & 0.13 \\
\hline & & 3 & $11.0 \%$ & $9.0 \%$ & 0.12 & 0.7297 & 0.02 \\
\hline & \multirow{2}{*}{ Female } & 28 & $9.0 \%$ & $9.3 \%$ & 0.00 & 1.0000 & 0.00 \\
\hline & & 3 & $6.5 \%$ & $9.5 \%$ & 0.43 & 0.5123 & 0.03 \\
\hline \multirow{4}{*}{ Investigating } & \multirow{2}{*}{ Male } & 28 & $85.7 \%$ & $84.9 \%$ & 0.03 & 0.8633 & 0.01 \\
\hline & & 3 & $82.2 \%$ & $85.5 \%$ & 0.35 & 0.5566 & 0.03 \\
\hline & \multirow{2}{*}{ Female } & 28 & $89.2 \%$ & $83.4 \%$ & 3.41 & 0.0649 & 0.08 \\
\hline & & 3 & $89.6 \%$ & $84.6 \%$ & 0.98 & 0.3217 & 0.05 \\
\hline \multirow{4}{*}{$\begin{array}{l}\text { Flehmen } \\
\text { Response }\end{array}$} & \multirow{2}{*}{ Male } & 28 & $10.5 \%$ & $5.7 \%$ & 4.50 & 0.0338 & 0.09 \\
\hline & & 3 & $13.7 \%$ & $6.6 \%$ & 3.77 & 0.0522 & 0.08 \\
\hline & \multirow{2}{*}{ Female } & 28 & $14.6 \%$ & $4.1 \%$ & 22.03 & $<0.0001$ & 0.19 \\
\hline & & 3 & $20.8 \%$ & $5.7 \%$ & 20.57 & $<0.0001$ & 0.18 \\
\hline
\end{tabular}

Table 4. The influences of visitation by male and female pumas on the display of behaviours by male pumas. Behaviours included scraping, body rubbing, investigating, and flehmen response. I tested the influence of females and other males in two time periods, whether the other puma had been present in the previous 28 days and if they had been present in the previous 3 days. I report the $\%$ of behaviours displayed, the p-value, and an effect size as phi coefficients.

Some of the communication behaviours displayed by male pumas also increased in response to visitation by females and other males within the previous month (Table 4). Scraping behaviour increased in response to female visitation $\left(d f_{1,676} X^{2}=4.27, p=0.0389\right.$, $p h i=0.08)$. Body rubbing increased in response to male visitation $\left(d f_{1,676} X^{2}=10.60, p=\right.$ 0.0011 , phi= 0.13 ), but decreased from $14.3 \%$ of visits with visitation within month to $11.0 \%$ 
of visits when visitation was within 3 days (Table 4). Investigating was marginally significant in response to female visitation $\left(d f_{1,676} X^{2}=3.41, p=0.0649\right)$. Flehmen response increased in response to female visitation $\left(d f_{1,676} X^{2}=22.03, p<0.0001\right.$, phi=0.19), increased from 14.6 $\%$ of visits when visitation was in the last month to $20.8 \%$ of visits when visitation was within 3 days (Table 4). Flehmen response increased in response to male visitation $\left(d f_{1,676} X^{2}\right.$ $=4.50, p=0.0338, p h i=0.09)$, and increased from $10.5 \%$ of visits when visitation was in the previous month to $13.7 \%$ of visits when visitation was within 3 days (Table 4).

\section{Discussion}

Mate selection strategies in pumas differed between males and females, and appeared to be influenced by a complex set of cues and behaviours at community scrapes. As previously hypothesized (Logan and Sweanor 2001), female visits to community scrapes occurred over the entire year, but visits of individuals were apparently correlated with oestrus cycles with frequent visitation occurring over short time periods (mean $=32$ days, which could overlap with 2 oestrus cycles). The irregularity in female visitation rates was in contrast to males who regularly visited community scrapes and advertised their presence. Females apparently selected mates based on multiple cues, as is common in other mammals (Candolin 2003). The two most important cues were visitation rate and weight, both of which suggest male fitness to females. For example, frequent visitation might be an indication of effective hunting skills allowing males to more frequently visit community scrapes. Body size on the other hand is more likely an indication of dominance over other males (Logan and Sweanor 2001, Sunquist and Sunquist 2002, Andersson and Simmons 2006). The use of the these

multiple cues likely allows females to evaluate overall quality as a mate, reduce errors in 
mate selection, and also allows for individuals to select traits they deem most important to the fitness of their offspring (Candolin 2003, Shuett et al. 2010).

The use of community scrapes is an important mechanism for communication with potential mates and competitors in a spatially dispersed population. Scrape visitation was predominately a male activity, with males apparently using a strategy of constant vigilance through visiting and advertising their presence for prospective mates as well as territorial rivals. Visitation and the behaviours displayed by males were influenced by visitation of both females (visitation rate, duration of visits, and displaying of scraping and flehmen response behaviours) and other males (visitation rate, duration of visits, and displaying of body rubbing and flehmen response behaviours). However, male pumas showed little reaction to how recently other males had visited (i.e. within a month was recent enough), with flehmen response behaviour the only behaviour which increased with recent visitation. In contrast, male pumas clearly responded to how recently a female had visited; for example, they exhibited increases in their visitation rate and duration of visits, and also more frequently displayed scraping and flehmen response behaviours when a female had recently visited. This suggests that male visitation and behaviours at community scrapes may be more in response to potential mates than competitors.

Contrary to my hypothesis, the number of scrapes created during a visit was apparently not a response to either potential mates or competitors. Instead, the number of scrapes created was inversely correlated with visitation, as male pumas created more scrapes during seasons with lower visitation rates. Females influenced other behaviours of males, including visitation rates (see above), and male visitation patterns correlated with seasonal patterns of female denning. Therefore, I suggest that seasonal variation in visitation and scraping is more likely a response to female visitation and reproductive status than a response 
to male competitors. It is possible that the varying number of scrapes created could be a dishonest signalling behaviour to compensate for less frequent visits during these seasons. For example, visitation was an important aspect of mate selection by females, and by creating more scrapes during visits in seasons with less frequent visitation male pumas may be able to over represent their actual visitation for both competitors and mates, and increase their chances of reproductive success.

I documented that female pumas are sometimes polyandrous, as I recorded 2 female pumas consorting with more than 1 male during visitation cycles $(14.2 \%$ of the consorting documented), and also genetically confirmed more than 1 sire in a litter of cubs $(12.5 \%$ of litters tested). Other mammals have shown increased reproductive success with polyandrous females (Hoogland 2013), and the same may be true of pumas. Female cryptic choice may play a role in mate selection among polyandrous females (Andersson and Simmons 2006), but there may be adaptive behaviour benefits for female pumas as well. For example, many male felids, including pumas, frequently kill cubs which are not their own in order to induce ovulation in females and increase their own reproductive success (Logan and Sweanor 2001, Balme et al. 2013, Balme and Hunter 2013). I hypothesize that the use of polyandry may therefore increase the survival probabilities of cubs, as it may lead to uncertainty of paternity and the male pumas the cubs encounter may be less likely to kill the cubs if they are regarded as their own (Balme and Hunter 2013).

Polyandry among females may reinforce the function of competition among males. Solitary felids are efficient hunters, and because of this, competition among males may be more likely for females than for food (e.g., Smith et al.1989, Mattisson et al. 2013). Male body size is an important adaptation for competition, as larger males have a competitive advantage over smaller males and may be able to prevent their access to females either 
through fighting or maintaining a territory. However, attempts to exclude other males are apparently not completely successful in spatially dispersed populations. For example, I recorded 3 incidents where non-resident males 'poached' females which were visiting community scrapes that previously had been used by only one male. Incidents of poaching may be triggered by female's caterwauling. The function of caterwauling is to advertise from a distance (Logan and Sweanor 2001, Chapter 2), and is therefore likely a mechanism to alert males to the presence of females they would otherwise be unaware of. Aggressive disputes are relatively infrequent among resident male felids due to the potential for serious injury (Enquist and Leimar 1990, Logan and Sweanor 2001, Mattisson et al. 2013), but access to reproductive females may temporarily outweigh risks associated with interactions with other males (Smith et al.1989, Mattisson et al. 2013).

In conclusion, I found that male pumas visit community scrapes and advertise for potential mates, while females actively select mates based on assessments of individual characteristics, such as body size and visitation rate, during their periodic visits to community scrapes. Males actively compete against each other, but my results suggest that their behaviours at community scrapes are more in response to potential mates than competitors. For example, male visitation varied among seasons, and correlated with female visitation patterns, and males showed stronger reactions in the display of behaviours in response to recent female visitation than male. There is apparently no aspect of competition in mate selection among females, and my novel observation of polyandry in female pumas may be a strategy of females to increase fitness in offspring. Together these findings provide a mechanistic understanding of the function of puma communication behaviours for mate selection. 


\section{Chapter 4}

\section{The Feeding and Spatial Ecology of Pumas}

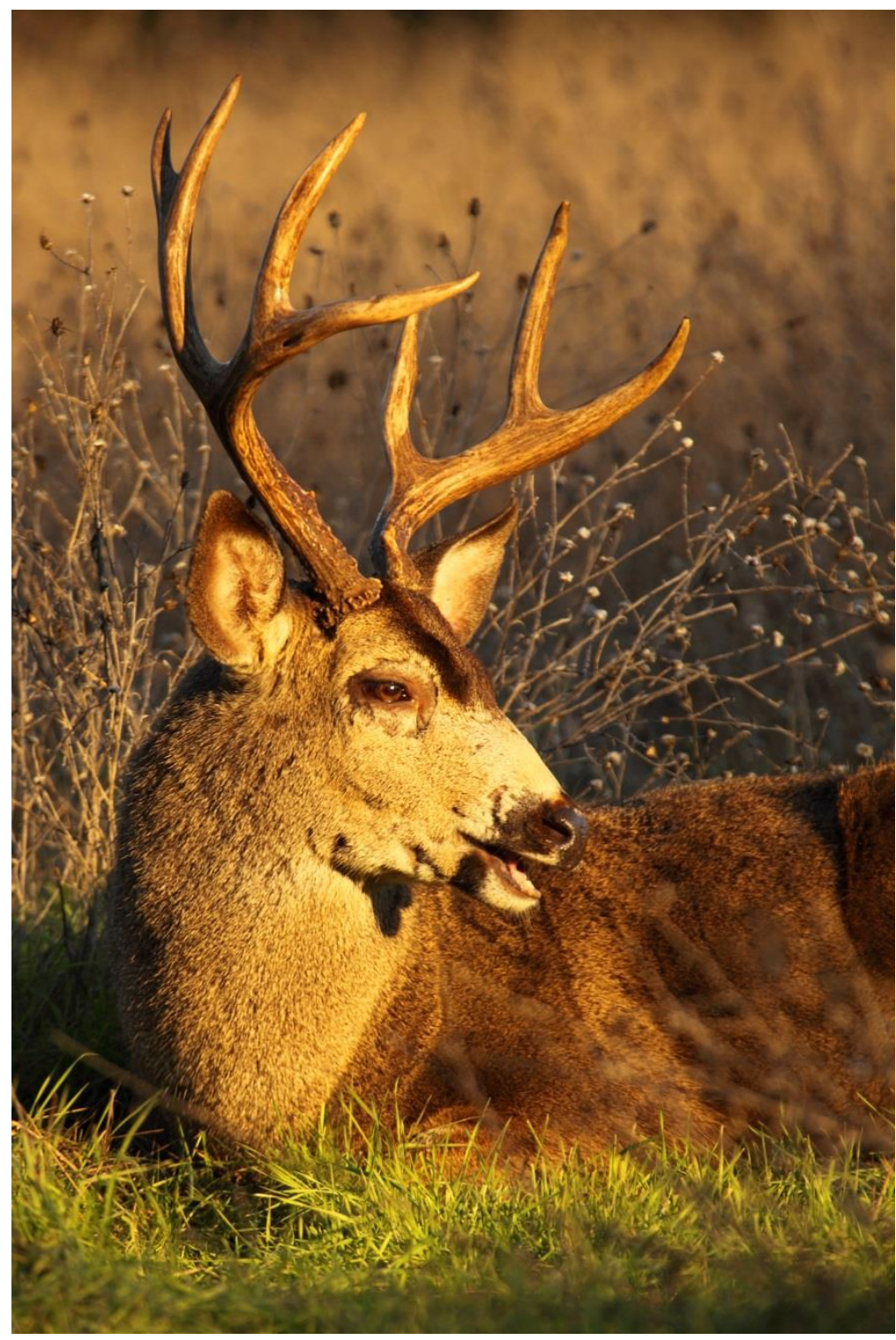


A version of this paper has been accepted for publication by the California Fish and Game Journal as:

Allen, M.L., L.M. Elbroch, D.S. Casady, and H.U. Wittmer. The Feeding and Spatial Ecology of Mountain Lions (Puma concolor) in Mendocino National Forest, California.

\section{Acknowledgements}

The California Department of Fish and Wildlife, the University of California at Davis, and the California Deer Association generously provided funding for the project. M. Allen was supported by a Victoria University of Wellington tuition scholarship. I thank B. Millsap, C. Wiley and D. Tichenor for their expertise and help in capturing pumas; and J. Golla, B. Evans, R. Carrothers, J. Smith, G. Schmidt, C. Wallace, and P. Johnston for their help on the project. 


\begin{abstract}
I conducted a study of puma (Puma concolor) feeding and spatial ecology in the Mendocino National Forest, California, a single-ungulate system in which their main prey were black-tailed deer (Odocoileus hemionus columbianus). Pumas displayed relatively high ungulate kill rates $(\bar{x}=1.07$ ungulates/week, and $\bar{x}=5.78 \mathrm{~kg} / \mathrm{day})$, and also displayed individual variation in diet composition. Pumas may have selected for deer in older age classes, with more females killed in the old age class ( $\geq 9$ years old) than in the prime age class (3-8 years old). Analyses of hunting behaviour found that prey types were killed in varying proportions among different time periods, with fawns more frequently killed during diurnal hours. I also found differences in habitat characteristics between kill sites and subsequent feeding sites, with feeding sites lower in elevation, flatter in slope, and with greater canopy density. Individual 95\% fixed kernel home ranges varied between 102 and $614 \mathrm{~km}^{2}$. Estimated population densities of pumas were comparatively low (0.61 pumas/100 $\left.\mathrm{km}^{2}\right)$.
\end{abstract}




\section{Introduction}

Pumas are the most widely-distributed carnivore in the western hemisphere (Sunquist and Sunquist 2002), and across their distribution they exhibit localized approaches in foraging behaviour and spatial use (Murphy and Ruth 2010, Hornocker and Negri 2010, Elbroch and Wittmer 2012a). For example, high prey biomass and the lack of large mammalian competitors in steppe habitats in Chilean Patagonia result in frequent use of open habitats that are largely avoided in North America (Beier 2012, Elbroch and Wittmer 2012a, Wilmers et al. 2013). More broadly, diet composition varies among ecosystems depending upon prey assemblages and prey densities and abundances (Murphy and Ruth 2010). In order to understand puma ecology it is therefore important to understand distinct strategies for and adaptations to unique ecosystems and thus the ecology of local populations.

The feeding ecology of pumas has been studied intensively aspects of their behaviour, due, in part, to broad interest in their effects on local prey populations including game species. Nevertheless, there remain aspects of puma feeding ecology that are under-studied or unknown. For example, ungulates are the main prey of pumas in terms of biomass (Hornocker 1970, Knopff 2010, Ruth and Murphy 2010a). However, kill rate estimates have shown large variation among studies, and there is debate as to whether these differences are attributable to environmental conditions including prey species or methodological differences, either in the field or in statistical analysis (Knopff et al. 2010, Ruth and Murphy 2010a). Also, studies using scat analyses indicate that smaller vertebrates are a frequent component of their diet, although their importance in terms of biomass remains debated (Murphy and Ruth 2010, Bacon et al. 2011). Previous research has also found that individual pumas specialize in their selection of prey, which in turn may have significant implications 
for modelling predator-prey dynamics, particularly when evaluating the effects of predation on rare prey (Ross et al. 1997, Elbroch and Wittmer 2013a).

Understanding the spatial ecology of pumas is also important to determine the effect of pumas on prey species. In particular, home range size and overlap among resident pumas determine population density, and therefore affect puma predation on local prey populations. Home range size and use, however, vary among ecosystems based on prey availability and distributions, as well as variation in the energetic demands of individual pumas (i.e. sex class, pregnancy, and age), and the presence and density of conspecifics (Logan and Sweanor 2001). In general, puma home ranges are smaller in areas of high quality habitats (i.e. with high prey density) (Grigione et al. 2002); while areas with high puma population densities generally have small home range sizes and large amounts of overlap among individuals (Logan and Sweanor 2001, Shaw 2010).

I initiated a study in the Mendocino National Forest, California, to further our understanding of the feeding and spatial ecology of pumas. My ultimate goal was to evaluate the effects of puma predation on a local, hunted black-tailed deer (Odocoileus hemionus columbianus) population in which only adult male deer were legally harvested. Particular objectives were to 1) determine puma diet composition and kill rates; 2) evaluate agedistribution and condition of ungulate prey; 3) further understand the cryptic hunting behaviours of pumas; and 4) to quantify home range sizes and density of the puma population. Given known variation among individuals within ecosystems in many aspects of puma ecology (e.g., Ross et al. 1997, Elbroch and Wittmer 2012a, Elbroch and Wittmer 2013a) I was particularly interested to determine consistency in observations among individuals. 


\section{Materials and Methods}

\section{Animal Captures}

Between June 2010 and November 2012, I captured 7 pumas using trained hounds and box traps. Upon capture, pumas were anesthetized with Telazol ${ }^{\circledR}$ (tiletamine $\mathrm{HCl}$ and zolazepam HCl; Fort Dodge Animal Health, Fort Dodge, IA). Ketamine HCL (Ketaset ${ }^{\circledR}$, Fort Dodge Animal Health, Fort Dodge, IA) was administered as needed to maintain anesthesia during processing. Once anesthetized, I determined the sex of pumas, and then weighed, measured, and fitted each with an ear tag and a combined ARGOS satellite GPS/radio telemetry collar (Lotek 7000SAW, New Market, Ontario). I used measurements of gum-line recession to determine the age of captured pumas (Laundré et al. 2000), and classified them as subadults ( $<3$ years) or adults $(\geq 3$ years). All capture methods were approved by an independent Institutional Animal Care and Use Committee at the University of California, Davis, and the Wildlife Investigations Laboratory of the California Department of Fish and Wildlife.

\section{Collar Programming and Field Methods}

I programmed collars to acquire GPS locations at 2-hr intervals, and downloaded location data via satellite every 3 days. I then displayed location data in ArcGIS 3.2 to visually identify clusters of GPS points and thus potential kill sites. In this study I defined GPS clusters as $\geq 5$ locations (or a minimum of 8 hours between first and last locations) within $150 \mathrm{~m}$ of each other that contained at least one crepuscular or nocturnal location (Elbroch and Wittmer 2013a), and I attempted to visit every GPS cluster for each individual puma. I performed field investigations after downloads of Argos-relayed GPS locations and used handheld GPS units (Garmin 60csx) to locate possible prey remains. 
I used the state of decay and locations of bite marks on prey carcasses to assess whether the prey had been killed or whether the puma had been scavenging. I classified prey species through skeletal features and external characteristics (hair and pelage, or feathers). At each feeding site (and a subset of kill sites - see below) I recorded the elevation, overhead tree species, and determined the primary microhabitat type at the location within a circle with a diameter $20 \mathrm{~m}^{2}$ and the carcass at its centre, based on descriptions of Mayer and Laundenslayer (1988). I then used a concave spherical densitometer to measure the canopy cover and a clinometer to measure the slope of the feeding site.

I estimated the age and health condition of black-tailed deer during my field investigations. I estimated the age of black-tailed deer killed by pumas to the closest month for individuals $<1$ year old based upon field observations and the assumption that fawns were born on June $16^{\text {th }}$ of each year. I estimated the age of black-tailed deer for individuals $1-2.5$ years using tooth irruption patterns (Heffelfinger 2010), and for individuals >2.5 years using cementum annuli analysis (Low and Cowan 1963) using an independent lab (Matson's Laboratory, Milltown, MT). I determined health condition for adult black-tailed deer from the colour and consistency of the bone marrow (Hornocker 1970) differentiating 4 categories: poor (red or red and pink marrow), fair (pink marrow), good (pink and white marrow), and excellent (white marrow). I estimated prey weights based on published literature. For deer, I used monthly sex-specific weights for fawns, and annual sex-specific weights for adults based on data from Sitka black-tailed deer (Odocoileus hemionus sitkensis) presented in Parker et al. (1993). For all other mammal species I used the average weights described in Jameson and Peeters (2004), and for bird species I used the mean weights described in Sibley (2005). 


\section{Statistical Analysis Overview}

I used program $R$ version 3.0.0 (R Core Team 2013) for my statistical analyses, except where noted. Following $R$ guidelines (R Core Team 2013), I cite associated packages used in the analyses. In each statistical test, I considered $P \leq 0.05$ to be statistically significant.

\section{Kill Rate and Diet Composition Statistical Analyses}

I determined the frequency of occurrence for each species in the diet of pumas through prey remains found at GPS clusters. I determined kill rates for each individual puma for the entire time each had a functional GPS collar, with the duration of monitoring periods shown in Table 1. I calculated kill rates in terms of both number of individuals killed (animals/week) and biomass (kg/day) for each collared puma. I calculated both types of kill rate for all prey items and then separately for just ungulates, with the number of ungulates killed per week allowing for comparison to previous studies of puma kill rates (summarized in Table 1 of Knopff et al. 2010).

\section{Hunting and Feeding Behaviour Statistical Analyses}

I hypothesized that individual pumas would vary in the proportion of non-ungulate prey in their diet. For each individual puma I therefore categorized each animal killed as ungulate or non-ungulate, and then used a chi-square test with a 7x2 contingency table (Sokal and Rohlf 1987) to test for differences in the proportion of the two prey types among individual pumas. For my analyses of age and condition of deer killed by pumas I only used kills where I found reliable teeth (irruption $n=34$, cementum annuli $n=38$ ) and long-bones $(n=89)$ needed to determine these variables. I hypothesized that male and female black- 
tailed deer would be killed at different ages because in hunted populations with male-only harvest restrictions there may be fewer male deer available in the old age class than sub-adult or prime age classes. Because of a low sample size in some classes, I used a Fisher's exact test (Sokal and Rohlf 1987) to test my hypothesis, with categories of sub-adults (1-2.5 years old), prime age (3-8 years old), and old ( $\geq 9$ years old) for deer of each sex.

I defined the time of kill for each prey carcass using the hour of the first waypoint at each puma GPS cluster, with 12 values available (12 am, 2 am, 4 am, 6 am, 8 am, 10 am, 12 pm, 2 pm, 4 pm, 6 pm, 8 pm, and 10 pm). I then grouped times into 3 categories: nocturnal, diurnal, and crepuscular (times within 1 hour of sunrise and sunset), based on daily local sunrise and sunset times. I hypothesized that because pumas display specialization in their prey killed (Ross et al. 1997, Elbroch and Wittmer 2013a), individual pumas might also vary in the times they hunt and kill prey. For each individual puma I categorized each kill by time period, and used a Fisher's exact test (Sokal and Rohlf 1987) to test for variation among individual pumas. I next split prey into 3 types: adult deer $(\geq 1$ year), fawns ( $<1$ year old), and non-ungulate prey. Because pumas are primarily nocturnal hunters (Currier 1983, Sweanor et al. 2008), I expected that each prey type would be killed in higher proportions during the night, and hypothesized that prey types would not vary in their proportions among time periods. I categorized each kill by prey type and the categories of times of kill and used a chi-square test with a $2 \times 3$ contingency table (Sokal and Rohlf 1987) to test my hypothesis. I used a post-hoc Bonferroni test to determine where significant differences occurred.

On 13 occasions I determined the location where pumas killed black-tailed deer and compared their characteristics to matched, subsequent feeding sites. To find the kill site I followed the trail of pumas backwards from the feeding site, to the point where the deer's tracks ended and the deer first hit the ground. At kill sites I recorded elevation, primary 
habitat type, overhead tree, canopy cover, and slope, following the same procedures as at feeding sites. I hypothesized feeding sites would be different from kill sites because pumas would choose refugia and concealment to feed (Murphy and Ruth 2010). I hypothesized that pumas would drag deer downhill (lower elevation) due to the mass of the deer and to flatter areas (less slope) for ease of feeding, while also choosing areas of high canopy cover to limit detection by avian scavengers (Elbroch and Wittmer 2013b). I first tested each variable (elevation, slope, and canopy cover) for normality with a Shapiro-Wilk normality test, and then tested for variance equality with a Levene's test (Sokal and Rohlf 1987). I then used a two-tailed Student's t-test with equal variances (Sokal and Rohlf 1987) to test for differences between kill and feeding sites for each variable.

\section{Spatial Use and Population Density Statistical Analyses}

I used two separate methods to estimate home ranges of pumas for the total time they wore GPS collars in my study area. My first method was the Minimum Convex Polygon (hereafter MCP) (Mohr 1947). MCP's were the most common form of home range estimation on previous puma studies, and thus calculating MCP's allowed me to directly compare my findings with previous results. I used the adehabitatHR package (Calenge 2006), by first translating my data into $\mathrm{R}$ spatial data using the $s p$ package (Pebesma and Bivand 2005, Bivand et al. 2008). I then used all of the collected GPS data for each individual puma to estimate cumulative $95 \% \mathrm{MCP}$ home ranges.

My second method of home range estimation was the fixed bivariate kernel method (Worton 1989), which allowed comparison of my data with more recent studies. As outlined above, I used the $s p$ package (Pebesma and Bivand 2005, Bivand et al. 2008) to translate my data in $\mathrm{R}$ spatial data, and then the adehabitatHR for calculations (Calenge 2006). I 
calculated the kernel smoothing factor (h) using least squares cross validation (Seaman and Powell 1996), and estimated 95\% kernel home ranges for each puma.

I calculated a minimum population density following methods outlined in Elbroch and Wittmer (2012a) and Rinehart et al. (2014). I employed a density estimate for AugustOctober 2011 using overlapping home ranges for that 3-month period. I based my minimum population estimate on my $402 \mathrm{~km}^{2}$ 'trapping area' (e.g., Rinehart et al. 2014), an area in which for that time period I believe I had captured every resident puma (I did not find any puma tracks in the area that could not be accounted for by pumas wearing GPS collars). Using ArcGIS 9.3 I created MCP home ranges for each puma by sex and age; I then summed the proportion of their overlapping home ranges within the trapping area (using Hawth's tools and ArcGIS 9.3) to determine the density of adult resident pumas for each sex, and then overall for pumas (including juveniles and kittens) in the study area. To avoid bias associated with scaling a density to a different spatial extent than that of the study area, I then reported densities per $402 \mathrm{~km}^{2}$ (Rinehart et al. 2014). With the understanding that I would negatively bias results by scaling down the population density, I also present densities per $100 \mathrm{~km}^{2}$ for comparison with other studies.

\section{Results}

\section{Kill Rate and Diet Composition}

I captured 7 pumas and monitored each puma for $\bar{x}=9.07 \pm 4.79 S D$ months (Table 1). I conducted field investigations of 598 out of 609 identified GPS clusters, and I investigated the ARGOS-relayed GPS clusters within $\bar{x}=6.78 \pm 8.18 S D$ (range 0-60) days after the puma left the kill. 


\begin{tabular}{|c|c|c|c|c|c|c|}
\hline \multirow[b]{3}{*}{ ID } & \multirow{3}{*}{$\begin{array}{l}\text { Monitoring } \\
\text { Period } \\
\text { (days)* }\end{array}$} & \multirow{3}{*}{$\begin{array}{l}\text { Percent } \\
\text { of Non- } \\
\text { ungulates } \\
\text { in Diet }\end{array}$} & \multicolumn{4}{|c|}{ Kill Rates } \\
\hline & & & \multicolumn{2}{|c|}{ All Prey } & \multicolumn{2}{|c|}{ Ungulates } \\
\hline & & & $\begin{array}{l}\text { Mass } \\
\text { (kg/day) }\end{array}$ & $\begin{array}{l}\text { Individuals } \\
\text { (animals/week) }\end{array}$ & $\begin{array}{l}\text { Mass } \\
\text { (kg/day) }\end{array}$ & $\begin{array}{l}\text { Individuals } \\
\text { (animals/week) }\end{array}$ \\
\hline $\mathrm{F} 1$ & 477 & $21.1 \%$ & 4.78 & 1.12 & 4.68 & 0.88 \\
\hline F17 & 328 & $8.9 \%$ & 5.82 & 1.20 & 5.81 & 1.09 \\
\hline F19 & 202 & $20.0 \%$ & 4.37 & 0.87 & 4.34 & 0.69 \\
\hline $\mathrm{F} 23$ & 186 & $44.7 \%$ & 5.27 & 1.81 & 4.77 & 0.98 \\
\hline F43 & 209 & $8.1 \%$ & 10.27 & 2.08 & 10.26 & 1.91 \\
\hline M33 & 386 & $5.7 \%$ & 6.84 & 1.29 & 6.71 & 1.20 \\
\hline M36 & 83 & $43.8 \%$ & 4.37 & 1.35 & 3.92 & 0.76 \\
\hline
\end{tabular}

*based on investigations of clusters with $>5$ locations

Table 1. The kill rates and percent of diet made up of non-ungulates for pumas monitored during the study. The duration of the monitoring period for each puma is shown in days. The percent of diet made up of nonungulates was calculated by occurrence of individual animals over the course of the entire monitoring period. Kill rates were calculated for all prey species and just ungulates, with kill rates of mass calculated as $\mathrm{kg} /$ day and kill rates of number of individuals calculated as animals/week.

I identified 352 puma kills, including 288 black-tailed deer, 2 black bears, and 62 small to medium-sized vertebrates (Figure 1), as well as 4 acts of puma scavenging. Kill rates for all prey species were $\bar{x}=1.39(95 \%$ CI 1.07-1.70) animals/week, and $\bar{x}=5.96(95 \% C I$ 4.40-7.51) $\mathrm{kg} / \mathrm{day}$ (Table 1). Kill rates for ungulates were $\bar{x}=1.07$ (95\% CI $=0.77-1.38)$ ungulates/week, and $\bar{x}=5.78(95 \% C I=4.16-7.40) \mathrm{kg} /$ day (Table 1). Black-tailed deer contributed $98.6 \%$ of prey biomass and $74.4 \%$ of deer killed by pumas were $\geq 1$ year old. 


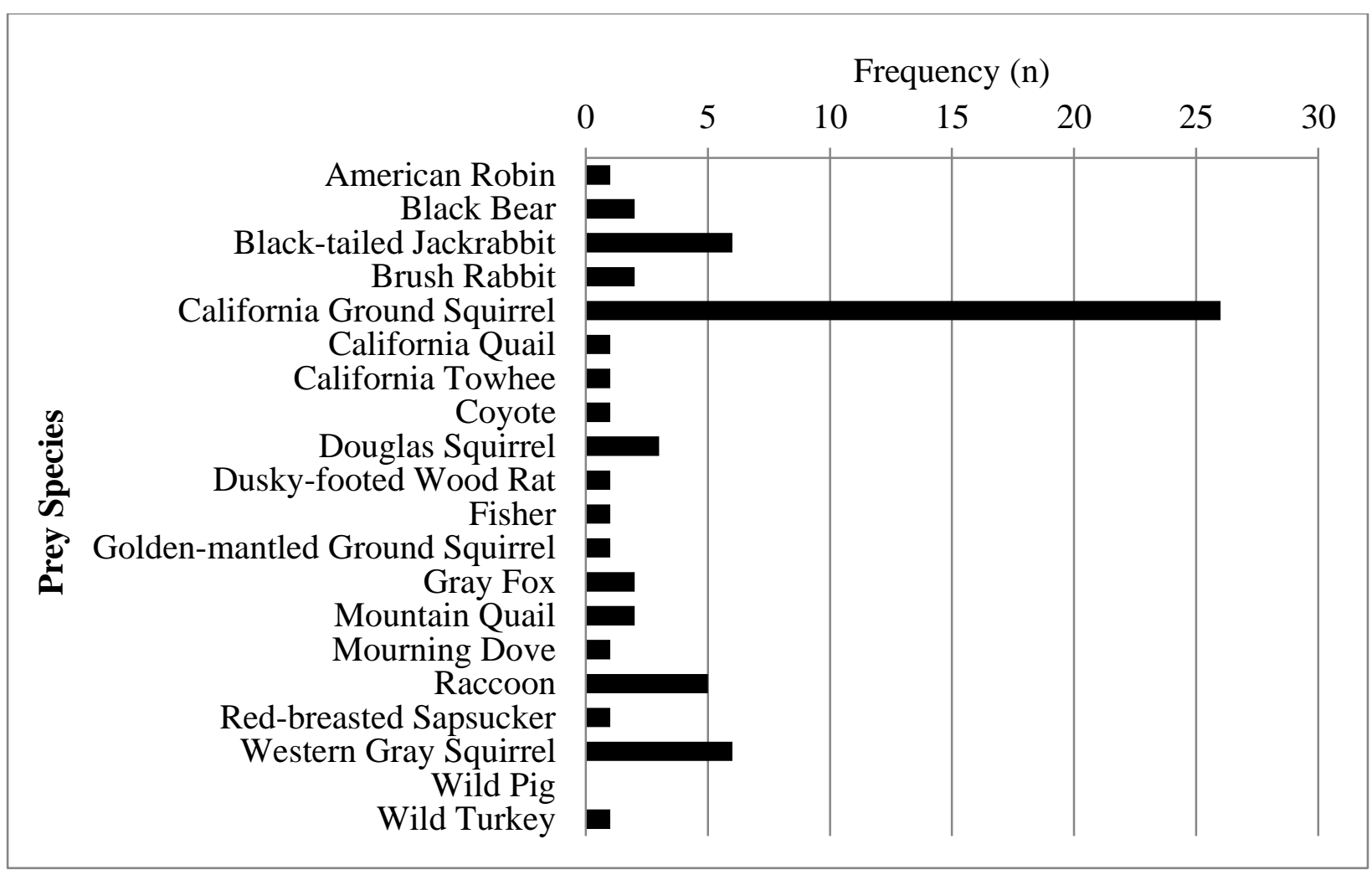

Figure 1. The frequency of occurrence for each non-ungulate prey species I documented pumas eating during the study.

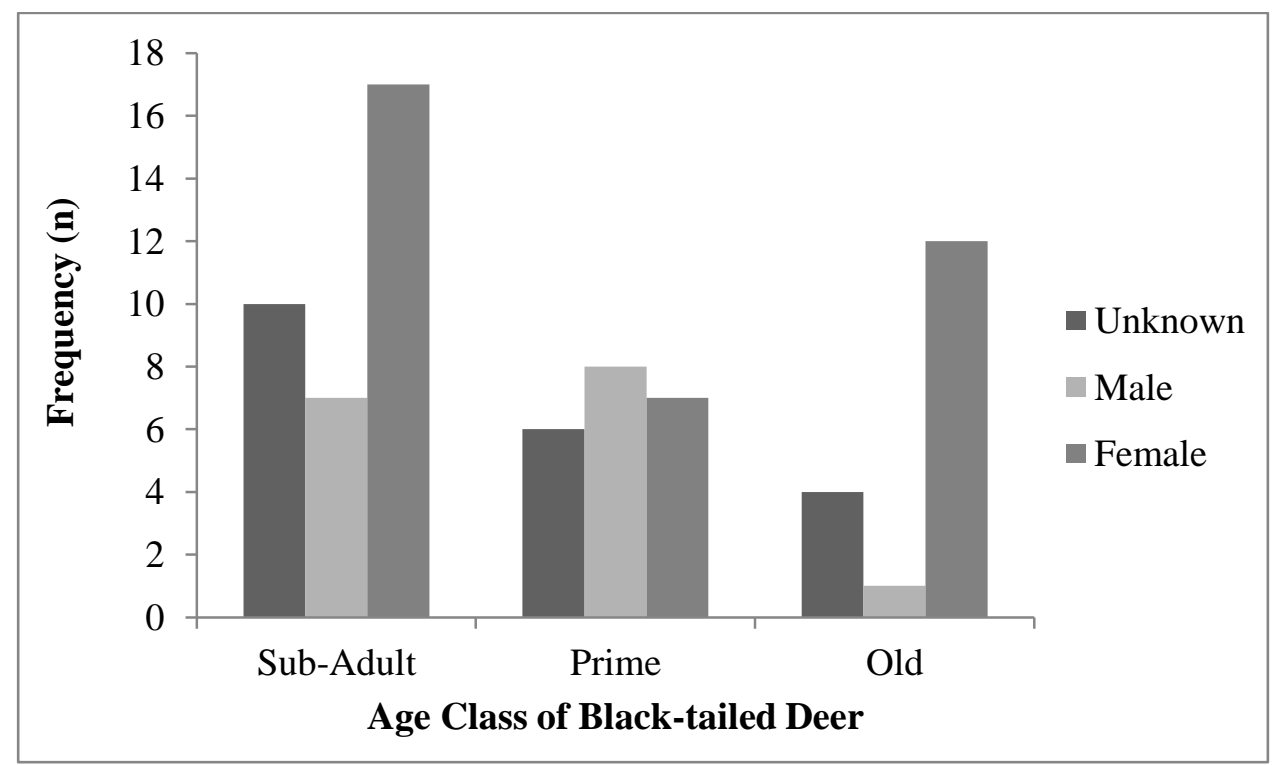

Figure 2. The frequency of black-tailed deer killed by pumas among age and sex classes. Male, female, and unknown deer are shown by class, with sub-adult representing deer 1-2.5 years old, prime representing deer 3-8 years old, and old representing deer 9-22 years old. Sub-adult deer were aged using teeth irruption, while prime and old deer were aged using cementum annuli analysis. 


\section{Hunting and Feeding Behaviour}

My chi-square analysis revealed a significant difference among individual pumas in the proportion of non-ungulate prey in their diet $\left(d f=6, X^{2}=45.03, p<0.0001\right)$ (Table 1). My analysis revealed a sex-specific difference in the proportion of deer killed in different age classes ( $d f=2, p=0.0378$ ) (Figure 2$)$, with more females in the old age class than prime age class. The health of black-tailed deer $\geq 1$ year old killed varied, with $12.4 \%$ of individuals in excellent condition, $32.6 \%$ in good condition, $32.6 \%$ in fair condition, and $22.4 \%$ in poor condition.

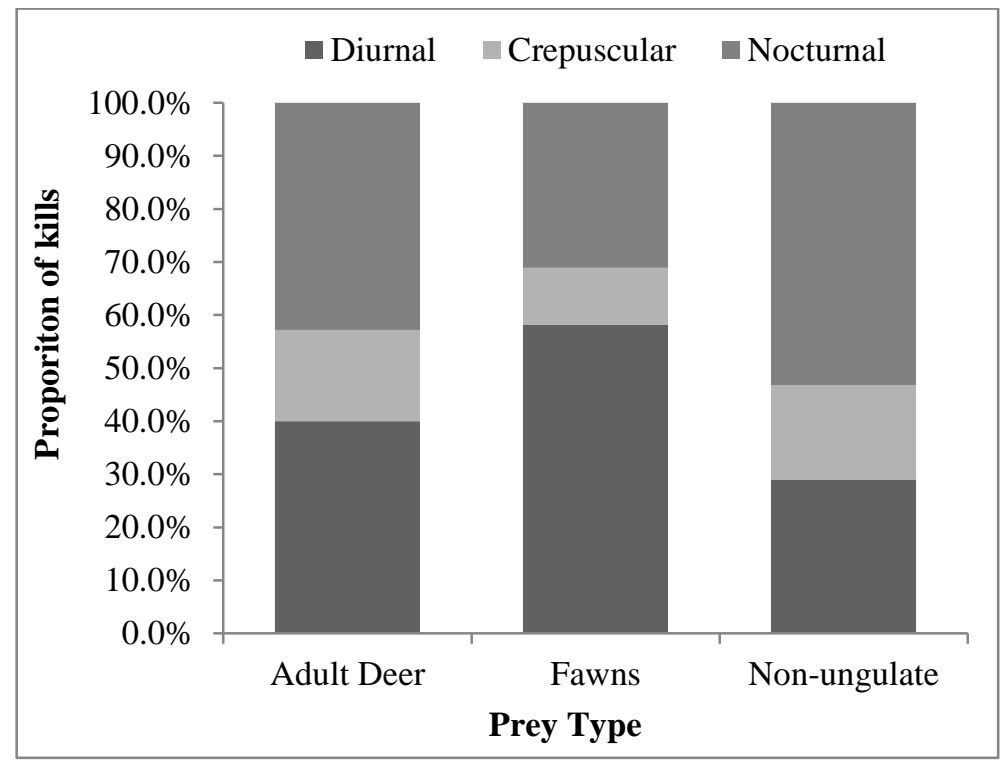

Figure 3. The proportion of kills made by pumas for each prey type by time period. The time periods were grouped into 3 categories: nocturnal, diurnal, and crepuscular (within 1 hour of sunrise or sunset).

My chi-square analyses did not reveal a significant difference among individual pumas in the time periods kills were made $\left(\mathrm{df}=12, X^{2}=11.43, p=0.4927\right)$, but did reveal significant differences in the time of kills for different prey types $\left(\mathrm{df}=4, X^{2}=12.82, p=\right.$ 
0.0122, Figure 3). My post hoc analyses revealed fawns were more likely to be killed in diurnal periods $\left(d f=2, X^{2}=10.18, P=0.0061\right)$, while non-ungulate prey were more frequently killed during nocturnal periods but were marginally insignificant $(p=0.0705)$.

Once black-tailed deer were killed, they were dragged $\bar{x}=21.7 \mathrm{~m} \pm 4.28 S E$ from the kill site to the preferred feeding site of the puma. $38.5 \%$ of the feeding sites had different primary habitats and overhead tree species than the kill sites. The elevation at feeding sites was significantly lower than at kill sites $(d f=12, p=0.0325)$, with feeding sites $\bar{x}=5.77 \mathrm{~m} \pm$ 2.39 SE lower in elevation than kill sites. The slope at feeding sites was significantly flatter than at kill sites $(d f=12, p=0.0174)$, with feeding sites $\bar{x}=13.54^{\circ} \pm 5.02 S E$ flatter in slope than kill sites. The canopy cover at feeding sites was significantly more dense than at kill sites $(d f=12, p=0.0101)$, with the canopy cover of feeding sites $\bar{x}=29.4 \% \pm 10.2 S E$ more dense than kill sites.

\section{Home Range Sizes and Population Density}

MCP home ranges were $\bar{x}=465 \pm 274 \mathrm{~km}^{2}$ for 4 adult females, $517 \mathrm{~km}^{2}$ for 1 subadult female, $681 \mathrm{~km}^{2}$ for 1 adult male, and $287 \mathrm{~km}^{2}$ for 1 subadult male (Table 2). Kernel home ranges were $\bar{x}=266 \pm 116 \mathrm{~km}^{2}$ for 4 adult females, $102 \mathrm{~km}^{2}$ for 1 subadult female, 348 $\mathrm{km}^{2}$ for 1 adult male, and $142 \mathrm{~km}^{2}$ for 1 subadult male (Table 2).

I calculated a snapshot population density of $1.57 / 402 \mathrm{~km}^{2}\left(0.39 / 100 \mathrm{~km}^{2}\right)$ for adult female pumas and $0.56 / 402 \mathrm{~km}^{2}\left(0.14 / 100 \mathrm{~km}^{2}\right)$ for adult males. Total puma density in the study area including known cubs was $2.45 / 402 \mathrm{~km}^{2}\left(0.61 / 100 \mathrm{~km}^{2}\right)$. 


\begin{tabular}{|c|c|c|c|c|c|c|}
\hline ID & $\begin{array}{c}\text { Age } \\
\text { (years) }\end{array}$ & Class & $\begin{array}{l}\text { Weight } \\
\text { (kg) }\end{array}$ & $\begin{array}{l}\text { Number of } \\
\text { GPS Points }\end{array}$ & $\begin{array}{l}95 \% \mathrm{MCP} \\
\text { home range } \\
\mathrm{km}^{2}\end{array}$ & $\begin{array}{l}95 \% \text { Kerne } \\
\text { home range } \\
\mathrm{km}^{2}\end{array}$ \\
\hline $\mathrm{F} 1$ & 6.5 & $\mathrm{AF}$ & 34.6 & 5342 & 1112 & 614.1 \\
\hline F17 & 1.4 & $\mathrm{SF}$ & 31.5 & 3695 & 517 & 102.4 \\
\hline F19 & 4.1 & $\mathrm{AF}$ & 33.6 & 1565 & 224 & 148.1 \\
\hline F23 & 4.2 & $\mathrm{AF}$ & 49.5 & 2125 & 201 & 158.6 \\
\hline F43 & 3.1 & FG & 38.1 & 2035 & 151 & 143.5 \\
\hline M33 & 7.0 & $\mathrm{AM}$ & 59.1 & 4255 & 681 & 347.8 \\
\hline M36 & 2.5 & SM & 48.1 & 971 & 287 & 141.8 \\
\hline
\end{tabular}

Class- AF $=$ Adult Female, $\mathrm{AM}=$ Adult Male, $\mathrm{SF}=$ Subadult Female, $\mathrm{SM}=$ Subadult Male, FG = Family Group

Table 2. The characteristics and home range sizes of pumas in Mendocino National Forest. The age, age class and weight at original capture are shown, along with the number of GPS points used in the home range analyses. Home ranges were calculated in $\mathrm{km}^{2}$ using $95 \%$ Minimum Convex Polygons (MCP), and 95\% kernels for the entire time the puma was collared.

\section{Discussion}

Pumas in my study area showed individual variation in some aspects of their ecology and behaviour. Individual pumas varied in the amount that non-ungulate prey species contributed to their diet, but not in the time of day they killed their prey. My limited sample did not permit testing for variation in kill rates among pumas of different age and sex classes, though kill rates appeared to vary among individuals. For example, F19's kill rate in ungulates/week was $36.1 \%$ of F43's, and F1's kill rate was only $46.1 \%$ of F43's. Given that F43 at the time of my observations was caring for two yearling kittens and F19 and F1 did not have kittens, this variation may have been due to the increased energetic demands associated with reproductive status (Laundré 2005). Understanding the variation among individuals is an important aspect to understanding the ecology of the species (Bolnick et al. 2003, Estes et al. 2003), and my results lend further support to previous suggestions that pumas show specializations not only to different ecosystems across their wide distribution, 
but as individuals within unique ecosystems (e.g., Ross et al. 1997, Elbroch and Wittmer 2013a).

I found relatively high ungulate kill rates and non-ungulate prey diversity when compared to previous studies that used GPS cluster methods to find puma kills. In particular, the mean kill rates of $1.07(95 \% \mathrm{CI}=0.77-1.38)$ ungulates/week $\mathrm{I}$ observed are among the highest kill rates reported for pumas to date (see summary in Table 1 of Knopff et al. 2010). These results, however, may be a consequence of intensive field methods rather than an indication of true differences in the feeding ecology of pumas in my study area. Alternatively, the higher kill rates could be a product of the single-prey system. For example, black-tailed deer are smaller than many ungulates (e.g. elk or moose) and hence pumas may need to kill black-tailed deer more often to fulfil their energy requirements. GPS cluster investigations may estimate different diet composition as compared to diets determined with scat analyses (Murphy and Ruth 2010, Bacon et al. 2011, Pitman et al. 2013), due to the shorter handling times pumas have for small prey and the difficulty of finding small prey when compared to deer. Although my study likely underestimated small prey items in the diet composition of pumas, my study further emphasized that studies utilizing intensive GPS investigation are capable of describing small prey in diet composition (Pitman et al. 2013).

Despite the diversity of prey species I observed, black-tailed deer were the most important prey of pumas (98.6\% of biomass). I found a significant difference in the body condition of deer $>1$ year old, which contrasts with results of previous studies (Hornocker 1970). The majority of deer $\geq 1$ year old killed by pumas $(65.2 \%)$ were in good or fair condition, and the age structure of adult female deer killed by pumas was skewed towards older individuals. As can be expected in a black-tailed deer population in which only males are heavily-hunted, only two male deer were killed past prime age and more females killed 
were in the old age class than in the prime age class. This included an individual aged 22 years old, and as suggested by Murphy and Ruth (2010), my results suggest increased success of killing individuals past their prime age.

My analyses of hunting behaviours suggest that I may need to rethink some assumptions used in previous studies. Pumas are predominantly active during nocturnal and crepuscular hours (Currier 1983, Sweanor et al. 2008), and it has thus been generally assumed that most of their kills occur during these periods. However, my results showed variation in time of kill by prey type, but also lower proportions of prey killed during nocturnal periods than expected. For example, adult black-tailed deer were killed in similar proportions during nocturnal and diurnal time periods, while deer $<1$ year old were killed significantly more frequently during diurnal time periods. This suggests that mountain lions are hunting during diurnal hours as opportunities arise, especially during summer when young ungulates are available. Additionally, most studies which attempt to link predation and predation risk to habitat have used the location of prey remains (e.g. Atwood et al. 2007, Elbroch and Wittmer 2012a, Apps et al. 2013). However, my results showed that the location of prey remains were different than the location of the actual kill in many respects, including primary habitat type. Kill sequences often occur over large areas, and if I inferred predation risk from habitat where prey remains were found, I would be evaluating preferences for feeding sites of pumas rather than habitats where deer are at risk of being killed. Future studies should take this assumption into account and attempt to define the scale of risk and locate kill sites when describing habitat-specific risks for prey.

The population density of pumas in my study area was lower than in many other studies, while observed home ranges were in the published range for pumas (Logan and Sweanor 2010). The reasons for the observed low population densities, however, are unclear. 
Hunting of pumas in California has been prohibited since 1972 (Torres et al. 1996) and puma populations from coastal California have historically had high population densities (Roberson and Lindzey 1984). For example, Hopkins et al. (1986) reported densities of $3.6 / 100 \mathrm{~km}^{2}$ in a coastal area in central California, almost 6 times higher than the densities I observed. Instead my population density was more comparable to the lowest recorded puma population densities of $0.37 / 100 \mathrm{~km}^{2}$ reported by Lindzey et al. (1994) in Utah. Given the relatively high abundance of black-tailed deer in the study area $\left(20 \mathrm{deer} / \mathrm{km}^{2}\right.$; Casady, unpublished data) it is doubtful that the low puma density was caused by low prey density. I speculate that the low densities were more likely a consequence of other factors such as illegal hunting or interference competition with dominant scavengers such as black bears. For example, previous studies have shown that poaching can greatly reduce puma population densities $\left(0.3-0.74 / 100 \mathrm{~km}^{2}\right.$ in areas with poaching compared to $1.55-2.89 / 100 \mathrm{~km}^{2}$ in areas without poaching) (Paviolo et al. 2009). Alternatively, the usurpation of kills by bears has been found to force solitary felids to kill deer more frequently (Krofel and Kos 2010, Krofel et al. 2012), and this may also be true of pumas, with lower available energy potentially resulting in low recruitment rates. Unknown factors or interplay between poaching and usurpation of kills by black bears could also account for low puma densities in the study area.

High ungulate kill rates together with seemingly low densities of pumas in my study area could have important implications for the future dynamics of black-tailed deer in the Mendocino National Forest. Changes to the abundance of large carnivores have wideranging, but hard to predict, effects on other species in the ecosystem (Prugh et al. 2009), and pumas may be influenced by the recent decision of the California legislature to ban the use of dogs to hunt black bears. It is conceivable that this change may result in increased puma densities in my study area (via a reduction of the illegal shooting of pumas caught as bycatch 
during bear hunting season) as well as a further increases in local black bear densities. In consequence, both of these changes may result in increased mortality rates of black-tailed deer. This is a concern, since high observed kill rates might currently be offset by low puma densities and thus any future increase in puma density without a concurrent reduction in kill rates may result in future population declines of black-tailed deer. Because of this, I recommend that the California Department of Fish and Wildlife continue to study both predator and prey in the Mendocino National Forest to obtain data required to effectively manage all species at an ecosystem level. 


\title{
Chapter 5
}

\author{
Seasonal Variation in the
}

Feeding Ecology of Pumas

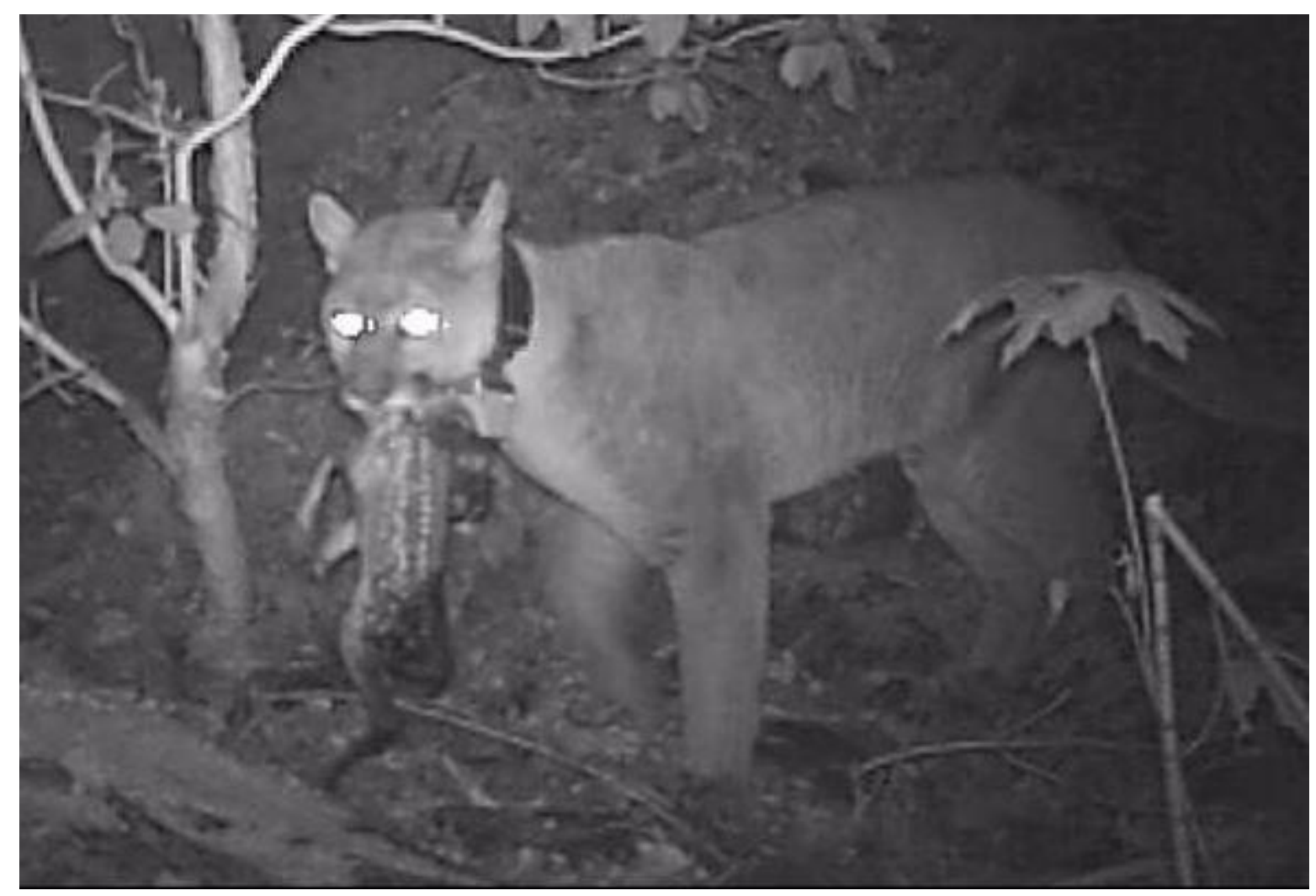


A version of this paper was published as:

Allen, M.L., L.M. Elbroch, D.S. Casady, and H.U. Wittmer. Seasonal Variation in the Feeding Ecology of Pumas (Puma concolor) in Northern California. Canadian Journal of Zoology 92: 397-403. DOI:10.1139/cjz-2013-0284.

\section{Acknowledgements}

The California Department of Fish and Wildlife, the University of California at Davis, and the California Deer Association generously provided funding for the project. M. Allen was supported by a Victoria University of Wellington tuition scholarship. I thank B. Millsap, C. Wiley and D. Tichenor for their expertise and help in capturing pumas; and J. Golla, B. Evans, R. Carrothers, J. Smith, G. Schmidt, B. Milano, C. Wallace, and P. Johnston for their help on the project. 


\begin{abstract}
The direct effects of predators depend upon factors that can vary across seasons, including variations in the abundance and vulnerability of migrating prey. Past studies show conflicting results of whether puma (Puma concolor) feeding ecology varies among seasons, which may be due to both statistical methods and variation in ecological conditions among studies. I employed GPS collars to study puma feeding ecology in a single-prey system with migratory black-tailed deer (Odocoileus hemionus columbianus). I found that kill rates in ungulates/week were significantly higher in summer and autumn than in winter, while kill rates in $\mathrm{kg}$ /day did not vary among seasons. The increase of kill rates in ungulates/week was most likely due to the increased availability and density of black-tailed deer fawns, which are small and easier to catch than adult black-tailed deer. The handling times of black-tailed deer $\geq 1$ year old showed an inverse relationship with kill rates in ungulates/week, and were significantly higher in winter than in spring, summer, or autumn. I speculated that reduced handling time in summer may have been influenced by black bear kleptoparasitism and possibly the decomposition of kills (i.e. higher temperatures and increased invertebrate activity). Pumas killed black-tailed deer at higher elevations in summer than in winter, spring, or autumn and elevations at which pumas killed black-tailed deer correlated significantly with seasonal elevations used by black-tailed deer. These data suggest that pumas exhibited seasonal foraging behaviours and tracked prey availability in a system with migrating prey.
\end{abstract}




\section{Introduction}

The keystone effects of top-level predators on prey populations and ecosystems are well established (Estes 1996, Ripple and Breschetta 2004). The direct effects of predators on their prey, however, are dependent on factors which may vary among seasons. In many terrestrial ecosystems, for example, ungulates migrate following changes in plant phenology to increase their access to forage, to avoid deep snows which limit their mobility and access to resources, and to reduce predation and parasite risk (Fryxell and Sinclair 1988, Hebblewhite and Merrill 2007). Ungulate migrations therefore result in significant redistributions of resources making it necessary for predators to respond to spatial and temporal variation in prey availability. Recent studies using GPS collar technology have shown that top-level predators respond to seasonal variation in prey availability and vulnerability in numerous ways, including temporal changes in diet and species-specific kill rates (Sand et al. 2008, Knopff et al. 2010, Metz et al. 2012, Elbroch et al. 2014).

Pumas are solitary top-level predators that prey upon ungulates throughout their range in North and South America (Sunquist and Sunquist 2002), and there are conflicting results and hypotheses concerning seasonal variation in puma feeding ecology (Knopff et al. 2010, Ruth and Murphy 2012a). Among kill rates, for example, previous studies have shown either no variation among seasons (Elbroch et al. 2014), an increase in winter, or an increase in summer (Knopff et al. 2010). Knopff et al. (2010) found higher kill rates in summer, and hypothesized that was due to the increased availability of ungulates born in early summer, which are easier to prey upon than adult ungulates. In contrast, Hornocker (1970) hypothesized ungulate kill rates would be lower in summer due to the increased availability of small non-ungulate prey. Changes in seasonal kill rates may also be driven by ungulate migrations. Cooley et al. (2008) and Pierce et al. (1999) found that pumas followed migratory deer herds, but Cooley et al. (2008) did not find variation in kill rates among seasons. In contrast, Elbroch et al. (2013) reported that pumas in the Southern Yellowstone Ecosystem 
remained in place and prey switched from abundant migratory elk in winter to abundant migratory deer in summer.

The seasonal behaviours of competitive scavengers and decomposers may also result in seasonal variation in puma kill rates. For example, brown bears (Ursus arctos) increase kill rates of Eurasian lynx (Lynx lynx) only during summer (Krofel and Kos 2010, Krofel et al. 2012), and Andean condors (Vultur gryphus) have been shown to increase puma kill rates throughout the year (Elbroch and Wittmer 2013b). Invertebrate and microbial decomposers also consume and spoil carcasses in warm seasons (Bischoff-Mattson and Mattson 2009). Finally, statistical methods may have played a role in the conflicting results of seasonal variation, as most past studies of seasonal variation in puma feeding ecology are based on a 2-season model which may be less effective than 4-season models for detecting variation among seasons (Metz et al. 2012).

I employed Argos-GPS collars to study the feeding ecology of pumas in the Coast Range of northern California. My objective was to understand the feeding ecology of pumas in a system where the availability and distribution of their sole ungulate prey, black-tailed deer (Odocoileus hemionus columbianus), varied seasonally. Black-tailed deer in the study area exhibit elevational migrations, behaviour hypothesized to be related to the seasonal availability of forage (Loft et al. 1984, Pierce et al. 1999). Predators sometimes focus on killing young ungulates during summer (Owen-Smith 2008), and ungulate species may synchronize their births in order to flood the ecosystem with young and limit the impact of predators (Estes 1978, Rutberg 1987). Black-tailed deer in my study area exhibited a birth pulse at high elevations in June. In addition, my study area supported an abundant population of black bears (U. americanus), a dominant scavenger which is capable of usurping kills from pumas (Ruth and Murphy 2010b). Many black bears hibernate, and were therefore more active in the study area from May to November. Possible causes of seasonal variation are sometimes confounding because they occur in conjunction with each other, making studies 
from different ecosystems necessary to determine broad ecological patterns. My study area, with a single-prey which migrates and exhibits a birth pulse, and also includes a seasonally abundant dominant scavenger, therefore offers an opportunity to examine the possible causes of variation in puma feeding ecology among seasons.

I hypothesized that the feeding ecology of pumas in our study area would vary among seasons, due to changes in the availability of migrating deer populations as well as activity patterns of competitors. Further, I hoped to assess for potential biases introduced by sampling kill rates or prey selection in one season (e.g., Metz et al. 2012), by comparing foraging ecology across seasons. In order to determine whether puma feeding ecology varied among seasons, I studied: 1) puma kill rates, 2) mean daily movements of collared pumas, 3) puma handling times of adult deer and their correlation with black bear presence, 4) the elevation at which black-tailed deer were killed, and 5) whether the elevations used by black-tailed deer correlated with the elevations used by pumas. Based on Knopff et al. (2010) and the increased availability of black-tailed deer fawns during the birth pulse in summer, I hypothesized that puma kill rates in ungulates/week and $\mathrm{kg} /$ day would be higher in summer and autumn than in winter and spring. Based on Cooley et al. (2008) and Pierce et al. (1999), I hypothesized that mean daily movements of pumas would be shorter in winter when blacktailed deer populations were more concentrated than during other seasons. I also hypothesized that puma handling time of black-tailed deer $\geq 1$ year old would be lowest in summer and autumn when bears were most active and higher temperatures tend to spoil meat faster and increase decomposition from invertebrates (Bischoff-Mattson and Mattson 2009, Ruth and Murphy 2010b, Krofel et al. 2012). Last, I hypothesized that pumas would track black-tailed deer migrations, and that there would be significant correlation between the elevation of puma kills and the elevations used by black-tailed deer; we expected pumas and deer to be at lowest elevations in winter and highest elevations in summer (Pierce et al. 1999, Cooley et al. 2008). 


\section{Materials and Methods}

\section{Animal Captures}

From June 2010-December 2012, I captured 7 pumas with trained hounds and box traps. Upon capture, pumas were anesthetized with Telazol ${ }^{\circledR}$ (tiletamine $\mathrm{HCl}$ and zolazepam $\mathrm{HCl}$; Fort Dodge Animal Health, Fort Dodge, IA). Ketamine HCL (Ketaset ${ }^{\circledR}$, Fort Dodge Animal Health, Fort Dodge, IA) was administered as needed to maintain anesthesia during processing. Once anesthetized, the sex and weight of the pumas were determined, and the pumas were then fitted with an ear tag and a combined ARGOS satellite GPS/radio telemetry collar (Lotek 7000SAW, New Market, Ontario). I used measurements of gum-line recession to determine the age of captured pumas (Laundré et al. 2000), and classified them as subadults ( $<3$ years) or adults ( $\geq 3$ years). I concurrently captured 27 adult female black-tailed deer from July 2009-August 2010 using methods described by Casady and Allen (2013), and fitted them with a combined store-on-board GPS/radio telemetry collar (either Lotek, New Market, Ontario, or Telonics, Mesa, Arizona).

\section{Collar Programming and Field Methods}

I programmed deer collars to acquire GPS locations at 5-hour intervals, and GPS locations and elevations were retrieved when collars automatically dropped off at the end of their life expectancy. I programmed puma collars to acquire GPS locations at 2-hr intervals, and downloaded location data via satellite every 3 days. Location data of pumas were displayed in ArcGIS 3.2, and I visually identified GPS clusters. In this study, I defined potential kill sites as GPS clusters with $\geq 5$ locations (or where pumas were present for at least 8 hours) within $150 \mathrm{~m}$ of each other that contained at least one crepuscular or nocturnal location (Elbroch and Wittmer 2013a). I performed field investigations after downloads of 
Argos-relayed GPS locations, and investigated GPS clusters in search of prey remains after loading them onto handheld GPS units (Garmin 60csx).

I used the age of the prey remains, evidence of evisceration and caching, parts of the body consumed, and the location of bite marks to determine whether the prey had been killed by a puma or whether the puma had been scavenging. I classified prey species through skeletal features and external characteristics (hair and pelage, or feathers). I documented black bear presence (i.e., tracks and scat) at the feeding sites of black-tailed deer $\geq 1$ year old that I visited $\leq 28$ days of it being created. I determined the age of black-tailed deer to the closest month for individuals < 1year old based upon field observations and the assumption that the mean date of birth for fawns was June $16^{\text {th }}$ of each year. I estimated the age for individuals $>1$ year based on tooth irruption and wear to the closest year based on Heffelfinger (2010). I calculated prey weights based on published literature. For black-tailed deer, I determined sex-specific weights for each month for fawns, and for adults for each year based on estimates for Sitka black-tailed deer (O. h. sitkensis) presented in Parker et al. (1993). For all other animals, I used the mean of weights described in Jameson and Peeters (2004), and Sibley (2005).

\section{Statistical Analysis}

I used program $R$ version 3.0.0 (R Core Team 2013) for my statistical analyses. Following $R$ guidelines (R Core Team 2013), I cite associated packages used in the analyses. Before each statistical analysis I tested each continuous variable data set for normality with a Shapiro-Wilk normality test, and then tested for variance equality with a Levene's test (Sokal and Rohlf 1987). In each statistical test, I considered $p \leq 0.05$ to be statistically significant.

For my analyses I used a definition of season based on weather and ecological patterns in the study area. Winter included December, January, and February, and was characterized by high precipitation and black-tailed deer living in concentrated winter groups 
at low elevations. Spring included March, April, and May, and was characterized by blacktailed deer moving higher in elevation following the melting snowpack. Summer included June, July, and August, and was characterized by hot temperatures and black-tailed deer giving birth on fawning grounds. Autumn included September, October, and November, and was characterized by black-tailed deer rut and migration to lower elevation winter range.

For each season we calculated ungulate kill rates for the monitored pumas (in both ungulates/week and kg/day), mean daily movement rates, handling times of deer $\geq 1$ year old, and elevation where pumas killed deer. I calculated ungulate kill rates in ungulates/week and $\mathrm{kg} /$ day for each monitoring period. I calculated mean daily movement rates $(\mathrm{km} /$ day $)$ for each individual puma for each season following the procedures of Elbroch and Wittmer (2012a). I used days as samples when at least 8 waypoints had been collected. I calculated the distance between consecutive GPS points using the great-circle distance methods and summed these figures for each day. I sampled the mean daily movement rates for each individual puma for each season they were monitored. I defined handling time as the amount of time (in hours) pumas spent at each kill site (Elbroch and Wittmer 2013b). I quantified handling time as the total hours spent at the kill from the first to last GPS location within $150 \mathrm{~m}$ of the kill site; this included the time pumas moved away from the kill site, for example to bed for the day, and later returned to feed again. I only used black-tailed deer $\geq 1$ year of age to eliminate variation in time spent at kills due to the smaller mass of fawns. I recorded the elevation of each black-tailed deer killed by each individual puma.

I used a series of 5 mixed-model analyses of variance (ANOVAs) using the nlme package (Pinheiro et al. 2013), to test for seasonal variation. I used mixed-model ANOVAs to control for variation in sample sizes and possible behavioural differences among individual pumas. The dependent variables included: puma kill rates in ungulates/week, puma kill rates in $\mathrm{kg} /$ day, puma mean daily movement rates, puma handling times of black-tailed deer $\geq 1$ year old, and elevations at which pumas killed black-tailed deer. For the two kill rates and 
mean daily movement rates, my sampling unit was each complete season. Based on Knopff et al. (2009), I included seasons where the individual puma was monitored for at least 28 consecutive days. For puma handling times of black-tailed deer $\geq 1$ year old, and elevations at which pumas killed black-tailed deer, each black-tailed deer was the sample unit and I then analysed across seasons.

I used the mixed-model ANOVAs to test if each of the dependent variables varied across seasons. In each mixed-model ANOVA I used the independent variables of season (assigned as fixed effects) and individual pumas (assigned as a random effect). The dependent variables of handling times of deer $\geq 1$ year old, and elevation at which pumas killed black-tailed deer lacked normality and homoscedasticity, and therefore I performed a logarithmic transformation on the data in order to meet the assumptions of the ANOVA (Sokal and Rohlf 1987). When I found significant differences using the mixed-model ANOVA in the number of ungulates/week kill rate among seasons, I performed post hoc pairwise comparisons using Tukey's HSD method for adjusting p-values in the lsmeans package (Lenth 2013) to determine where the differences occurred.

I determined if a black bear had detected a puma kill, by documenting black bear tracks and scat concentrated at the cache site. To examine if handling times of deer $\geq 1$ year old were correlated with the percentage of puma kills detected by black bears in each season I first used a chi-square $2 \times 4$ contingency table to determine if black bear detection of puma kills varied by season. I then used a linear regression analysis to determine if there was a significant correlation between handling times of adult deer and detection by black bears, using the seasonal mean handling times of adult deer as my dependent variable, and the seasonal mean percentage of puma kills detected by black bears as my independent variable.

I performed an additional analysis to test if the monthly elevations used by blacktailed deer correlated with the monthly elevations at which pumas killed black-tailed deer. I calculated the mean monthly elevation used by 27 individual black-tailed deer that were 
monitored for an associated study (Wittmer, unpublished data), and then calculated the mean elevation used by the population from values of each individual black-tailed deer. I calculated the mean elevation at which pumas killed black-tailed deer for each month for each individual puma, and then calculated the mean elevation for the population from the values of each individual puma. I used the monthly mean elevations at which pumas killed black-tailed deer as my dependent variable and used the monthly means of elevation used by black-tailed deer as my independent variable. Due to the lack of normality and homoscedasticity I performed a logarithmic transformation on each set of the data in order to meet the assumptions of the linear regression (Sokal and Rohlf 1987).

\begin{tabular}{ccccl}
\hline & $\begin{array}{c}\text { Age } \\
\text { (years) }\end{array}$ & Class & $\begin{array}{c}\text { Weight } \\
(\mathrm{kg})\end{array}$ & $\begin{array}{l}\text { Continuous } \\
\text { Monitoring } \\
\text { Period (days) }\end{array}$ \\
ID & 6.5 & AF & 34.6 & 477 \\
F1 & 1.4 & SF & 31.5 & 328 \\
F17 & 4.1 & AF & 33.6 & 202 \\
F23 & 4.2 & AF & 49.5 & 186 \\
F43 & 3.1 & FG & 38.1 & 209 \\
M33 & 7.0 & AM & 59.1 & 386 \\
M36 & 2.5 & SM & 48.1 & 83 \\
\hline \multicolumn{2}{l}{ Class- AF $=$ Adult Female, AM = Adult Male, SF = Subadult }
\end{tabular}

Female, $\mathrm{SM}=$ Subadult Male, $\mathrm{FG}=$ Family Group

Table 1. The physical characteristics and monitoring period for each individual puma, including age and weight at the initial capture, age and sex class, and the days in their continuous monitoring periods.

\section{Results}

I captured 7 pumas and monitored each puma for a mean of $9.07 \pm 4.79 S D$ months (Table 1). I conducted field investigations of a total of 598 out of 609 GPS clusters within $6.78 \pm 8.18 S D$ (range 0-60) days of the time the puma left the kill. I identified 352 kills, of which 288 were black-tailed deer. Black-tailed deer contributed $98.6 \%$ of the biomass of the prey killed by pumas. During summer, fawns accounted for $39.8 \%$ of ungulates killed by 
pumas and $10.2 \%$ of ungulate biomass killed by pumas. In autumn, fawns accounted for $27.5 \%$ of ungulates killed by pumas and $14.0 \%$ of ungulate biomass killed by pumas.

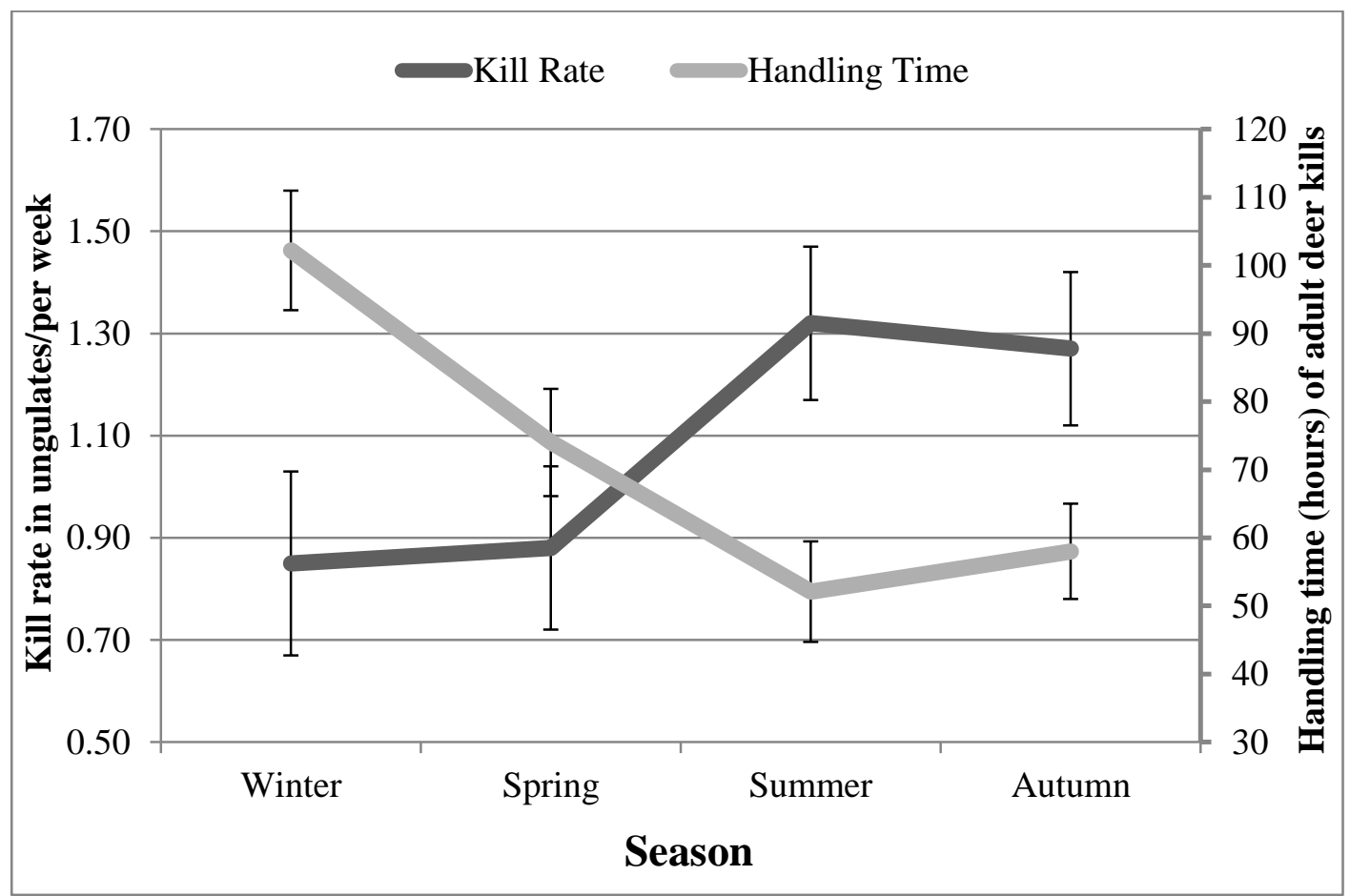

Figure 1. Average monthly kill rates and handling times of black-tailed deer $\geq 1$ year old for each season by pumas. Kill rates and handling times were created for each individual puma for each month they were monitored, and then pooled by season to test if the average monthly puma kill rates and handling times varied across seasons. Kill rates for individuals are ungulates/week and are represented as bars including standard errors. Handling times for black-tailed deer $\geq 1$ year old are in hours and are represented as a line including error bars representing the standard errors (SE).

For kill rates in ungulates/week my mixed-model ANOVA analysis revealed a significant difference among seasons $\left(F_{3,14}=5.14, p=0.0133\right.$, Figure 1$)$. My post hoc Tukey HSD analyses revealed that kill rates in summer were significantly higher than in winter or spring $\left(p_{\text {winter }}=0.0272, p_{\text {spring }}=0.0158\right.$, Table 2$)$, and kill rates in autumn were also significantly higher than in winter or spring $\left(p_{\text {winter }}=0.0437, p_{\text {spring }}=0.0048\right.$, Table 2$)$. Ungulate kill rates in $\mathrm{kg} /$ day did not differ among seasons $\left(F_{3,14}=0.56, p=0.6487\right.$, Table 2$)$. 
Mean daily movement rates also did not differ among seasons $\left(F_{3,14}=0.57, p=0.6473\right.$,

Table 2).

\begin{tabular}{|c|c|c|c|c|c|}
\hline & $\begin{array}{l}\text { Number of } \\
\text { Ungulates } \\
\text { Kill Rate } \\
\text { (ungulates/week) }\end{array}$ & $\begin{array}{l}\text { Mass Kill Rate } \\
\text { (kg/day) }\end{array}$ & $\begin{array}{l}\text { Mean Daily } \\
\text { Movements } \\
\text { (km/day) }\end{array}$ & $\begin{array}{l}\text { Elevation of } \\
\text { deer kills } \\
\text { (meters) }\end{array}$ & $\begin{array}{l}\text { Handling time } \\
\text { (hours) }\end{array}$ \\
\hline Season & Mean $(95 \%$ CI) & Mean (95\% CI) & Mean $(95 \%$ CI) & Mean (95\% CI) & Mean (95\% CI) \\
\hline $\begin{array}{l}\text { Winter } \\
\text { Spring }\end{array}$ & $0.85(0.51-1.20)$ & $\begin{array}{l}6.00(3.95-8.05) \\
5.63(3737.52\end{array}$ & $\begin{array}{l}6.88(4.71-9.04) \\
654(455-8.53)\end{array}$ & $\begin{array}{l}1006(840-1172) \\
1012(857-1166)\end{array}$ & $\begin{array}{r}102.2(85.0-119.4) \\
740(586-895)\end{array}$ \\
\hline Summer & $1.32(1.03-1.62)$ & $6.40(4.67-8.14)$ & $7.13(5.23-9.03)$ & $1307(1167-1446)$ & $52.1(37.6-66.5)$ \\
\hline Autumn & $1.27(0.98-1.55)$ & $6.74(5.05-8.43)$ & $7.78(6.03-9.53)$ & $1168(1031-1305)$ & $58.0(44.3-71.7)$ \\
\hline
\end{tabular}

Table 2. Average monthly values for variables used in my analyses of variation across seasons. Values were averaged for each individual puma for each month they were monitored, and then pooled by season to test if puma behaviours varied across seasons. Values include kill rate of ungulates/week, kill rates of $\mathrm{kg} / \mathrm{day}$, the elevation of black-tailed deer kills, handling time of black-tailed deer $\geq 1$ year old, and mean daily movement rate, and are reported as a mean and $95 \%$ confidence intervals.

For the handling times of black-tailed deer $\geq 1$ year old my mixed-model ANOVA analysis revealed a significant difference among seasons $\left(F_{3,201}=10.69, p<0.0001\right.$, Figure 1). My post hoc Tukey HSD analyses found handling times in winter significantly higher than in spring, summer, or autumn $\left(p_{\text {spring }}=0.0240, p_{\text {summer }}<0.0001, p_{\text {autumn }}<0.0001\right.$, Table 1). Handling times in spring were higher than in summer or autumn, but were marginally insignificant $\left(p_{\text {summer }}=0.0566, p_{\text {autumn }}=0.1181\right.$, Table 2$)$, possibly due to my low sample size pumas. My chi-square test showed that detection of puma kills by black bears varied by season $\left(\mathrm{df}=3, X^{2}=24.16, p<0.0001\right)$, with $31.6 \%$ in winter, $70.3 \%$ in spring, $87.2 \%$ in summer, and $80.3 \%$ in autumn. My linear regression analysis revealed a significant relationship between puma handling time of adult deer and detection rates of puma kills by black bears $\left(\mathrm{df}=1, p=0.0114, R^{2}=0.98\right)$. 


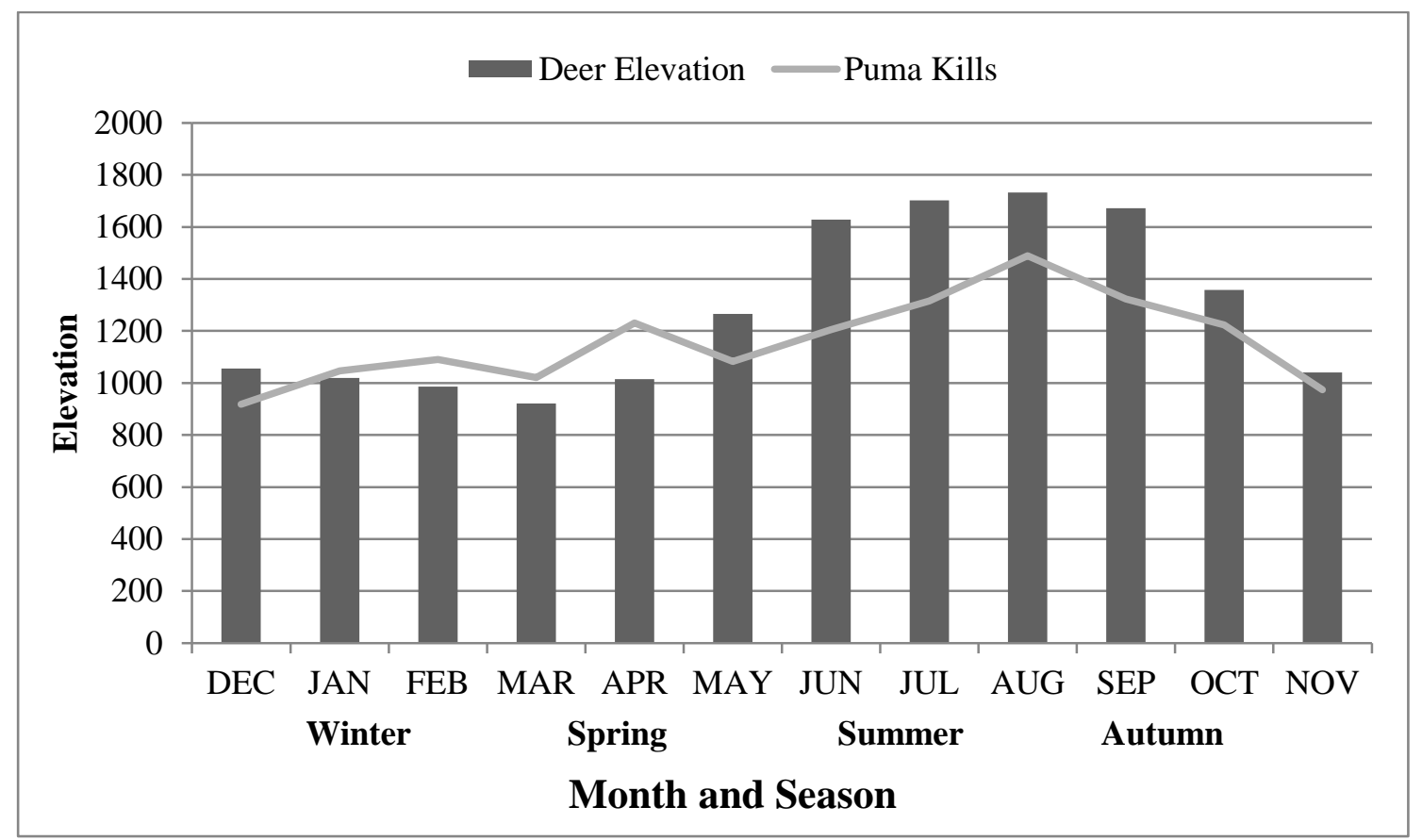

Figure 2. Elevations (in meters) used by adult female black-tailed deer and elevation at which pumas kill black-tailed deer during each month of the year. Location data from GPS collars was averaged for each individual black-tailed deer for each month, and are represented as bars. The elevation pumas killed black-tailed deer were averaged for each individual puma for each month they were monitored.

For elevation at which pumas killed black-tailed deer, my mixed-model ANOVA analysis revealed a significant difference among seasons $\left(F_{3,279}=10.42, p<0.0001\right.$, Table 2). My post hoc Tukey HSD analyses indicated that kills in summer occurred at significantly higher elevations than in winter, spring, or autumn $\left(p_{\text {winter }}=0.0001, p_{\text {spring }}=0.0002, p_{\text {autumn }}=\right.$ 0.0178), while kills in autumn were apparently at higher elevation than either winter or spring, but were marginally insignificant $\left(p_{\text {winter }}=0.0689, p_{\text {spring }}=0.0739\right)$. Additionally my linear regression analysis showed a relationship between the monthly elevation at which pumas killed black-tailed deer and the monthly elevations used by black-tailed deer $(\mathrm{df}=1, p$ $\left.=0.0012, R^{2}=0.67\right)($ Figure 2$)$. 


\section{Discussion}

My objective was to quantify the seasonal feeding ecology of pumas in a system with migrating prey. I studied 4 aspects of puma foraging ecology and the relationship between seasonal changes in black bear detection of puma kills and elevations used by black-tailed deer. My results supported my hypothesis that pumas would exhibit seasonal variation in kill rates in ungulates/week. My results did not support my hypothesis that pumas would exhibit variation among seasons in kill rates in $\mathrm{kg} / \mathrm{day}$, or in mean daily movement rates, although this may be partly due to my low sample sizes. I found that handling times of black-tailed

deer $\geq 1$ year old varied among seasons, and were significantly correlated with detection of kills by black bears. Additionally, the elevation at which pumas killed black-tailed deer varied among seasons, and elevations where pumas killed deer were correlated with the elevations of marked black-tailed deer.

As noted by Metz et al. (2012), kill rate metrics need to be interpreted with caution due to the biological differences in kill rates based on individuals per unit time and kill rates based upon mass per unit time. In my study, there was a significant difference in kill rates in ungulates/week among seasons, while there was not a significant difference in kill rates in $\mathrm{kg} /$ day. Taken alone each kill rate metric would tell a different story. Comparing kill rates in ungulates/week suggests pumas exhibit strong seasonal variation, whereas comparing kill rates in $\mathrm{kg} /$ day suggest that regardless of numbers of animals killed per unit of time, pumas kill an equivalent amount of meat. Kill rates in $\mathrm{kg}$ /day suggest pumas might be following or meeting some energetic threshold irrespective of prey availability (Jeschke 2007). while together they point to the complexity of predator-prey relationships in a multi-predator system. I found that pumas killed a greater number of black-tailed deer in summer and autumn, which coincided with the birth pulse of fawns in summer. Past studies have hypothesized that increases in puma and grey wolf (Canis lupus) kill rates during summer were due to increased availability of vulnerable young ungulates (Sand et al. 2008, Knopff et 
al. 2010, Metz et al. 2012), and the number of fawns killed in summer and autumn in my study area supports this hypothesis. However, the notably lower handling times in summer and autumn may also have contributed to the increase in puma kill rates in summer and autumn, and suggest additional potential mechanisms may be influencing puma kill rates.

Handling times in winter were $196 \%$ greater than in summer and $176 \%$ greater than in autumn, and this may be due to interactions with decomposers and dominant scavengers. Based upon research conducted by Bischoff-Mattson and Mattson (2009), I speculate that higher summer temperatures and increased invertebrate activity may lead to faster carcass decomposition and could therefore shorten handling times by pumas. In addition, interactions with black bears may also be causing a decrease in handling times during summer and autumn when black bears are most active. For example, brown bears that have been shown to exact foraging costs on solitary felids, including forcing the abandonment of carcasses (Krofel and Kos 2010, Krofel et al. 2012). If black bear kleptoparasitism is the cause of the large reductions in handling times of deer $>1$ year old, this could have important ecological influences, including causing pumas to hunt and kill more frequently during seasons when black bears are most active. My results therefore support the conclusions of Elbroch and Wittmer (2013b) which suggest that future analyses of large carnivore kill rates should take into account the energetic losses to the scavenger guild in order to understand their influence on ecological communities.

The seasonal variation in the elevation where pumas killed black-tailed deer was correlated with the spatial distribution of black-tailed deer. The change in elevation of puma kills and their correlation with black-tailed deer elevation use supports the findings of Pierce et al. (1999) and Cooley et al. (2008) that pumas in my study area followed black-tailed deer migrations. This is to be expected in a system where pumas rely on 1 ungulate species and different from populations where pumas do not need to follow migratory prey if other ungulate prey become seasonally available (Elbroch et al. 2014). However, because pumas 
made kills where deer were most abundant in each season and puma kill rates were highest in summer, contrary to my expectations, black-tailed deer migration did not appear to decrease puma predation. Black-tailed deer exhibit a birth pulse and change their spatial distribution to concentrate their populations at high elevations during fawning, which is likely in response to the high predation risk of newborn fawns. Perhaps instead, the elevational migration and synchronous birth pulse exhibited by black-tailed deer in northern California reduces agespecific predation risk from other predators that focus on fawns, such as coyotes, bobcats (Lynx rufus), and black bears (e.g., Griffin et al. 2011).

In summary, I found that puma kill rates and feeding ecology varied among seasons due to seasonal variation in behaviour and abundance of their prey and competitors. Ecologists have long noted that ungulates are limited by both the top-down and bottom-up forces that structure ecosystems (Hopcraft et al. 2010, Forrester and Wittmer 2013). Here, I provide evidence that a top predator, in turn, is directly influenced by the seasonal behaviour of their main prey and apparently by scavengers. My results highlight the importance of future research that aims to understand the mechanisms driving seasonal variation in the feeding ecology of pumas and other carnivores. Topics of future research could include a mechanistic understanding of how scavengers influence puma foraging, and how pumas alter their behaviour to compensate for changing densities and behaviours of their prey. 


\title{
Chapter 6
}

\section{Trophic Facilitation or Limitation?}

\section{Comparative Effects of Pumas and Black Bears}

\author{
on the Scavenger Community
}

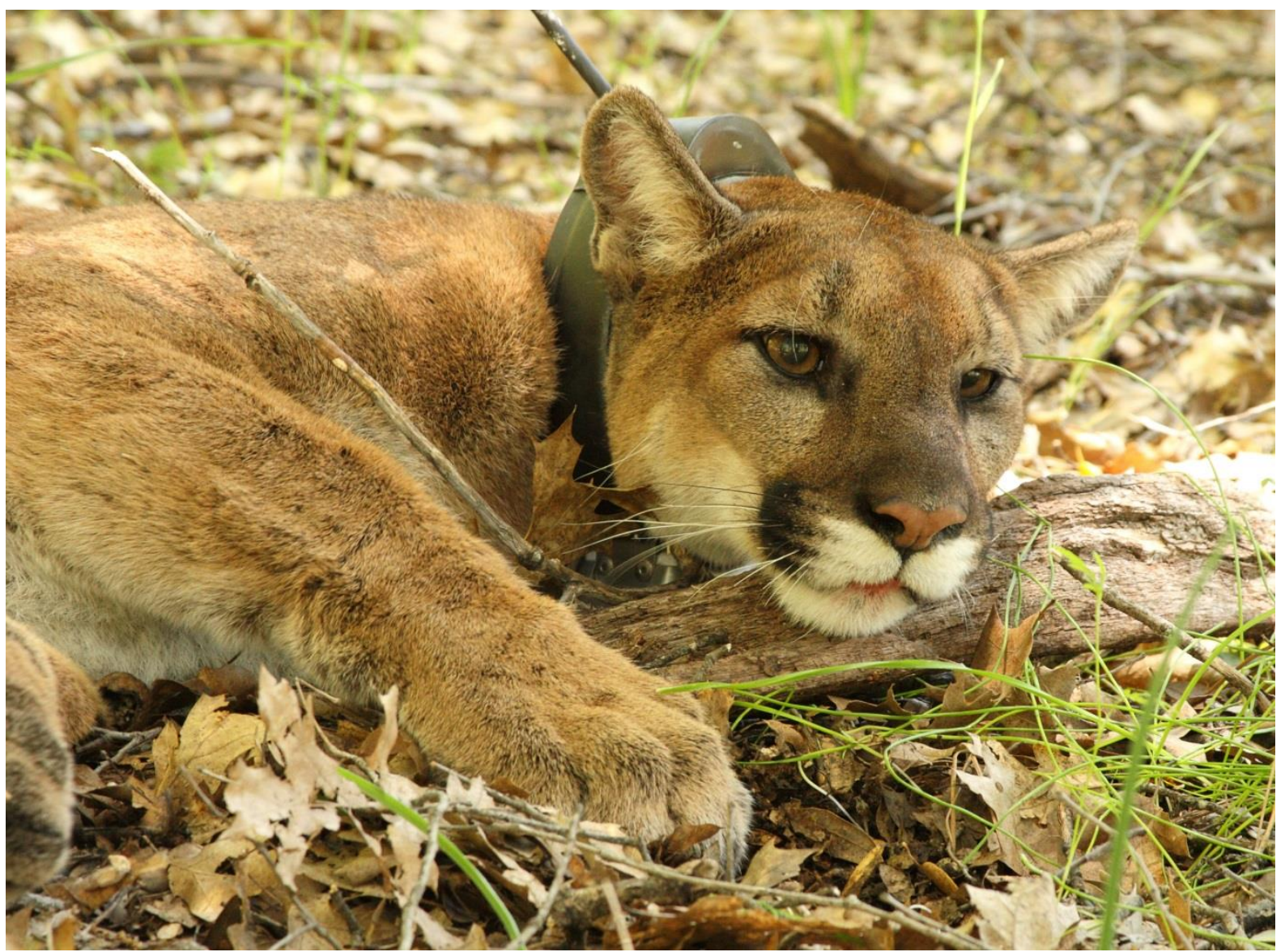


A version of this chapter was accepted for publication in PLoS One as:

Allen, M.L., L.M. Elbroch, C.C. Wilmers, and H.U. Wittmer. Trophic facilitation or limitation? Comparative effects of pumas and black bears on the scavenger community

\section{Acknowledgements}

The California Department of Fish and Wildlife, and the University of California at Davis generously provided funding for the project. M. Allen was supported by a Victoria University of Wellington tuition scholarship. I would like to thank D. Casady, B. Millsap, J. Golla, B. Evans, C. Wiley, D. Tichenor, B. Milano, J. Smith, P. Johnston, and G. Schmidt for their help on the project. 


\begin{abstract}
Scavenging is a widespread behaviour and an important process influencing food webs and ecological communities, but studies of what constrains the acquisition of carrion by scavengers are limited. Large carnivores facilitate the movement of energy across trophic levels through the scavenging and decomposition of their killed prey, but competition with large carnivores is also likely to constrain acquisition of carrion by scavengers. I used an experimental approach based on motion-triggered video cameras at black-tailed deer (Odocoileus hemionus columbianus) carcasses to measure the comparative influences of two large carnivores in the facilitation and limitation of carrion acquisition by scavengers. I found that pumas (Puma concolor) and black bears (Ursus americanus) both significantly limited scavenger species richness and sum feeding times, but their effects on their ecological communities were different due to their ecological roles. Pumas, as a top-level predator, facilitated the consumption of carrion by scavengers, but had a small negative effect on scavenger species richness $(d=-0.27)$, and a medium negative effect on scavenger feeding times $(d=-0.41)$. Black bears, as the dominant scavenger in the system, limited consumption of carrion by scavengers, and had a medium negative effect on scavenger species richness $(d$ $=-0.56)$ and a large negative effect on scavenger feeding times $(d=-1.08)$. In addition, we found that pumas and black bears both increased the nestedness (a higher level of order among species present) of the scavenger community. The increased nestedness at carcasses might allow scavengers to exploit limited available resources, and strategically increase their individual fitness. Our results suggest that scavengers have species-specific adaptions to exploit carrion provided by large carnivores, that large carnivores can influence the structure and composition of scavenger communities, and that the interactions between large carnivores and scavengers should be considered in future studies of food webs and ecological communities.
\end{abstract}




\section{Introduction}

Carrion is an essential but temporal resource for countless species ranging from microbes to vertebrates (DeVault et al. 2003, Wilmers 2003a, Barton et al. 2013). Both the direct and indirect effects of carrion, and the intense competition that occurs over these resources, are increasingly being recognized as important processes in structuring ecological communities (Wilmers et al. 2003a, Wilmers et al. 2003b, Selva and Fortuna 2007, Wilson and Wolkovich 2011, Barton et al. 2013). For example, by transferring energy across trophic levels, scavengers are thought to increase the stability of ecological communities and food webs (DeVault et al. 2003, Wilmers et al. 2003a, Wilson and Wolkovich 2011). In fact, Wilson and Wolkovich (2011) reported that in many food webs, a greater amount of energy is transferred through scavenging of carrion than through direct predation. This is at least partly due to the numerous vertebrate species which adopt scavenging to increase reproductive success and survival, and hence their individual fitness (e.g. Watson et al. 1992, Angerbjorn et al. 1991, Selva et al. 2005). Despite scavenging being a wide-spread and ecologically significant behaviour, my understanding of the biotic constraints that limit access to carrion for vertebrate scavengers is limited (DeVault et al. 2003, Barton et al. 2013).

Carcasses of large bodied ungulate species are a particularly rich source of nutrition, especially during lean seasons such as late winter in North America when many species, including carnivores, struggle to meet their energetic requirements (Angerbjorn et al. 1991, Wilmers 2003a, Selva and Fortuna 2007, Barton et al. 2013). However, ungulate carcasses are also patchily distributed and only available for short periods of time (DeVault et al. 2003, Wilson and Wolkovich 2011, Barton et al. 2013). Competition, one of the most important processes in evolution and ecology (Begon et al. 2006), among facultative scavenger species is therefore likely to be an important factor in the acquisition of carrion, with the potential to influence community assemblages at larger scales (Wallace and Temple 1987, Hunter et al. 2006, Wilmers 2003b). 
Many large carnivores facilitate the acquisition of carrion for scavengers and decomposers which feed on their kills (Wilmers et al. 2003a, Wilmers et al. 2003b, Elbroch and Wittmer 2012b). Large carnivores also provide carrion to their respective ecological communities throughout the year, rather than in seasonal pulses (Wilmers et al. 2003b). However, large carnivores also actively try to limit the consumption of carrion by smaller scavengers (Wilmers et al. 2003a, Hunter et al. 2006). Therefore the potential exists for large carnivores to influence the presence and behaviours of scavengers at carrion resources, as well as potentially influence the structure and composition of the scavenger community. Recent studies have shown resource partitioning, specific niches, and nested relationships within the scavenger community (Houston 1995, Selva and Fortuna 2007, Blazquez et al. 2009). Nested relationships (nestedness is an analysis of presence and absence used to measure order and disorder in patterns of species occurrence, Guimaraes and Guimaraes 2006) suggest that the diversity of scavengers present in a location is governed by specific circumstances as well as complex processes and relationships.

Pumas (Puma concolor) and black bears (Ursus americanus) are sympatric large carnivores occurring across much of North America but with different ecological niches. Pumas are top-level predators that frequently kill ungulates (Ruth and Murphy 2010b), while bear species are dominant facultative scavengers (Krofel et al. 2012). Scavengers frequently feed at puma kills (Knopff et al. 2010, Ruth and Murphy 2010b, Elbroch and Wittmer 2012a, Elbroch and Wittmer 2013b), suggesting that pumas facilitate the acquisition of carrion by scavengers, and may play a keystone role by supporting a diverse scavenger community (Ruth and Murphy 2010b, Elbroch and Wittmer 2012a). In contrast, black bears rarely kill adult ungulates, and instead opportunistically feed on juvenile ungulates or carcasses of adults when available (Matthews and Porter 1988, Schwartz and Franzmann 1991, Svoboda et al. 2011). Black bears are also able to usurp kills from other large carnivores (Murphy et al. 1998, Ruth and Murphy 2010b, Krofel et al. 2012). This suggests that black bears may be a 
dominant scavenger that has a competitive advantage in the consumption of carrion over other scavenger species.

I attempted to determine the influence of pumas and black bears on species richness, feeding time, and nestedness of the scavenger community at ungulate carcasses. To achieve my objective, I conducted a series of in situ experiments at black-tailed deer (Odocoileus hemionus columbianus) carcasses which I monitored with motion-triggered video cameras. I compared activity at deer killed by pumas wearing GPS collars to paired control carcasses, and used carcasses distributed by researchers to compare activity where black bears were present and absent. This design allowed me to compare the influence of large carnivores on three aspects of scavenger ecology: 1) scavenger species richness (the number of scavenger species at each carcass), 2) scavenger sum feeding times (the total time scavengers spent at each carcass), and 3) the nestedness of the scavenger community at these carcasses. I also examined how the first two of these variables varied seasonally. I hypothesized that pumas and black bears would both limit scavenger species richness and sum feeding times, while also increasing the nestedness of the scavenger community. This contrasts with previous studies about the effect of dominant scavengers, which found that dominant scavengers do not influence scavenger species richness or the nestedness of the scavenger community (e.g., Olson et al. 2012, Sebastian-Gonzales 2013). However, as a large carnivore we expected black bears would have larger effects on the scavenger community than avian scavengers or mesocarnivores. Further, we expected the effects of pumas and black bears to be of a similar magnitude, but that the net effect of pumas and black bears as sources of trophic facilitation and limitation of the scavenger community would vary based on their different ecological roles as a top predator and dominant scavenger. 


\section{Materials and Methods}

\section{Experimental Design and Field Methods}

I employed motion-triggered video cameras with infrared flash at black-tailed deer carcasses to measure the effects of pumas and black bears on scavenger activity (species richness, sum feeding times, and nestedness of occurrence). To test for effects of pumas, I compared scavenger activity at kills made by pumas $\left(\mathrm{n}=58 ; \mathrm{n}_{\text {winter }}=10, \mathrm{n}_{\text {spring }}=11, \mathrm{n}_{\text {summer }}=\right.$ $\left.16, \mathrm{n}_{\text {autumn }}=21\right)$ to control carcasses that I placed simultaneously on the landscape in areas with matching habitat characteristics $\left(\mathrm{n}=58 ; \mathrm{n}_{\text {winter }}=10, \mathrm{n}_{\text {spring }}=11, \mathrm{n}_{\text {summer }}=16, \mathrm{n}_{\text {autumn }}=\right.$ 21). In the puma experiments, black bears were considered a scavenger. To test for the effects of black bears, I distributed a different set of black-tailed deer carcasses in different habitat types across the study area, and determined their effects by comparing scavenger activity at carcasses where black bears were present $\left(n=43 ; n_{\text {winter }}=1, n_{\text {spring }}=15, n_{\text {summer }}=15, n_{\text {autumn }}\right.$ $=12)$ to carcasses where they were absent $\left(n=47 ; n_{\text {winter }}=25, n_{\text {spring }}=20, n_{\text {summer }}=1, n_{\text {autumn }}\right.$ $=1)$.

I used black-tailed deer killed through vehicle collisions for puma control carcasses and all of the carcasses used for the black bear experiments. Deer were collected from highways in Mendocino, Lake, Glenn, Sonoma, and Marin Counties. I only collected fresh deer in good condition allowing me to replicate the decomposition states of deer at puma kills. Each deer collected had clear, unclouded eyes, lacked discoloration in the abdominal region, and lacked obvious external wounds (broken bones, punctures of skin, or abrasions). Before transporting the carcasses I removed their head, entrails, and lungs in order to limit any disease transmission among disjunct deer populations, as required by the California Department of Fish and Wildlife. This procedure meant that small scavengers were not dependent on large carnivores or other scavengers to open the carcasses for them.

Between June 2010 and December 2012, I captured 7 pumas and fitted them with a combined ARGOS satellite GPS/radio telemetry collar (Lotek 7000SAW, New Market, 
Ontario), using the methods described in Chapter 4. In order to find fresh deer killed by pumas, I programmed the collars to acquire GPS locations at 2-hr intervals throughout each 24-hr period, and downloaded the location data via satellite connection every 3 days. Location data were displayed in ArcGIS 3.2, and I defined GPS clusters as $\geq 2$ locations within $150 \mathrm{~m}$ of each other that contained at least one crepuscular or nocturnal location (Elbroch and Wittmer 2013a). I loaded GPS clusters onto handheld GPS units (Garmin 60csx), and investigated any GPS cluster where the puma appeared to still be present on the same day as the Argos-relayed GPS downloads in order to find puma kills while they were fresh and the pumas were still active at the site.

Upon arrival in the vicinity of the GPS cluster, I listened for the puma's presence with a handheld telemetry receiver (Communication Specialists Model R1000, Orange, CA). If the puma was in the immediate vicinity I considered it active at the feeding site. I then approached the potential feeding site during mid-day when pumas are least active. I limited visits to $5 \mathrm{~min}$ at the site in order to reduce disturbance and avoid possible carcass abandonment. When I found at least half of the deer still left I used the site for my experiments. I attached a wire cable to the carcass to hold it within $1 \mathrm{~m}$ of its location, and deployed a motion-triggered camera (Bushnell TrophyCam, Overland Park, KS) to monitor the carcass and document scavenger activity. The motion-triggered cameras were set to record the maximum amount of activity: 60 s of video and inter-video lengths of 1 s before the next event was recorded. I then recorded primary and secondary habitat characteristics of the site based on Mayer and Laundenslayer (1988). I also recorded the location and elevation of the kill using a handheld GPS unit, and then estimated the distance to the secondary habitat by pacing off the distance. Finally, I measured the percent canopy cover directly over the carcass with a spherical concave densiometer (Ben Meadows, Janesville, WI), and the tree species with the highest percentage of overhead cover. 
In finding potential matching sites for puma control carcasses I attempted to choose habitat characteristics as closely as possible to the following variables at puma kills (listed in order of importance): 1) primary habitat type, 2) overhead tree species, 3) percent canopy cover, 4) secondary habitat type, 5) distance to secondary habitat, 6) elevation (Appendix A). Paired carcasses were placed at least $1 \mathrm{~km}$ from puma kills to reduce detection by the same individual scavengers, and each carcass site was used only once to avoid conditioning scavengers. Before arriving at the control sites, I prepared road-killed black-tailed deer to match the amount of meat and stage of decomposition of carcasses found at puma kills. Puma control carcasses were prepared and deployed soon after I visited the puma-killed carcass (a mean of 1.51 hours $\pm 0.18 \mathrm{SE}$ ) to rule out possible effects from weather, and were also secured with a wire cable.

For the black bear experiments I placed 100 black-tailed deer carcasses in the study area from December 2009-October 2012. Carcasses were placed in a variety of habitat conditions (Appendix B) in order to provide a diverse sample of the vertebrate scavenger community. Habitat conditions measured included primary habitat type, secondary habitat type, the distance to secondary habitat, overhead tree species, percent canopy cover, slope, aspect, and elevation. I anchored each carcass in place with a wire cable, and placed a motion-triggered camera (Cuddeback IR, De Pere, WI) on a nearby tree. The motiontriggered cameras were set to record the maximum amount of activity, with 30s of video with a pause of 60 s before the next trigger.

I then determined the effects of black bears by comparing scavenger activity at carcasses where black bears were present (defined as where they were the $1^{\text {st }}$ or $2^{\text {nd }}$ scavenger to arrive) to carcasses where they were absent (defined as where they were absent or one of the last scavengers to arrive and spent $\leq 10 \mathrm{~min}$ at the carcass). When black bears were the $3^{\text {rd }}$ or later scavenger to arrive and spent $>10$ min at the carcass, I considered the black bears to have an unknown influence $(\mathrm{n}=10)$, and I removed these carcasses from my analysis. I also 
removed carcasses from my analyses which had incomplete data due to camera malfunctions or camera displacements by black bears $(\mathrm{n}=11)$.

\section{Statistical Analyses}

I determined the number of scavenger species at each carcass and the amount of time they spent feeding to the closest min using the videos I recorded. I calculated the duration of each feeding bout by a scavenger by subtracting the time at the start of a visit by the time at the end of a visit. For visits of $<30 \mathrm{sec}$ I considered the species present for $1 \mathrm{~min}$ rather than Omin, and I rounded all other visits to the closest min. Total feeding times were calculated as the sum of all feeding bouts for all scavengers at a given carcass. I then preformed analyses to determine the effects of pumas and black bears on scavenger species richness, scavenger sum feeding times, and the nestedness of the observed scavenger communities. Each analysis determined the influence of either pumas (kills vs. control carcasses) or black bears (present vs. absent). There was, however, limited utility in comparing the effects of black bears to pumas directly due to the varying amounts of meat, the different camera models used, and how these variables could affect scavenger presence and feeding times. Therefore, I used post hoc effect sizes (Nakagawa and Cuthill 2007) to compare the effects of pumas and black bears on scavengers. Prior to performing statistical analyses I tested each data set with

continuous variables for normality and variance equality with a Shapiro-Wilk test and a Levene's test (Sokal and Rohlf 1987). In each analysis, I considered $p \leq 0.05$ significant, and the statistical analyses were conducted using the program R (R Core Team 2013), except where specifically noted otherwise.

I first tested whether black bear detection of carcasses would vary among seasons because of expected variation in abundance among seasons due to hibernation using a Fisher's exact test (Sokal and Rohlf 1987). For this analysis, and the later analyses which included the predictor variable of season, I assigned seasons based on ecological patterns in 
the study area. Winter included December, January, and February; spring included March, April, May; summer included June, July, and August; and autumn included September, October, November (see Chapter 5).

For species richness I used all scavenger species, but eliminated rodents and small birds (i.e. American robin, Turdus migratorius, scrub jay, Aphelocoma californica, and Steller's jay, Cyanocitta stelleri) for sum feeding times due to limitations in my ability to accurately detect their feeding times. I transformed each data set using logarithmic transformations to meet assumptions of ANOVAs (Sokal and Rohlf). I used one-way ANOVA models to determine the importance of each individual variable (puma carcass type, bear carcass type, season), and used Type II factorial ANOVA models to assess the importance of interaction between variables, using the car package (Fox and Weisberg 2011). I used a post hoc Tukey's HSD test to determine where significant differences occurred, and calculated AIC scores to evaluate each of the models, using the AICcmodavg package (Mazerolle 2013). Last, I calculated post hoc effect sizes using Cohen's $d$ score for scavenger species richness and sum feeding times in order to understand the magnitude of effects, and I considered scores of 0.20 small effects, 0.50 medium effects, and 0.80 large effects (Cohen 1992).

My hypothesized limitation of scavenger species richness and sum feeding times could cause an increase in the order or disorder of the scavengers present at different carcass types. For instance, competition with a puma or black bear could cause the species which are present and able to feed to be more random. In contrast, if specific scavengers have developed strategies to overcome competitive restraints from pumas and black bears this would cause their presence at a particular carcass to be more structured. Based on Selva and Fortuna (2007), I therefore hypothesized that the scavenger community of each carcass type would be more structured than random null models. In addition, as noted previously, we hypothesized that the scavenger community would be more nested at puma kills than control 
carcasses, while the nestedness of carcasses where black bears were present and absent would not vary significantly. To test this, I used a nestedness analysis following the methods which Selva and Fortuna (2007) used for a vertebrate scavenger community in Europe. An analogy often used to explain nestedness is the species occurrence among a series of same-size islands moving away from the mainland. In a system which is nested due to dispersal from the mainland, the species are structured by their distance from the mainland. If instead the island system were based on a random process, for example with species being distributed during tropical storms, the species present on each island would be less predictable and hence less nested.

I calculated the nestedness temperature (T) (Atmar and Patterson 1993, Guimaraes and Guimaraes 2006) for each carcass type using the program ANINHADO (Guimaraes and Guimaraes 2006), with $T$ expressed as a score between 0-1. I then calculated the level of nestedness $(N)$ as used by Selva and Fortuna (2007) who defined $N$ as $N=(100-T) / 100$ for each carcass type. I also calculated the idiosyncratic temperature (IT) first for each individual carcass and second for each scavenger species. I then calculated the nestedness contribution $(N C)$ for each individual carcass and each scavenger species based on Selva and Fortuna (2007) who defined $N C$ as $N C=(100-I T) / 100 . T$ is the mean value of the $I T$ scores of all individual carcasses, or alternatively the mean of all individual scavengers since both sides of the matrix have the same mean, and hence $N$ is the mean value of either of their $N C$ scores. Higher $\mathrm{N}$ and $\mathrm{NC}$ scores meant the scavenger community or species was structured and hence nested, while low scores meant less structure and hence disordered.

I first determined if each carcass type was significantly more nested than random by comparing each to random null models. For each carcass type I generated 100 null models with randomized matrices for each of two null model types (null model 1 lacking heterogeneity and nestedness, and null model 2 lacking nestedness) using the program ANINHADO (Guimaraes and Guimaraes 2006). I then tested the $N$ score for each type of 
carcass against both types of their randomly generated null models using ANOVA models (Sokal and Rohlf 1987), and when I found significant differences I used a post hoc Tukey's HSD test (Sokal and Rohlf 1987) to determine where the significant differences occurred. Lastly, I determined if pumas and black bears increased or decreased the nestedness, and hence the structure, of the scavenger community. I used the individual $N C$ scores from each individual carcass as my values, and used a two-tailed Student's t-test with equal variances (Sokal and Rohlf 1987) determine differences in $N$ caused by pumas and black bears.

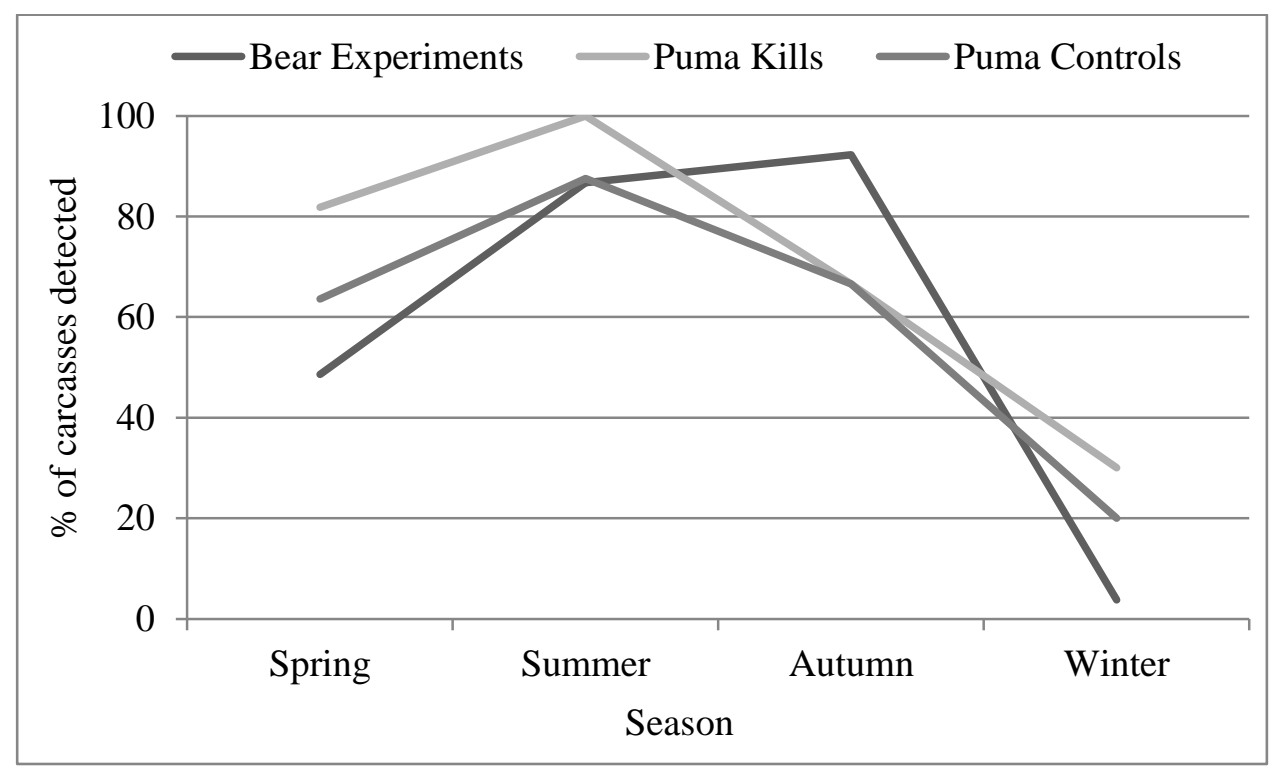

Figure 1. The detection rate of black bears among seasons at different carcass types. Detection varied among seasons, and the detection for deer carcasses used for the black bear experiments, those killed by pumas, and the matching puma control carcasses are shown.

\section{Results}

I monitored 58 puma kills and 58 puma control carcasses. I set up cameras at the puma kills a mean of 39.8 ( $\pm 2.9 \mathrm{SE}$ ) hours after the presumed time of kill, and pumas stayed within $150 \mathrm{~m}$ of the kills I monitored for a mean of 75.1 ( $\pm 5.9 \mathrm{SE})$ hours. For the black bear experiments I monitored 46 carcasses where black bears were absent, and monitored 33 
carcasses where black bears were present. Black bear occurrence at carcasses varied by season ( $\mathrm{df}=3, p<0.0001$, Figure 1 ), as would be expected based on their seasonal activity patterns. Black bears were present at $92.8 \%$ and $90.0 \%$ of experimental carcasses during summer and autumn respectively, compared to $48.6 \%$ in spring and $3.8 \%$ in winter.

\section{Scavenger Species Richness}

I recorded a total of 20 species at puma kills with a mean of $3.07( \pm 0.24 S E)$ species per carcass, and a total of 25 species at paired control carcasses with a mean of $3.52( \pm 0.20$ $S E)$ species per carcass, resulting in a small negative effect attributable to pumas $(d=-0.27)$ (Table 1). Puma carcass type (kill vs. control) was a significant factor in scavenger species richness ( $\mathrm{df}=1, F=4.21, p=0.0425$, Table 2 ). Season alone was not a significant factor in scavenger species richness (Table 2). However, the interaction between season and puma carcass type was significant ( $\mathrm{df}=1, F=4.22, p=0.0424$, Table 2, Figure 2 ), while the interaction between puma carcass type and season was not significant. Puma carcass type was the best model with the lowest AIC value to explain scavenger richness (Table 2).

\begin{tabular}{|l|ccc|ccc|}
\hline & \multicolumn{3}{|c|}{ Scavenger Richness } & \multicolumn{3}{c|}{ Sum Feeding Time } \\
Carcass Type & mean & 95\% CI & $d$ & mean & 95\% CI & $d$ \\
\hline Puma Kill & 3.07 & $2.60-3.54$ & \multirow{2}{*}{-0.27} & 165.7 & $124.1-207.3$ & \\
Puma Control & 3.52 & $3.13-3.90$ & & 246.3 & $187.3-305.3$ & -0.41 \\
Bear Present & 1.79 & $1.30-2.28$ & -0.87 & 42.5 & $21.7-63.3$ & \\
Bear Absent & 3.09 & $2.65-3.53$ & & 359.5 & $261.2-457.8$ & -1.20 \\
\hline
\end{tabular}

Table 1. The mean scavenger species richness and scavenger sum feeding time, along with the effect size attributable to pumas and black bears. For each variable and carcass type the mean, 95\% confidence intervals, and effect sizes (Cohen's $d$ score) are reported. Negative effect sizes indicate limitation, with effect sizes of 0.20 indicating small effects, 0.50 indicating medium effects, and 0.80 indicating large effects. 
I recorded a total of 14 species at carcasses where black bears were present with a mean of $1.79( \pm 0.25 \mathrm{SE})$ species per carcass, and a total of 18 species at carcasses where black bears were absent with a mean of $3.09( \pm 0.22$ SE) species per carcass, resulting in a large negative effect attributable to black bears $(d=-0.87)$ (Table 1). Black bear carcass type (present vs. absent) was a significant factor in scavenger species richness ( $\mathrm{df}=1, F=20.17$, $p<0.0001$, Table 2). Season alone was also a significant factor in scavenger species richness at black bear carcasses ( $\mathrm{df}=3, F=5.24, p=0.0025$, Table 2 ), with significantly less species per carcass in summer than in spring $(p=0.0145)$ or winter $(p=0.0057)$. The model of black bear carcass type and season was also significant $(\mathrm{df}=1, F=6.44, p=0.0133$, Table 2, Figure 3), although the interaction was not significant (Table 2). Black bear carcass type was the best model with the lowest AIC value to explain scavenger richness (Table 2).

\begin{tabular}{|cll|cccc|cccc|}
\hline & & & \multicolumn{4}{|c|}{ Scavenger Richness } & \multicolumn{4}{|c|}{ Sum Feeding Time } \\
Model & Test & Variables & df & F & $p$ & AIC & df & F & $p$ & AIC \\
\hline 1 & ANOVA & PUMA & 1 & 4.21 & 0.0425 & 23.65 & 1 & 4.03 & 0.0471 & 258.05 \\
2 & ANOVA & SEAS & 3 & 0.35 & 0.7899 & 30.78 & 3 & 1.07 & 0.1780 & 261.01 \\
3 & FANOVA & PUMA & 1 & 4.22 & 0.0424 & 29.07 & 1 & 4.39 & 0.0386 & 253.90 \\
& & SEAS & 3 & 0.37 & 0.7777 & & 3 & 1.83 & 0.1457 & \\
& & PUMA:SEAS & 3 & 1.74 & 0.1637 & & 3 & 3.55 & 0.0170 & \\
\hline 1 & ANOVA & BEAR & 1 & 20.17 & $<0.0001$ & 66.96 & 1 & 58.37 & $<0.0001$ & 191.80 \\
2 & ANOVA & SEAS & 3 & 5.24 & 0.0025 & 74.32 & 3 & 11.43 & $<0.0001$ & 210.64 \\
3 & FANOVA & BEAR & 1 & 6.44 & 0.0133 & 72.06 & 1 & 23.51 & $<0.0001$ & 193.48 \\
& & SEAS & 3 & 1.04 & 0.3813 & & 3 & 2.33 & 0.0819 & \\
& & BEAR:SEAS & 2 & 0.75 & 0.4768 & & 2 & 0.51 & 0.6033 & \\
\hline
\end{tabular}

Tests: ANOVA = Analysis of Variance, FANOVA = Factorial Analysis of Variance.

Model variables: PUMA = puma carcass type (puma kill or puma control carcass), SEAS = season of year (winter, spring, summer, or autumn), BEAR = black bear carcass type (carcasses where black bear is present or carcass where black bear is absent).

Table 2. The results modelled for the interaction of season with scavenger species richness and sum feeding time. The variables include pumas (puma kill vs. control), black bears (black bear present vs. absent), and the 4 seasons. The statistical significance and Akaike's Information Criterion of each model is reported. 

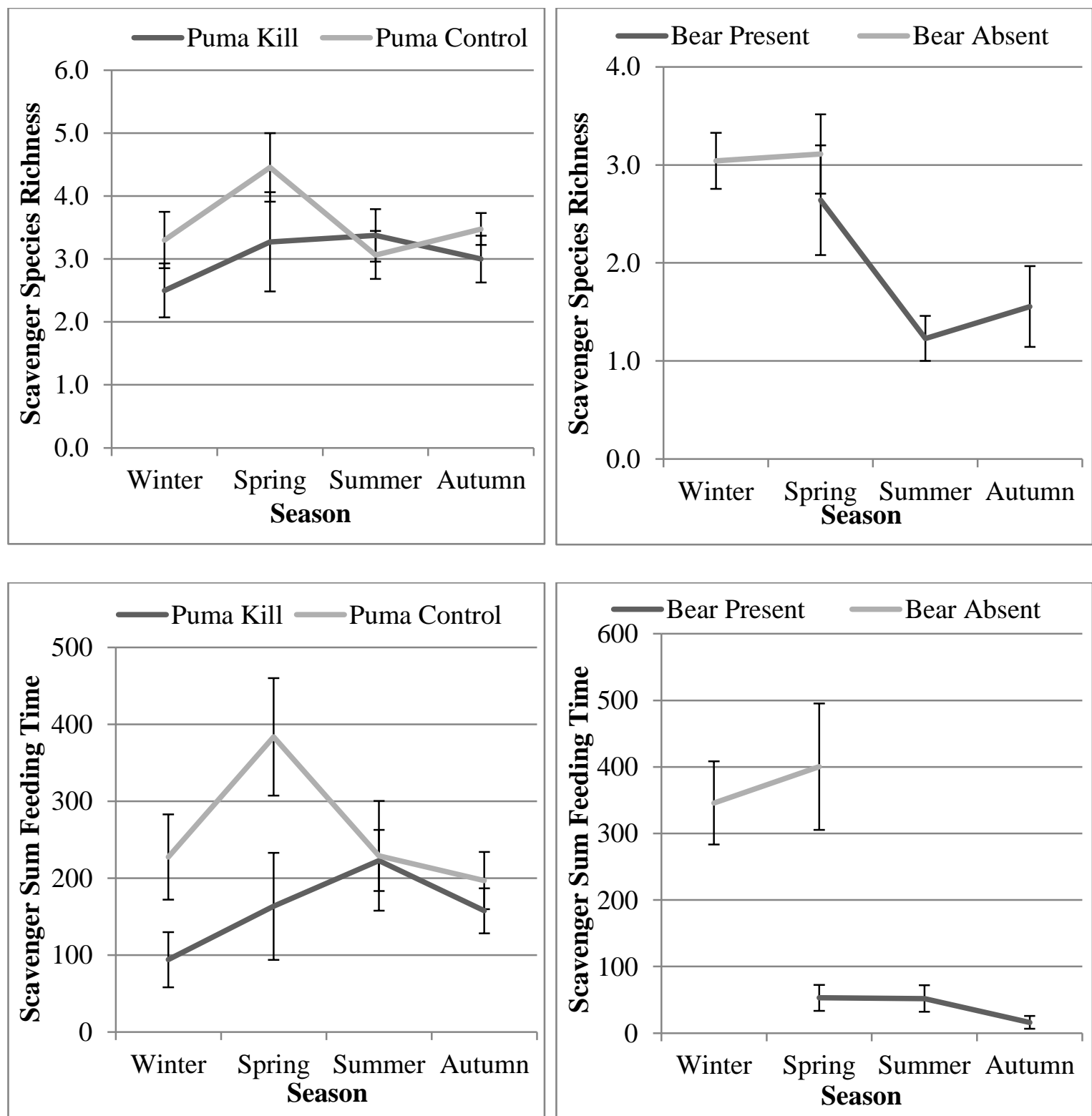

Figure 2. The seasonal distribution of scavenger species richness (number of scavengers present) and sum feeding time in minutes (total time scavengers spent feeding). Each season is represented as a mean with the error bars representing standard error. I did not include samples on the graphs where there were $<3$ samples for a season.

\section{Scavenger Sum Feeding Times}

At puma kills scavengers fed for a mean of $165.7( \pm 21.2 \mathrm{SE}) \mathrm{min}$, and at puma control carcasses scavengers fed for a mean of $246.3( \pm 30.1 \mathrm{SE})$ min, resulting in a medium negative effect attributable to pumas $(\mathrm{d}=-0.41)$ (Table 1). Puma carcass type (kill vs. control) was a significant factor in scavenger sum feeding times ( $\mathrm{df}=1, F=4.03, p=0.0471$, 
Table 2). Season alone was not a significant factor of scavenger sum feeding times (Table 2).

However, the models of puma carcass type and season $(\mathrm{df}=1, F=4.39, p=0.0386$, Table 2 ,

Figure 2) and the interaction between puma carcass type and season were significant $(\mathrm{df}=3$, $F=3.55, p=0.0170$, Table 2). The model of puma carcass type and season was the best model with the lowest AIC value to explain scavenger sum feeding times (Table 2).

At carcasses where black bears were present scavengers fed for a mean of $42.5( \pm$ 10.6 SE) min, while at carcasses where bears were absent scavengers fed for a mean of 359.5 $( \pm 50.2 \mathrm{SE}) \mathrm{min}$, resulting in a large negative effect attributable to black bears $(d=-1.20)$ (Table 1). Black bear carcass type (present vs. absent) was a significant factor in scavenger sum feeding times ( $\mathrm{df}=1, F=58.73, p<0.0001$, Table 2). Season alone was also a significant factor in scavenger sum feeding times $(\mathrm{df}=3, F=11.43, p<0.0001$, Table 2$)$, with significantly higher sum feeding times in spring and winter than in summer $\left(p_{\text {spring }}=\right.$ $\left.0.0164, p_{\text {winter }}=0.0020\right)$ or autumn $\left(p_{\text {spring }}=0.0002, p_{\text {winter }}<0.0001\right)$. The model of black bear carcass type and season was also significant $(\mathrm{df}=1, F=23.51, p<0.0001$, Table 2, Figure 2), but not the interaction between black bear carcass type and season. Black bear carcass type was the best model with the lowest AIC value to explain scavenger sum feeding times (Table 2).

\begin{tabular}{|l|l|lll|ll|ll|}
\hline & & \multicolumn{3}{|c|}{ ANOVA } & \multicolumn{2}{c|}{ Null Model 1 } & \multicolumn{2}{c|}{ Null Model 2 } \\
Carcass Type & $N$ & $d f$ & $F$ & $P$ & $N(S E)$ & $P$ & $N(S E)$ & $P$ \\
\hline Puma Kill & 0.88 & 2,198 & 250.46 & $<0.0001$ & $0.55(0.01)$ & $<0.0001$ & $0.67(0.01)$ & $<0.0001$ \\
Puma Control & 0.83 & 2,198 & 206.23 & $<0.0001$ & $0.58(0.01)$ & $<0.0001$ & $0.69(0.01)$ & 0.0012 \\
Black Bear Present & 0.88 & 2,198 & 82.28 & $<0.0001$ & $0.59(0.01)$ & $<0.0001$ & $0.69(0.01)$ & 0.0003 \\
Black Bear Absent & 0.81 & 2,198 & 159.14 & $<0.0001$ & $0.53(0.01)$ & $<0.0001$ & $0.64(0.01)$ & 0.0003 \\
\hline
\end{tabular}

Table 3. Comparison of the nestedness $(N)$ scores of each carcass type with two types of randomly generated null models. Null models of type 1 lacked heterogeneity and nestedness, and while null models of type 2 lacked nestedness. Nestedness $(N)$ is represented for each carcass type, along with the results of the ANOVA analyses, and the results from post hoc Tukey's HSD analyses. The mean nestedness $(N)$ and the standard error are represented for null model types. 


\section{Nestedness of Scavenger Communities}

My analyses revealed that each carcass type (puma kill, puma control, black bear present, black bear absent) was significantly more nested than the randomly generated null models (Table 3); showing structured and nested relationships among the scavenger community at each carcass type. The randomly generated null models of type 1 lacked heterogeneity and nestedness, and were significantly lower than each carcass type ( $p_{\text {puma kill }}<$ $\left.0.0001, p_{\text {puma control }}<0.0001, p_{\text {bear present }}<0.0001, p_{\text {bear absent }}<0.0001\right)$. The randomly generated null models of type 2 lacked nestedness, and were significantly lower than each carcass type $\left(p_{\text {puma kill }}<0.0001, p_{\text {puma control }}=0.0012, p_{\text {bear present }}=0.0003, p_{\text {bear absent }}=0.0003\right)$.

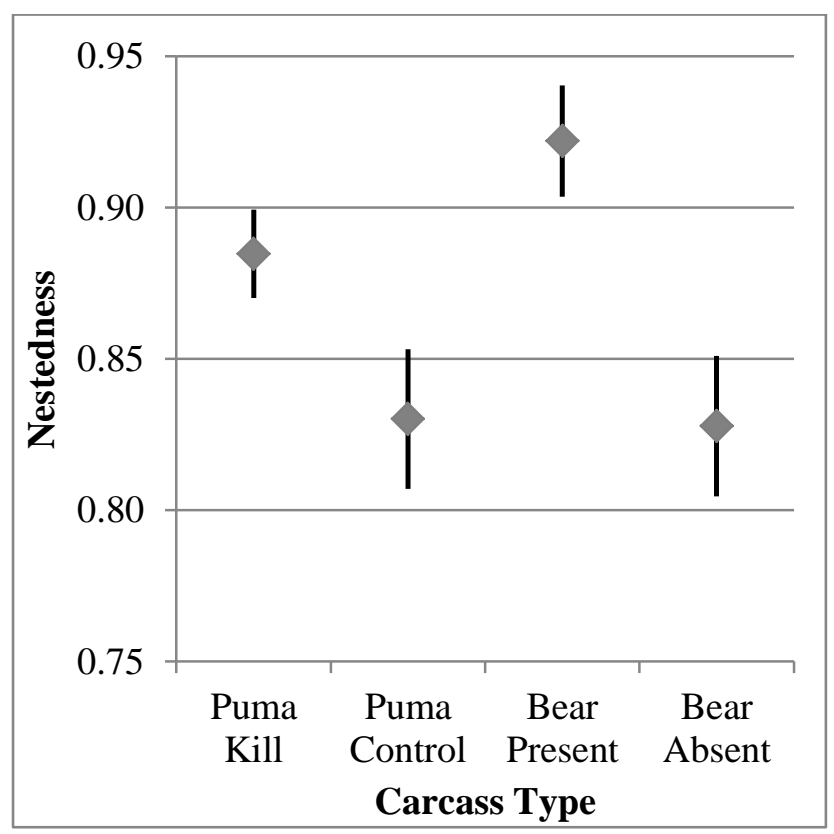

Figure 3. The nestedness $(N)$ of the scavenger community at each carcass type. Overall nestedness was calculated as the mean of the nestedness contribution $(N C)$ of each individual carcass, and error bars indicate the standard error $(S E)$ of the nestedness estimate. Pumas and black bears both increased the nestedness of the scavenger community.

Further analyses revealed that both pumas and black bears increased the nestedness $(N)$, and hence structure, of the scavenger community. The scavenger community at puma kills were significantly more nested than puma control carcasses $(\mathrm{df}=113, p=0.0468)$. Nestedness amounted to $N=0.88( \pm 0.01 \mathrm{SE})$ at puma kills, and $N=0.83( \pm 0.02 \mathrm{SE})$ at 
puma control carcasses, indicative of a medium effect attributable to pumas $(d=0.38)$ (Figure 3). The scavenger community was significantly more nested at carcasses where black bears were present than carcasses where black bears were absent $(\mathrm{df}=73, p=0.0052)$. Nestedness amounted to $N=0.92( \pm 0.02 \mathrm{SE})$ at carcasses where black bears were present, and $N=0.83( \pm 0.02 \mathrm{SE})$ at carcasses where black bears were absent, indicative of a large effect attributable to black bears $(d=0.68)$ (Figure 3$)$.

\begin{tabular}{|lcccc|}
\hline Species & $\begin{array}{c}\text { Puma } \\
\text { Kill }\end{array}$ & $\begin{array}{c}\text { Puma } \\
\text { Control }\end{array}$ & $\begin{array}{c}\text { Black } \\
\text { Bear } \\
\text { Present }\end{array}$ & $\begin{array}{c}\text { Black Bear } \\
\text { Absent }\end{array}$ \\
\hline Bobcat & 0.91 & 0.77 & 0.72 & 0.45 \\
Common Raven & 0.77 & 0.78 & 0.86 & 0.67 \\
Coyote & 0.75 & 0.81 & 0.98 & 0.60 \\
Fisher & 0.89 & 0.53 & 0.98 & 0.74 \\
Gray Fox & 0.93 & 0.85 & 0.97 & 0.94 \\
Spotted Skunk & 0.83 & 0.86 & - & 0.88 \\
Turkey Vulture & 0.72 & 0.65 & 0.85 & 0.45 \\
\hline
\end{tabular}

Table 4. The nestedness contribution $(N C)$ scores for the 7 most frequent scavenger species at each carcass type. A higher NC score indicates that the occurrence of the species is more structured.

The nestedness contribution $(N C)$ scores of scavengers showed apparent differences between carcass types (puma kill vs. control, or black bear present vs. absent), with the NC scores for the most common scavenger species (those present at more than 20 carcasses) noted in Table 4. Four of these species contributed more to the nestedness of the scavenger community at puma kills, including bobcats (Lynx rufus), fishers (Martes pennanti), gray foxes (Urocyon cinereoargenteus), and turkey vultures (Cathartes aura). Six of these species contributed more to the nestedness of the scavenger community at carcasses where black bears were present, including bobcat, common ravens (Corvus corvax), coyotes (Canis latrans), fishers, gray foxes, and turkey vultures. 


\section{Discussion}

A driving force for the evolution of carnivores is the adaptations needed to overcome continually evolving defence strategies of prey species (Begon et al. 2006). Competitive interactions among vertebrate scavengers may be as complex as predator-prey relationships (Selva and Fortuna 2007), and should also be the subject of co-evolutionary adaptations and strategies among carnivores and their associated scavenger community. My results suggest that large carnivores, when acting as either a top predator or dominant scavenger, influence the structure of the scavenger community by both facilitating and limiting the acquisition of carrion by different scavenger species. Considering the importance of interspecific interactions in the acquisition of carrion, large carnivores may be an important cause of adaptation for many vertebrate scavenger species.

The nestedness, or structure of the scavenger community, increased at carcasses where pumas and black bears were present. The scavenger community at each carcass type (puma kill, puma control, bear present, bear absent) was more nested than randomly generated null models, supporting findings of Selva and Fortuna (2007). But more importantly, my findings suggest species-specific responses to large carnivores (both positive and negative), and that large carnivores are an important influence on the structure and composition of the vertebrate scavenger community whether they are acting as a predator or scavenger. The increased nestedness is likely due to a combination of two factors: 1) competition with pumas and black bears structures the exploitation of carcasses by different species, and 2) scavengers with increased nestedness have evolved behaviours and strategies to allow them to take advantage of carrion despite large carnivores. I hypothesize these behaviours are adaptations to increase the predictability of carrion resources, which are generally uncertain and temporal (Barton et al. 2013, DeVault et al. 2003, Wilson and Wolkovich 2011). Increased predictability of carrion could allow scavengers to acquire and 
exploit the limited available carrion resources, and strategically increase their individual fitness.

Pumas and black bears also directly limited the species richness and sum feeding times of scavengers. The magnitude of this effect, however, differed between pumas and black bears. Black bears had large effect sizes on scavenger species richness $(d=-0.87)$ and sum feeding times $(d=-1.20)$, while pumas had a small effect size on scavenger species richness $(d=-0.27)$, and a medium effect size on sum feeding times $(d=-0.41)$. Although pumas limited scavengers, they also acted as an important facilitator of energy to scavengers in ecosystems. For example, 20 vertebrate scavenger species fed at puma kills, and these scavengers fed for a mean of $165.7 \mathrm{~min}$ at each kill. This suggests that pumas provide resources for a large number of scavengers, and may act as a keystone species subsidizing the scavenger community (Elbroch and Wittmer 2012b, Elbroch and Wittmer 2013b). Furthermore pumas may increase ecosystem stability by facilitating the movement of energy to different trophic levels (DeVault et al. 2003, Wilson and Wolkovich 2011). In contrast, black bears are a dominant scavenger, which compete for carrion resources and rarely provide energy to other scavengers (e.g. by killing adult ungulates on their own) (Svoboda et al. 2011). The large negative effects of black bears suggest a decrease in the complimentary use of carrion by other scavengers in the community, and therefore the effects of black bears may best classified as trophic limitation. Although both large carnivores limited scavenger species richness and sum feeding times, and hence could have direct effects on the individual fitness and populations of scavengers, their overall effects are likely to be dependent upon their respective ecological roles.

The seasonal effects of pumas and black bears varied, which is likely due to the variation in seasonal abundance of black bears as explained by hibernation. During seasons they were not hibernating, black bears directly decreased the species richness and sum feeding times of other scavengers at carcasses where they were present, apparently 
decreasing the amount of carrion available for other species. Black bears may also have influenced the scavenger community at puma kills, as sum feeding times at puma kills and control carcasses did not vary in summer and autumn, suggesting that black bears may have competitive advantages over other scavengers for the available resources at both types of carcasses. My results therefore suggest that pumas may act as a resource buffer for scavengers, by killing ungulates and facilitating scavengers with carrion resources throughout the year (Wilmers 2003a). However, black bears may dampen the beneficial effect of the year-round buffer provided by pumas, and make carrion less available to other scavengers in seasons when they are active. The combined influences of seasonality and predictability of carrion availability are important factors to consider in the evolution of scavenger ecology. Past studies, using two season models, have shown that facultative scavengers scavenge more frequently during winter than summer (Selva et al. 2005, Krofel et al. 2012). However, my study suggests that this may be less due to changes in their preferences or metabolic needs, and instead due to competition with bears and obligative scavengers like vultures, which are less abundant in winter.

In summary, results from my study suggest that large carnivores exert important influences on vertebrate scavengers, which may have implications for community assemblages at larger scales. Pumas apparently facilitate the acquisition of carrion by the scavenger community through the use of carrion from their kills. This suggests that pumas may be provisioning the scavenger community with carrion, and the large amount of carrion provided to scavengers suggest that pumas may be a keystone species for the scavenger community. In contrast, black bears are apparently dominant scavengers, and carrion appears to be an important source of nutrition for them. Black bears were a large source of limitation for the scavenger community, which may have important consequences for the rest of the scavenger community. However, black bears vary in their seasonal abundance due to hibernation, and competition with black bears during seasons they are active may influence 
scavenger survival and population dynamics. Large carnivores apparently have different influences based on their ecological role, and also may cause the energy available from carrion resources to be partitioned by specific species or across trophic levels (Barton et al. 2013). My results suggest that the influences of large carnivores on the scavenger community should be considered in future studies of food webs and species interactions within ecological communities. 


\title{
Chapter 7
}

\section{The Comparative Influences of}

\author{
Large Carnivores on the
}

Acquisition of Carrion by Scavengers

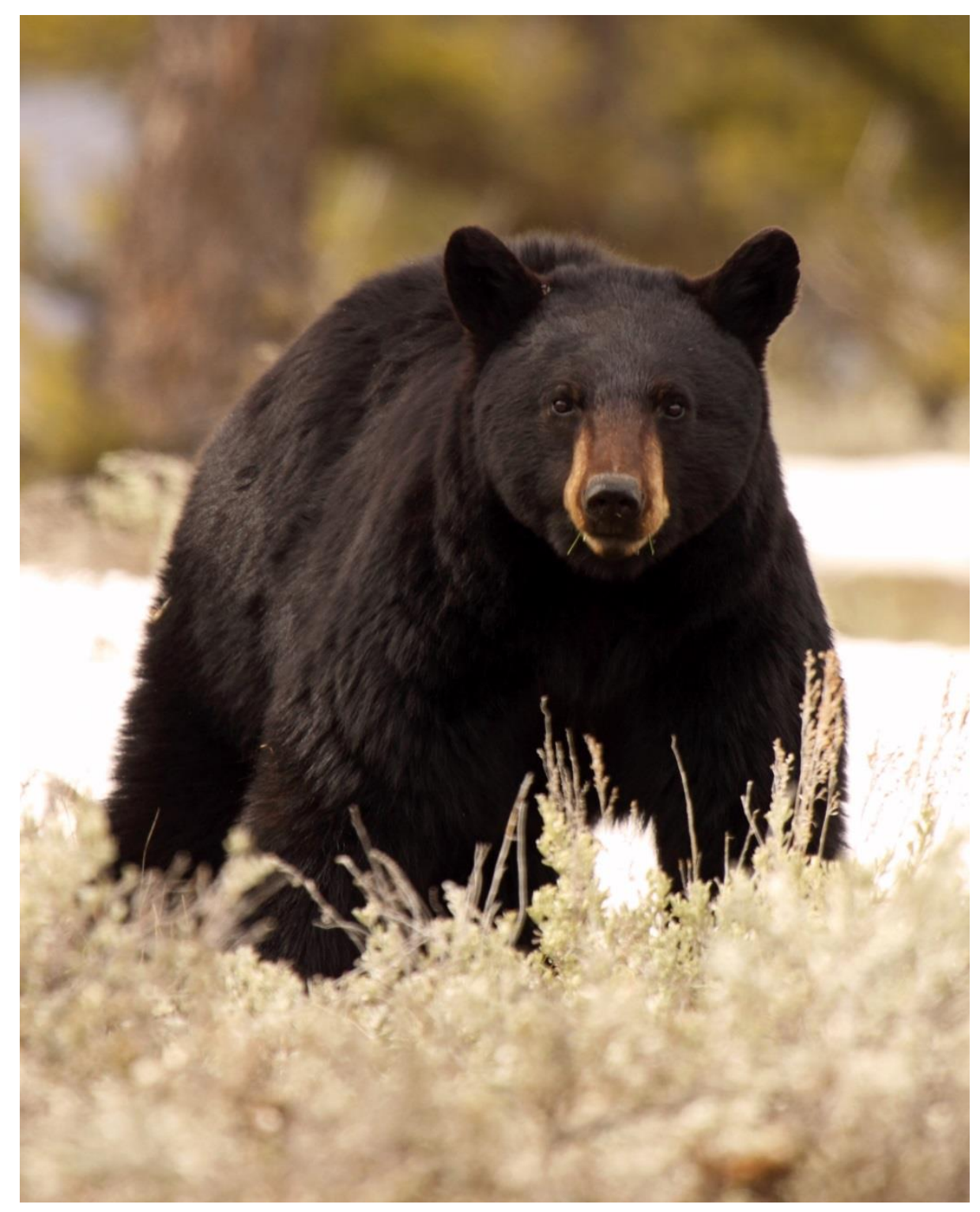


This paper will be submitted for publication as:

Allen, M.L., L.M. Elbroch, C.C. Wilmers, and H.U. Wittmer. The comparative influences of large carnivores on the acquisition of carrion by scavengers.

\section{Acknowledgements}

The California Department of Fish and Wildlife, and the University of California at Davis generously provided funding for the project. M. Allen was supported by a Victoria University of Wellington tuition scholarship. I thank D. Casady, B. Millsap, J. Golla, B. Evans, C. Wiley, and many field technicians for their help on the project. 


\begin{abstract}
In North America, two large carnivores which influence scavenger population dynamics are pumas (Puma concolor), a top-level predator capable of both provisioning and limiting scavengers' acquisition of carrion, and black bears (Ursus americanus), a dominant scavenger capable of limiting acquisition of carrion by other scavengers through competition. My experimental design used motion-triggered video cameras deployed at deer carcasses to determine how pumas and black bears affected scavengers. I determined their influence on the distribution of energy to different scavenger classes and species by monitoring 3 aspects of carrion acquisition by scavengers: occurrence, total feeding time, and mean feeding bout durations. I found that the provisioning and limitation of carrion acquisition by pumas was not equal among scavengers and that by limiting the acquisition of carrion to mesocarnivores pumas increased opportunities for small carnivores. In contrast, black bears monopolized carrion resources and limited all 3 aspects of carrion acquisition for every scavenger class, and strongly limited acquisition of carrion for 7 of the most common scavenger species. Black bears also limited puma feeding behaviours at their own kills, which could increase puma kill rates of ungulates and indirectly affect the rest of the ecological community. Overall I propose that pumas act as a source of energy available to scavengers, and black bears act as a limitation. The varying influences of pumas and black bears on scavengers could be a mechanism explaining previously observed population level effects of large carnivores on other carnivores which are facultative scavengers.
\end{abstract}




\section{Introduction}

The effects of large carnivores in structuring ecological communities, including initiating trophic cascades, are well-established (Estes and Palmisano 1974, Ripple et al. 2014). For example, by suppressing smaller carnivores, large carnivores have been shown to indirectly influence abundances of other species including birds and herbivores (Estes and Palmisano 1974, Rogers and Caro 1998, Courchamp et al. 1999, Prugh et al. 2009). Large carnivores also have cascading effects solely on other carnivores. For example, the return of gray wolves (Canis lupus) to Minnesota resulted in suppression of coyotes (Canis latrans), which in turn allowed an increase in red foxes (Vulpes vulpes) (Levi and Wilmers 2013). Within their respective communities, large carnivores are thought to exert population level influences on other species either directly via predation or indirectly as a result of behavioural changes to avoid predation that result in lower fitness (Sargeant et al. 1987, Atwood et al. 2007, Ripple et al. 2001, Ripple and Beschta 2004, Ripple et al. 2014). An underappreciated mechanism for the effects large carnivores have on ecological communities may be interactions at carrion, where they may influence the feeding and carrion acquisition of smaller carnivores.

Scavenging is a widespread behaviour, where species compete for limited resources in order to gain nutritional benefits and hence increase individual fitness (Houston 1995, DeVault et al. 2003, Selva et al. 2003, Wilson and Wilkovich 2011). For example, numerous facultative scavengers use scavenging to increase their breeding success (e.g. Watson et al. 1992, Angerbjorn et al. 1991). In addition, recent studies have highlighted the importance of scavenging to ecosystem function and the transfer of energy between trophic levels (DeVault et al. 2003, Selva and Fortuna 2007, Wilson and Wolkovich 2011, Chapter 6). Interactions at carrion also appear to be one of the most frequent opportunities for interactions among carnivores, and these interactions result in complex ecological relationships and resource partitioning (Selva and Fortuna 2007, Chapter 6). 
Large carnivores are likely to be an important influence on how carrion is distributed among scavengers. Large carnivores provision scavengers with carrion from their kills (Wilmers et al. 2003a, Elbroch and Wittmer 2013b, Chapter 6), and benefit the scavenger community in other ways. For example, some large carnivores facilitate the availability of energy from carrion throughout the year rather than in seasonal pulses (Wilmers and Getz 2005). Large carnivores, however, are also a source of limitation for the scavenger community, both through competition for carrion resources and actively limiting scavengers at their kills (Hunter et al. 2006, Chapter 6). This suggests that large carnivores have important influences on scavengers, and may also affect access to carcasses at larger spatial scales.

In North American ecological communities two large carnivores which may have important influences on scavengers are pumas (Puma concolor), and black bears (Ursus americanus) (Chapter 6). Pumas are solitary predators which frequently kill ungulates, and are an important source of provisioning for the scavenger community (Elbroch and Wittmer 2012b, Chapter 6). Pumas use behaviours like caching to minimize detection by scavengers (Bischoff-Mattson and Mattson 2009, Ruth and Murphy 2010b), but commonly interact with scavengers at their kills (Ruth and Murphy 2010b). In contrast, black bears rarely kill adult ungulates (Svoboda et al. 2011), but are able to usurp carrion and kills from most other carnivores (Murphy et al. 1998, Ruth and Murphy 2010b). These behaviours make black bears a dominant scavenger, and a source of limitation for the scavenger community (Chapter 6).

The effects of pumas and black bears on the acquisition of carrion are unlikely to be equally distributed among scavengers. In Chapter 6 I hypothesized that differences in body sizes and other adaptions may allow some scavengers to access and exploit carrion better than others. I attempted to determine how pumas and black bears influence the acquisition of carrion by scavengers, by conducting a series of in situ experiments at black-tailed deer 
(Odocoileus hemionus columbianus) carcasses. I analysed 3 aspects of carrion acquisition: occurrence, total feeding time, and mean feeding bout duration, and used effect statistics to determine the importance of biological interactions and the magnitude of their difference (Cohen 1992, Nakagawa and Cuthill 2007). I first analysed the variables for effects on scavenger classes to understand broad-scale effects, then for effects on individual species to understand interspecific dynamics, and last for the effects pumas and black bears had on each other. In each case I expected pumas and black bears to limit each aspect of carrion acquisition, but expected variation in effect sizes based on adaptive strategies of scavenger species.

\section{Methods}

\section{Experimental Design and Field Methods}

To determine the influences of pumas and black bears on the acquisition of carrion by scavengers I used the experimental design described in detail in Chapter 6. I used motiontriggered video cameras with infrared flash at black-tailed deer carcasses to record and compare the acquisition of carrion by scavengers. For pumas, I compared the acquisition of carrion by scavengers at kills made by pumas to control carcasses with matching habitat characteristics that I placed simultaneously on the landscape. For black bears, I distributed black-tailed deer carcasses in varying habitats across the study area, and compared scavenger acquisition of carrion at carcasses where black bears were present to carcasses where they were absent. For puma control carcasses and the black bear experiments I used black-tailed deer which were killed through vehicle collisions, which were fresh and in good condition to replicate the freshness and the same decomposition state as puma kills (Chapter 6).

From June 2010-December 2012, I captured 7 pumas, and fitted them with a combined ARGOS satellite GPS/radio telemetry collar (Lotek 7000SAW, New Market, Ontario) (Chapter 4). I downloaded the location data via satellite connection every 3 days, 
and investigated any GPS clusters where a monitored puma had spent $\geq 2$ hours within $150 \mathrm{~m}$ and appeared to still be present on the same day as the Argos-relayed GPS downloads (Chapter 4). I approached these potential feeding sites during mid-day when pumas are least active, and limited my visits to $5 \mathrm{~min}$ at the site in order to limit disturbance of the puma and avoid possible carcass abandonment. I secured the carcass with a wire cable to hold it within $1 \mathrm{~m}$ of its location for monitoring, and then deployed a motion-triggered camera (Bushnell ScoutCam, Overland Park, KS) to document the feeding behaviours of scavengers at the kill. I set the motion-triggered cameras to record the maximum amount of activity, with 60 s of video recorded at each trigger with a pause of $1 \mathrm{~s}$ before becoming active at the next trigger. I recorded the habitat characteristics of the site, and then found the site for the puma control carcass by matching the habitat characteristics as closely as possible to (listed in order of importance): 1) primary habitat type, 2) overhead tree species, 3) canopy cover, 4) secondary habitat type, 5) distance to secondary habitat, 6) elevation (Chapter 6). Before arriving at the site of the control carcass, I prepared a black-tailed deer carcass to provide an equivalent amount of meat, in the same stage of decomposition, as at the puma kill, and then secured the carcass and deployed another camera (Chapter 6).

For the black bear experiments, from December 2009-October 2012 I placed 100 black-tailed deer carcasses in a variety of habitat conditions, in order to provide a diverse sample of the vertebrate scavenger community (Chapter 6). I secured each carcass in place with a wire cable, and monitored the carcass for scavenger activity with a motion-triggered video camera with infrared flash (Cuddeback IR, De Pere, WI). I set the motion-triggered cameras to record the maximum amount of activity, with 30 s of video with a pause of 60 s before the next trigger. In order to understand the influences of black bears, I compared the effects of black bears at carcasses where black bears were present (defined as where they were the $1^{\text {st }}$ or $2^{\text {nd }}$ scavenger to arrive, Chapter 6) to carcasses where they were absent (defined as where they were absent or one of the last scavengers to arrive and spent $\leq 10 \mathrm{~min}$ 
at the carcass, Chapter 6). I removed carcasses from my analyses when 1) black bears had an unknown influence (when they were the $3^{\text {rd }}$ or later scavenger to arrive and spent $>10$ min at the carcass) $(\mathrm{n}=10)$, and 2) and any carcasses with incomplete data due to camera malfunctions or camera displacements by black bears $(n=11)$.

\section{Statistical Analyses}

In order to determine the influences of pumas and black bears on scavengers, I considered 3 aspects of carrion acquisition: 'occurrence', 'total feeding time', and 'mean feeding bout duration', which I considered proxies for the energy a scavenger gained from a given carcass. Occurrence was a proxy for whether a scavenger species was able to derive energy from a given carcass. Total feeding times were a proxy for the sum energetic gain of a scavenger from a given carcass. Mean feeding bout durations were a proxy for the amount of energetic gain for a scavenger during a particular visit before having to incur energetic losses from travel to and from the carcass. Occurrence was calculated as the per cent of carcasses at which a given scavenger appeared. I calculated the duration of a given feeding bout by subtracting the time at the start of a visit by the time at the end of a visit. For visits of $<30 \mathrm{sec}$ I considered the species present for $1 \mathrm{~min}$ rather than $0 \mathrm{~min}$, and I rounded all other visits to the closest min. Total feeding times were calculated as the sum of all feeding bouts at a given carcass, and mean feeding bout durations were calculated as the mean duration of all feeding bouts at a given carcass.

I calculated summary statistics for each outcome variable, using the program $R(R$ Core Team 2013), and then calculated effect sizes. For occurrence, I calculated effect sizes as phi coefficients (Cohen 1992, Nakagawa and Cuthill 2007) using the vcd package (Meyer et al. 2013), and considered effects of 0.1 small, 0.3 medium, and 0.5 large (Cohen 1992). For total feeding times and mean feeding bout durations, I calculated effect sizes as Cohen's $d$ scores (Cohen 1992), and considered effects of 0.2 small, 0.5 medium, and 0.8 large (Cohen 
1992, Nakagawa and Cuthill 2007). Each analysis performed was for either pumas (puma kills vs. puma control carcasses) or black bears (carcasses where black bears were present vs. carcasses where black bears were absent). Negative scores indicated a decrease in the acquisition of carrion attributable to pumas or black bears, and positive scores indicated an increase.

\begin{tabular}{|ll|}
\hline Scavenger Class & Scavenger Species \\
\hline Large Carnivore & $\begin{array}{l}\text { black bear (Ursus americanus), coyote (Canis latrans), domestic dog } \\
\text { (Canis familiaris), puma (Puma concolor) }\end{array}$ \\
\hline Mesocarnivore & $\begin{array}{l}\text { bobcat (Lynx rufus), fisher (Martes pennanti), gray fox (Ucrocyon } \\
\text { cinereoargenteus), raccoon (Procyon lotor) }\end{array}$ \\
\hline Small Carnivore & $\begin{array}{l}\text { ringtail (Bassariscus astutus), striped skunk (Mephitis mephitis), western } \\
\text { spotted skunk (Spirogale gracilis) }\end{array}$ \\
\hline Avian & $\begin{array}{l}\text { bald eagle (Haliaeetus leucocephalus), common raven (Corvus corax), } \\
\text { golden eagle (Aquila chrysaetos), great horned owl (Bubo virginianus), } \\
\text { northern goshawk (Accipiter gentilis), red-tailed hawk (Buteo jamaicensis), } \\
\text { turkey vulture (Cathartes aura) }\end{array}$ \\
\hline
\end{tabular}

Table 1. The species composition for each of the 4 scavenger classes I tested for influences from pumas and black bears. Scavenger species were grouped into classes based on their weight.

I performed my analyses of the 3 aspects of carrion acquisition on 3 different groups: scavenger classes, individual scavenger species, and the effects of pumas and black bears on each other. I analysed effect sizes for each scavenger class in order to understand broad-scale effects and the distribution of energy to similar scavengers. Each scavenger species was placed into 1 of 4 classes based on their weight (Table 1). Next, I analysed effect sizes for the 10 most frequent scavenger species, in order to understand which species were critically limited by pumas and black bears. Because medium effect sizes are 0.3 for $p h i$ coefficients and 0.5 for $d$ scores, the sum of the 3 effect sizes is 1.3 , and I therefore considered scavenger species with combined effect sizes $>1.3$ to be strongly limited. Last, I analysed the effect sizes of pumas and black bears on each other in 3 ways: 1) the influence of pumas on black 
bears at puma kills and control carcasses, 2) the effect of black bears on puma scavenging behaviour at black bear experimental carcasses, and 3) the influence of black bears on pumas at their kills, determined by the feeding behaviours of pumas at their kills before and after the arrival of black bears.

\section{Results}

I monitored 58 puma kills which recorded 10,775 videos of animal activity, and 58 puma control carcasses which recorded 9,663 videos of animal activity. Based on GPS data, pumas stayed within $150 \mathrm{~m}$ of kills I monitored for a mean of 75.1 ( $\pm 5.9 \mathrm{SE})$ hours during the study. I set up cameras at the puma kills a mean of $39.8( \pm 2.9 \mathrm{SE})$ hours after the puma made the kill, and I set up the paired cameras within a mean of $1.51( \pm 0.18 \mathrm{SE})$ hours after the camera was set up at the puma kill. I monitored 33 carcasses where black bears were present, which recorded 3,039 videos of animal activity; and monitored 46 carcasses where black bears were absent, which recorded 9,038 videos of animal activity. Black bears detected carcasses in a mean of $48.5( \pm 12.1 \mathrm{SE})$ hours. Black bears had total feeding times of $105.9( \pm 25.6 \mathrm{SE})$ min, and had mean feeding bout durations of $4.8( \pm 0.9 \mathrm{SE}) \min$.

\section{Effects on Scavenger Classes}

Pumas limited the acquisition of carrion by some scavengers at their kills (Table 2). Pumas had a small effect size on mean feeding bout durations $(d=-0.15)$ of large carnivores (Figure 1). For mesocarnivores, pumas had a small effect size on occurrence $(p h i=-0.16)$, and medium effect sizes on total feeding time $(d=-0.71)$, and mean feeding bout durations $(d$ $=-0.71)$ (Figure 1). Pumas had medium effect sizes on total feeding times $(d=-0.72)$, and mean feeding bout durations $(d=-0.64)$ of avian scavengers (Figure 2). In contrast, at puma kills all 3 feeding behaviours of small carnivores increased (Table 2), including small effect sizes on occurrence $(p h i=0.05)$, and total feeding times $(d=0.32)$, and a medium effect size on mean feeding bout durations $(d=0.54)$ (Figure 1). 


\begin{tabular}{|c|c|c|c|c|c|c|c|c|c|}
\hline & \multicolumn{3}{|c|}{ Occurrence } & \multicolumn{3}{|c|}{ Total Feeding Time } & \multicolumn{3}{|c|}{ Mean Feeding Bout Duration } \\
\hline & $\begin{array}{c}\text { Kill } \\
\% \text { Detected }\end{array}$ & $\begin{array}{c}\text { Control } \\
\% \text { Detected }\end{array}$ & phi & $\begin{array}{c}\text { Kill } \\
\text { mean }(95 \% \mathrm{CI})\end{array}$ & $\begin{array}{c}\text { Control } \\
\text { mean }(95 \% \mathrm{CI})\end{array}$ & $d$ & $\begin{array}{c}\text { Kill } \\
\text { mean }(95 \% \mathrm{CI})\end{array}$ & $\begin{array}{c}\text { Control } \\
\text { mean }(95 \% \mathrm{CI})\end{array}$ & $d$ \\
\hline Large Carnivore & $79.3 \%$ & $82.8 \%$ & -0.04 & $136.1(90.3-181.8)$ & $127.3(72.4-182.3)$ & 0.05 & $7.9(5.8-10.0)$ & $9.0(7.0-11.0)$ & -0.15 \\
\hline Mesocarnivore & $44.8 \%$ & $60.3 \%$ & -0.16 & $58.8(29.7-87.8)$ & $135.1(93.3-177.0)$ & -0.71 & $2.3(1.7-2.9)$ & $3.8(3.0-4.6)$ & -0.71 \\
\hline Small Carnivore & $25.9 \%$ & $22.4 \%$ & 0.05 & $47.0(7.7-86.3)$ & $26.8(5.6-48.0)$ & 0.32 & $3.9(0.8-7.0)$ & $1.5(1.1-1.9)$ & 0.54 \\
\hline Avian & $37.9 \%$ & $36.2 \%$ & 0.02 & $50.4(43.6-57.2)$ & $152.9(65.9-239.8)$ & -0.72 & $3.3(2.1-4.5)$ & $5.6(3.8-7.3)$ & -0.64 \\
\hline Black Bear & $72.4 \%$ & $62.1 \%$ & 0.11 & $145.9(98.5-193.2)$ & $151.8(81.2-222.3)$ & -0.03 & $8.9(6.6-11.2)$ & $13.8(9.2-18.3)$ & -0.45 \\
\hline Bobcat & $8.6 \%$ & $15.5 \%$ & -0.11 & $7.8(-1.7-17.3)$ & $37.7(-34.0-109.3)$ & -0.33 & $1.7(0.8-2.6)$ & $1.2(0.9-1.5)$ & 0.64 \\
\hline Common Raven & $22.4 \%$ & $27.6 \%$ & -0.06 & $29.1(4.6-53.5)$ & $47.9(21.9-73.8)$ & -0.38 & $3.1(1.4-4.7)$ & $4.0(2.5-5.5)$ & -0.30 \\
\hline Coyote & $25.9 \%$ & $36.2 \%$ & -0.11 & $8.0(1.9-14.1)$ & $16.5(6.6-26.3)$ & -0.44 & $1.5(1.0-2.0)$ & $2.7(1.6-3.8)$ & -0.60 \\
\hline Domestic Dog & $1.7 \%$ & $13.8 \%$ & -0.23 & $7.0(7.0-7.0)$ & $28.0(-0.3-56.3)$ & -0.51 & $1.4(1.4-1.4)$ & $3.7(1.1-6.3)$ & -0.60 \\
\hline Fisher & $17.2 \%$ & $22.4 \%$ & 0.07 & $8.3(0.2-16.5)$ & $82.3(-0.2-164.9)$ & -1.01 & $1.9(0.5-3.4)$ & $3.3(2.1-4.5)$ & -0.60 \\
\hline Gray Fox & $37.9 \%$ & $48.3 \%$ & -0.10 & $81.4(11.0-151.9)$ & $96.3(48.8-143.9)$ & -0.17 & $2.3(1.7-2.9)$ & $3.9(3.0-4.8)$ & -0.77 \\
\hline Raccoon & $1.7 \%$ & $3.4 \%$ & -0.05 & $2.0(2.0-2.0)$ & $1.0(1.0-1.0)$ & - & $2.0(2.0-2.0)$ & $1.0(1.0-1.0)$ & - \\
\hline Ringtail & $15.5 \%$ & $6.9 \%$ & 0.14 & $51.0(-20.2-122.2)$ & $36.5(-1.6-74.6)$ & 0.20 & $2.9(1.7-4.2)$ & $2.2(1.2-3.2)$ & 0.47 \\
\hline Spotted Skunk & $17.2 \%$ & $13.8 \%$ & 0.05 & $45.0(-26.1-116.1)$ & $20.2(-3.8-44.2)$ & 0.40 & $3.9(-0.7-8.6)$ & $1.3(0.9-1.7)$ & 0.50 \\
\hline Turkey Vulture & $19.0 \%$ & $22.4 \%$ & 0.04 & $66.5(27.8-105.1)$ & $178.8(57.3-300.2)$ & -0.66 & $4.4(2.1-6.7)$ & $8.3(4.2-12.4)$ & -0.64 \\
\hline
\end{tabular}

Table 2. The effects of pumas on scavenger classes and scavenger species. I compared scavenger feeding behaviours (occurrence, total feeding times, and mean feeding bout durations) at puma kills and control carcasses. For occurrence I report the per cent of carcasses detected, and report the effect size as a phi coefficient. For total feeding times and mean feeding bout durations I report the mean and $95 \%$ confidence intervals, and report effect sizes as Cohen's $d$ scores. Positive effect sizes indicate an increase in the feeding behaviour, and negative effects sizes indicate a decrease. 


\begin{tabular}{|c|c|c|c|c|c|c|c|c|c|}
\hline & \multicolumn{3}{|c|}{ Occurrence } & \multicolumn{3}{|c|}{ Total Feeding Time } & \multicolumn{3}{|c|}{ Mean Feeding Bout Duration } \\
\hline & $\begin{array}{c}\text { Present } \\
\% \text { Detected }\end{array}$ & $\begin{array}{c}\text { Absent } \\
\% \text { Detected }\end{array}$ & phi & $\begin{array}{c}\text { Present } \\
\text { mean }(95 \% \mathrm{CI})\end{array}$ & $\begin{array}{c}\text { Absent } \\
\text { mean }(95 \% \mathrm{CI})\end{array}$ & $d$ & $\begin{array}{c}\text { Present } \\
\text { mean }(95 \% \mathrm{CI})\end{array}$ & $\begin{array}{c}\text { Absent } \\
\text { mean }(95 \% \mathrm{CI})\end{array}$ & $d$ \\
\hline Large Carnivore & $18.2 \%$ & $63.0 \%$ & -0.45 & $10.0(-0.8-20.8)$ & $49.7(23.8-75.5)$ & -0.60 & $1.5(0.8-2.3)$ & $3.8(2.1-5.5)$ & -0.53 \\
\hline Mesocarnivore & $27.3 \%$ & $84.8 \%$ & -0.58 & $6.1(3.1-9.1)$ & $269.1(167.1-371.2)$ & -0.89 & $1.1(0.9-1.3)$ & $4.8(3.7-5.9)$ & -1.17 \\
\hline Small Carnivore & $6.1 \%$ & $17.4 \%$ & -0.17 & $1.0(1 .-1.0)$ & $15.0(0.0-30.0)$ & -0.69 & $1.0(1.0-1.0)$ & $1.7(1.0-2.4)$ & -0.79 \\
\hline Avian & $60.6 \%$ & $65.2 \%$ & -0.05 & $50.4(26.5-74.3)$ & $180.8(109.6-252.0)$ & -0.82 & $3.1(2.0-4.2)$ & $6.4(3.5-9.3)$ & -0.51 \\
\hline Bobcat & $6.1 \%$ & $28.3 \%$ & -0.28 & $1.0(1.0-1.0)$ & $217.8(108.2-327.4)$ & -1.12 & $1.0(1.0-1.0)$ & $4.0(2.7-5.3)$ & -1.32 \\
\hline Common Raven & $33.3 \%$ & $43.5 \%$ & -0.10 & $8.3(3.3-13.2)$ & $94.3(19.1-169.5)$ & -0.62 & $1.9(0.5-3.3)$ & $3.2(1.3-5.1)$ & -0.34 \\
\hline Coyote & $18.2 \%$ & $41.3 \%$ & -0.26 & $9.7(-1.3-20.6)$ & $36.6(20.4-52.7)$ & -0.83 & $1.5(0.8-2.3)$ & $2.9(1.5-4.3)$ & -0.50 \\
\hline Domestic Dog & $3.0 \%$ & $19.6 \%$ & -0.25 & $1.0(1.0-1.0)$ & $27.1(-4.0-58.2)$ & -0.55 & $1.0(1.0-1.0)$ & $3.5(1.3-5.7)$ & -0.75 \\
\hline Fisher & $9.1 \%$ & $32.6 \%$ & -0.28 & $8.0(3.1-12.9)$ & $144.7(20.4-269.0)$ & -0.58 & $2.2(0.7-3.7)$ & $4.3(2.7-6.0)$ & -0.67 \\
\hline Golden Eagle & $12.1 \%$ & $13.0 \%$ & -0.01 & $11.0(-4.2-26.2)$ & $177.3(57.1-297.6)$ & -1.37 & $3.2(0.4-6.0)$ & $10.2(3.1-17.3)$ & -0.97 \\
\hline Gray Fox & $15.2 \%$ & $60.9 \%$ & -0.46 & $8.0(4.1-11.9)$ & $171.2(66.9-275.4)$ & -0.62 & $1.0(0.9-1.1)$ & $4.8(3.3-6.3)$ & -0.96 \\
\hline Ringtail & $0.0 \%$ & $6.5 \%$ & -0.17 & - & $7.3(-2.3-17.0)$ & - & - & $1.6(1.0-2.2)$ & - \\
\hline Spotted Skunk & $0.0 \%$ & $10.9 \%$ & -0.22 & - & $19.4(-4.1-42.9)$ & - & - & $1.9(0.8-3.0)$ & - \\
\hline Turkey Vulture & $51.5 \%$ & $21.7 \%$ & 0.31 & $53.3(26.4-80.2)$ & $222.7(110.0-335.4)$ & -1.43 & $3.7(2.4-5.0)$ & $9.4(3.4-15.4)$ & -0.93 \\
\hline
\end{tabular}

Table 3. The effects of black bears on scavenger classes and scavenger species. I compared scavenger feeding behaviours (occurrence, total feeding times, and mean feeding bout durations) at carcasses where black bears were present and absent. For occurrence I report the per cent of carcasses detected, and report the effect size as a phi coefficient. For total feeding times and mean feeding bout durations I report the mean and 95\% confidence intervals, and report effect sizes as Cohen's $d$ scores. Positive effect sizes indicate an increase in the feeding behaviour, and negative effects sizes indicate a decrease. 
At carcasses where black bears were present all 3 aspects of carrion acquisition were limited for every scavenger class (Table 3). For large carnivores, black bears had a large effect size on occurrence $(p h i=-0.45)$, and medium effect sizes on total feeding time $(d=-$ $0.60)$ and mean feeding bout durations $(d=-0.53)$ (Figure 1). For mesocarnivores, black bears had large effect sizes on occurrence $(p h i=-0.58)$, total feeding times $(d=-0.89)$, and mean feeding bout durations $(d=-1.17)$ (Figure 1). For small carnivores, black bears had a small effect size on occurrence $(p h i=-0.17)$, a medium effect size on total feeding times $(d=$ $-0.69)$, and a large effect size on mean feeding bout durations $(d=-0.79)$ (Figure 2). For avian scavengers, black bears had a small effect size on occurrence ( $p h i=-0.05)$, a large effect size on total feeding times $(d=-0.82)$, and a medium effect size on mean feeding bout durations $(d=-0.51)$ (Figure 1).

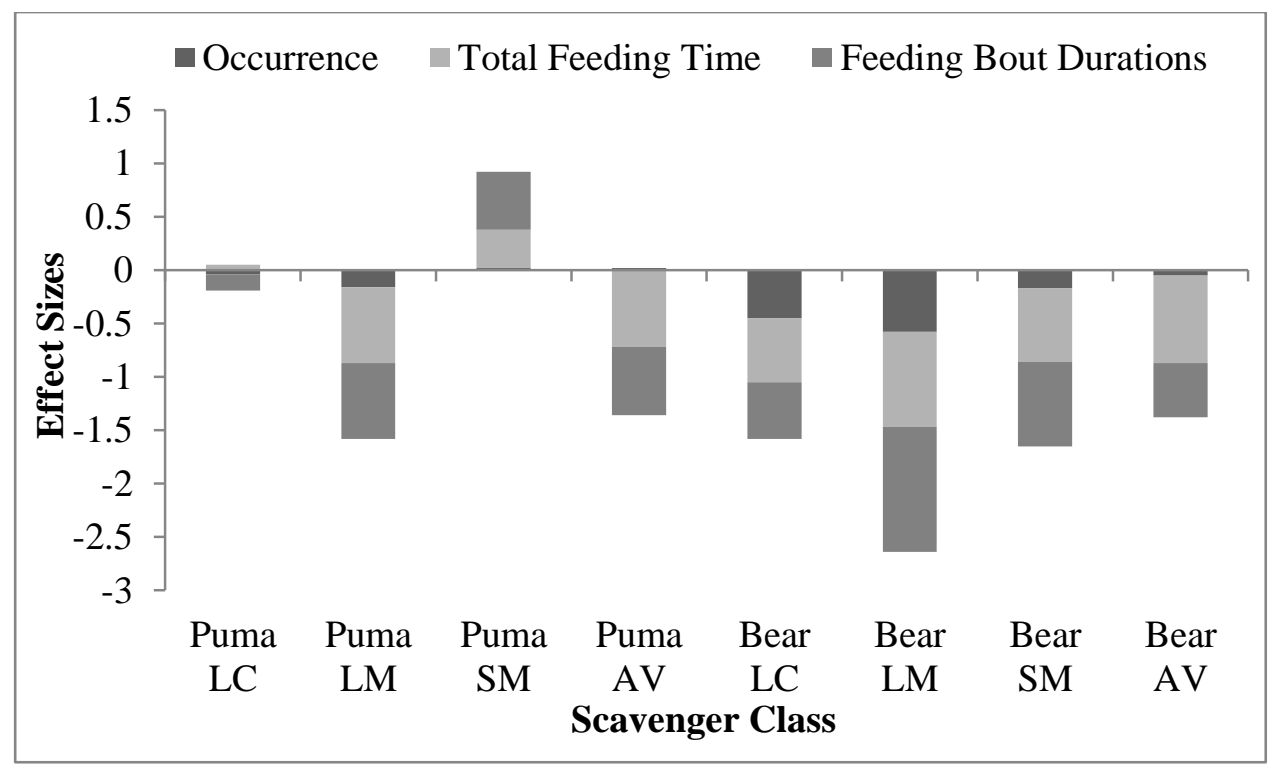

$\mathrm{LC}=$ large carnivore, $\mathrm{MC}=$ mesocarnivore, $\mathrm{SC}=$ small carnivore, $\mathrm{AV}=$ avian

Figure 1. The combined effect sizes on the feeding behaviours of scavenger classes which are attributable to pumas and black bears. I calculated the effect sizes for 3 variables: occurrence ( $p h i$ coefficients), total feeding times (Cohen's $d$ scores), and mean feeding bout durations (Cohen's $d$ scores). 


\section{Effects on Scavenger Species}

At puma kills the acquisition of carrion by 2 scavenger species were strongly limited (Table 2). This included fishers (combined effect sizes -1.54 (phi $=0.07, d_{\text {total time }}=-1.01$, $\left.d_{\text {feeding bout duration }}=-0.60\right)$ ), and domestic dogs $\left(\right.$ combined effect sizes $-1.34\left(p h i=-0.23, d_{\text {total }}\right.$ $\left.\left.{ }_{\text {time }}=-0.51, d_{\text {feeding bout duration }}=-0.60\right)\right)($ Figure 2$)$.

At carcasses where black bears were present the acquisition of carrion by 7 scavenger species were strongly limited (Table 3). Four species had combined effect sizes >2.0 including bobcats $\left(-2.72\left(p h i=-0.38, d_{\text {total time }}=-1.12, d_{\text {feeding bout duration }}=-1.32\right)\right)$, golden eagles $\left(-2.35\left(p h i=-0.01, d_{\text {total time }}=-1.37, d_{\text {feeding bout duration }}=-0.97\right)\right)$, turkey vultures $(-2.05$ $\left.\left(p h i=0.31, d_{\text {total time }}=-1.43, d_{\text {feeding bout duration }}=-0.93\right)\right)$, and gray foxes $(-2.04(p h i=-0.46$, $\left.\left.d_{\text {total time }}=-0.62, d_{\text {feeding bout duration }}=-0.96\right)\right)($ Figure 2$)$. Other species strongly limited by bears included coyotes $\left(-1.59\left(p h i=-0.26, d_{\text {total time }}=-0.83, d_{\text {feeding bout duration }}=-0.50\right)\right)$, domestic dogs $\left(-1.55\left(p h i=-0.25, d_{\text {total time }}=-0.55, d_{\text {feeding bout duration }}=-0.75\right)\right)$, and fisher $(-1.53(p h i=-$ $\left.\left.0.28, d_{\text {total time }}=-0.58, d_{\text {feeding bout duration }}=-0.67\right)\right)($ Figure 2$)$.

\section{Effects of Pumas and Black Bears on Each Other}

Compared to control carcasses, black bears had higher occurrences at puma kills, but the effect attributable to pumas was small ( $p h i=0.11$, Table 2). Black bears, however, had shorter mean feeding bout durations at puma kills, albeit with a small effect size $(d=-0.45$, Table 2). There was no difference in effect between puma kills and control carcasses for total feeding time.

Puma scavenging occurrence were lower at carcasses where black bears were present, with a medium effect size $(p h i=0.26$, occurrence present $=0.0 \%$, occurrence absent $=15.2 \%)$. Because pumas did not scavenge at any carcass where bears were present I could not 
calculate effect sizes for total feeding times $\left(95 \% C I_{a b s e n t}=-25.3-133.0 \mathrm{~min}\right)$ or mean feeding bout durations $\left(95 \% C I_{a b s e n t}=-2.1-24.3 \mathrm{~min}\right)$.
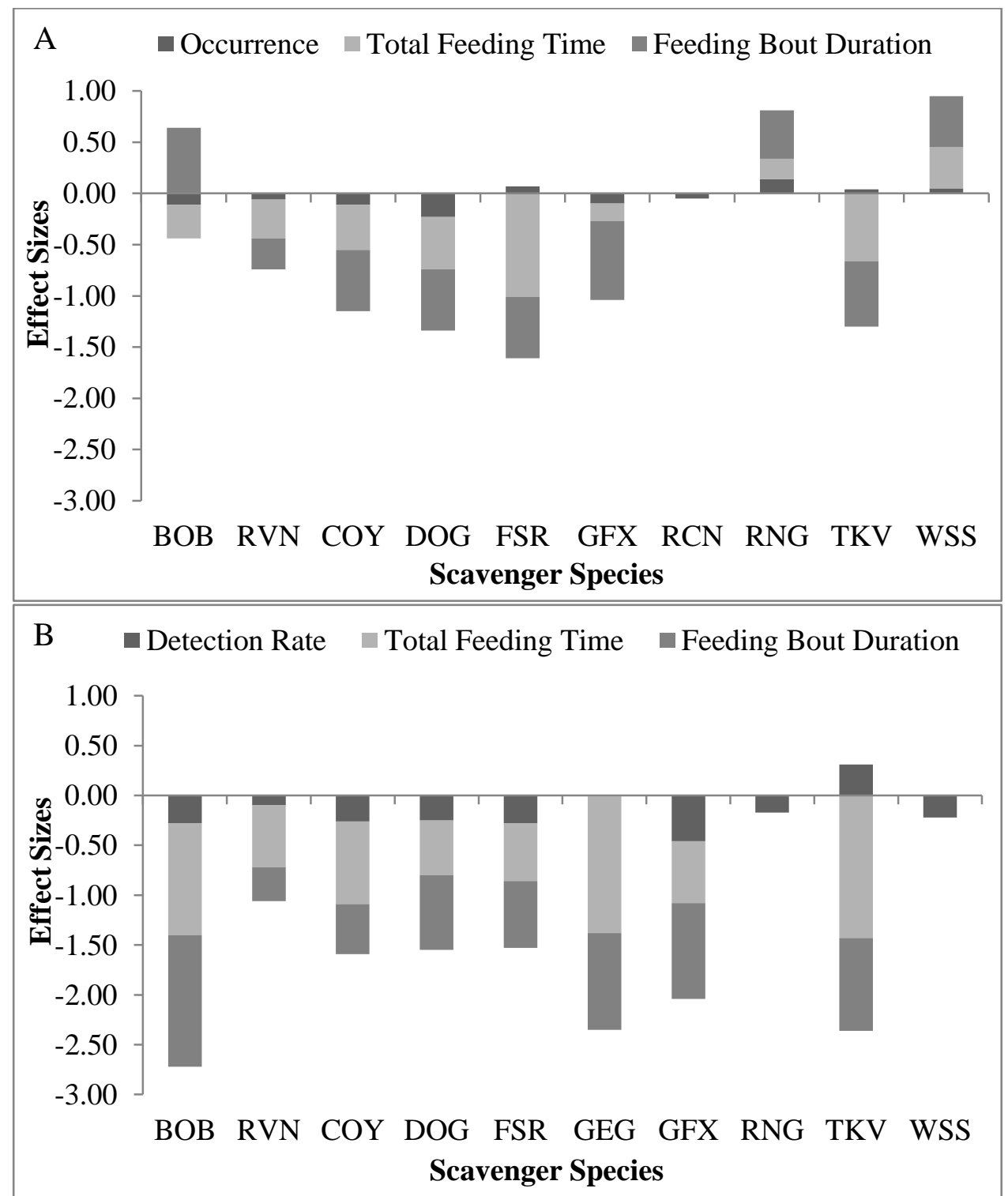

$\mathrm{BOB}=$ bobcat, $\mathrm{RVN}=$ common Raven, $\mathrm{COY}=$ coyote, $\mathrm{DOG}=$ domestic Dog, $\mathrm{FSR}=$ fisher, $\mathrm{GEG}=$ golden Eagle, GFX=gray fox, RNG=ringtail, TKV=turkey vulture, WSS=western spotted skunk

Figure 2. The combined effect sizes of pumas and black bears on scavenger species. Figure 2a represents the effects of pumas for each scavenger class, and $2 b$ represents the effects for black bears. The effect sizes were calculated for significant effects for 3 variables: occurrence, total feeding time, and mean feeding bout duration. 
Puma feeding at their own kills were also affected by black bears. After the arrival of a black bear, pumas did not return to $72.4 \%$ of their kills and only returned for 1 additional visit at another $13.8 \%$ of kills. Black bears fed for a mean of $145.9 \min (95 \% C I=98.5-$ 193.2min) at puma kills, and puma feeding times were limited when pumas did return. When compared to before and after arrival, black bears had a large effect on total feeding times $(d=$ $\left.-0.96,95 \% C I_{\text {after }}=3.3-30.2 \mathrm{~min}, 95 \% C I_{\text {before }}=66.2-146.9 \mathrm{~min}\right)$ and medium effect size on mean feeding bout durations $\left(d=-0.65,95 \% C I_{\text {after }}=0.9-13.7 \mathrm{~min}, 95 \% C I_{\text {before }}=11.5-\right.$ 27.1min). In 1 instance, a puma killed a black bear attempting to usurp their kill.

\section{Discussion}

My results suggest that pumas and black bears had important influences on the scavenger community by influencing the acquisition of carrion of specific scavengers. While pumas limited carrion acquisition by some scavengers at their kills they inadvertently provided many species with substantial energy. In contrast, black bears did not provide any carrion to scavengers, and had a competitive advantage that allowed them to monopolize carrion resources and limit the acquisition of carrion by other scavengers. The influences of pumas and black bears on the energy available from carrion may have effects on the composition of the scavenger community. For example, most species are facultative scavengers to some degree (Wilson and Wolkovich 2011), and in some food webs there is a greater amount of energy transferred through the scavenging of carrion than through direct predation (Wilson and Wolkovich 2011). How large carnivores influenced the feeding behaviors of specific scavengers directly influenced their energy intake, and therefore may influence the populations and composition of facultative scavengers in ecological communities. 
My broad-scale analyses of scavenger classes revealed an interesting cascading pattern in the interactions of pumas with scavengers of different sizes. Pumas limited all 3 aspects of carrion acquisition by mesocarnivores, and by doing so apparently increased the ability of small carnivores to feed, as small carnivores increased all 3 aspects of carrion acquisition at puma kills. Since energy intake of scavengers from carrion can influence fitness and reproductive ability (e.g. Watson et al. 1992, Angerbjorn et al. 1991), these interactions with pumas may affect the population dynamics of scavengers. My results therefore suggest that large carnivores may limit mesocarnivores through direct predation (Prugh et al. 2009) and by restricting their acquisition of carrion. This cascading pattern also provides an alternate explanation for observed trophic cascades among carnivores (Levi and Wilmers 2013), suggesting that the cascading patterns initiated by large carnivores on the populations of smaller carnivores are the outcome of how large carnivores influence their acquisition of carrion.

The effects attributable to black bears were less intricate and of a higher magnitude than those of pumas. Black bears monopolized carrion resources they found, and limited all 3 aspects of carrion acquisition for every scavenger class, and for nearly every scavenger species (the occurrence of turkey vultures increased, while black bears completely excluded ringtails and spotted skunks). This suggests black bears are an important source of limitation of other scavengers, and the magnitude of their effects suggests that black bears act as a major limitation of energy concerning carrion resources in the ecological community. Other dominant scavengers also monopolize the available carrion resources (Cortez-Avizanda et al. 2012), and it is important to understand the influences dominant scavengers have on the populations of other facultative scavengers and their effects on ecosystem processes. 
Black bears also affected pumas at their kills. This supports the growing body of evidence that solitary felids are negatively affected by dominant scavengers which can usurp their kills (Hunter et al. 2006, Krofel and Kos 2010, Krofel et al. 2012, Elbroch and Wittmer 2013b, Allen et al. 2013, Chapter 5). Pumas abandoned 72.4\% of their kills once black bears arrived, a similar behaviour to cheetahs (Acinonyx jubatus), which limit risk by abandoning their kills after the arrival of dominant scavengers (Hunter et al. 2006). This limits the energetic intake of pumas, and could force pumas to kill more often to satisfy energetic requirements (Krofel and Kos 2010, Krofel et al. 2012, Elbroch and Wittmer 2013b, Chapter 5) or negatively influence their breeding success (Krofel et al. 2012). Facultative scavengers are generally not believed to affect population dynamics of species they are consuming during scavenging (Wilson and Wolkovich 2011). However, if black bears are causing pumas to increase their kill rates, they are also indirectly affecting prey populations, and could have wider repercussions for the ecological community (sensu Elbroch and Wittmer 2013b). Pumas and black bears clearly have important but different effects on the acquisition of carrion by scavengers. Pumas apparently created a cascading pattern in the energy available from carrion to scavenger classes, and were also a source of carrion for scavengers among different trophic levels. The influences on how energy is distributed may be keystone effects (e.g., Elbroch and Wittmer 2012a), and, therefore, changes in puma populations may have important effects on the ecological community. In contrast, black bears were a dominant scavenger that greatly limited the ability of all other scavengers to take advantage of carrion resources, and also influenced pumas at their own kills. This suggests that black bears have direct effects on the scavenger community, and could have important indirect effects on other aspects of the ecological community, including ungulate populations. My study highlights how the complexity of competition among scavengers influences the structure and dynamics of ecological communities. 


\section{Chapter 8}

\section{General Discussion}

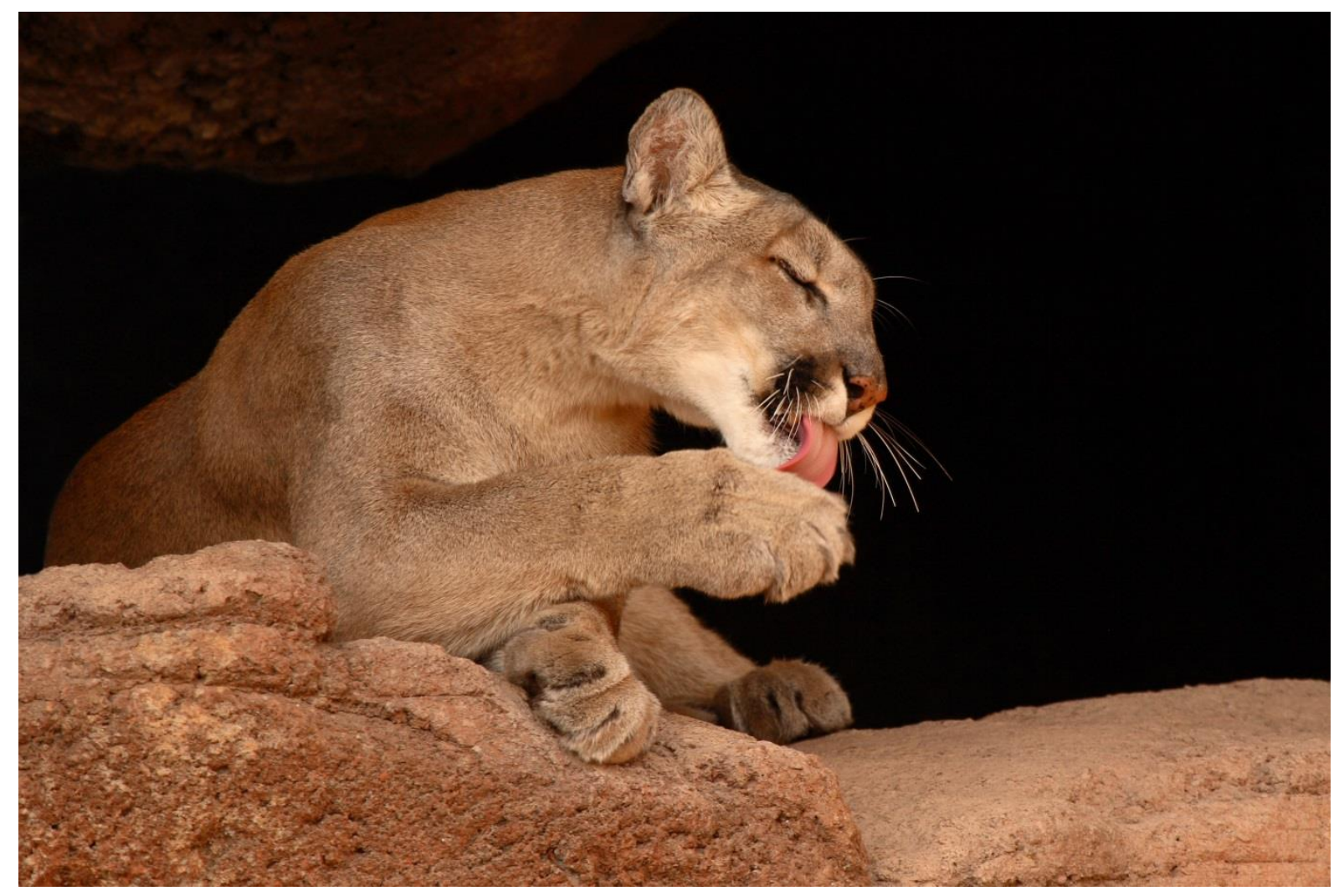




\section{Introduction}

In order to understand the function of an ecological system, it is necessary to understand broad influences like climate change, and narrower influences such as species specific effects on ecological communities. It is well established that large carnivores influence the composition and stability of ecological communities (Estes and Palmisano 1974, Ripple et al. 2014). However, the exact effects of large carnivores can be difficult to predict (Ripple et al. 2001, Prugh et al. 2009), as the effects of large carnivores are influenced by their population densities and those of their prey. In addition, because the ecological niches of large carnivore species are unique and do not necessarily overlap, each large carnivore has species specific effects (Ripple et al. 2014). Therefore, in order to gain insight into the influences of large carnivores it is necessary to gain a mechanistic understanding of interactions specific large carnivores have with their ecological community.

In my dissertation I made new contributions to puma (Puma concolor) ecology through studying their intra- and inter-specific interactions in a natural system. Because pumas are the most widely-distributed carnivore in the western hemisphere (Sunquist and Sunquist 2002), they are an important species for understanding the role of large carnivores in shaping ecological communities. My findings support the previous suggestions that as a large carnivore, pumas are keystone species (i.e. a species which has larger effects on ecosystems than expected based on their relative abundance, Power et al. 1996) for their respective ecological communities, with important direct and indirect effects from predation. Intraspecific interactions determine population size and density, and ultimately influence local adaptations of pumas to their environment. Interspecific interactions determine how pumas influence and are influenced by their ecology community. Through the mechanistic approach of my research of the intra- and inter-specific interactions of pumas I contribute to 
our knowledge of how large carnivores influence the composition and function of ecological communities.

By studying pumas in a system with a single ungulate prey, I was able to discern direct effects of pumas on prey, as well as the effects of prey and competitors on pumas. For example, I was able to determine kill rates and handling times of black-tailed deer (Chapters $4 \& 5$ ) and how they change among seasons (Chapter 5). This would have been more complicated in a system with multiple prey of varying sizes, as pumas would likely have longer handling times of larger prey (Ruth and Murphy 2010a), which in turn would influence their search time and hence kill rate (Holling 1959). In addition, I was able to determine how pumas adjust to behaviours of their prey (e.g. following elevational migrations, Chapter 5), and also how pumas are influenced by scavengers (reduced handling times due to kills being usurped by black bears, Chapters $5 \& 7$ ).

Pumas are, of course, cryptic and difficult to study, and the technology and field methodologies I used to overcome these limitations were important aspects of my dissertation. I found ARGOS satellite collars and motion-triggered video cameras to be very useful tools, but both technologies had shortcomings. By using ARGOS satellite collars I was able to make real-time investigations, which allowed me to document more small prey items than in many previous studies, and also to locate black-tailed deer carcasses while pumas were still feeding on them. However, the intensive GPS point collection meant that batteries died in 7 months, which necessitated frequent recaptures of pumas to replace batteries. In addition, the satellite downloads rarely worked as advertised; often transmitting half of the GPS points or missing downloads entirely. The use of motion-triggered video cameras allowed me to document and analyse previously under-studied aspects of puma communication behaviours and interactions with scavengers. However, I had to make the 
assumption that they were accurately triggering upon motion, and that they were accurately recording what was occurring at deer carcasses and community scrapes.

\section{The Importance of Intraspecific Interactions}

Male and female pumas vary in many aspects of their behaviour and life history. For example, they exhibit differences in territorial behaviour (Logan and Sweanor 2001, Logan and Sweanor 2010), kill rates and prey selection (Knopff et al. 2010, Elbroch and Wittmer 2013a), and home range size (Logan and Sweanor 2001, Grigione et al. 2002). The findings of my dissertation suggest that male and female pumas also use communication behaviours differently. For example, males and females varied in their display of communication behaviours (Chapter 2); and males spent longer durations on producing behaviours while females spent longer durations on consuming behaviours (Chapter 2). Males were also more frequent visitors to community scrapes, while females were irregular visitors whose visitation was apparently correlated with oestrus (Logan and Sweanor 2001, Chapter 3). These findings suggest that male reproductive strategy is based on advertisement for possible mates, while female reproductive strategy is based on assessment of potential mates.

An important aspect of female puma behaviour is the raising of young, including selecting mates that offer the best fitness to their offspring. Surprisingly, I documented that females are sometimes polyandrous (Chapter 3), and this is probably an adaptive response to confuse paternity and avoid infanticide by resident males. Infanticide by males is an important cause of mortality for puma cubs (Logan and Sweanor 2001), and females avoid male pumas while raising young, including limiting visitation to community scrapes, while raising young. When females did visit community scrapes, it was apparently in order to assess and select a mate. My results suggest that mate selection by females was complex and based on multiple cues, including male visitation, behaviours, and ornamentation (Chapter 3). 
However, it is possible that males are using competition and/or dishonest signals to increase their chances of reproduction despite their limitations to their fitness. For example, smaller males may patrol a smaller home range and visit community scrapes more frequently in order to appear as a dominant male. An area for future research is to determine if female pumas are selecting the mate with best chance of increasing fitness for offspring.

A male puma's ability to visit community scrapes and advertise for mates is dependent on other aspects of their ecology. For example, their ability to kill quickly reduces their search time for prey and may allow more frequent visitation, while a large home range size allows access to more potential mates. My analyses suggested that the two most important criteria for being selected by a female were visitation to community scrapes and weight (Chapter 3), but these two traits are also linked. For example larger males are more likely to win fights with a competitor, which is probably the main adaptive advantage of larger size, but large males will also be able to maintain large territories and possibly have higher visitation rates. In addition, male visitation and behaviours were influenced by potential mates and competitors (Chapter 3), but males exhibited larger responses in visitation and behaviours to recent visitation by females than to males, and also exhibited seasonal patterns in visitation which correlate with visitation by females (Chapter 3). This suggests that potential mates are a stronger driver of male visitation and behaviours at community scrapes than competitors, and potential mates may also be the main source of adaptation in male pumas.

The communication behaviours and intraspecific interactions of pumas are likely to have influences on other species in their ecological communities. The spatially dispersed population structure of pumas necessitates indirect intraspecific communication through scent-marking, and other species may also be using these cues. For example, pumas provision scavengers with carrion energy from their kills (Chapters $6 \& 7$ ), and scavengers 
may use scent-marks to follow pumas to their kills in order to increase their energetic intake. In addition, many species are known to shift their behaviour to avoid predation from large carnivores (Brown et al. 1999, Ripple and Beschta 2004), and other species may use puma scent-marks in order to avoid pumas and the risk of predation.

My chapters on communication are a foundation for future research about puma communication. My finding that female pumas are sometimes polyandrous was an important novel finding, and future research could focus on the benefits of polyandrous behaviour, and the adaptations it may cause among male pumas. In addition, a study with a larger sample size could more clearly elucidate the traits selected for in mates by individual pumas, and how male pumas strategically use behaviours to increase their chances of reproductive success. The importance of community scrapes highlights the need to understand how these sites are selected, including if they are selected using different scales of behaviour or specific habitat features. Research should also focus on how puma communication behaviours and population densities are influenced by habitat fragmentation.

\section{The Influence of Pumas on Other Species}

Predation is one of the most-studied subjects for pumas, because researchers have traditionally been interested in how pumas affect ungulate game species, and the direct effects pumas have on their ecological community are thought to be predominantly based on their predation (Ruth and Murphy 2010a). In my Mendocino study area, pumas focused their predation upon black-tailed deer, and predation by pumas was apparently the main source of mortality for adult female deer. Black-tailed deer constituted $98.6 \%$ of the mass killed by pumas (Chapter 4), and the high kill rates exhibited (mean $=1.07$ ungulates/week, and mean $=5.78 \mathrm{~kg} / \mathrm{day}$, Chapter 4) were a top-down pressure on the black-tailed deer population. An important influence carnivores have on ungulate populations is through killing young animals 
and thus negatively affecting recruitment (Begon et al. 2006). However, my data indicate that pumas displayed little predation on neonatal fawns (Chapter 4), and therefore it is possible that other carnivores in the system which focus their predation on the more vulnerable neonatal fawns (e.g. black bears, Ursus americanus, and coyotes, Canis latrans) could be having a larger impact on the population of black-tailed deer than pumas.

In my dissertation, I demonstrated that the provisioning of scavengers is a key indirect effect of puma predation. For example, pumas were a source of carrion energy for scavengers (Chapter 7), and also apparently created a cascading influence on the feeding behaviours of scavengers at their kills (Chapter 7). Pumas also made carrion more predictable (Chapter 6), which may allow scavengers to exploit the limited available carrion resources, and pumas may also cause carrion resources to be more predictable at temporal and spatial scales. For example, pumas provisions scavengers with carrion throughout the year (Chapter 6), and because pumas follow the elevational migration of deer (Chapter 5), the elevation at which carrion is available in a given season should also be more predictable. The provisioning of scavengers and increased predictability of carrion likely leads to increased fitness and breeding success of scavengers, and may have population level effects for scavengers.

The risk of predation from large carnivores is known to cause changes in the behaviour of other species (Brown et al. 1999, Ripple and Beschta 2004). My findings suggest that large carnivores could be an important source of adaptation and development of behaviours for scavengers (Chapter 6), both to increase their acquisition of carrion and to minimize their risk of injury or mortality. This raises the question if scavengers have different strategies and behaviours to exploit the carrion resources created by social and solitary large carnivores. In Africa, pack size in African lions (Panthera leo) and spotted hyenas (Crocuta crocuta) have been linked to the ability to kill prey and defend carrion from scavengers (Cooper 1991, Honer et al. 2002). In North America scavengers apparently benefit from both 
social and solitary carnivores (Wilmers et al. 2003a, Chapter 7), but research is needed in North America to understand the differences in behaviours for carrion defence between social and solitary carnivores, and how this influences the acquisition of carrion by scavengers.

The results of my dissertation suggest that pumas may be a keystone species for the scavenger community (Chapters $6 \& 7$ ), which is an important subset of the ecological community. Moquet et al. (2012) recently speculated that some ecological communities act as keystone communities within meta-communities. The scavenger community have important influences on herbivores, vegetation and decomposers through predation and the cycling of carrion nutrients (DeVault et al. 2003, Wilson and Wilkovich 2011). In addition, in many ecological communities there is more energy transferred through scavenging than predation (Wilson and Wilkovich 2011). The scavenger community therefore has extensive influence on nutrient flow and food webs, and for these reasons I speculate that the scavenger community could be a keystone community.

\section{The Influence of Other Species on Pumas}

The top-down pressures that pumas exert on their local environment do not exist in a vacuum, and are instead influenced by other species in their ecological community. This is exhibited by pumas displaying variation in feeding ecology across their range (Ross et al. 1997, Ruth and Murphy 2010a), with the variations likely to be adaptations to the selective pressures from the local environment. In my study, pumas were influenced by the behaviour and annual cycles of both their main prey (black-tailed deer, Chapters $4 \& 5$ ) and competitors (black bears, Chapters $5 \& 7$ ). Other species also have the potential to influence pumas, whether it is smaller prey species in the local environment that may influence seasonal prey selection, or the losses to scavengers other than black bears, or interactions with other large carnivores. 
I documented that black-tailed deer had direct effects on pumas through their use of elevational migration and their birth pulse. The elevations at which pumas killed black-tailed deer correlated significantly with elevations used seasonally by black-tailed deer (Chapter 5). This suggests that pumas exhibited a seasonal shift in their foraging behaviour to follow their migrating prey to the elevations where they were most abundant. Pumas also apparently exhibited a functional response to the increase of prey abundance and density due to the birth pulse exhibited by black-tailed deer by increasing their kill rate (Chapter 5). This finding was made possible by my real-time investigations, which allowed me to document more frequent predation of fawns than in most previous studies (Murphy and Ruth 2010). However, I did not find that pumas preyed upon sedentary neonatal fawns, and instead preyed upon older fawns (Chapter 5). This could have been a limitation of my methods, as cases where pumas fed for less than 8 hours could have led to an underestimation of predation on neonatal fawns.

The influence of black bears on pumas has the potential to be one of the most important ecological results of my dissertation. I found that kill rates increased substantially in seasons when bears were present (196\% higher in summer than winter, Chapter 5), and seasonal kill rates were inversely correlated with handling times of adult deer. In Chapter 5, I speculated that was due to the usurpation of carcasses, and in Chapter 7 I documented that black bears caused a high rate of kill abandonment (72.4\%) by pumas (Chapter 7$)$. This supports my previous speculation and suggests there is a strong correlation between usurpation of kills by black bears and increases in puma kill rates. The black bear population in the study area was a high density (96\% occupancy, T. Forrester unpublished data), however, because black bears have the highest population of large carnivores in North America (Ripple et al. 2014), and therefore they may have similar effects across their range. These findings could have wide repercussions for the management of ungulates and understanding the effects of large carnivore predation. For example, losses to black bears 
could influence puma breeding success and density, and if black bears cause increases in puma kill rates this could also influence ungulate populations.

Large carnivores are difficult to census (Gompper et al. 2006, Long et al. 2008), and accurate census methods for large carnivore populations is a major area in need of further research. Among large carnivores, pumas are a particularly difficult species to census (Cougar Management Working Group 2005, Choate et al. 2006), but my findings in Chapter 2 have potential applications for creating an accurate census of puma populations. First, my success in monitoring pumas at community scrapes suggest monitoring in these locations may increase the likelihood of detection, and second my experiments suggest that developing methods using visual cues will be more effective than methods using olfactory cues.

The interactions between large carnivores and how they influence ecological communities is a subject which needs further research. For example, research should focus on whether black bears influence puma density and/or kill rates, and in turn, how this influences prey populations and the composition of ecological communities. In addition, pumas are also apparently influenced by other large carnivores which are sympatric in some parts of their range, including gray wolves (Canis lupus), grizzly bears (Ursus horriblis), and jaguars (Panthera onca) (Atwood et al. 2007, Ruth and Murphy 2010b). An important limitation in my findings is that this was only studied in one area with a particular subset of large carnivores and scavengers. A larger comparison across study areas with and without large carnivores, including pumas and black bears, and with variable scavenger communities would be valuable.

\section{Conclusions}

Overall, my research highlights the importance of understanding intra- and interspecific interactions of large carnivores when attempting to understand their effects on 
ecological communities. A good example of why mechanistic views are important is looking at the relatively simple calculation of puma kill rates. Kill rates are important because they can have a direct influence on prey species (in my study black-tailed deer). However, kill rates also influence the ability of male pumas to find mates, and influence the ability of female pumas to successfully raise young. Puma kill rates are also influenced by their prey, for example, pumas need to follow migrating black-tailed deer to where they are most abundant, and are also influenced by changes in prey density and abundance. In addition, puma kill rates are influenced by competitors, and kill rates increase substantially in response to competition with black bears. This suggests that we cannot just simply calculate kill rates, or other aspects of puma ecology, but instead need to understand the underlying behaviours and mechanisms that determine puma ecology.

In summary, Chapters $2 \& 3$ are among the first published studies on puma scrape behaviour and mate selection. My findings provide an understanding of the function of variation among sex and age classes in the communication strategies used by pumas. They also provide a mechanistic view of how male pumas try to increase their reproductive success and the traits female pumas select in mates. Chapters $4 \& 5$ contribute to understanding puma predation and how pumas influence and are influenced by their local environment. My findings of puma feeding ecology provide novel insights into seasonal variation and hunting behaviour, and suggest that pumas are influenced substantially by their local environment. Chapters $6 \& 7$ focus on the interactions of large carnivores with scavengers and contribute to our understanding the influences large carnivores have on the scavenger community. My findings suggest that pumas can affect scavengers both positively and negatively, and the keystone effects of pumas on the scavenger community became apparent through comparisons with black bears, which had larger limitations on scavenger behaviours than pumas. 
In conclusion, in my dissertation I provided a mechanistic understanding of the intraand inter-specific interactions of pumas with their ecological communities, and through this provided novel findings and an increased understanding of puma behaviour and ecology. Together, my chapters provide a mechanistic understanding for how these interactions influence pumas and how pumas influence their respective ecological communities. My dissertation provides a foundation for future research in many areas, including the study of intra- and inter-specific interactions of large carnivores, puma communication behaviours, and how large carnivores influence the composition and function of ecological communities. 


\section{Literature Cited}

Allen, M.L., L.M. Elbroch, D.S. Casady, and H.U. Wittmer. 2014. Seasonal variation in the feeding ecology of pumas (Puma concolor) in northern California. Canadian Journal of Zoology 92: 397-403.

Allen, M.L., L.M. Elbroch, C.C. Wilmers, and H.U. Wittmer. 2014. Trophic facilitation or limitation? Comparative effects of pumas and black bears on the scavenger community. PLoS One.

Allen, M.L., L.M. Elbroch, and H.U. Wittmer. 2013. Encounter competition between a cougar, Puma concolor, and a western spotted skunk, Spilogale gracilis. Canadian Field-Naturalist 127: 64-66.

Allen, M.L., H.U. Wittmer, and C.C. Wilmers. 2014. Puma scrape and communication behaviors: Understanding functional use and variation by sex and age. Behaviour 151: 819-840.

Altendorf, K.B., J.W. Laundré, C.A. Lopez, and J.S. Brown. 2001. Effects of predation on foraging of mule deer. Journal of Mammalogy 82: 430-439.

Anderson, C.R. Jr., and F. Lindzey. 2003. Estimating cougar predation rates from GPS location clusters. Journal of Wildlife Management 67: 307-316.

Anderson, C.R. Jr., F. Lindzey, K.H. Knopff, M.G. Jalkotzy, and M.S. Boyce. 2010. Cougar management in North America. In Cougar: ecology and conservation, edited by M. Hornocker and S. Negri. University of Chicago Press, Chicago: 41-56.

Andersson, M., and L.W. Simmons. 2006. Sexual selection and mate choice. Trends in Ecology and Evolution 21: 296-302.

Angerbjorn, A., B. Arvidson, E. Noren, and L. Stromgren. 1991. The effect of winter food on reproduction in the arctic fox. Journal of Animal Ecology 60: 705-714. 
Apps, C.D., B.N. McLellan, T.A. Kinley, R. Serrouya, D.R. Seip, and H.U. Wittmer. 2013. Spatial factors related to mortality and population decline of endangered mountain caribou. Journal of Wildlife Management 77: 1409-1419.

Ashman, D. G.C. Christensen, M.L. Hess, G.K. Tsukamoto, and M.S. Wickersham. 1983. The mountain lion in Nevada. Nevada Game and Fish Department, final report for project W-48-15.

Atmar, W., and B.D. Paterson. 1993. The measure of order and disorder in the distribution of species in fragmented habitats. Oecologia 96: 373-382.

Atwood, T.C., E.M. Gese, and K.E. Kunkel. 2007. Comparative patterns of predation by cougars and recolonizing wolves in Montana's Madison Range. Journal of Wildlife Management 71: 1098-1106.

Bacon, M.M., G.M. Becic, M.T. Epp, and M.S. Boyce. 2011. Do GPS clusters really work? Carnivore diet from scat analysis and GPS telemetry methods. Wildlife Society Bulletin 35: 409-415.

Bailey, T.N. 1974. Social organization in a bobcat population. Journal of Wildlife Management 38: 435-446.

Bailey, T.N. 1993. The African leopard: ecology and behavior of a solitary felid. The Blackburn Press: Caldwell, NJ.

Balme, G.A., A. Batchelor, N. De Woronin Britz, G. Seymour, M. Grover, L. Hes Po, D.W. MacDonald, and L.T.B. Hunter. 2013. Mammal Review 43: 221-237.

Balme, G.A., and L.T.B. Hunter. 2013. Why do leopards commit infanticide? Animal Behaviour 86: 791-799.

Barton, P.S., S.A. Cunningham, D.B. Lindenmayer, and A.D. Manning. 2013. The role of carrion in maintaining biodiversity and ecological processes in terrestrial ecosystems. Oecologia 171: 761-772. 
Bates, D., M. Maechler, and B. Bolker. 2013. lme4: Linear mixed-effects models using S4 classes. R package version 0.999999-2. http://CRAN.R-project.org/package=lme4.

Begon, M., C.R. Townsend, and J.L. Harper. 2006. Ecology: from individuals to ecosystems. Wiley-Blackwell, Boston.

Beier, P. 1991. Cougar attacks on humans in the United States and Canada, 1890-1990. Wildlife Society Bulletin 19: 403-412.

Beier, P. 1993. Determining minimum habitat areas and habitat corridors for cougars. Conservation Biology 7: 94-108.

Beier, P. 1995. Dispersal of juvenile cougars in fragmented habitat. Journal of Wildlife Management 59: 228-237.

Beier, P. 2010. A focal species for conservation planning. In Cougar: ecology and conservation, edited by M. Hornocker and S. Negri. University of Chicago Press, Chicago: $177-189$.

Bischoff-Mattson, Z., and D. Mattson. 2009. Effects of simulated mountain lion caching on decomposition of ungulate carcasses. Western North American Naturalist 69: 343350.

Bivand, R.S., E.J. Pebesma, and V. Gomez-Rubio. 2008. Applied spatial data analysis with R. Springer, NY. http://www.asdar-book.org/.

Blazquez , M., J.A. Sanchez-Zapata, F. Botella, M. Carrete, and S Egura. 2009. Spatiotemporal segregation of facultative avian scavengers at ungulate carcasses. Acta Oecologica 35: 645-650.

Bolnick D.I., R. Svanback, J.A. Fordyce, J.A. L.H. Yang, J.M. Davis, C.D. Hulsey, and M.L. Forister. 2003. The ecology of individuals: incidence and implications of individual specialization. American Naturalist 161: 1-28. 
Borer, E.T., and D.S. Gruner. 2009. Top-down and bottom-up regulation of communities. In The Princeton Guide to Ecology, edited by S.A. Levin. Princeton University Press, Princeton, NJ: 296-305.

Branton, M. and J.S. Richardson. 2010. Assessing the value of the umbrella-species concept for conservation planning with meta-analysis. Conservation Biology 25: 9-20.

Breed, M.D., and J. Moore. 2011. Animal behavior. Academic Press, San Diego, CA.

Brown, J.S., J.W. Laundré, and M. Gurung. 1999. The ecology of fear: optimal foraging, game theory, and trophic interactions. Journal of Mammalogy 80: 385-399.

Bruskotter, J.T, and L.B. Shelby. 2010. Human dimensions of large carnivore management and conservation: introduction to the special issue. Human Dimensions of Wildlife 15: $311-314$.

Calenge, C. 2006. The package adehabitat for the R software: a tool for the analysis of space and habitat use by animals. Ecological Modelling 197: 516-519.

Candolin, U. 2003. The use of multiple cues in mate choice. Biological Reviews 78: 575595.

Caro, T.M. 1999. The behaviour-conservation interface. Trends in Ecology and Evolution 14: $366-369$.

Caro, T.M. 2003. Umbrella species: critique and lessons from East Africa. Animal Conservation 6:171-181.

Casady, D.S., and M.L. Allen. 2013. Handling adjustments to reduce chemical capturerelated mortality in black-tailed deer. California Fish and Game 99: 104-109.

Choate, D.M., M.L. Wolfe, and D.C. Stoner. 2006. Evaluation of Cougar Population Estimators in Utah. Wildlife Society Bulletin 34: 782-799.

Cohen, J. 1992. A power primer. Psychological Bulletin 112: 155-159. 
Cooley, H.S., H.S. Robinson, R.B. Wielgus, and C.S. Lambert. Cougar prey selection in a white-tailed deer and mule deer community. 2008. Journal of Wildlife Management 72: $99-106$.

Cooper, S.M. 1991. Optimal hunting group size: the need for lions to defend their kills against loss to spotted hyenas. African Journal of Ecology 29: 130-136.

Cortes-Avizanda, A., N. Selva, M. Carrete, and J.A. Donazar. 2009. Effects of carrion resources on herbivore spatial distribution are mediated by facultative scavengers. Basic and Applied Ecology 10: 265-272.

Cougar Management Working Group. 2005. Cougar management guidelines. Wild Futures: Bainbridge, WA.

Courchamp, F., M. Langlais, and G. Sugihara. 1999. Cats protecting birds: modelling the mesopredator release effect. Journal of Animal Ecology 68: 282-292.

Croll, D.A., J.L. Maron, J.A. Estes, E.M. Danner, and G.V. Byrd. 2005. Introduced predators transform subarctic islands from grassland to tundra. Science 307: 1959-1961.

Crooks, K.R. 2002. Relative sensitivities of mammalian carnivores to habitat fragmentation. Conservation Biology 16: 488-502.

Culver, M. 2010. Lessons and insights from evolution, taxonomy, and conservation genetics. In Cougar: ecology and conservation, edited by M. Hornocker and S. Negri. University of Chicago Press, Chicago: 27-40.

Currier, M.J.P. 1983. Felis concolor. Mammalian Species 200: 1-7.

Darwin, C. 1859. On the origin of species by means of natural selection. John Murray: London.

Davies, N.B., J.R. Krebs, and S.A. West. 2012. An introduction to behavioural ecology. Wiley-Blackwell, Boston. 
de Boer J.N. 1977 The age of olfactory cues functioning in chemocommunication among male domestic cats. Behavioural Processes 2: 209-225.

DeVault, T.L., O.E. Rhodes, Jr., and J.A. Shivik. 2003. Scavenging by vertebrates: behavioral, ecological, and evolutionary perspectives on an important energy transfer pathway in terrestrial ecosystems. Oikos 102: 225-234.

Elbroch, L.M. 2003. Mammal tracks and sign: a guide to North American species. Stackpole Books, Mechanicsburg, PA.

Elbroch, L.M., P.E. Lendrum, J. Newby, H. Quigley, and D. Craighead. 2014. Seasonal foraging ecology of non-migratory cougars in a system with migrating prey. PLoS One 8: e83375.

Elbroch, L.M., T.H. Mwampamba, M. Zylberberg, M.J. Santos, L. Liebengerg, J. Minyer, C. Mosser, and E. Reddy. 2011. The value, limitations, and challenges of employing local experts in conservation research. Conservation Biology 25: 1195-1202.

Elbroch, L.M., and H.U. Wittmer. 2012a. Puma spatial ecology in open habitats with aggregate prey. Mammalian Biology 77: 377-384.

Elbroch, L. M., and H. U. Wittmer. 2012b. Table scraps: inter-trophic provisioning by pumas in Patagonia. Biology Letters 8: 776-779.

Elbroch, L.M., and H.U. Wittmer. 2013a. The effects of puma prey selection and specialization on less abundant prey in Patagonia. Journal of Mammalogy 94: 259268.

Elbroch, L. M., and H. U. Wittmer. 2013b. Nuisance ecology: do scavenging condors exact foraging costs on pumas in Patagonia? PLoS ONE 8: e53595.

Enquist, M., and O. Leimar. 1990. The evolution of fatal fighting. Animal Behaviour 39: 1-9.

Estes, J.A. 1996. Predators and ecosystem management. Wildlife Society Bulletin 24: 390396. 
Estes, J.A., and J.F. Palmisano. 1974. Sea otters: their role in structuring nearshore communities. Science 185: 1058-1060.

Estes, J.A., M.L. Riedman, M.M. Staedler, M.T. tinker, and B.E. Lyon. 2003. Individual variation in prey selection by sea otters: patterns, causes and implications. Journal of Animal Ecology 72: 144-155.

Estes, R.D. 1976. The significance of breeding synchrony in the wildebeest. East African Wildlife Journal 14: 135-152.

Forrester, T.D., and H.U. Wittmer. 2013. A review of the population dynamics of mule deer and black-tailed deer Odocoileus hemionus in North America. Mammal Review 43: 292-308.

Fox, J., and S. Weisberg. 2011. An R companion to applied regression. Sage Publications: 472 pages.

Fryxell, J.M., and A.R.E. Sinclair. 1988. Causes and consequences of migration by large herbivores. Trends in Ecology and Evolution 3: 237-241.Gibson, R.M., and T.A. Langen. 1996. How do animals choose their mates? Trends in Ecology and Evolution 11: $468-470$.

Gill, R.B. 2010. To save a mountain lion: evolving philosophy of nature and cougars. In Cougar: ecology and conservation, edited by M. Hornocker and S. Negri. University of Chicago Press, Chicago: 5-16.

Gompper, M.E., R.W. Kays, J.C. Ray, S.D. Lapoint, D.A. Bogan, and J.R. Cryan. 2006. A comparison of non-invasive techniques to survey carnivore communities in northeastern North America. Wildlife Society Bulletin 34: 1142-1151.

Griffin, K.A., M. Hebblewhite, P. Zager, P., H.R. Robinson, S. Barber-Meyer, D. Christianson, S. Creel, N.C. Harris, M.A. Hurley, D.H. Jackson, B.K. Johnson, L.D. Mech, W.L. Myers, J.D. Raithel, M. Schlegel, B.L. Smith, C. White, and P.J. White. 
2011. Neonatal mortality of elk driven by climate, predator phenology and predator diversity. Journal of Animal Ecology 80: 1246-1257.

Grigione, M.M., P. Beier, R.A. Hopkins, D. Neal, W.D. Padley, C.M. Schonewald, and M.L. Johnson. 2002. Ecological and allometric determinants of home-range size for mountain lions (Puma concolor). Animal Conservation 5: 317-324.

Guimaraes, P. R., P. Guimaraes. 2006. Improving the analyses of nestedness for large sets of matrices. Environmental Modelling and Software. 21: 1512-1513.

Gunderson, H.L.1996. Mammalogy. McGraw-Hill, New York.

Hairston, N.G., F.E. Smith, and L.B. Slobodkin. 1960. Community structure, population control, and competition. American Naturalist 94:421-425.

Harmsen, B.J., R.J. Foster, S.M. Gutierrez, S.Y. Marin, and C.P. Doncaster. 2010. Scrapemarking behaviour of jaguars (Panthera onca) and pumas (Puma concolor). Journal of Mammalogy 91: 1225-1234.

Harrell, F.E. Jr. 2013. rms: regression modeling strategies. R package version 4.1-0. http://CRAN.R-project.org/package-rms.

Hebblewhite, M., and E.H. Merrill. 2007. Multiscale wolf predation risk for elk: does migration reduce risk? Oecologia 152: 377-387.

Heffelfinger, J. 2010. Age criteria for Southwestern game animals. Arizona Game and Fish Department Special Report \#19, 40 pages.

Holling, C.S. 1959. The components of predation as revealed by a study of small mammal predation of the European pine sawfly. Canadian Entomologist 91: 293-320.

Honer, O.P., B. Wachter, M.L. East, and H. Hofer. 2002. The response of spotted hyenas to long-term changes in prey populations: functional response and interspecific kleptoparasitism. Journal of Animal Ecology 71: 236-246. 
Hoogland, J.L. 2013. Why do female prairie dogs copulate with more than one male?Insights from long-term research. Journal of Mammalogy 94: 731-744.

Hopcraft, J.G.C., H. Olff, and A.R.E. Sinclair. 2010. Herbivores, resources and risks: alternating regulation along primary environmental gradients in savannas. Trends in Ecology \& Evolution 25: 119-128.

Hopkins, R.A. 1990. The ecology of the puma in the Diablo Range, California. Ph.D. Dissertation, University of California, Berkeley.

Hornocker, M.G. 1970. An analysis of mountain lion predation upon mule deer and elk in the Idaho Primitive Area. Wildlife Monographs 21: 3-39.

Hornocker, M., and Negri, eds. 2010. Cougar: ecology and conservation. University of Chicago Press, Chicago.

Hosmer, D.W., and S. Lemeshow. 2000. Applied logistic regression. John Wiley and Sons: New York, NY.

Hothorn, T., F. Bretz, and P. Westfall. 2008. Simultaneous inference in general parametric models. Biometrical Journal 50: 346-363.

Houston, D.C. 1995. The adaptations of scavengers. In Serengeti: dynamics of an ecosystem, edited by A.R.E. Sinclair and M. Norton-Griffiths. University of Chicago Press, Chicago: 263-286.

Hunter, J.S., S.M. Durant, and T.M. Caro. 2006. Patterns of scavenger arrival at cheetah kills in Serengeti National Park Tanzania. African Journal of Ecology 45: 275-281.

Hunter, M.D., and P.W. Price. 1992. Playing chutes and ladders: heterogeneity and the relative roles of bottom-up and top-down forces in natural communities. Ecology 73: 724-732.

Hurst, J.L., and R.J. Benyon. 2004. Scent wars: the chemobiology of competitive signalling in mice. BioEssays 26: 1288-1298. 
Jameson, E. W., and H. J. Peeters. 2004. Mammals of California. University of California Press, Berkeley, CA.

Jeschke, J. M. 2007. When carnivores are "full and lazy". Oecologia 152: 357-364.

Kellert, S. R. 1997. The value of life: biological diversity and human society. Island Press, Covelo, CA.

Kelly, M.J., A.J. Noss, M.S. DiBitetti, L. Maffei, R.L.Arispe, A. Paviolo, C.D. DeAngelo, and Y.E. DiBlanco. 2008. Estimating puma densities from camera trapping across three study sites: Bolivia, Argentina, and Belize. Journal of Mammalogy 89: 408-418.

Knopff, K.H., A.A. Knopff, A. Kortello, and M.S. Boyce. 2010. Cougar kill rate and prey composition in a multiprey system. Journal of Wildlife Management 74: 1435-1447.

Knopff, K.H., A.A. Knopff, M.B. Warren, and M.S. Boyce. 2009. Evaluating global positioning system telemetry techniques for estimating cougar predation parameters. Journal of Wildlife Management 73: 586-597.

Krofel, M., and I. Kos. 2010. Modeling potential effects of brown bear kleptoparasitism on the predation rate of Eurasian Lynx. Acta Biologica Slovenica 53: 47-54.

Krofel, M., I. Kos, and K. Jerina. 2012. The noble cats and the big bad scavengers: effects of dominant scavengers on solitary predators. Behavioral Ecology and Sociobiology 66: $1297-1304$.

Laliberte, A.S., and W.J. Ripple 2004. Range contractions of North American carnivores and ungulates. Bioscience 54: 123-138.

Laundré, J.W. 2005. Puma energetics: a recalculation. Journal of Wildlife Management 69: 723-732.

Laundré, J.W., L. Hernandez, D. Streubel, K. Altendorf, and C.L. Gonzalez. 2000. Aging mountain lions using gum-line recession. Wildlife Society Bulletin 28: 963-966. 
Lenth, R.V. 2013. Lsmeans: least-square means. R package version 1.06-05. http://CRAN.Rproject.org/package=lsmeans.

Levi, T., and C.C. Wilmers. 2012. Wolves-coyotes-foxes: a cascade among carnivores. Ecology 93: 921-929.

Lindzey, F.G., W.D. Van Sickle, B.B. Ackerman, D. Barnhurst, T.P. Hemker, and S.P. Laing. 1994. Cougar population dynamics in southern Utah. Journal of Wildlife Management 58: 619-624.

Loft, E.R., J.W. Menke, and T.S. Burton. 1984. Seasonal movements and summer habitats of female black-tailed deer. Journal of Wildlife Management 48: 1317-1325.

Logan, K., and L. Sweanor. 2001. Desert puma: evolutionary ecology and conservation of an enduring carnivore. Island Press, Covelo, CA.

Logan, K., and L. Sweanor. 2010. Behavior and social organization of a solitary carnivore. In Cougar: ecology and conservation, edited by Maurice Hornocker and Sharon Negri. University of Chicago Press, Chicago: 105-117.

Long, E.S., D.M. Feckske, R.A. Sweitzer, J.A. Jenks, B.M. Pierce, and V.C. Bleich. 2003. Efficacy of photographic scent stations to detect mountain lions. Western North American Naturalist 63: 529-532.

Long, R.A. P. MacKay, J. Ray, and W. Zielinski. 2008. Noninvasive survey methods for carnivores. Island Press: Washington, D.C.

Low, W.A., I.M. Cowan. 1963. Age determination of deer by annular structure of dental cementum. Journal of Wildlife Management 27: 466-471.

Matthews, N.E., and W.F. Porter. 1988. Black bear predation of white-tailed deer neonates in the central Adirondacks. Canadian Journal of Zoology 66: 1241-1242. 
Mattisson, J., P Segerstrom, J. Perssson, M. Aronsson, G.R. Rauset, G. Samelius, and H. Andren. 2013. Lethal male-male interactions in Eurasian Lynx. Mammalian Biology 78: $304-308$.

Mayer, K.E., and W.F. Laundenslayer, editors. 1988. A guide to wildlife habitats in California. State of California, The Resources Agency, Department of Forestry and Fire Protection, Sacramento, CA.

Mazerolle, M.J. 2013. AICcmodavg: Model selection and multimodel inference based on

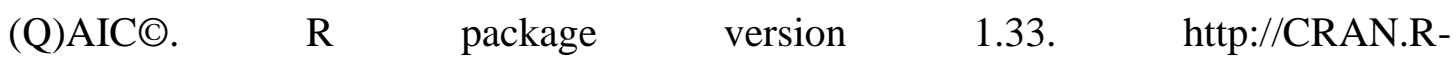
project.org/package=AICcmodavg.

McBride, R., and C. McBride. 2010. Florida panther flehmen response recorded at baited trail camera site. Southeastern Naturalist 9: 629-631.

McBride, R., and R. Sensor. 2012. Photographic evidence of wild Florida panthers scentmarking with facial glands. Southeastern Naturalist 11: 349-354.

McLaren, B.E., and R.O. Peterson. 1994. Wolves, moose and tree rings on Isle Royale. Science 266:1555-1558.

Mech, L.D. 1996. A new era for carnivore conservation. Wildlife Society Bulletin 24: 397401

Melis, C., N. Selva, I. Teurlings, C. Skarpe, J.D.C. Linnell, J.D.C., and R. Andersen. 2007. Soil and Vegetation Nutrient Response to Bison Carcasses in Bialowieza Primeval Forest, Poland. Ecological Research 22: 807-813.

Mellen, J.D. 1993. A comparative analysis of scent-marking, social and reproductive behavior in 20 species of small cats. American Zoologist 33: 151-166.

Metz, M.C., D.W. Smith, J.A. Smith, J.A. Vucetich, D.R. Stahler, and R.O. Peterson. 2012. Seasonal patterns of predation for gray wolves in the multi-prey system of Yellowstone National Park. Journal of Animal Ecology 81: 553-563. 
Meyer, D., A. Zeileis, and K. Hornik. 2013. vcd: visualizing categorical data. R package version $1.3-1$.

Mohr, C. 1947. Table of equivalent populations of North American small mammals. American Midland Naturalist 37: 223-249.

Moquet, N., D. Gravel, F. Massol, and V. Calcagno. 2012. Extending the concept of keystone species to communities and ecosystems. Ecology Letters 16: 1-8.

Murphy, K.M., G.S. Felzien, M.G. Hornocker, and T.K. Ruth. 1998. Encounter competition between bears and cougars: some ecological implications. Ursus 10: 55-60.

Murphy, K., and T.K. Ruth. 2010. Diet and prey selection of a perfect predator. In Cougar: ecology and conservation, edited by M. Hornocker and S. Negri. University of Chicago Press, Chicago: 118-137.

Nakagawa, S., and I.C. Cuthill. 2007. Effect size, confidence interval and statistical significance: a practical guide for biologists. Biological Reviews 82: 591-605.

Noss, R.F., H.B. Quigley, M.G. Hornocker, T. Merrill, and P.C. Paquet. 1996. Conservation biology and carnivore conservation in the Rocky Mountains. Conservation Biology 10: 949-963.

Olson Z.H., J.C. Beasley, T.L. DeVault, O.E. Rhodes Jr. 2012. Scavenger community response to the removal of a dominant scavenger. Oikos 121: 77-84.

Owen-Smith, N. 2008. Changing vulnerability to predation related to season and sex in an African ungulate assemblage. Oikos 117: 602-610.

Parker K. L., P. Gillinghamm, A. Hanleyt, and C. T. Robbins. 1993. Seasonal patterns in body mass, body composition, and water transfer rates of free-ranging and captive Black-tailed deer (Odocoileus hemionus sitkensis) in Alaska. Canadian Journal of Zoology 71: 1397-1404. 
Paviolo, A., Y.E Di Blanco, C.D. De Angelo, and M.S. Di Bitetti. 2009. Protection affects the abundance and activity patterns of pumas in the Atlantic forest. Journal of Mammalogy 90: 926-934.

Pebesma, E.J., R.S. Bivand. 2005. Classes and methods for spatial data in R. R News 5. http://cran.r-project.org/doc/Rnews/.

Pierce, B.M., V.C. Bleich, J.D. Wehausen, and R.T. Bowyer. 1999. Migratory patterns of mountain lions: implications for social regulation and conservation. Journal of Mammalogy 80: 986-992.

Pinheiro, J., D. Bates, S. DebRoy, and D. Sarkar. 2013. nmle: linear and nonlinear mixed effect models. R package version 3.1-108.

Pitman, R.T., J. Mulvaney, P.M. Ramsay, E. Jooste, and L.H. Swanepoel. 2013. Global Positioning System-located kills and faecal samples: a comparison of leopard dietary estimates. Journal of Zoology. doi: 10.1111/jzo.12078

Power, M.E., D. Tilman, J.A. Estes, B.A. Menge, W.J. Bond, L.S. Mills, G. Daily, J.C. Castilla, J. Lubchenco, and R.T. Paine. 1996. Challenges in the quest for keystones. Bioscience 46: 609-620.

Prugh, L.R., C. J. Stoner, C. W. Epps, W.T. Bean, W.J. Ripple, A.S. Laliberte, and J.S. Brashares. 2009. The rise of the mesopredator. Bioscience 59: 779-791.

Quigley, H., and M. Hornocker 2010. Cougar population dynamics. In Cougar: ecology and conservation, edited by M. Hornocker and S. Negri. University of Chicago Press, Chicago: 59-75.

R Core Team. 2013. R: A language and environment for statistical computing. R foundation for statistical computing, Vienna, Austria. ISBN 3-900051-07-0, URL http://www.Rproject.org/. 
Rinehart, K.A., L.M. Elbroch, and H.U. Wittmer. 2014. Common biases in density estimation based on home range overlap with reference to pumas in Patagonia. Wildlife Biology 20: 19-26.

Ripple, W.J., and R.L. Beschta. 2004. Wolves and the ecology of fear: can predation risk structure ecosystems? Bioscience 54: 755-766.

Ripple, W.J., J.A. Estes, R.L. Beschta, C.C. Wilmers, E.G. Ritchie, M. Hebblewhite, J. Berger, B. Elmhagen, M. Letnic, M.P. Nelson, O.J. Schmitz, D.W. Smith, A.D. Wallach, and A.J. Wirsing. 2014. Status and ecological effects of the world's largest carnivores. Science 343: 1241484. DOI: 10.1126/science.1241484.

Ripple, W.J., E.J, Larsen, R.A. Renkin, and D.W. Smith. 2001. Trophic cascades among wolves, elk and aspen on Yellowstone National Park's northern range. Biological Conservation102: 227-234.

Roberge, J.M., and P.E.R. Angelstam. 2004. Usefulness of the umbrella species concept as a conservation tool. Conservation Biology 18:76-85.

Roberson, J., and F. Lindzey, editors. 1984. Proceedings of the second mountain lion workshop. November 27-29, 1984. Zion National Park.

Robinson, W.L., and E.G. Bolen. 1989. Wildlife ecology and management. Macmillan Publishing, New York.

Ross, P.I., M.G. Jalkotzy, M. Fiesta-Bianchet. 1997. Cougar predation on bighorn sheep in southwestern Alberta during winter. Canadian Journal of Zoology 75: 771-775.

Rutberg, A.T. 1987. Adaptive hypotheses of birth synchrony in ruminants: an intraspecific test. American Naturalist 130: 692-710.

Ruth, T.K., and K. Murphy. 2010a. Cougar-prey relationships. In Cougar: ecology and conservation, edited by M. Hornocker and S. Negri. University of Chicago Press, Chicago: 138-162. 
Ruth, T.K., and K. Murphy. 2010b. Competition with other carnivores for prey. In Cougar: ecology and conservation, edited by M. Hornocker and S. Negri. University of Chicago Press, Chicago: 163-172.

Sand, H., P. Wabakken, B. Zimmerman, O. Johansson, H.C. Pederson, and O. Liberg. 2008. Summer kill rates and predation pattern in wolf-moose system: can we rely on winter estimates? Oecologia 156: 53-64.

Sargeant, A.B., S.H. Allen, and J.O. Hastings. 1987. Spatial relationships between sympatric coyotes and red foxes in North Dakota. Journal of Wildlife Management 51: 285-293.

Schwartz, C.C., and A.W. Franzmann. 1991. Interrelationship of black bears to moose and forest succession in the northern coniferous forest. Wildlife Monographs 113: 3-58.

Seaman, D.E., and R.A. Powell. 1996. An analysis of the accuracy of kernel density estimators for home range analysis. Ecology 77: 2075-2085.

Sebastian-Gonzales E., J.A. Sanchez-Zapata, J.A. Donazar, N. Selva, A. Cortez-Avizanda, F. Hiraldo, M. Blazquez, F. Botella, M. Moleon. 2013. Interactive effects of obligate scavengers and scavenger community richness on lagomorph carcass consumption patterns. Ibis 155: 881-885.

Seidensticker, J.C. IV, M.G. Hornocker, W.V. Wiles, and J.P. Messick. 1973. Mountain lion social organization in the Idaho primitive area. Wildlife Monographs 35: 3-60.

Selva, N., and M.A. Fortuna. 2007. The nested structure of a scavenger community. Proceedings of the Royal Society of London B 274: 1101-1108.

Selva, N., B. Jedrzejewska, W. Jedrzejewski, and A. Wajrak. 2003. Scavenging on European bison carcasses in Bialowieza Primeval Forest (eastern Poland). Ecoscience 10: 303311. 
Selva, N., B. Jedrzejewska, W. Jedrzejewski, and A. Wajrak. 2005. Factors affecting carcass use by a guild of scavengers in European temperate woodland. Canadian Journal of Zoology 83: 1590-1601.

Shaw, H. 2010. The emerging cougar chronicle. In Cougar: ecology and conservation, edited by M. Hornocker and S. Negri. University of Chicago Press, Chicago: 17-26.

Shivik, J.A. 2006. Tools for the edge: what's new for conserving carnivores. Bioscience 56: $253-259$.

Shuett, W., T. Tregenza, and S.R.X. Dall. 2010. Sexual selection and animal personality. Biological Reviews 85: 217-246.

Sibley, D. A. 2005. The Sibley field guide to birds of western North America. Alfred A. Knopf Publishing, New York.

Sikes, R.S., W.L. Gannon, and the Animal Care and Use Committee of the American Society of Mammalogists. 2011. Guidelines of the American Society of Mammalogists for the use of wild mammals in research. Journal of Mammalogy 92: 235-253.

Sinclair, A.R.E., and C.J. Krebs. 2002. Complex numerical responses to top-down and bottom-up processes in vertebrate populations. Philosophical Transactions of the Royal Society of the London Biological Sciences 357: 1121-1131.

Smith, J.L.D., C. McDougal, and D. Miquelle. 1989. Scent marking in free-ranging tigers, Panthera tigris. Animal Behaviour 37: 1-10.

Sokal, R.S., and F.J. Rohlf. 1987. Introduction to biostatistics. W.H. Freeman and Company, New York.

Stein, A.B., and V. Hayssen 2013. Panthera pardus. Mammalian Species 47: 30-48.

Stenström, D., S. Dahlblom, C. Jones Fur, and J. Höglund. 2000: Rutting pit distribution and the significance of fallow deer Dama dama scrapes during the rut. Wildlife Biology 6: $23-29$. 
Sunquist, M., and F. Sunquist. 2002. Wild cats of the world. University of Chicago Press, Chicago.

Sutherland, W.J. 1998. The importance of behavioural studies to conservation biology. Animal Behaviour 56: 801-809.

Svoboda, N.J., J.L. Belant, D.E. Beyer, J.F. Duquette, H.K. Sticker, C.A. Albright. 2011. American black bear predation of an adult white-tailed deer. Ursus 22: 91-94.

Sweanor, L.L., K.A. Logan, J.W. Bauer, B. Millsap, W.M. Boyce. 2008. Puma and human spatial and temporal use of a popular California State Park. Journal of Wildlife Management 72: 1076-1084.

Thonhauser, K.E., S. Raveh, A. Hettyey, H. Beissmann, and D.J. Penn. 2013. Scent marking increases male reproductive success in wild house mice. Animal Behaviour 86: 10131021.

Torres, S.G., T.M Mansfield, J.E. Foley, T. Lupo, and A. Brinkhaus. 1996. Mountain lion and human activity in California: testing speculations. Wildlife Society Bulletin 24: 451460.

Venables, W.N., and B.D. Ripley. 2002. Modern applied statistics with S. $4^{\text {th }}$ edition. Springer, New York.

Walker, S., and A. Novaro. 2010. The world's southernmost pumas in Patagonia and the southern Andes. In Cougar: ecology and conservation, edited by Maurice Hornocker and Sharon Negri. University of Chicago Press, Chicago: 91-99.

Wallace, M.P., and S.A. Temple. 1987. Competitive interactions within and between species in a guild of avian scavengers. The Auk 104: 290-295.

Watson, J., S.R. Rae, and R. Stillman. 1992. Nesting density and breeding success of golden eagles in relation to food supply in Scotland. Journal of Animal Ecology 61: 543-550. 
Wilmers, C.C., R.L. Crabtree, D.W. Smith, K.M. Murphy, and W.M. Getz. 2003a. Trophic facilitation by introduced top predators: grey wolf subsidies to scavengers in Yellowstone National Park. Journal of Animal Ecology 72: 909-916.

Wilmers, C.C., D.R. Stahler, R.L. Crabtree, D.W. Smith, and W.M. Getz. 2003b. Resource dispersion and consumer dominance: scavenging at wolf- and hunter-killed carcasses in greater Yellowstone, USA. Ecology Letters 6: 996-1003.

Wilmers, C.C., and W.M. Getz. 2005. Gray wolves as climate change buffers in Yellowstone. PLoS Biology 3: e92.

Wilmers, C.C., Y. Wang, B. Nickel, P. Houghtaling, Y. Shakeri, M.L. Allen, J. KermishWells, V. Yovovich, and T. Williams. 2013. Scale dependent behavioural responses to human development by a large predator, the puma. PLoS One 8: e60590.

Wilson, E.E., and E.M. Wolkovich. 2011. Scavenging: how carnivores and carrion structure communities. Trends in Ecology \& Evolution 26: 129-135.

Wittmer, H.U. A.R.E. Sinclair, and B.N. McLellan. 2005. The role of predation in the decline and extirpation of woodland caribou. Oecologia 144: 257-267.

Woodruffe, R., and J.R. Ginsberg. 1998. Edge effects and extinctions of populations inside protected areas. Science 280: 2126-2128.

Worton, B.J. 1989. Kernel methods for estimating the utilization distribution in home-range studies. Ecology 70: 164-168.

Verberne, G., and P. Leyhausen. 1976. Marking behaviour of some viverridae and felidae: time-interval analysis of the marking pattern. Behaviour 58: 192-253.

Yule, G.U. (1912). On the methods of measuring the association between two attributes. Journal of the Royal Statistical Society 75: 579-652. 


\section{Appendixes}

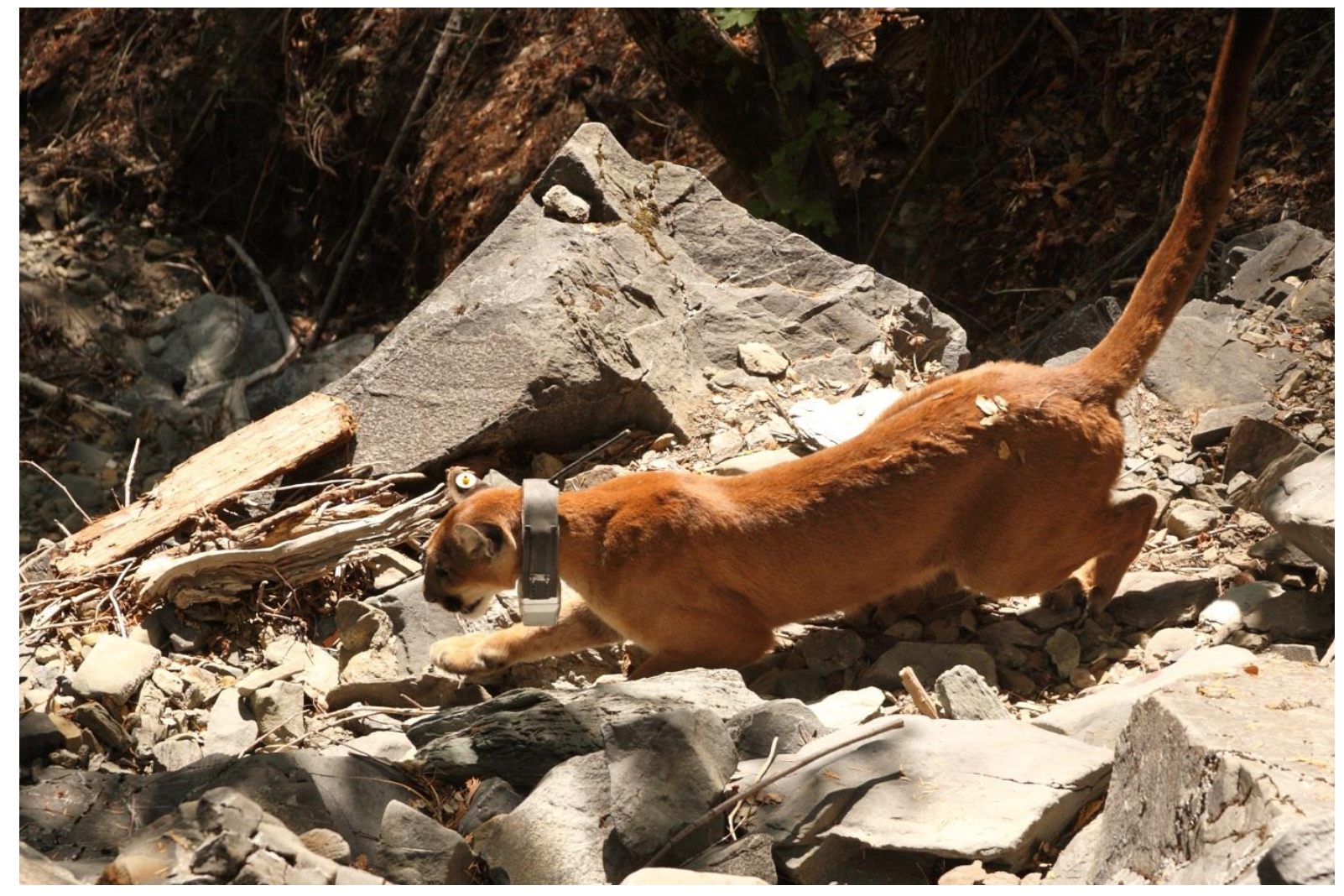




\section{Appendix A - Habitat characteristics at puma experimental carcasses}

The habitat conditions at monitored puma kills and matching puma control carcasses. The first table is for puma kills, the second is for paired control carcasses. Abbreviations for habitat follow all appendixes.

\begin{tabular}{|c|c|c|c|c|c|c|c|c|}
\hline $\begin{array}{l}\text { Kill Carcass } \\
\text { Name }\end{array}$ & $\begin{array}{l}\text { Primary } \\
\text { Habitat }\end{array}$ & $\begin{array}{l}\text { Secondary } \\
\text { Habitat }\end{array}$ & Distance & Elevation & $\begin{array}{l}\text { Canopy } \\
\text { Cover }\end{array}$ & Slope & Aspect & Overhead Tree \\
\hline K_F1_052011 & $\mathrm{MCH}$ & CRC & 16 & 1192 & $100 \%$ & 18 & 228 & Scrub Oak \\
\hline K_M36_052211 & MHW & $\mathrm{AG}$ & 20 & 853 & $97 \%$ & 3 & 265 & Live Oak \\
\hline K_M36_052611 & $\mathrm{KMC}$ & PPN & 42 & 994 & $100 \%$ & 16 & 64 & Black Oak \\
\hline K_M36_060511 & DFR & KMC & 2 & 1310 & $100 \%$ & & & Douglas Fir \\
\hline K_M36_061111 & MHW & PPN & 14 & 1572 & $100 \%$ & 34 & 104 & Live Oak \\
\hline K_F1_062111 & KMC & MHC & 15 & 1656 & $85 \%$ & 22 & 48 & Red Fir \\
\hline K_F1_063011 & MHC & $\mathrm{MCP}$ & 1 & 1308 & $100 \%$ & 3 & 206 & Black Oak \\
\hline K_F1_070311 & $\mathrm{MHC}$ & $\mathrm{AG}$ & 3 & 1202 & $95 \%$ & 6 & 88 & Black Oak \\
\hline K_F17_082811 & KMC & PPN & 10 & 1413 & $86 \%$ & 10 & 344 & Ponderosa Pine \\
\hline K_M33_091711 & $\mathrm{MHC}$ & KMC & 6 & 1277 & $100 \%$ & 9 & 198 & Douglas Fir \\
\hline K_F23_091711 & KMC & MHC & 12 & 1332 & $100 \%$ & 18 & 51 & Incense Cedar \\
\hline K_F17_100311 & $\mathrm{MHC}$ & KMC & 6 & 1677 & $96 \%$ & 20 & 344 & Ponderosa Pine \\
\hline K_M33_100911 & $\mathrm{KMC}$ & MCP & 8 & 1681 & $100 \%$ & 14 & 141 & White Fir \\
\hline K_F19_101611 & MHW & $\mathrm{MCH}$ & 20 & 897 & $97 \%$ & 16 & 48 & Black Oak \\
\hline K_F17_102011 & $\mathrm{MHC}$ & $\mathrm{AG}$ & 8 & 1354 & $79 \%$ & 4 & 263 & Brewer's Oak \\
\hline K_F19_102511 & $\mathrm{MCH}$ & MHW & 4 & 1193 & $100 \%$ & 19 & 226 & Manzanita \\
\hline K_F23_102811 & MHW & MHC & 4 & 1103 & $100 \%$ & 18 & 187 & Live Oak \\
\hline K_F19_110611 & $\mathrm{MCH}$ & $\mathrm{AG}$ & 25 & 1081 & $100 \%$ & 24 & 262 & Scrub Oak \\
\hline K_F17_110911 & MHW & MCP & 2 & 919 & $93 \%$ & 28 & 251 & Black Oak \\
\hline K_F23_111111 & MRI & BOP & 35 & 585 & $97 \%$ & 17 & 23 & Dogwood \\
\hline K_F17_112011 & $\mathrm{MHC}$ & MHW & 12 & 913 & $93 \%$ & 16 & 331 & Scrub Oak \\
\hline K_F23_112211 & MHW & $\mathrm{MHC}$ & 16 & 1133 & $100 \%$ & 16 & 148 & Scrub Oak \\
\hline K_M33_112211 & DFR & MHC & 6 & 989 & $100 \%$ & 9 & 288 & Douglas Fir \\
\hline K_F23_113011 & $\mathrm{CRC}$ & $\mathrm{AG}$ & 12 & 1075 & $91 \%$ & 21 & 215 & Scrub Oak \\
\hline K_M33_121511 & $\mathrm{MHC}$ & DFR & 50 & 1168 & $97 \%$ & 12 & 267 & Douglas Fir \\
\hline K_M33_121811 & $\mathrm{MHC}$ & DFR & 50 & 1164 & $97 \%$ & 12 & 267 & Douglas Fir \\
\hline K_F17_123111 & DFR & MHC & 8 & 938 & $97 \%$ & 5 & 261 & Douglas Fir \\
\hline K_F17_010412 & KMC & MHW & 12 & 1708 & $81 \%$ & 19 & 151 & Ponderosa Pine \\
\hline
\end{tabular}




\begin{tabular}{|c|c|c|c|c|c|c|c|c|}
\hline K F19 011612 & $\mathrm{MCH}$ & $\mathrm{MHC}$ & 30 & 816 & $100 \%$ & 2 & 50 & Scrub Oak \\
\hline K_F17_012412 & $\mathrm{KMC}$ & MHC & 13 & 1244 & $99 \%$ & 7 & 308 & Douglas Fir \\
\hline K_F17_020612 & $\mathrm{MHC}$ & $\mathrm{AG}$ & 16 & 966 & $99 \%$ & 3 & 208 & Douglas Fir \\
\hline K_F19_020912 & MHW & MHC & 45 & 614 & $89 \%$ & 7 & 69 & Live Oak \\
\hline K_M33_022512 & $\mathrm{MCH}$ & MHW & 5 & 900 & $98 \%$ & 12 & 137 & Scrub Oak \\
\hline K_F17_022912 & MHW & $\mathrm{AG}$ & 25 & 710 & $80 \%$ & 40 & 300 & Big Leaf Maple \\
\hline K_M33_031412 & MCP & $\mathrm{KMC}$ & 85 & 1269 & $94 \%$ & 4 & 142 & Manzanita \\
\hline K_F17_032212 & DFR & $\mathrm{MHC}$ & 10 & 1091 & $99 \%$ & 2 & 67 & Douglas Fir \\
\hline K_M33_032212 & $\mathrm{MHC}$ & $\mathrm{KMC}$ & 60 & 1160 & $99 \%$ & 10 & 288 & Live Oak \\
\hline K_M33_041412 & MCP & DFR & 5 & 1071 & $91 \%$ & 14 & 241 & Manzanita \\
\hline K_F43_042412 & KMC & $\mathrm{MHC}$ & 9 & 1063 & $100 \%$ & 8 & 192 & Douglas Fir \\
\hline K_F43_051012 & MHW & $\mathrm{MHC}$ & 9 & 976 & $100 \%$ & 5 & 262 & Scrub Oak \\
\hline K_F17_051112 & MCP & $\mathrm{MHC}$ & 6 & 1491 & $72 \%$ & 12 & 219 & Ceanothus \\
\hline K_M33_051812 & $\mathrm{KMC}$ & $\mathrm{AG}$ & 12 & 1397 & $100 \%$ & 3 & 241 & Douglas Fir \\
\hline K_M33_061212 & $\mathrm{KMC}$ & $\mathrm{MCP}$ & 3 & 1754 & $100 \%$ & 2 & 158 & Incense Cedar \\
\hline K_F43_062012 & $\mathrm{MHC}$ & $\mathrm{KMC}$ & 7 & 1282 & $99 \%$ & 9 & 121 & Ponderosa Pine \\
\hline K_F43_062312 & $\mathrm{MHC}$ & MHW & 8 & 1512 & $97 \%$ & 24 & 164 & Douglas Fir \\
\hline K_M33_062412 & $\mathrm{KMC}$ & MHC & 16 & 1487 & $100 \%$ & 3 & 120 & Douglas Fir \\
\hline K_F43_062812 & RFR & $\mathrm{KMC}$ & 4 & 1886 & $96 \%$ & 14 & 330 & Red Fir \\
\hline K_M33_070612 & MCP & $\mathrm{KMC}$ & 4 & 1565 & $93 \%$ & 12 & 87 & Chamise \\
\hline K_F43_071712 & $\mathrm{KMC}$ & MCP & 3 & 1853 & $69 \%$ & 23 & 307 & Incense Cedar \\
\hline K_F43_072812 & $\mathrm{KMC}$ & $\mathrm{MCP}$ & 3 & 1790 & $97 \%$ & 10 & 40 & White Fir \\
\hline K_F43_080912 & BAR & $\mathrm{KMC}$ & 3 & 1985 & $24 \%$ & 22 & 122 & Incense Cedar \\
\hline K_F43_081812 & MRI & WTR & 2 & 861 & $92 \%$ & 4 & 321 & Alder \\
\hline K_F43_091312 & DFR & KMC & 3 & 1652 & $100 \%$ & 3 & 123 & Douglas Fir \\
\hline K_M33_091412 & MRI & WTM & 4 & 1808 & $100 \%$ & 2 & 187 & Willow \\
\hline K_F43_092712 & DFR & KMC & 3 & 1630 & $98 \%$ & 8 & 19 & Douglas Fir \\
\hline K_F43_100712 & MHW & MHC & 12 & 1451 & $91 \%$ & 21 & 186 & Black Oak \\
\hline K_F43_101312 & MHC & DFR & 12 & 1171 & $99 \%$ & 9 & 278 & Black Oak \\
\hline K_F43_101812 & MRI & MHW & 20 & 737 & $100 \%$ & 24 & 250 & Alder \\
\hline
\end{tabular}




\begin{tabular}{|c|c|c|c|c|c|c|c|c|}
\hline $\begin{array}{l}\text { Paired Control } \\
\text { Carcass Name }\end{array}$ & $\begin{array}{l}\text { Primary } \\
\text { Habitat }\end{array}$ & $\begin{array}{l}\text { Secondary } \\
\text { Habitat }\end{array}$ & Distance & Elevation & $\begin{array}{l}\text { Canopy } \\
\text { Cover }\end{array}$ & Slope & Aspect & Overhead Tree \\
\hline P_F1_052011 & $\mathrm{MCH}$ & MHC & 20 & 1283 & $100 \%$ & 26 & 82 & Scrub Oak \\
\hline P_M36_052211 & MHW & BAR & 14 & 483 & $100 \%$ & 4 & 32 & Live Oak \\
\hline P_M36_052611 & MHW & $\mathrm{AG}$ & 8 & 461 & $100 \%$ & 11 & 296 & California Buckeye \\
\hline P_M36_060511 & DFR & KMC & 18 & 1575 & $100 \%$ & 14 & 42 & Douglas Fir \\
\hline P_M36_061111 & MHW & KMC & 12 & 1378 & $100 \%$ & 22 & 302 & Live Oak \\
\hline P_F1_062111 & KMC & MHC & 15 & 1497 & $85 \%$ & 19 & 72 & Red Fir \\
\hline P_F1_063011 & MHC & $\mathrm{MCP}$ & 3 & 1520 & $100 \%$ & 6 & 243 & Black Oak \\
\hline P_F1_070311 & $\mathrm{MHC}$ & MCP & 12 & 756 & $98 \%$ & 8 & 160 & Black Oak \\
\hline P_F17_082811 & KMC & DFR & 10 & 1333 & $93 \%$ & 12 & 11 & Ponderosa Pine \\
\hline P_M33_091711 & $\mathrm{MHC}$ & KMC & 2 & 1266 & $100 \%$ & 8 & 194 & Douglas Fir \\
\hline P_F23_091711 & KMC & MHC & 15 & 1334 & $100 \%$ & 19 & 348 & Incense Cedar \\
\hline P_F17_100311 & MHC & KMC & 2 & 1594 & $99 \%$ & 18 & 89 & Ponderosa Pine \\
\hline P_M33_100911 & $\mathrm{KMC}$ & WFR & 12 & 1674 & $99 \%$ & 12 & 59 & Ponderosa Pine \\
\hline P_F19_101611 & MHW & $\mathrm{MCH}$ & 10 & 983 & $96 \%$ & 20 & 334 & Brewer's Oak \\
\hline P_F17_102011 & MHC & $\mathrm{AG}$ & 25 & 1468 & $91 \%$ & 6 & 260 & Black Oak \\
\hline P_F19_102511 & $\mathrm{MCH}$ & MHW & 3 & 1306 & $100 \%$ & 17 & 93 & Manzanita \\
\hline P_F23_102811 & MHW & MHC & 6 & 1039 & $100 \%$ & 11 & 164 & Live Oak \\
\hline P_F19_110611 & $\mathrm{MCH}$ & $\mathrm{AG}$ & 7 & 1080 & $99 \%$ & 22 & 99 & Scrub Oak \\
\hline P_F17_110911 & MHW & MCP & 3 & 1034 & $92 \%$ & 19 & 179 & Black Oak \\
\hline P_F23_111111 & MRI & BOP & 5 & 540 & $93 \%$ & 16 & 25 & Dogwood \\
\hline P_F17_112011 & $\mathrm{MHC}$ & MHW & 14 & 1002 & $97 \%$ & 15 & 303 & Scrub Oak \\
\hline P_F23_112211 & MHW & MHC & 3 & 1328 & $100 \%$ & 18 & 108 & Scrub Oak \\
\hline P_M33_112211 & DFR & MHC & 7 & 1071 & $100 \%$ & 8 & 324 & Douglas Fir \\
\hline P_F23_113011 & $\mathrm{MCH}$ & $\mathrm{AG}$ & 6 & 964 & $98 \%$ & 14 & 276 & Scrub Oak \\
\hline P_M33_121511 & $\mathrm{MHC}$ & DFR & 10 & 1206 & $96 \%$ & 4 & 71 & Douglas Fir \\
\hline P_M33_121811 & $\mathrm{MHC}$ & DFR & 40 & 1175 & $95 \%$ & 5 & 100 & Douglas Fir \\
\hline P_F17_123111 & DFR & $\mathrm{MHC}$ & 12 & 1435 & $98 \%$ & 7 & 97 & Douglas Fir \\
\hline P_F17_010412 & KMC & MHW & 9 & 1602 & $84 \%$ & 16 & 112 & Ponderosa Pine \\
\hline P_F19_011612 & MHW & MHC & 20 & 1140 & $100 \%$ & 20 & 97 & Scrub Oak \\
\hline P_F17_012412 & KMC & $\mathrm{MHC}$ & 50 & 1043 & $98 \%$ & 10 & 131 & Douglas Fir \\
\hline
\end{tabular}




\begin{tabular}{|lllllllll|} 
P_F17_020612 & MHC & AG & 16 & 898 & $98 \%$ & 9 & 100 & Douglas Fir \\
P_F19_020912 & MHW & MHC & 35 & 1017 & $92 \%$ & 11 & 147 & Live Oak \\
P_M33_022512 & MCH & MHW & 5 & 1245 & $98 \%$ & 18 & 157 & Live Oak \\
P_F17_022912 & MHW & AG & 6 & 949 & $89 \%$ & 21 & 332 & Big Leaf Maple \\
P_M33_031412 & MCP & KMC & 25 & 1273 & $94 \%$ & 2 & 253 & Manzanita \\
P_F17_032212 & DFR & MHC & 12 & 1255 & $99 \%$ & 4 & 9 & Douglas Fir \\
P_M33_032212 & MHC & KMC & 40 & 1044 & $99 \%$ & 8 & 214 & Live Oak \\
P_M33_041412 & MCP & DFR & 3 & 875 & $88 \%$ & 16 & 229 & Manzanita \\
P_F43_042412 & KMC & MHC & 8 & 1162 & $100 \%$ & 5 & 221 & Douglas Fir \\
P_F43_051012 & MHW & MHC & 6 & 971 & $100 \%$ & 7 & 296 & Scrub Oak \\
P_F17_051112 & MCP & MHC & 4 & 1986 & $62 \%$ & 9 & 244 & Ceanothus \\
P_M33_051812 & KMC & AG & 5 & 1218 & $100 \%$ & 4 & 291 & Douglas Fir \\
P_M33_061212 & KMC & MCP & 4 & 1621 & $98 \%$ & 2 & 182 & Incense Cedar \\
P_F43_062012 & MHC & KMC & 15 & 1194 & $93 \%$ & 7 & 236 & Ponderosa Pine \\
P_F43_062312 & MHC & MHW & 14 & 1203 & $98 \%$ & 8 & 330 & Douglas Fir \\
P_M33_062412 & KMC & MHC & 18 & 1743 & $100 \%$ & 14 & 86 & Douglas Fir \\
P_F43_062812 & RFR & KMC & 2 & 1831 & $97 \%$ & 18 & 308 & Red Fir \\
P_M33_070612 & MCP & KMC & 5 & 1743 & $89 \%$ & 5 & 51 & Chamise \\
P_F43_071712 & KMC & MCP & 2 & 1783 & $72 \%$ & 6 & 93 & Incense Cedar \\
P_F43_072812 & KMC & MCP & 8 & 1790 & $97 \%$ & 10 & 100 & White Fir \\
P_F43_080912 & BAR & KMC & 4 & 1950 & $20 \%$ & 23 & 258 & Incense Cedar \\
P_F43_081812 & MRI & WTR & 4 & 1116 & $95 \%$ & 3 & 306 & Alder \\
P_F43_091312 & DFR & KMC & 6 & 1682 & $100 \%$ & 4 & 82 & Douglas Fir \\
P_M33_091412 & MRI & WTM & 2 & 1861 & $100 \%$ & 6 & 93 & Willow \\
P_F43_092712 & DFR & KMC & 5 & 1537 & $99 \%$ & 14 & 71 & Douglas Fir \\
P_F43_100712 & MHW & MHC & 6 & 1377 & $97 \%$ & 23 & 205 & Black Oak \\
P_F43_101312 & MHC & DFR & 5 & 1141 & $99 \%$ & 8 & 322 & Black Oak \\
P_F43_101812 & MRI & MHW & 18 & 1121 & $100 \%$ & 13 & 292 & Alder \\
\hline
\end{tabular}




\section{Appendix B - Habitat characteristics at black bear experimental carcasses}

The habitat conditions at the black-tailed deer carcasses for the black bear experiments. Abbreviations for habitat follow all appendixes.

\begin{tabular}{|c|c|c|c|c|c|c|c|c|c|c|}
\hline Name & $\begin{array}{l}\text { Carcass } \\
\text { Type }\end{array}$ & $\begin{array}{l}\text { Date Set } \\
\text { Out }\end{array}$ & Habitat & $\begin{array}{l}\text { Secondary } \\
\text { Habitat }\end{array}$ & $\begin{array}{l}\text { Distance } \\
\text { (meters) }\end{array}$ & $\begin{array}{c}\text { Elevation } \\
\text { (meters) }\end{array}$ & $\begin{array}{l}\text { Overhead Tree } \\
\text { Species }\end{array}$ & $\begin{array}{l}\text { Canopy } \\
\text { Cover }\end{array}$ & Slope & Aspect \\
\hline B010810-1 & Absent & $1 / 8 / 2010$ & BOW & $\mathrm{AG}$ & 8 & 1045 & Blue Oak & $81 \%$ & 8 & 15 \\
\hline B013110-1 & Absent & $1 / 31 / 2010$ & $\mathrm{MCP}$ & $A G$ & 1 & 874 & Manzanita & $16 \%$ & 12 & 183 \\
\hline B013110-2 & Absent & $1 / 31 / 2010$ & BOW & $\mathrm{AG}$ & 4 & 845 & Scrub Oak & $95 \%$ & 12 & 39 \\
\hline B013110-3 & Excluded & $1 / 31 / 2010$ & MHW & WTR & 6 & 883 & Mountain Mahogany & $84 \%$ & 1 & 143 \\
\hline B013110-4 & Excluded & $1 / 31 / 2010$ & BOP & $\mathrm{AG}$ & 2 & 851 & Gray Pine & $89 \%$ & 22 & 172 \\
\hline B020410-1 & Absent & $2 / 4 / 2010$ & $\mathrm{MHC}$ & WTR & 12 & 774 & Douglas Fir & $100 \%$ & 24 & 137 \\
\hline B020610-1 & Absent & $2 / 6 / 2010$ & MCP & PPN & 18 & 833 & Manzanita & $93 \%$ & 11 & 101 \\
\hline В022110-1 & Absent & $2 / 21 / 2010$ & PPN & $\mathrm{AG}$ & 8 & 1323 & Ponderosa Pine & $73 \%$ & 2 & 342 \\
\hline B022110-2 & Absent & $2 / 21 / 2010$ & $\mathrm{KMC}$ & $A G$ & 2 & 1400 & Black Oak & $15 \%$ & 6 & 53 \\
\hline В022710-1 & Absent & $2 / 27 / 2010$ & MHW & $A G$ & 30 & 1200 & Live Oak & $100 \%$ & 31 & 87 \\
\hline B030210-1 & Excluded & $3 / 2 / 2010$ & $\mathrm{MCH}$ & $A G$ & 26 & 963 & Scrub Oak & $97 \%$ & 21 & 271 \\
\hline B030210-2 & Absent & $3 / 2 / 2010$ & MHW & $A G$ & 21 & 1147 & Live Oak & $95 \%$ & 25 & 216 \\
\hline B030210-3 & Absent & $3 / 2 / 2010$ & MHC & $A G$ & 15 & 1156 & Ponderosa Pine & $95 \%$ & 4 & 103 \\
\hline В032910-1 & Absent & $3 / 29 / 2010$ & MHW & $\mathrm{AG}$ & 12 & 1198 & Live Oak & $100 \%$ & 18 & 74 \\
\hline B033010-1 & Absent & $3 / 30 / 2010$ & MHC & $A G$ & 1 & 1537 & Brewers Oak & $57 \%$ & 9 & 266 \\
\hline B033010-2 & Absent & $3 / 30 / 2010$ & PPN & $\mathrm{AG}$ & 8 & 1825 & Ponderosa Pine & $86 \%$ & 7 & 2 \\
\hline B033010-3 & Present & $3 / 30 / 2010$ & MHC & MHW & 12 & 1219 & Ponderosa Pine & $78 \%$ & 5 & 210 \\
\hline B040710-1 & Present & 4/7/2010 & MHW & $\mathrm{AG}$ & 22 & 1122 & Black Oak & $99 \%$ & 3 & 140 \\
\hline B041010-1 & Excluded & $4 / 10 / 2010$ & MHC & MHW & 12 & 1195 & Douglas Fir & 0.97 & 9 & 266 \\
\hline B041610-1 & Excluded & $4 / 16 / 2010$ & MHC & $\mathrm{MCH}$ & 8 & 1164 & Live Oak & $95 \%$ & 18 & 220 \\
\hline B041610-2 & Absent & $4 / 16 / 2010$ & $\mathrm{AG}$ & BOW & 6 & 1290 & Ponderosa Pine & $61 \%$ & 16 & 38 \\
\hline B041610-3 & Absent & $4 / 16 / 2010$ & PPN & $\mathrm{MHC}$ & 9 & 1252 & Ponderosa Pine & $100 \%$ & 4 & 246 \\
\hline B041910-1 & Absent & $4 / 19 / 2010$ & $\mathrm{MHC}$ & $\mathrm{AG}$ & 13 & 1194 & Ponderosa Pine & $98 \%$ & 17 & 302 \\
\hline B050110-1 & Present & $5 / 1 / 2010$ & $\mathrm{MHC}$ & $\mathrm{AG}$ & 24 & 1202 & Live Oak & $97 \%$ & 2 & 171 \\
\hline B050410-1 & Excluded & $5 / 4 / 2010$ & $\mathrm{AG}$ & MHW & 9 & 1106 & Black Oak & $44 \%$ & 17 & 328 \\
\hline
\end{tabular}




\begin{tabular}{|c|c|c|c|c|c|c|c|c|c|c|}
\hline B052710-1 & Present & $5 / 27 / 2010$ & KMC & AG & 1 & 1375 & Ponderosa Pine & $43 \%$ & 19 & 294 \\
\hline B052710-2 & Present & $5 / 27 / 2010$ & MHW & MHC & 7 & 917 & Manzanita & $64 \%$ & 19 & 324 \\
\hline B052710-3 & Present & $5 / 27 / 2010$ & MHC & $\mathrm{AG}$ & 12 & 1191 & Live Oak & $98 \%$ & 3 & 304 \\
\hline B080910-1 & Excluded & $8 / 9 / 2010$ & DFR & WTM & 6 & 1589 & Douglas Fir & $100 \%$ & 1 & 62 \\
\hline B102210-1 & Present & $10 / 22 / 2010$ & $\mathrm{MHC}$ & MCP & 8 & 1354 & Live Oak & $99 \%$ & 28 & 64 \\
\hline B102210-2 & Excluded & $10 / 22 / 2010$ & MHC & DFR & 6 & 1242 & Scrub Oak & $100 \%$ & 10 & 276 \\
\hline B102910-1 & Excluded & $10 / 29 / 2010$ & KMC & $\mathrm{MCH}$ & 16 & 1514 & Douglas Fir & $99 \%$ & 19 & 61 \\
\hline B011411-1 & Absent & $1 / 14 / 2011$ & $\mathrm{MCH}$ & $\mathrm{KMC}$ & 10 & 954 & Manzanita & $100 \%$ & 11 & 316 \\
\hline B020511-1 & Absent & $2 / 5 / 2011$ & $\mathrm{KMC}$ & PPN & 10 & 1237 & & $100 \%$ & 15 & 20 \\
\hline B020911-1 & Excluded & $2 / 9 / 2011$ & $\mathrm{KMC}$ & $\mathrm{AG}$ & 5 & 1339 & White Fir & $100 \%$ & 12 & 188 \\
\hline В022611-1 & Absent & $2 / 26 / 2011$ & MHC & $\mathrm{MCH}$ & 10 & 1226 & Black Oak & $95 \%$ & 14 & 41 \\
\hline B031411-1 & Present & $3 / 14 / 2011$ & MHW & $\mathrm{KMC}$ & 14 & 907 & Live Oak & $100 \%$ & 19 & 344 \\
\hline В031611-1 & Present & $3 / 16 / 2011$ & $\mathrm{MCH}$ & $\mathrm{AG}$ & 3 & 862 & Manzanita & $26 \%$ & 2 & 301 \\
\hline B040311-1 & Absent & $4 / 3 / 2011$ & PPN & $\mathrm{AG}$ & 4 & 1299 & Ponderosa Pine & $92 \%$ & 5 & 304 \\
\hline В040311-2 & Absent & $4 / 3 / 2011$ & MHC & $\mathrm{MCH}$ & 6 & 925 & Black Oak & $99 \%$ & 9 & 283 \\
\hline B040511-1 & Absent & $4 / 5 / 2011$ & DFR & BAR & 3 & 1192 & Douglas Fir & $97 \%$ & 26 & 25 \\
\hline В040611-1 & Absent & 4/6/2011 & MHW & $\mathrm{AG}$ & 14 & 1178 & Manzanita & $97 \%$ & 5 & 28 \\
\hline B041011-1 & Absent & $4 / 10 / 2011$ & $\mathrm{MCH}$ & MHW & 9 & 976 & Manzanita & $99 \%$ & 3 & 164 \\
\hline B041111-1 & Excluded & $4 / 11 / 2011$ & $\mathrm{MCH}$ & KMC & 5 & 1261 & Manzanita & & 2 & 341 \\
\hline B041911-1 & Excluded & $4 / 19 / 2011$ & MHW & BOW & 15 & 1049 & Scrub Oak & $96 \%$ & 10 & 14 \\
\hline B042211-1 & Present & $4 / 22 / 2011$ & MHW & $\mathrm{AG}$ & 1 & 1001 & White Oak & $86 \%$ & 5 & 95 \\
\hline B042611-1 & Present & $4 / 26 / 2011$ & PPN & $\mathrm{AG}$ & 4 & 1299 & Ponderosa Pine & $92 \%$ & 5 & 304 \\
\hline B060611-1 & Present & 6/6/2011 & DFR & MHW & 9 & 912 & Douglas Fir & $100 \%$ & 12 & 352 \\
\hline B060611-2 & Present & $6 / 6 / 2011$ & DFR & MHW & 14 & 879 & Douglas Fir & $95 \%$ & 4 & 318 \\
\hline B060611-3 & Present & $6 / 6 / 2011$ & $\mathrm{KMC}$ & MHC & 18 & 1221 & Ponderosa Pine & $98 \%$ & 3 & 194 \\
\hline B060811-1 & Present & $6 / 8 / 2011$ & PPN & MHW & & 1423 & Ponderosa Pine & $99 \%$ & 4 & 206 \\
\hline В070711-1 & Present & 7/7/2011 & $\mathrm{MHC}$ & $\mathrm{AG}$ & 6 & 967 & Black Oak & $100 \%$ & 10 & 38 \\
\hline B071111-1 & Present & 7/11/2011 & PPN & $\mathrm{AG}$ & 8 & 1402 & Ponderosa Pine & $99 \%$ & 6 & 347 \\
\hline B111311-1 & Present & $11 / 13 / 2011$ & $\mathrm{MHC}$ & $\mathrm{KMC}$ & 8 & 1254 & Blue Oak & $76 \%$ & 2 & 214 \\
\hline B111611-1 & Absent & $11 / 16 / 2011$ & MHC & DFR & 17 & 1172 & Douglas Fir & $99 \%$ & 6 & 223 \\
\hline B112111-1 & Present & $11 / 21 / 2011$ & $\mathrm{MHC}$ & MCP & 8 & 1259 & Ponderosa Pine & $95 \%$ & 9 & 279 \\
\hline B122111-1 & Absent & $12 / 21 / 2011$ & PPN & MHC & 25 & 1369 & Ponderosa Pine & $88 \%$ & 7 & 161 \\
\hline
\end{tabular}




\begin{tabular}{|c|c|c|c|c|c|c|c|c|c|c|}
\hline B123111-1 & Absent & $12 / 31 / 2011$ & MHW & MHC & 4 & 1160 & Live Oak & $100 \%$ & 12 & 296 \\
\hline B010112-1 & Absent & $1 / 1 / 2012$ & KMC & MRI & 6 & 1327 & Douglas Fir & $93 \%$ & 6 & 181 \\
\hline B010112-2 & Absent & $1 / 1 / 2012$ & WFR & KMC & 12 & 1435 & White Fir & 98 & 7 & 97 \\
\hline B011112-1 & Absent & $1 / 11 / 2012$ & MHC & $\mathrm{KMC}$ & 50 & 965 & Manzanita & $58 \%$ & 7 & 301 \\
\hline B012112-1 & Absent & $1 / 21 / 2012$ & MHW & $\mathrm{AG}$ & 12 & 812 & Madrone & $99 \%$ & 10 & 158 \\
\hline B012112-2 & Absent & $1 / 21 / 2012$ & DFR & MHC & 8 & 924 & Douglas Fir & $99 \%$ & 4 & 332 \\
\hline B012412-1 & Absent & $1 / 24 / 2012$ & $\mathrm{KMC}$ & $\mathrm{MHC}$ & 17 & 1340 & Doug Fir & $98 \%$ & 2 & 260 \\
\hline B012712-1 & Absent & $1 / 27 / 2012$ & $\mathrm{MHC}$ & $\mathrm{KMC}$ & 20 & 1258 & Live Oak & $88 \%$ & 9 & 304 \\
\hline B020512-1 & Absent & $2 / 5 / 2012$ & $\mathrm{MHC}$ & KMC & 50 & 965 & Manzanita & $58 \%$ & 7 & 301 \\
\hline B022112-1 & Absent & $2 / 22 / 2012$ & $\mathrm{MHC}$ & $\mathrm{KMC}$ & 50 & 951 & Manzanita & $82 \%$ & 6 & 301 \\
\hline B022112-2 & Absent & $2 / 22 / 2012$ & $\mathrm{KMC}$ & MHC & 25 & 949 & Black Oak & $97 \%$ & 5 & 248 \\
\hline B022612-1 & Absent & $2 / 26 / 2012$ & KMC & $\mathrm{MHC}$ & 25 & 971 & Douglas Fir & $93 \%$ & 4 & 230 \\
\hline B022812-2 & Absent & $2 / 28 / 2012$ & MHW & $\mathrm{AG}$ & 35 & 864 & Manzanita & $94 \%$ & 5 & 157 \\
\hline B022912-1 & Excluded & $2 / 29 / 2012$ & DFR & KMC & 70 & 1518 & Douglas Fir & $99 \%$ & 14 & 25 \\
\hline B031112-1 & Excluded & $3 / 11 / 2012$ & MHC & MHW & 30 & 1494 & Ponderosa Pine & 0.02 & 0 & 348 \\
\hline B031112-2 & Absent & $3 / 11 / 2012$ & MHW & MHC & 10 & 1349 & Brewers Oak & $91 \%$ & 13 & 286 \\
\hline B031112-3 & Absent & $3 / 11 / 2012$ & KMC & MHC & 100 & 1424 & Douglas Fir & $99 \%$ & 19 & 131 \\
\hline B031112-4 & Absent & $3 / 11 / 2012$ & $\mathrm{MHC}$ & MHW & 35 & 1210 & Douglas Fir & $93 \%$ & 1 & 273 \\
\hline B031112-5 & Excluded & $3 / 11 / 2012$ & $\mathrm{MHC}$ & KMC & 110 & 1359 & Deer Brush & 0.6 & 3 & 22 \\
\hline B032012-1 & Absent & $3 / 20 / 2012$ & KMC & MHC & 110 & 1236 & Douglas Fir & $97 \%$ & 1 & 314 \\
\hline B032812-1 & Absent & $3 / 28 / 2012$ & DFR & $\mathrm{MHC}$ & 70 & 1286 & Douglas Fir & $99 \%$ & 2 & 265 \\
\hline B032812-2 & Excluded & $3 / 28 / 2012$ & $\mathrm{MHC}$ & $\mathrm{KMC}$ & 40 & 928 & Douglas Fir & $97 \%$ & 2 & 298 \\
\hline B032812-3 & Excluded & $3 / 28 / 2012$ & DFR & $\mathrm{MHC}$ & 90 & 974 & Douglas Fir & $99 \%$ & 3 & 330 \\
\hline B032812-4 & Excluded & $3 / 28 / 2012$ & $\mathrm{MHC}$ & DFR & 35 & 728 & Madrone & $94 \%$ & 10 & 273 \\
\hline B041512-1 & Absent & $4 / 15 / 2012$ & MCP & DFR & 3 & 875 & Manzanita & $88 \%$ & 16 & 229 \\
\hline B042212-1 & Excluded & $4 / 22 / 2012$ & DFR & MHC & 3 & 952 & Douglas Fir & $95 \%$ & 21 & 253 \\
\hline B053112-1 & Present & $5 / 31 / 2012$ & DFR & $\mathrm{KMC}$ & 11 & 1523 & Douglas Fir & $100 \%$ & 4 & 233 \\
\hline B061012-1 & Present & $6 / 10 / 2012$ & MRI & $\mathrm{AG}$ & 12 & 1194 & Big-leaf Maple & $98 \%$ & 14 & 272 \\
\hline B061612-1 & Present & $6 / 16 / 2012$ & BOW & $\mathrm{AG}$ & 12 & 809 & Blue Oak & $100 \%$ & 9 & 241 \\
\hline B061612-2 & Present & $6 / 16 / 2012$ & PPN & $\mathrm{AG}$ & 9 & 1312 & Ponderosa Pine & $100 \%$ & 7 & 132 \\
\hline B062212-1 & Absent & $6 / 22 / 2012$ & $\mathrm{MHC}$ & $\mathrm{AG}$ & 7 & 1078 & Black Oak & $97 \%$ & 12 & 352 \\
\hline B080412-1 & Present & $8 / 4 / 2012$ & DFR & $\mathrm{MHC}$ & 5 & 1217 & Douglas Fir & $98 \%$ & 12 & 360 \\
\hline
\end{tabular}




\begin{tabular}{|c|c|c|c|c|c|c|c|c|c|c|}
\hline B080612-1 & Present & $8 / 6 / 2012$ & KMC & $\mathrm{MCP}$ & 2 & 1793 & Ponderosa Pine & $89 \%$ & 7 & 305 \\
\hline B080612-2 & Present & $8 / 6 / 2012$ & $\mathrm{MHC}$ & $\mathrm{KMC}$ & 15 & 1480 & Douglas Fir & $99 \%$ & 6 & 164 \\
\hline B081512-1 & Present & $8 / 15 / 2012$ & MHW & MCP & 13 & 1482 & Black Oak & $98 \%$ & 21 & 354 \\
\hline B091512-2 & Present & $9 / 15 / 2012$ & WFR & RFR & 2 & 1912 & White Fir & $87 \%$ & 9 & 85 \\
\hline B091612-1 & Excluded & $9 / 16 / 2012$ & $\mathrm{KMC}$ & MRI & 10 & 1263 & Incense Cedar & $86 \%$ & 13 & 16 \\
\hline B092412-1 & Present & $9 / 24 / 2012$ & $\mathrm{MHC}$ & $\mathrm{MCH}$ & 7 & 1121 & Douglas Fir & $86 \%$ & 14 & 351 \\
\hline B092412-2 & Present & $9 / 24 / 2012$ & $\mathrm{MHC}$ & PPN & 7 & 1428 & Ponderosa Pine & $89 \%$ & 17 & 208 \\
\hline B093012-1 & Present & $9 / 30 / 2012$ & $\mathrm{MHC}$ & KMC & 10 & 1495 & Brewer's Oak & $89 \%$ & 7 & 127 \\
\hline B100112-1 & Present & $10 / 1 / 2012$ & $\mathrm{MHC}$ & MHW & 7 & 1390 & Brewer's Oak & $97 \%$ & 16 & 246 \\
\hline B100112-2 & Present & $10 / 1 / 2012$ & KMC & $\mathrm{MHC}$ & 13 & 1495 & Ponderosa Pine & $82 \%$ & 2 & 124 \\
\hline B100612-1 & Excluded & $10 / 6 / 2012$ & MRI & $\mathrm{AG}$ & 2 & 1182 & Alder & $100 \%$ & 8 & 286 \\
\hline
\end{tabular}

Habitat abbreviations: $\mathrm{AG}=$ annual grassland, $\mathrm{BAR}=$ barren, $\mathrm{BOP}=$ blue oak-foothill pine, $\mathrm{BOW}=$ blue oak woodland, $\mathrm{CRC}=$ chamiseredshank chaparral, DFR $=$ Douglas fir, $\mathrm{KMC}=$ Klamath mixed conifer, $\mathrm{MCH}=$ mixed chaparral, $\mathrm{MCP}=$ montane chaparral, $\mathrm{MHC}=$ montane hardwood conifer, MHW = montane hardwood, MRI = montane riparian, PPN = ponderosa pine, $\mathrm{RFR}=$ red fir, WFR $=$ white fir, $\mathrm{WTM}=$ wet meadow, $\mathrm{WTR}=$ water . 


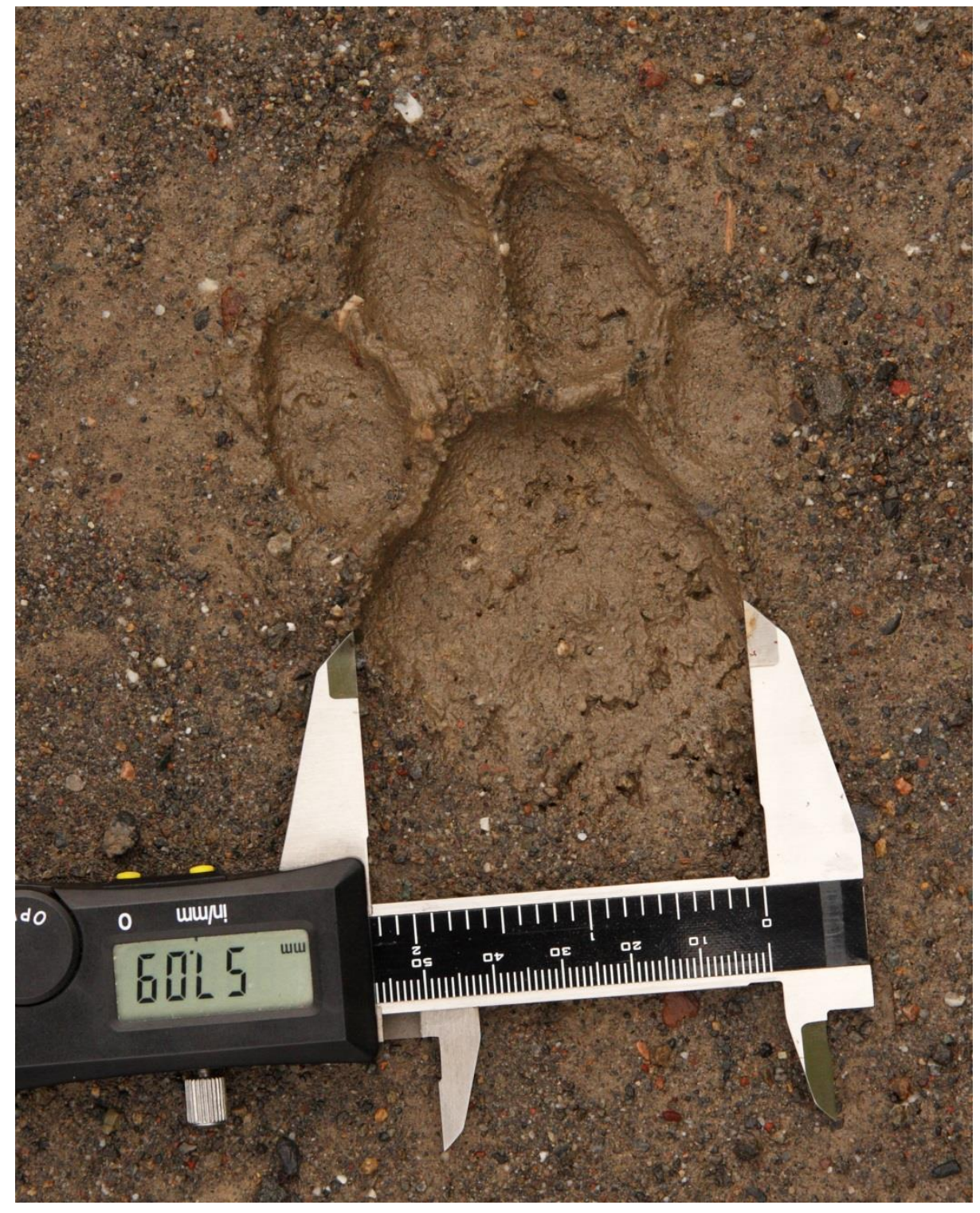

Figure 1. The track of a male puma in the Mendocino study area. 